Final Report

On the Project Entitled

\title{
Development of a Novel Efficient Solid-Oxide Hybrid for Co-generation of Hydrogen and Electricity Using Nearby Resources for Local Application
}

\author{
Sponsored by \\ Golden Field Office, U.S. Department of Energy \\ Contract No. DE-FG36-05GO15194 \\ Submitted to: \\ Project Manager: Dr. David Peterson \\ Golden Field Office \\ U.S. Department of Energy \\ 1617 Cole Blvd. \\ Golden, CO 80401 \\ Submitted by \\ Dr. Greg Gege Tao (Principal Investigator) \\ Materials and Systems Research, Inc. (MSRI) \\ 5395 West 700 South \\ Salt Lake City, UT 84104 \\ Phone: (801) 530-4987 \\ FAX: (801) 530-4820
}

Effective Date of Contract: September 30, 2005

Contract Expiration Date: June 30, 2009

Reporting Period: 09/30/2005 - 06/30/2009 


\section{DISCLAIMER}

"This report was prepared as an account of work sponsored by an agency of the United States Government. Neither the United States Government nor any agency thereof, nor any of their employees, makes any warranty, expressed or implied, or assumes any legal liability or responsibility for the accuracy, completeness, or usefulness of any information, apparatus, product, or process disclosed, or represents that its use would not infringe privately owned rights. Reference herein to any specific commercial product, process, or service by trade name, trademark, manufacturer, or otherwise, does not necessarily constitute or imply its endorsement, recommendation, or favoring by the United States Government or any agency thereof. The views and opinions of authors expressed herein do not necessarily state or reflect those of the United States Government or any agency thereof." 


\section{EXECUTIVE SUMMARY}

Developing safe, reliable, cost-effective, and efficient hydrogen-electricity co-generation systems is an important step in the quest for national energy security and minimized reliance on foreign oil. This project aimed to, through materials research, develop a cost-effective advanced technology cogenerating hydrogen and electricity directly from distributed natural gas and/or coal-derived fuels. This advanced technology was built upon a novel hybrid module composed of solid-oxide fuel-assisted electrolysis cells (SOFECs) and solid-oxide fuel cells (SOFCs), both of which were in planar, anode-supported designs. A SOFEC is an electrochemical device, in which an oxidizable fuel and steam are fed to the anode and cathode, respectively. Steam on the cathode is split into oxygen ions that are transported through an oxygen ion-conducting electrolyte (i.e. YSZ) to oxidize the anode fuel. The dissociated hydrogen and residual steam are exhausted from the SOFEC cathode and then separated by condensation of the steam to produce pure hydrogen. The rationale was that in such an approach fuel provides a chemical potential replacing the external power conventionally used to drive electrolysis cells (i.e. solid oxide electrolysis cells). A SOFC is similar to the SOFEC by replacing cathode steam with air for power generation. To fulfill the cogeneration objective, a hybrid module comprising reversible SOFEC stacks and SOFC stacks was designed that planar SOFECs and SOFCs were manifolded in such a way that the anodes of both the SOFCs and the SOFECs were fed the same fuel, (i.e. natural gas or coal-derived fuel). Hydrogen was produced by SOFECs and electricity was generated by SOFCs within the same hybrid system. A stand-alone $5 \mathrm{~kW}$ system comprising three SOFEC-SOFC hybrid modules and three dedicated SOFC stacks, balance-of-plant components (including a tailgas-fired steam generator and tailgas-fired process heaters), and electronic controls was designed, though an overall integrated system assembly was not completed because of limited resources. An inexpensive metallic interconnects fabrication process was developed in-house. BOP components were fabricated and evaluated under the forecasted operating conditions. Proof-of-concept demonstration of cogenerating hydrogen and electricity was performed, and demonstrated SOFEC operational stability over 360 hours with no significant degradation. Cost analysis was performed for providing an economic assessment of the cost of hydrogen production using the targeted hybrid technology, and for guiding future research and development.

The project accomplishments are briefly described below. Details will be delineated within the body of this final technical report.

1. Synthesized a p-type ( $\mathrm{La}, \mathrm{Sr})(\mathrm{Cr}, \mathrm{Mn}) \mathrm{O}_{3}(\mathrm{LSCM})$ cathode material and $\mathrm{Sm}$-doped $\mathrm{CeO}_{2}$ (SDC) and Gd-doped $\mathrm{CeO}_{2}$ (GDC) n-type cathode materials, and fabricated a composite material consisting of both p-type and n-type conductors.

2. Explored other perovskites as n-type materials for SOFEC application, including ( $\mathrm{La}, \mathrm{Sr}) \mathrm{TiO}_{3}$ (LST).

3. Demonstrated redox stability of the LSCM-based composite cathode.

4. Completed fabrication of defect-free anode-support SOFECs and SOFCs needed for 5 $\mathrm{kW}$ hybrid cogeneration modules with optimized anode porosities and microstructure. 
5. Developed testing protocols to evaluate the effects of porosity, composition, temperature, microstructure and physical dimension on the mechanical properties of the anode support, experimental results were used to optimiz the anode design for increased reliability and performance.

6. Developed a finite element model to simulate the indentation processes on the anode substates and electrolyte structures.

7. Identified alkaline earth silicate-based glass compositions with requisite thermal properties.

8. Demonstrated stability and hermeticity of the glass seal materials for up to 100 days in air and in a wet reducing atmosphere, and over 30 thermal cycles.

9. Developed new interconnect manifolds for the SOFEC-SOFC hybrid stack with heat transfer-enhancement and in-stack pressure drop reduction features.

10. Developed an interconnect brazing system imparting significant cost-savings in materials, and completed fabrication of non-cell repeat stack units.

11. Constructed and evaluated $\mathrm{kW}$ stacks operating respectively in SOFEC and SOFC modes for hydrogen production and power generation directly from syngas.

12. Demonstrated SOFEC operational stability for 360 hours with no significant degradation.

13. Constructed and demonstrated hybrid stack modules comprised of SOFECs and SOFECs co-generating hydrogen and electricity directly from hydrocarbon fuels, including syngas and methane.

14. Completed the design of a stand-alone $5 \mathrm{~kW}$ co-generation system.

15. Fabricated and evaluated major balance-of-plant (BOP) components. 


\section{TABLE OF CONTENTS}

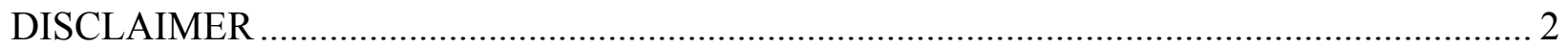

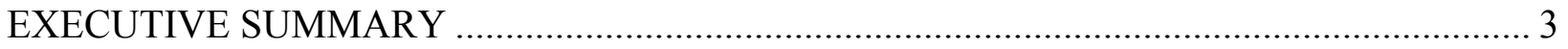

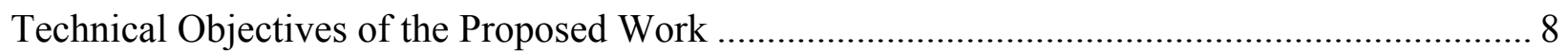

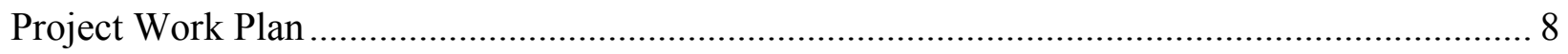

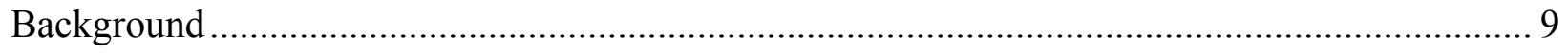

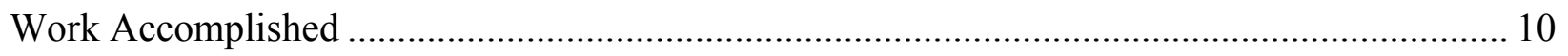

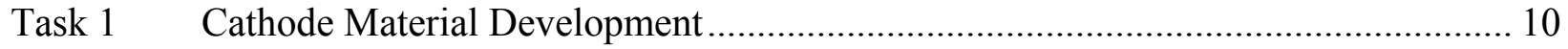

Task 1.1 Characterization of p-type perovskites (LSCr, LSM and LSCM) ........................... 10

Task 1.2 Construction and evaluation of LSCM electrode for reversible SOFEC/SOFC

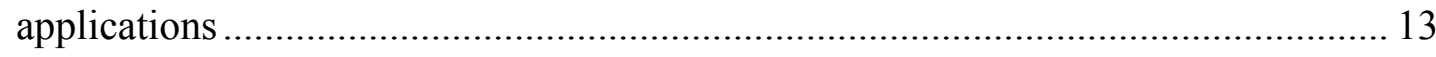

Task 1.3 Long-term stability test of LSCM electrodes ....................................................... 17

Task 1.4 Characterization of a mixture of LSCM (p-type) and LST (n-type) perovskites ...... 18

Task 1.5 Characterization of SDC- and GDC- based n-type perovskites ...............................26

Task 1.6 Composite LSCM and SDC cathode development ............................................... 32

Task 2 Fabrication of Anode-Supported, Thin Film YSZ-based Solid Oxide Electrochemical

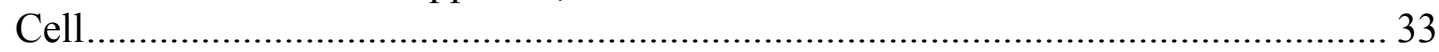

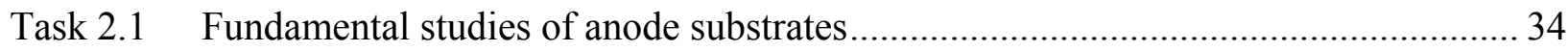

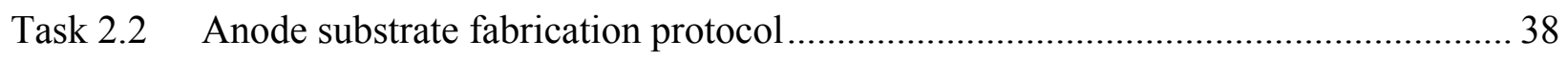

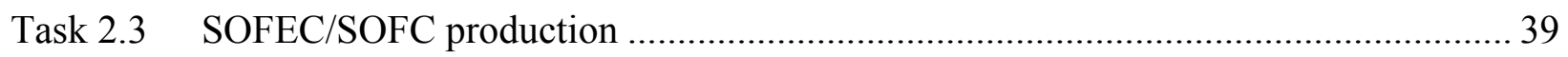

Task 3 Anode Substrate Thermo-mechanical Properties Investigation ................................ 40

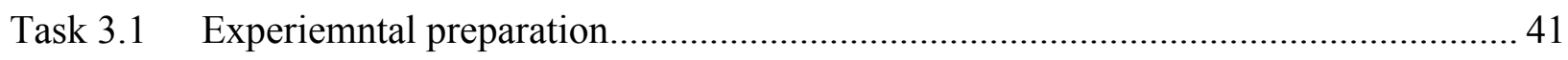

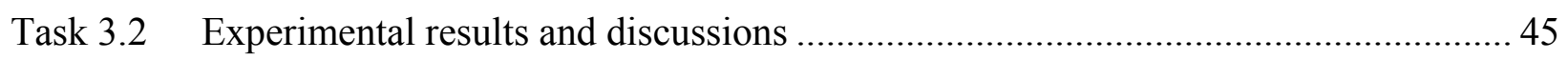

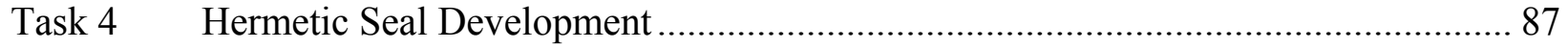

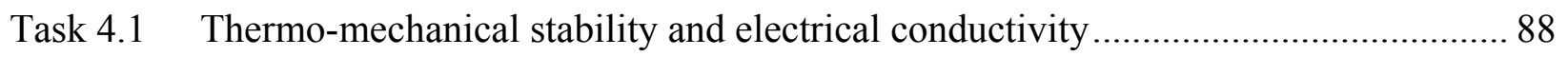

Task 4.2 Influence of glass particle size on crystallization behavior ........................................ 89

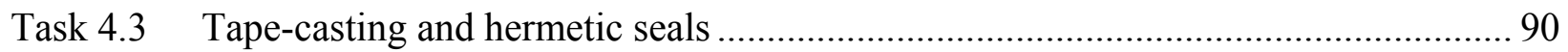

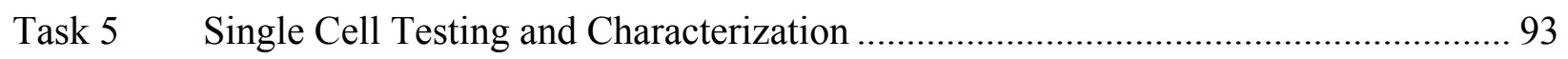

Task 5.1 Evaluation of effects of anode substrates on cells performance ................................ 93

Task 5.2 Development of a new approach for depositing cathodes ........................................ 95

Task 5.3 Development and evaluation of LSCM-based cathode ...........................................98

Task 6 Design of Hybrid SOFEC-SOFC Stacks and a 5 kW System .................................... 103

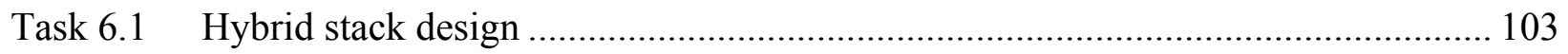




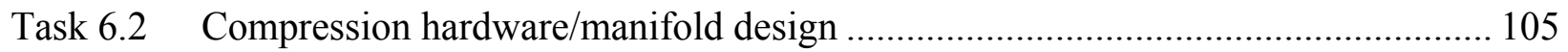

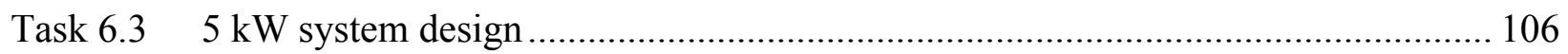

Task 6.4 Balance-of-plant component design ................................................................... 113

Task 7 Proof-of-concept Demonstration of the SOFEC-SOFC Hybrid Co-generating $\mathrm{H}_{2}$ and Electricity in Short Stacks of Anode-support Cells ................................................ 115

Task 7.1 SOFEC concept validation on 10-cell stacks....................................................... 115

Task 7.2 Proof-of-concept demonstration of SOFEC-SOFC hybrid co-generating $\mathrm{H}_{2}$ and

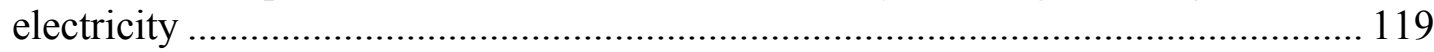

Task 7.3 SOFEC-SOFC hybrid stack performance characteristics under electrically selfsustaining operating condition................................................................................ 123

Task 8 Development and Testing of a 5 kW SOFEC-SOFC Hybrid System ....................... 131

Task 8.1 Development of an interconnect fabrication process.............................................. 132

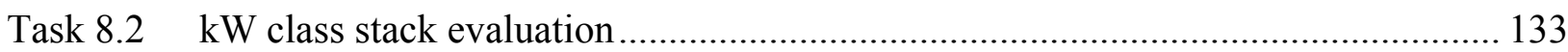

Task 8.3 Balance-of-plant component evaluations .......................................................... 135

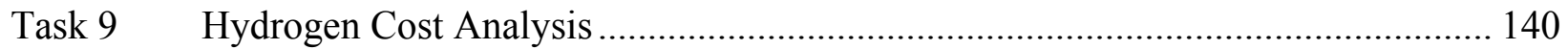

Task $10 \quad$ Project Management and Reporting ..................................................................... 141

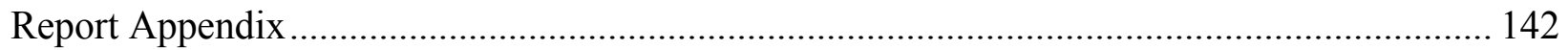

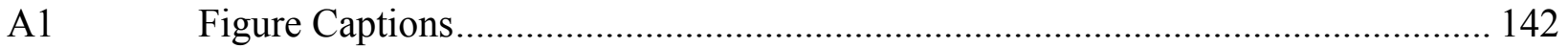

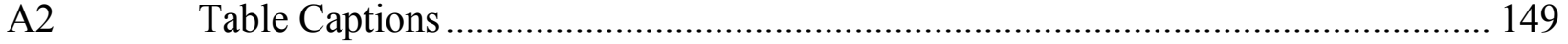

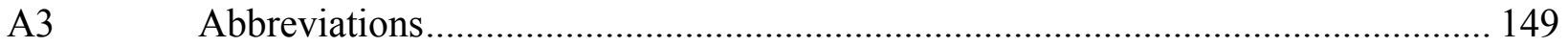




\section{MANAGEMENT REPORTING - Final Report}

\section{Project Title:}

Development of a Novel Efficient Solid-Oxide Hybrid for Co-generation of Hydrogen and Electricity Using Nearby Resources for Local Application

\section{Project Period:}

September 30, 2005 to June 30, 2009

\section{Recipient:}

Materials and Systems Research, Inc.

Award Number:

DE-FG36-05GO15194

Working Partners:

Materials and Systems Research, Inc. (MSRI): Dr. Greg G. Tao

University of Alaska Fairbanks (UAF): Dr. Sukumar Bandopadhyay and Dr. Nithyanantham Thangomani

Missouri University of Science and Technology (MS\&T): Dr. Harlan U. Anderson and Dr. Richard K. Brow

University of Utah (Utah): Dr. Anil V. Virkar

\section{Contact:}

Greg Gege Tao, Ph.D. (Principal Investigator)

Phone: (801) 530-4987 Ext. 30

Email: gtao@msrihome.com

DOE Manager:

David Peterson, Ph.D. (Golden Field Office, Project Officer)

Phone: (303) 275-4956

Email: david.peterson@go.doe.gov 


\section{Technical Objectives of the Proposed Work}

The objective of this project was to develop a solid oxide fuel-assisted electrolysis technique to generate both hydrogen and electricity directly from hydrocarbon fuels. The objectives included:

- Develop and optimize composite cathodes that were chemically and electrocatalytically stable under both reducing and oxidizing environments.

- Evaluate the performance of the cathode materials by measuring the electrical conductivity and impedance spectrum as a function of temperature and oxygen activity.

- Fabricate anode-supported solid oxide fuel cells (SOFCs) and solid oxide fuel-assisted electrolysis cells (SOFECs) with Ni-YSZ anode supports, thin film YSZ electrolytes, and composite cathodes.

- Quantify the issues affecting the mechanical stability (particularly the strength) of the anode supports.

- Evaluate the thermo-elastic properties of the anode support in both air and reducing atmospheres.

- Characterize the structural properties, fracture mechanisms, creep behavior and residual stresses of the anode supports.

- Develop glass-ceramic seal compositions that demonstrate hermeticity and material compatibility with stack components under SOFC-SOFEC operational conditions.

- Demonstrate hbrid SOFC-SOFEC modules co-generating hydrogen and electricity directly from hydrocarbon fuels.

- Design a $5 \mathrm{~kW}$ module-based SOFC-SOFEC co-generation system with improved thermal and fluid management.

- Design, manufacture, and evaluate the balance-of-plant (BOP) components for the $5 \mathrm{~kW}$ system.

- Construct and test the $5 \mathrm{~kW}$ system to demonstrate co-generation of hydrogen and electricity directly from syngas or natural gas.

- Develop a cost analysis model for hydrogen production using the hybrid SOFC-SOFEC technology.

\section{Project Work Plan}

Task 1 Cathode Materials Development

Task 2 Fabrication of Anode-supported, Thin Film YSZ-based Solid Oxide Electrochemical Cell

Task 3 Anode Substrate Thermo-mechanical Properties Investigation

Task 4 Hermetic Seal Development

Task 5 Single Cell Testing and Characterization

Task 6 Design of Hybrid SOFEC-SOFC Stacks and a 5 kW System

Task 7 Proof-of-Concept Demonstration of the SOFEC-SOFC Hybrid Co-generating $\mathrm{H}_{2}$ and Electricity in Short Stacks of Anode-support Cells

Task 8 Development and Testing of a 5 kW SOFEC-SOFC Hybrid System

Task 9 Hydrogen Cost Analysis

Task 10 Project Management and Reporting 


\section{Background}

Developing safe, reliable, cost-effective, and efficient hydrogen-electricity co-generation systems is an important step in the quest for national energy security and minimized reliance on foreign oil, and also promises the opportunity to reduce greenhouse gases emissions. Hydrogen, as a secondary energy carrier, doesn't exist in an elemental form in the environment to an appreciable extent; but can be produced by reacting a variety of widely available primary energy carriers, such as fossil fuels, wastes, biomass, or by using renewable energy sources, either directly or indirectly. There are numerous processes to produce hydrogen, such as conventional electrolysis and the steam reforming of natural gas or coal on an industrial scale, and thermochemical water splitting, photoelectrochemical processes, and small scale biological processes. As of yet, however, none of these technologies are sufficient to meet the needs of a hydrogen-based economy. Conventional steam electrolysis using a solid-oxide electrolysis cell (SOEC) consumes $34.2 \mathrm{kWh}$ to produce $1 \mathrm{~kg}$ of hydrogen when it operates at the thermo-neutral voltage $(1.28 \mathrm{~V})$. The cost of hydrogen produced by other conventional electrolyzers is typically about $53.4 \mathrm{kWh}$ per kg hydrogen for alkaline or PEM-based electrolyzers. These high electricity costs and low system efficiencies have made hydrogen production with the electrolysis technologies less competitive with other processes, such as steam reformation of natural gas or coal. However, purification of the hydrogen stream, separation of the effluent carbon dioxide, and additional infrastructure (hydrogen storage, distribution pipeline build-up, supply chain, and transportation from hydrogen central production factory to hydrogen end user), add appreciable costs, and make steam reformation inappropriate for small-scale applications.

The purpose of this program was to, through the materials research, enable the development of a cost-effective solid-oxide hybrid module cogenerating hydrogen and electricity directly from fuel (i.e., natural gas, coal-derived syngas, and/or bio-fuels) for distributed small-scale applications. The resultant innovative hybrid system used reversible solid-oxide fuel-assisted electrolysis cells (SOFECs) integrated with solid-oxide fuel cells (SOFCs), both of which were planar, anodesupported solid oxide electrochemical cells. A SOFEC is an electrochemical device which is similar to a SOFC, which generates electricity from a fuel on the anode and air on the cathode, but it replaces the air on the SOFC cathode with steam as an oxidant. By doing so, the SOFEC produces hydrogen by electrochemically dissociating the steam into hydrogen and oxygen. Along with residual steam, the dissociated hydrogen exhausts from the SOFEC cathode and are then separated by condensation of the steam, leaving a pure hydrogen gas. In the hybrid module, the SOFECs and SOFCs were manifolded in a stack such that the anodes of both the SOFECs and the SOFCs were fed the same fuel. Hydrogen was produced by SOFECs and electricity was generated by SOFCs within the same hybrid system. Because of the modular nature of the composite SOFEC-SOFC stack, it can be integrated with other renewable resources (i.e. biomass, solar and wind), and used for storing energy from those intermittent sources as hydrogen. Hydrogen can then be distributed or used later to generate electricity (by running the stack as an SOFC, or as feedstock for PEM based fuel cells).

The development efforts of this program were performed by a team led by Materials and Systems Research Inc., (MSRI), and supported by University of Alaska Fairbanks (UAF), Missouri University of Science and Technology (MS\&T), and the University of Utah (Utah). Redox stable cathodes for the reversible SOFECs were studied, using composite cathodes 
comprising p-type and n-type materials. The performance of each composite was carefully evaluated as a cathode and suitable materials were selected and optimized. Although the main factors influencing the solid-oxide hybrid design were electro-chemical in nature, the requirement to operate the components at elevated temperatures and the need for thermal cycling between room and operation temperature had made thermomechanical aspects of the components extremely important. Robust NiO+YSZ-based anode supports were developed and substaintial investigations were performed to understand the effects of several factors, (i.e., microstructure, temperature, porosity, rapid thermal cycling, and anode layer thickness) on various mechanical properties of the anodes, including strength, elastic properties, fracture mechanisms, thermal expansion behavior, etc. In order to achieve the high power densities for SOFC-SOFEC hybrid stacks, reliable hermetic sealing technologies were developed. Previous knowledge and experience of system design, large stacks development, and key balance-of-plant components build were implemented to this program for the development of a $5 \mathrm{~kW}$ hybrid system.

\section{Work Accomplished}

Work completed in this program is described below.

\section{Task 1 Cathode Material Development}

Cathode materials development was a joint effort by MS\&T and MSRI in which prospective cathode materials for the reversible SOFEC application were developed and characterized successfully.

Cathode materials considerations: The cathode materials used in reversible SOFECs must possess good electronic and ionic conductivity and maintain sufficiently low area-specific resistance (ASR) to be useful in both oxidizing (SOFC mode) and reducing (SOFEC mode) gas atmospheres. At the present time, there are no known materials which completely satisfy these aforementioned criteria. P-type perovskites, such as LSM, LSCF, LSCr and LSCM are known to be stable materials at high temperatures, and have been extensively investigated at MS\&T. Ntype materials such as ( $\mathrm{LaSr}) \mathrm{TiO}_{3}$ (LST) and Gd- or Sm- doped ceria (GDC or SDC) are also known to be stable materials in a reducing atmosphere. The key goal of this research was to develop composite cathode materials which possess the p-type and n-type conductivity at the same time to offer satisfactory performance during both SOFEC and SOFC application. The cathodes made from the composites of an ionic conductor (i.e. SDC and GDC), a p-type conductor (i.e. LSCr, LSM and LSCM), and an n-type conductor (i.e. LST) were investigated. Upon the development of the cathode materials, the cell performance was evaluated.

\section{Task 1.1 Characterization of p-type perovskites (LSCr, LSM and LSCM)}

Electrical conductivity measurement of LSCr, LSM and LSCM: The oxygen activity limits before a chemical/mechanical breakdown of LSM $\left(\mathrm{La}_{0.84} \mathrm{Sr}_{0.15} \mathrm{MnO}_{3}\right), \mathrm{LSCr}\left(\mathrm{La}_{0.8} \mathrm{Sr}_{0.2} \mathrm{CrO}_{3}\right)$, and LSCM $\left(\mathrm{La}_{0.75} \mathrm{Sr}_{0.25} \mathrm{Cr}_{0.5} \mathrm{Mn}_{0.5} \mathrm{O}_{3}\right)$ were investigated by measuring the electrical conductivity as a function of oxygen activity and temperature. The density of a sintered sample was measured to be $\sim 64 \%$ of the theoretical value for LSM and LSCr, and $80 \%$ for LSCM. All the cathode samples were sintered at $1400^{\circ} \mathrm{C}$ for 5 hours in air. 
The electrical conductivity measurement was conducted in a controlled environment with oxygen activity varying from 1 to $10^{-30}$ atmospheres. The sample temperature also varied from $500^{\circ} \mathrm{C}$ to $800^{\circ} \mathrm{C}$. Even though the electrical conductivity measurement didn't represent the actual value due to a relatively high porosity of the cathode samples, the electrical conductivity as a function of oxygen activity was independent of the density of the specimen. Figure 1 shows the results of the electrical conductivity measurements of LSCr, LSM, and LSCM as a function of oxygen activity at $800^{\circ} \mathrm{C}$. As shown in Figure 1, the oxygen activity at which the electrical conductivity starts to decrease is composition dependent, with LSCr being the most stable, LSM the least stable, and LSCM in between. The LSM was found to dissociate at an oxygen activity of $\sim 10^{-20} \mathrm{~atm}$. However, LSCr and LSCM remained single phase with the oxygen activity as low as $10^{-23} \mathrm{~atm}$. These results suggested that the addition of Cr to LSM gave the material sufficient stability for use in the oxygen activity range of $10^{-20} \sim 10^{-15}$ atm which fits the SOFEC operational requirements.

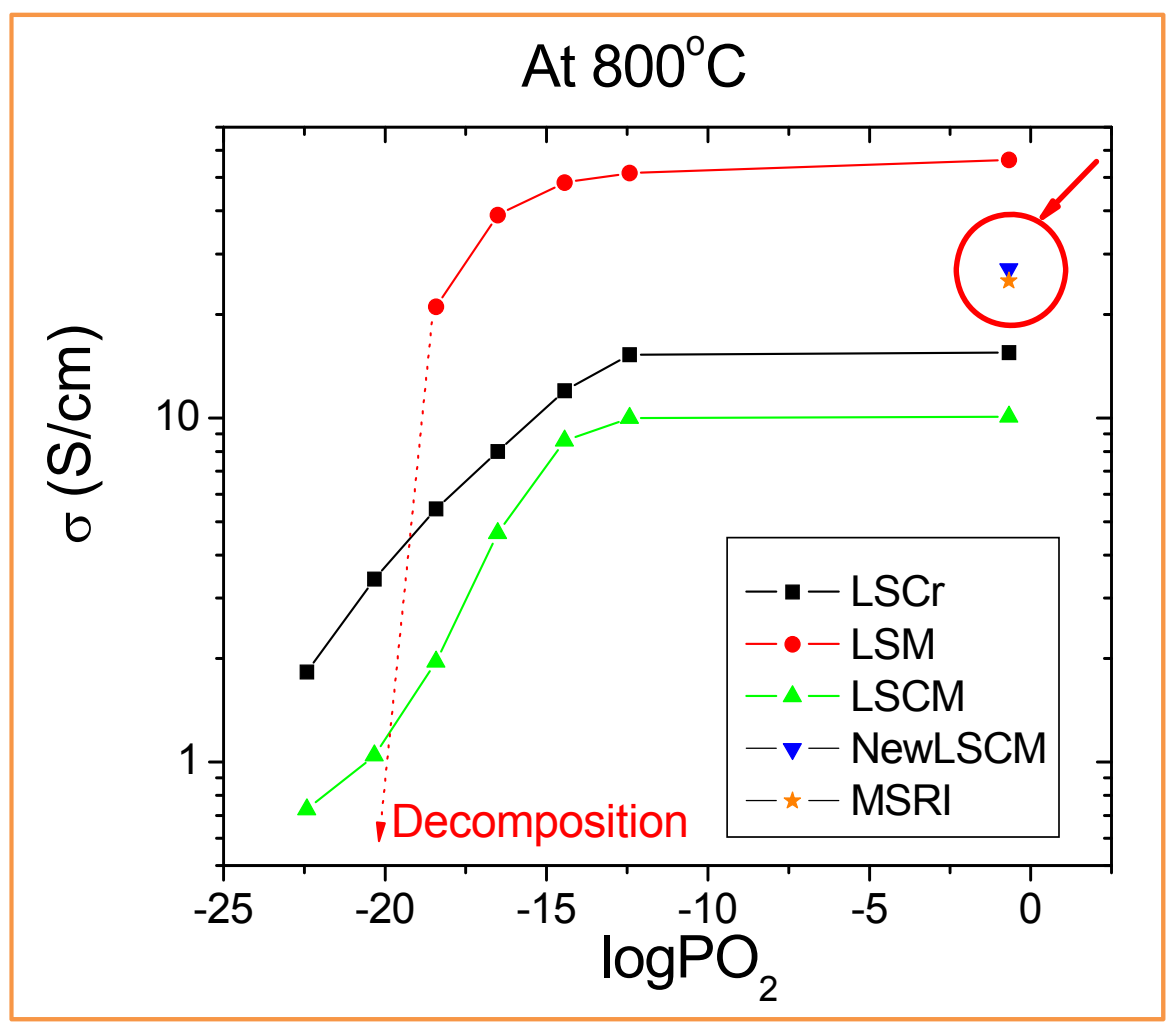

Figure 1. Electrical conductivity of LSCr, LSM and LSCM as a function of oxygen activity measured at $800^{\circ} \mathrm{C}$

Electrical conductivities were also measured at various temperatures in air. Measurements showed that the electrical conductivities of LSCr, LSM and LSCM were about $4 \sim 10,49 \sim 56$ and $13 \sim 15 \mathrm{~S} / \mathrm{cm}$ at temperatures ranging from $500^{\circ} \mathrm{C}$ to $800^{\circ} \mathrm{C}$, respectively. When a LSCM sample with $95 \%$ of the theoretical density was prepared by sintering in argon environment at $1500^{\circ} \mathrm{C}$, the electrical conductivity increased to $27.1 \mathrm{~S} / \mathrm{cm}$ at $800^{\circ} \mathrm{C}$ in air which closely matched the conductivity value reported. 
The electrical conductivities of LSM and LSCM were measured and plotted in Figure 2 and Figure 3, as a function of oxygen activity and temperature, respectively. Figure 2 shows the electrical conductivity of LSM. As shown in the figure, all the measurements were reversible at the temperatures between 500 and $800^{\circ} \mathrm{C}$ as a function of oxygen activity, indicating that LSM was chemically and mechanically stable and fully reversible at least in terms of electrical conductivity in the operation conditions (in air and $50 \% \mathrm{CO}$ bal. $\mathrm{CO}_{2}$, which are equivalent to the oxygen activity range between $0.21 \mathrm{~atm}$ and $8 \times 10^{-30} \sim 4 \times 10^{-19} \mathrm{~atm}$, respectively). Therefore, this conductivity study suggested that LSM would have sufficient stability as a cathode for the proposed reversible electrolysis cell application.

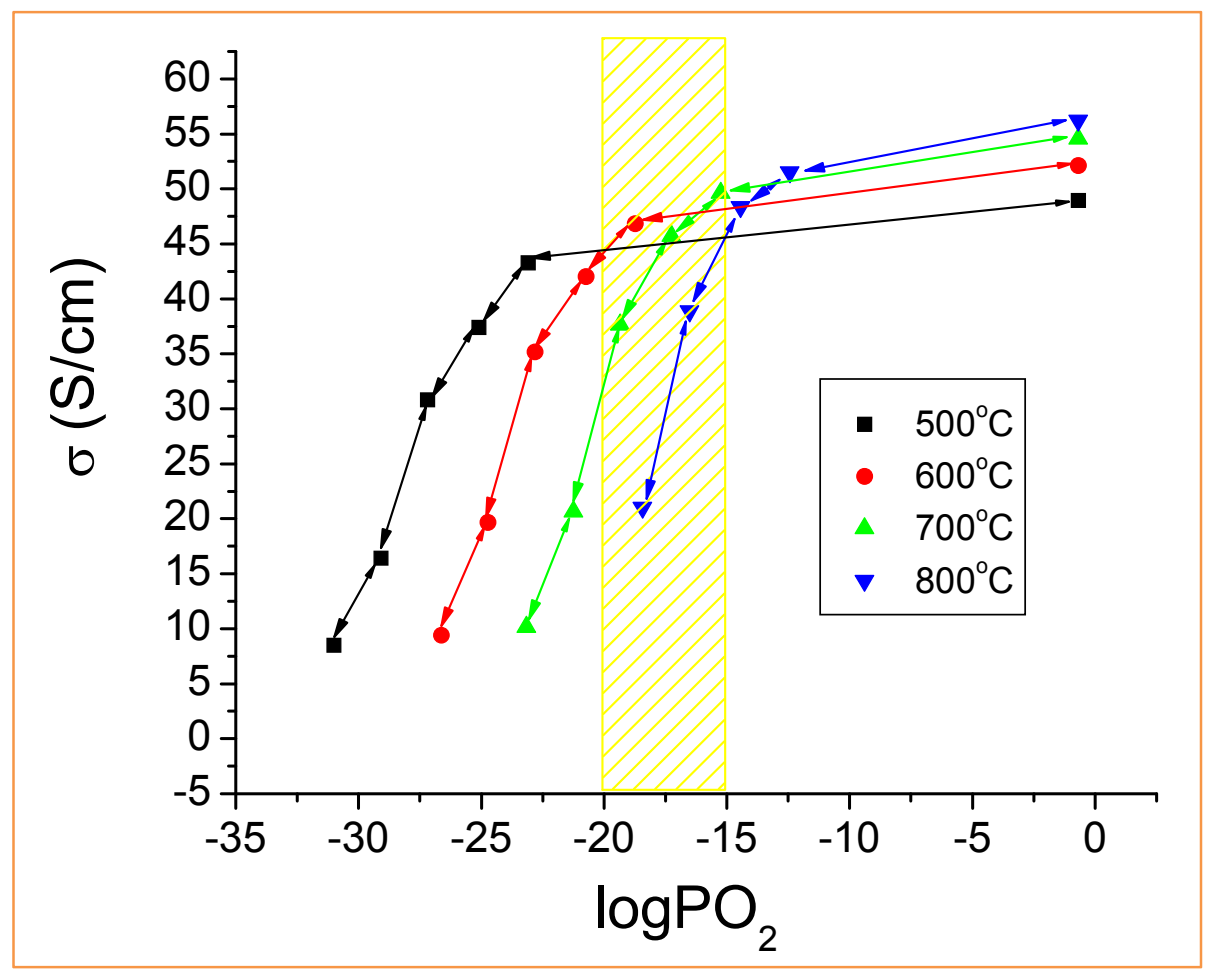

Figure 2. Electrical conductivity of LSM as a function of oxygen activity and temperatures

As shown in Figure 1, comparing with LSM and LSCr, the electrical conducitiviy of LSCM is about $27 \mathrm{~S} / \mathrm{cm}$ in air, suggesting that the LSCM was more stable than LSM, though it was not proven. However, as shown in Figure 1, the conductivity of LSCM leveled off, exhibiting that LSCM had the tendency of having higher conductivity than LSCr below oxygen activity of $4.6 \times 10^{-21} \mathrm{~atm}$. Therefore, LSCM could be the best fitting material as a SOFEC cathode. This electrical conductivity also appeared to be reversible when cycled between air and $90 \% \mathrm{CO}$ bal. $\mathrm{CO}_{2}$ at $800^{\circ} \mathrm{C}$, corresponding to oxygen activity between 0.21 and $4.6 \times 10^{-21}$ atm, respectively, as shown in Figure 3. 


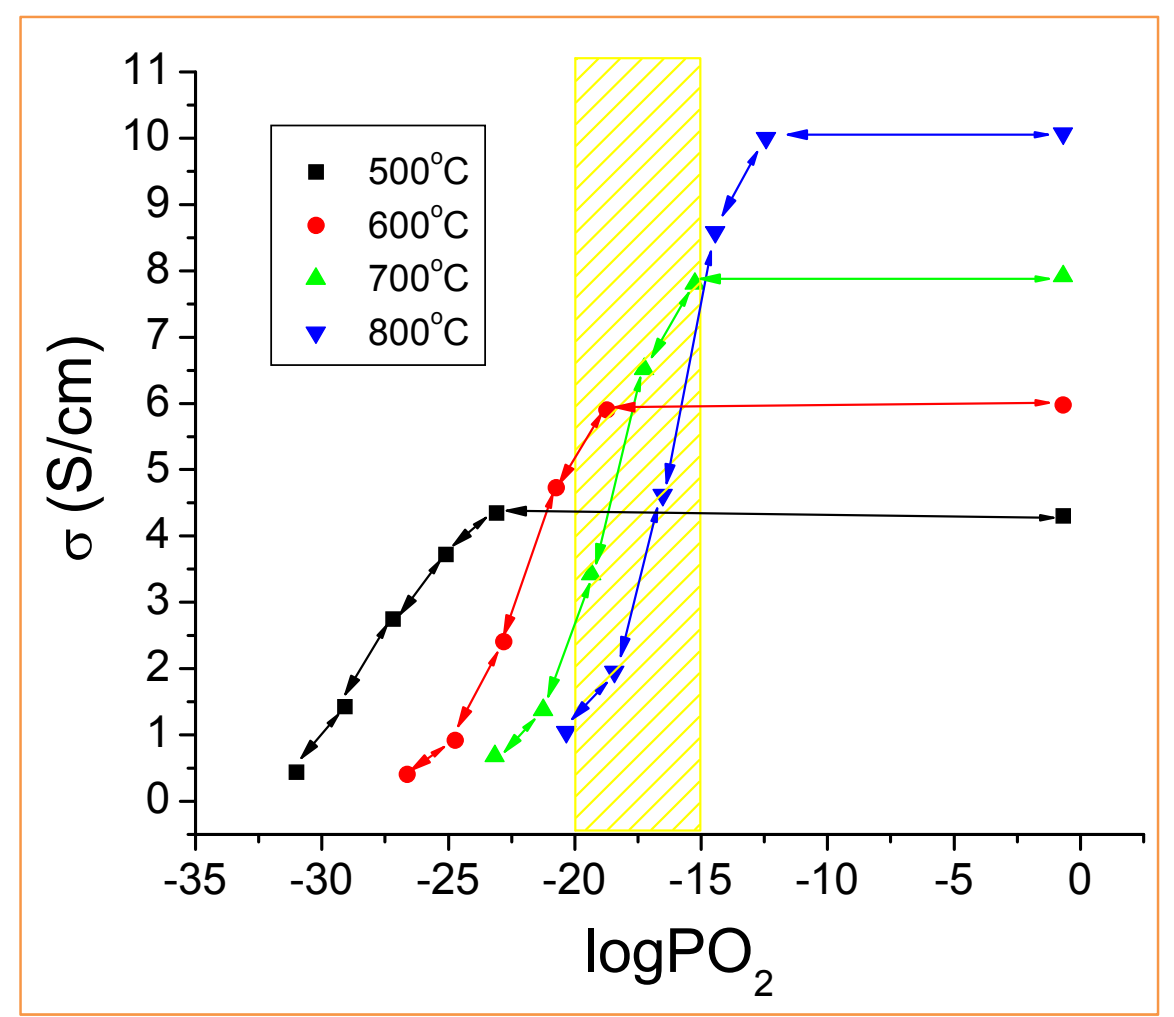

Figure 3. Electrical conductivity of LSCM as a function of oxygen activity and temperatures

Task 1.2 Construction and evaluation of LSCM electrode for reversible SOFEC/SOFC applications

Symmetric cells were constructed with YSZ electrolyte sandwiched between two LSCM electrodes. Ag paste was applied over the LSCM electrode as a current collecting layer. Impedance spectroscopy was employed to evaluate the LSCM electrode performance at various working temperatures. Figure 4 shows representative impedance spectra of a symmetrical cell tested at temperatures from $650^{\circ} \mathrm{C}$ to $800^{\circ} \mathrm{C}$. As shown in the figure, the overpotential of the LSCM symmetrical cell was less than $1 \Omega$ at $800^{\circ} \mathrm{C}$ but increased to $5.5 \Omega$ when the temperature decreased to $650^{\circ} \mathrm{C}$. The intersection of the semicircle at a high frequency with the $Z$ ' axis was taken as the ohmic resistance, which was estimated $\sim 1.5 \Omega$ at $800^{\circ} \mathrm{C}$ but increased to $\sim 3.7 \Omega$ as the temperature decreased to $650^{\circ} \mathrm{C}$. 


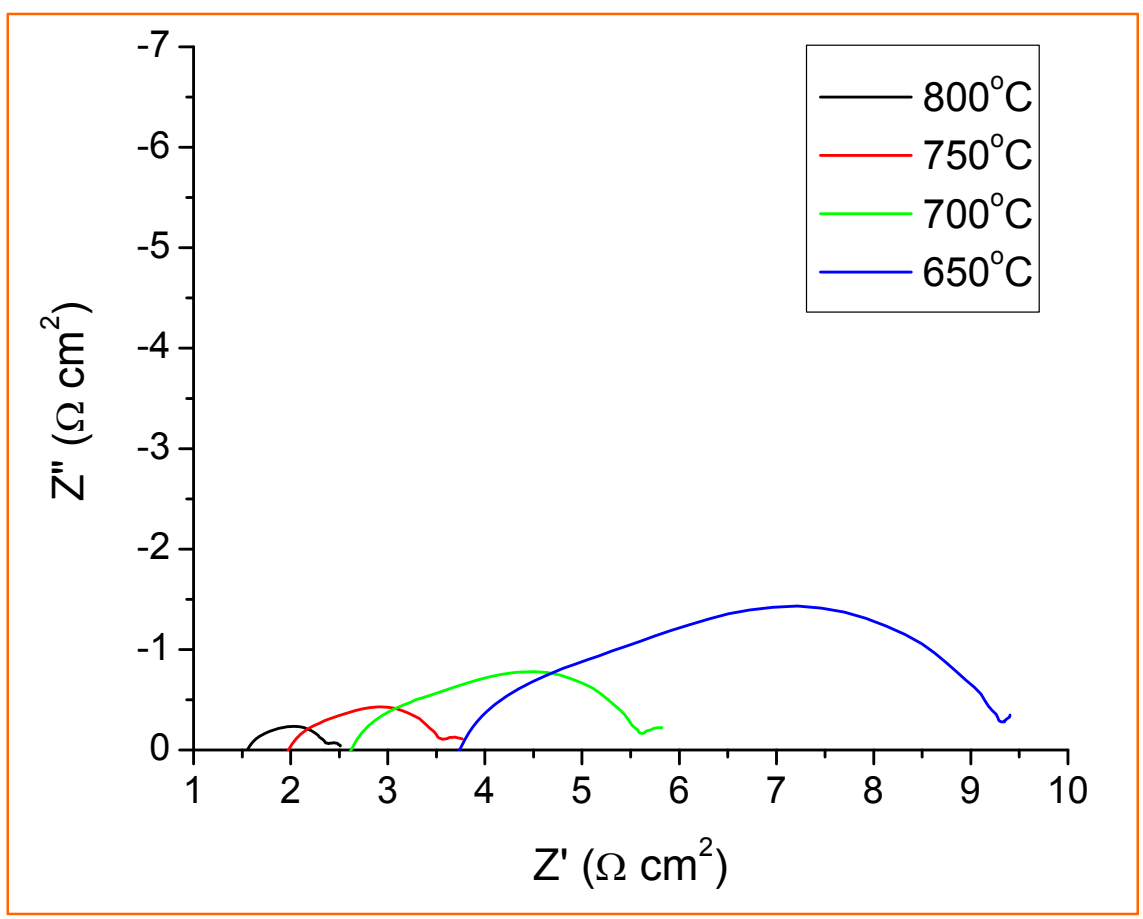

Figure 4. Impedance spectroscopy of LSCM in air

Degradation of a LSCM electrode at $800^{\circ} \mathrm{C}$ was evaluated by subjecting the electrode to a dry gas comprising $10 \% \mathrm{H}_{2}$ bal. $\mathrm{N}_{2}$ (corresponding to oxygen activity $\sim 10^{-23}-10^{-25} \mathrm{~atm}$ ) followed by impedance measurement in air. Figure 5 shows the impedance results. At $800^{\circ} \mathrm{C}$, the ohmic resistance and overpotential respectively increased to $3.4 \Omega$ and $4.7 \Omega$. Post-test analysis showed that the degradation was caused by a weak contact between LSCM and the current collector.

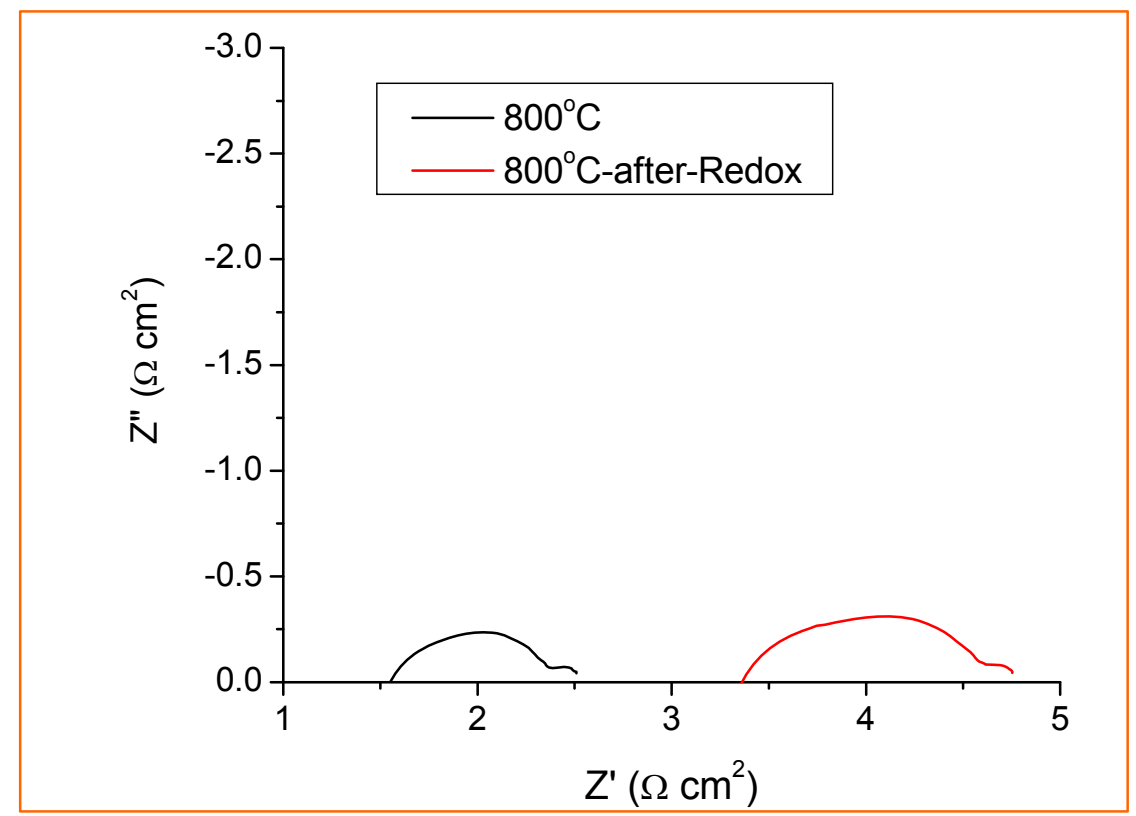

Figure 5. Impedance spectroscopy of LSCM-Ag in air after redox process 
Fuel cell tests were performed at different temperatures from $650^{\circ} \mathrm{C}$ to $800^{\circ} \mathrm{C}$ with dry $10 \% \mathrm{H}_{2}$ bal. $\mathrm{N}_{2}$ gas as the fuel and air as the oxidant. Figure 6 shows the electrochemical impedance spectroscopy of a symmetric cell. Large overpotentials were observed in a low frequency range.

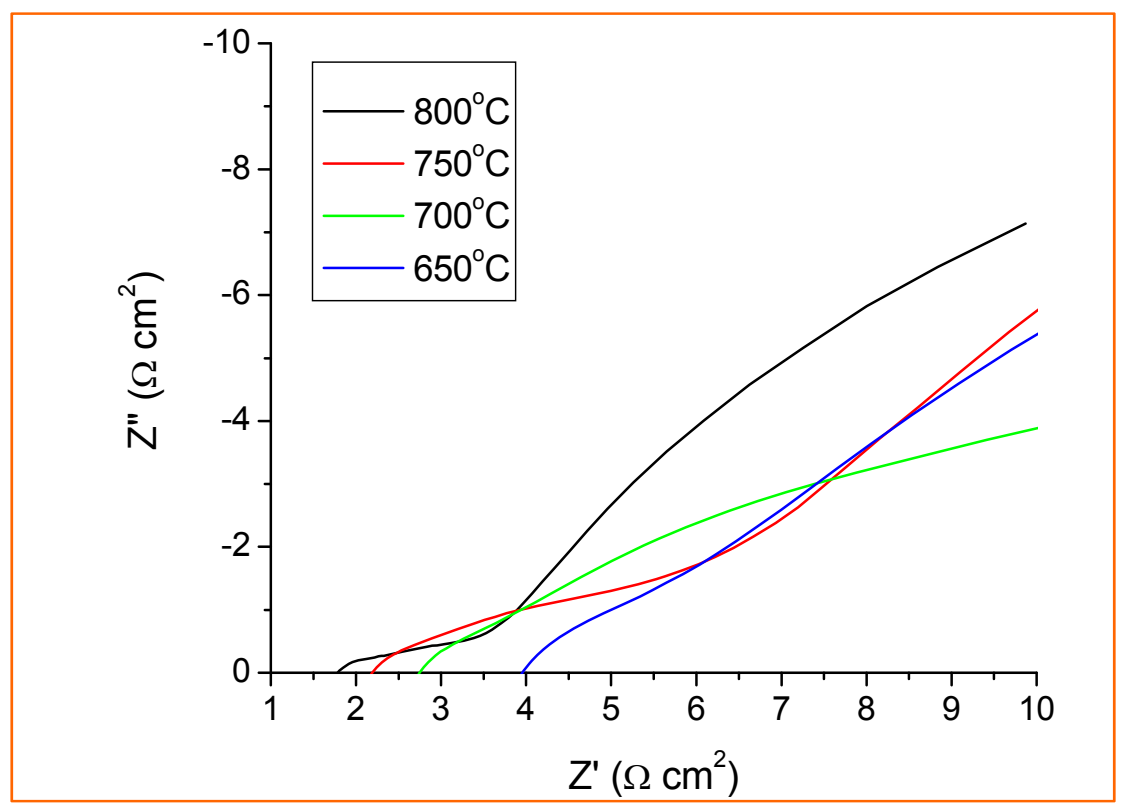

Figure 6. Impedance spectroscopy of LSCM-Ag during fuel cell test

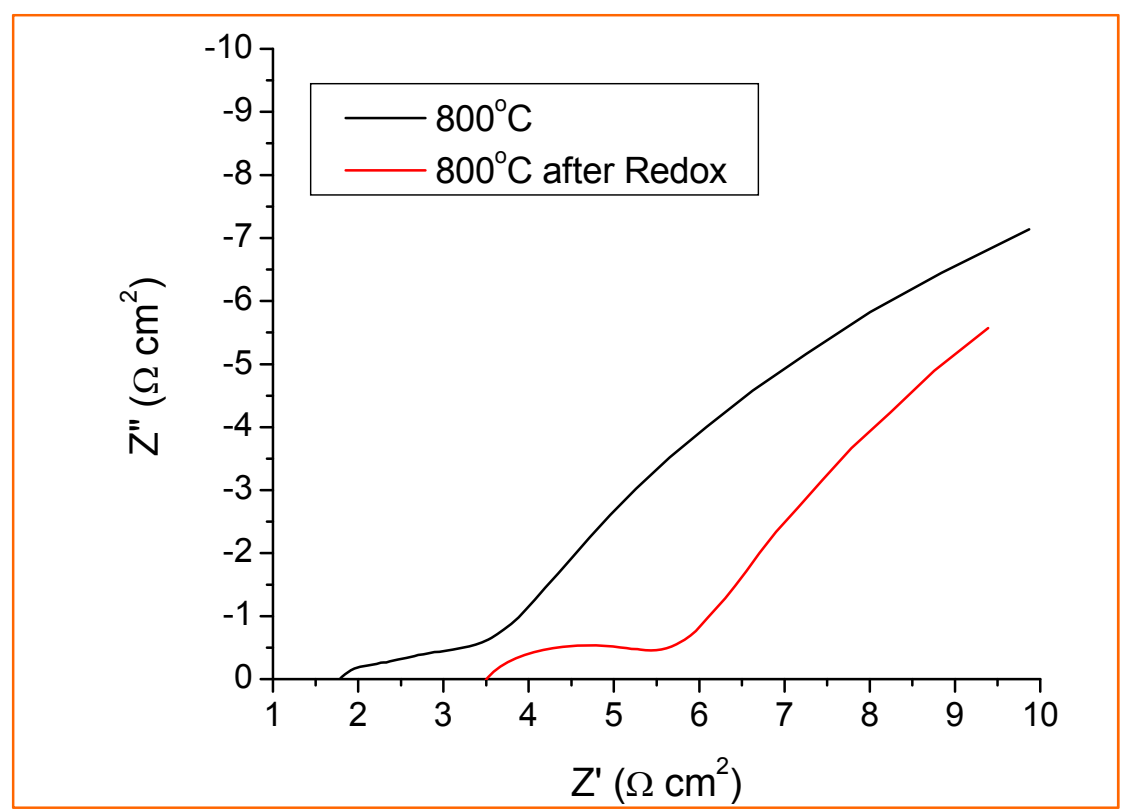

Figure 7. Impedance spectroscopy of LSCM-Ag after fuel cell test

Fuel cell performance after reduction and oxidation processes were measured at $800^{\circ} \mathrm{C}$. As shown in Figure 7, the ohmic resistance increased from 1.8 to $3.5 \Omega$, and the overpotential in the high frequency range increased from 1 to $2 \Omega$. Thess results were very similar to the result shown in Figure 5 except that the large overpotential occurred in the low frequency range. This 
suggested that the degradation might not be fully recovered after the oxidation process. Analysis of a microstructure of the cell after the redox test and testing at high oxygen activities which are closer to those expected to occur in the electrolyzer needs to be performed to determine the most likely location of failure under use conditions.

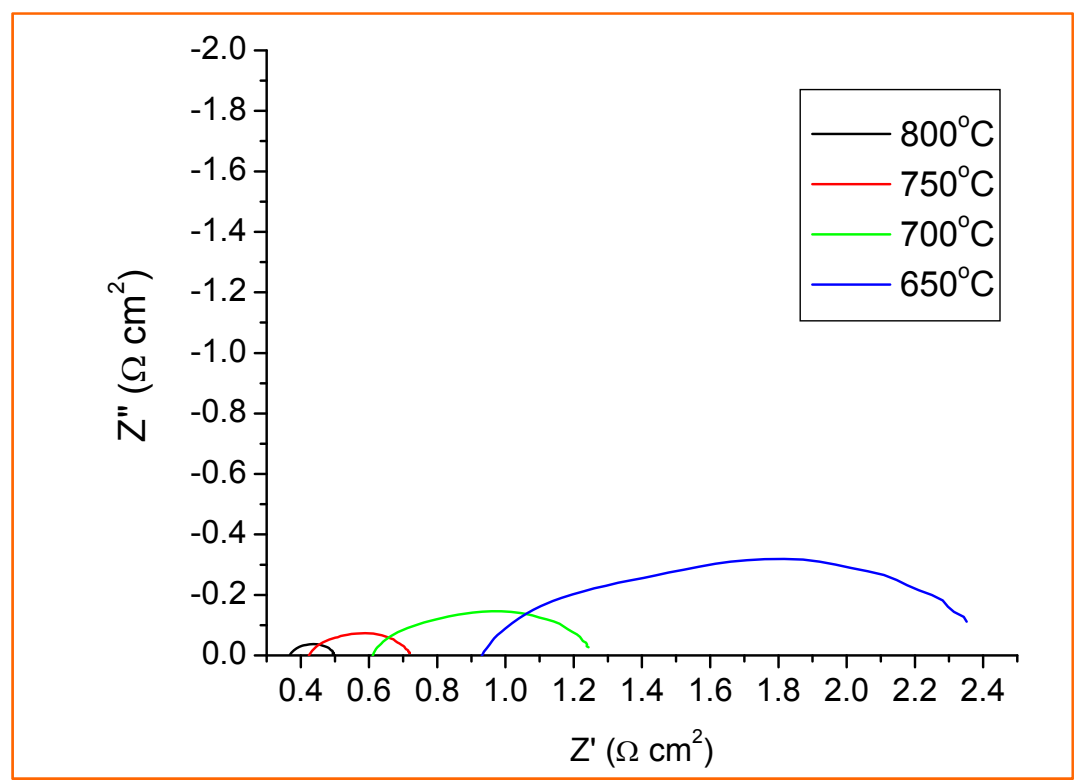

Figure 8. Impedance spectroscopy of LSCrM with Pt current collector in air

V-I characteristics and power density were measured on a Pt/LSCM/YSZ/LSCM/Ag symmetrical cell. The open circuit voltage was about 1.2 volts at all temperatures and the current density at short circuit was about $1.3 \mathrm{~A} / \mathrm{cm}^{2}$ at $800^{\circ} \mathrm{C}$, as shown in Figure 9, when a dry $10 \% \mathrm{H}_{2}$ bal. $90 \% \mathrm{~N}_{2}$ gas was used as fuel. The maximum power density reached $320 \mathrm{~mW} / \mathrm{cm}^{2}$ at $800^{\circ} \mathrm{C}$, as shown in Figure 10.

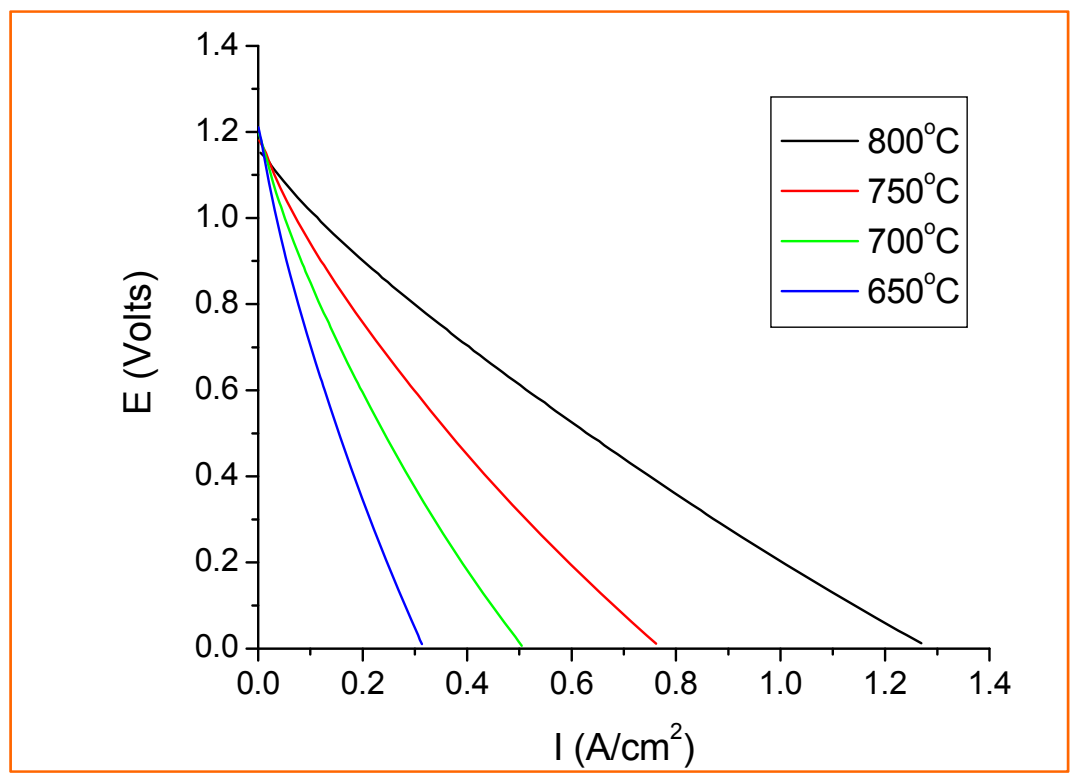

Figure 9. I-V charge profile of LSCM with Pt collector 


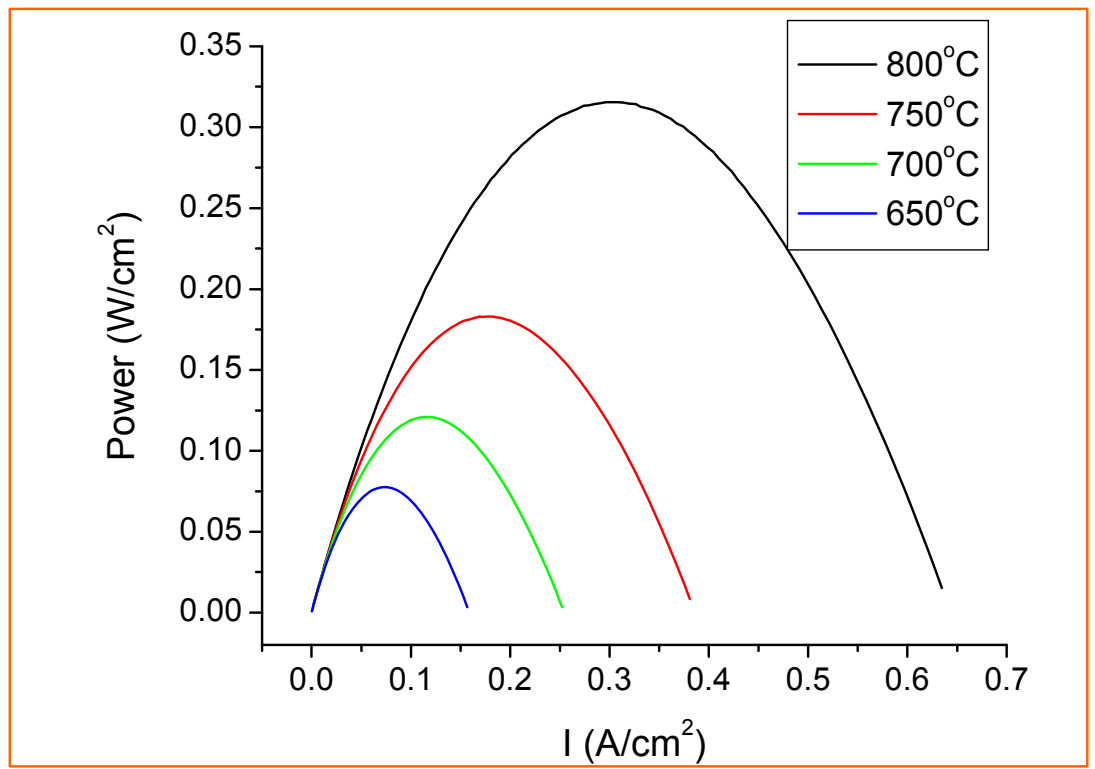

Figure 10. The power density of a symmetric cell printed with LSCM cathode and Pt collector

Task 1.3 Long-term stability test of LSCM electrodes

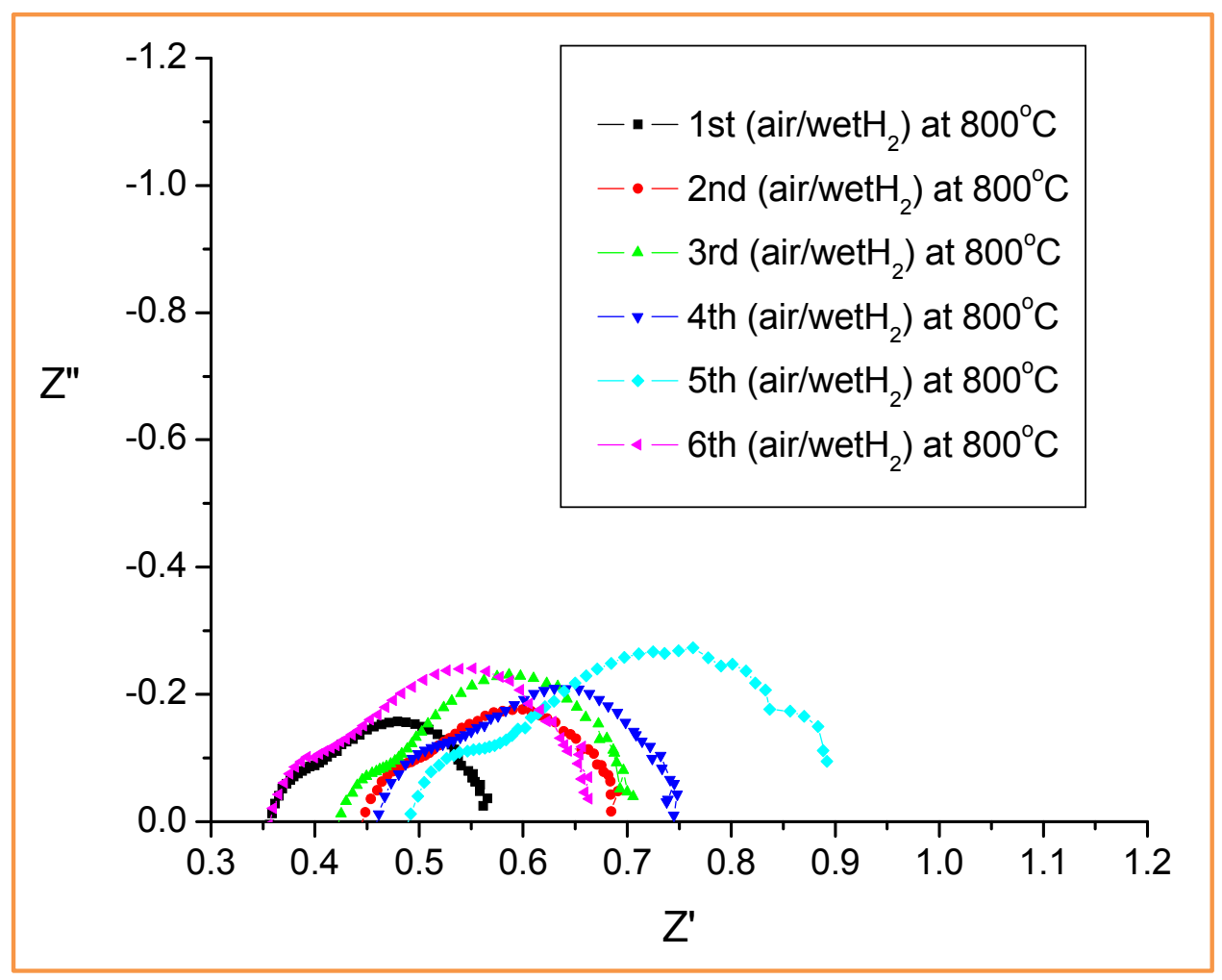

Figure 11. Impedance spectroscopy of LSCM in both air and wet $10 \% \mathrm{H}_{2}$ at $800^{\circ} \mathrm{C}$

Another symmetrical cell (LSCM/YSZ/LSCM) was constructed and tested over a couple of hundred hours in both oxidizing and reducing atmosperes. Impedance Spectroscopy was carried 
out at scheduled times during the 200-hour tests. Figure 11 shows the impedance measurement at $800^{\circ} \mathrm{C}$. As shown in the figure, the ohmic ASR, defined as the intersection between the semicircle and the $Z$ '-axis (at a high frequency range), was at an initial value of $0.35 \Omega \mathrm{cm}^{2}\left(1^{\text {st }}\right.$ test). After 150 hours, the ASR increased to $0.48 \Omega \mathrm{cm}^{2}$, which corresponds to over $35 \%$ degradation. A platinum current collector was re-applied to the LSCM electrode surface before the last impedance test $\left(6^{\text {th }}\right.$ test), after which the ASR returned to $0.35 \Omega \mathrm{cm}^{2}$, suggesting that the source of degradation was actually from contact between the current collector and electrode.

\section{Task 1.4 Characterization of a mixture of LSCM (p-type) and LST (n-type) perovskites}

As mentioned above, the SOFEC cathode material must be chemically stable under its working environment and possesses good electronic and ionic conductivity with good electrocatalytic properties. To pursue this objective, in this subtask, a mixture of p-type and n-type oxides was selected and their powders were prepared using the water based chemical solution process to fabricate non-agglomerated but well dispersed nano powders. The oxide systems, LST $\left(\mathrm{La}_{0.8} \mathrm{Sr}_{0.2} \mathrm{TiO}_{3}\right)$ and $\mathrm{LSCM}\left(\mathrm{La}_{0.8} \mathrm{Sr}_{0.2} \mathrm{Cr}_{0.5} \mathrm{Mn}_{0.5} \mathrm{O}_{3}\right)$ were selected in the study as the n-type and p-type materials, respectively. The prepared oxides were mixed, pressed and sintered at various temperatures. XRD and optical microscopy studies were performed on the prepared powders and SEM analysis was done on the sintered samples.

Powder preparation: Photomicrographs and X-ray diffraction patterns of the prepared LST and LSCM powders are shown from Figure 12 to Figure 15. As seen in Figure 14 and Figure 15, both XRD patterns are similar, suggesting that both oxides are single phase. The objective of the powder preparation was to find the optimum solution chemistry to fabricate the powders as small and soft as possible, thus allowing preparation of well-dispersed nano sized powders. More than 20 chemical solution combinations were tried to find the optimum solution chemistry for LST and LSCM. As can be seen in Figure 12 and Figure 13, the large agglomerated particles with the size of about $20-100 \mu \mathrm{m}$ (as shown in Figure 12-a and Figure 13-a) became nano sized particles after ball-milling with zirconia balls for 48 hours (Figure 12-b and Figure 13-b). 


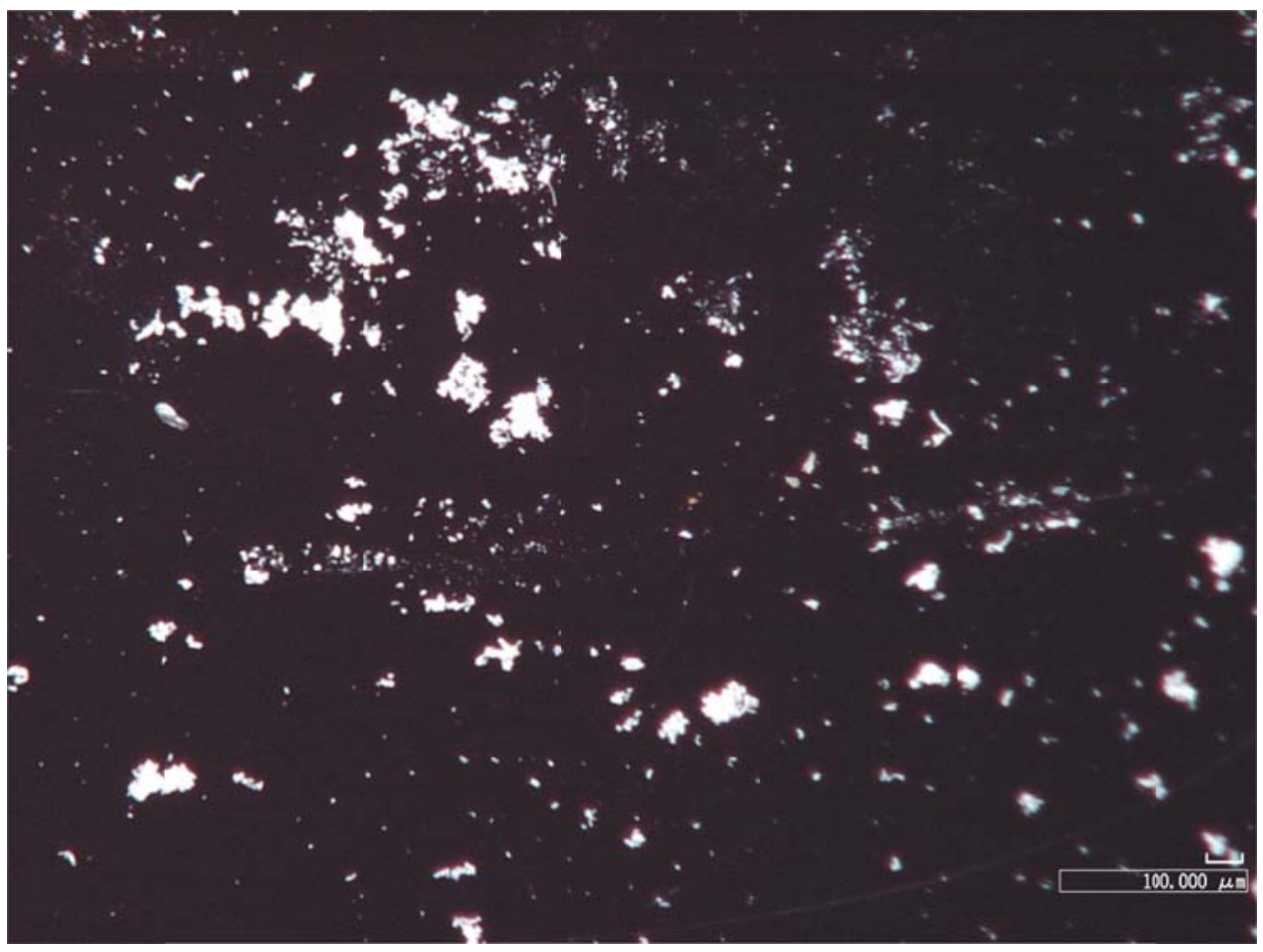

(a) As prepared LST annealed at $600^{\circ} \mathrm{C}$

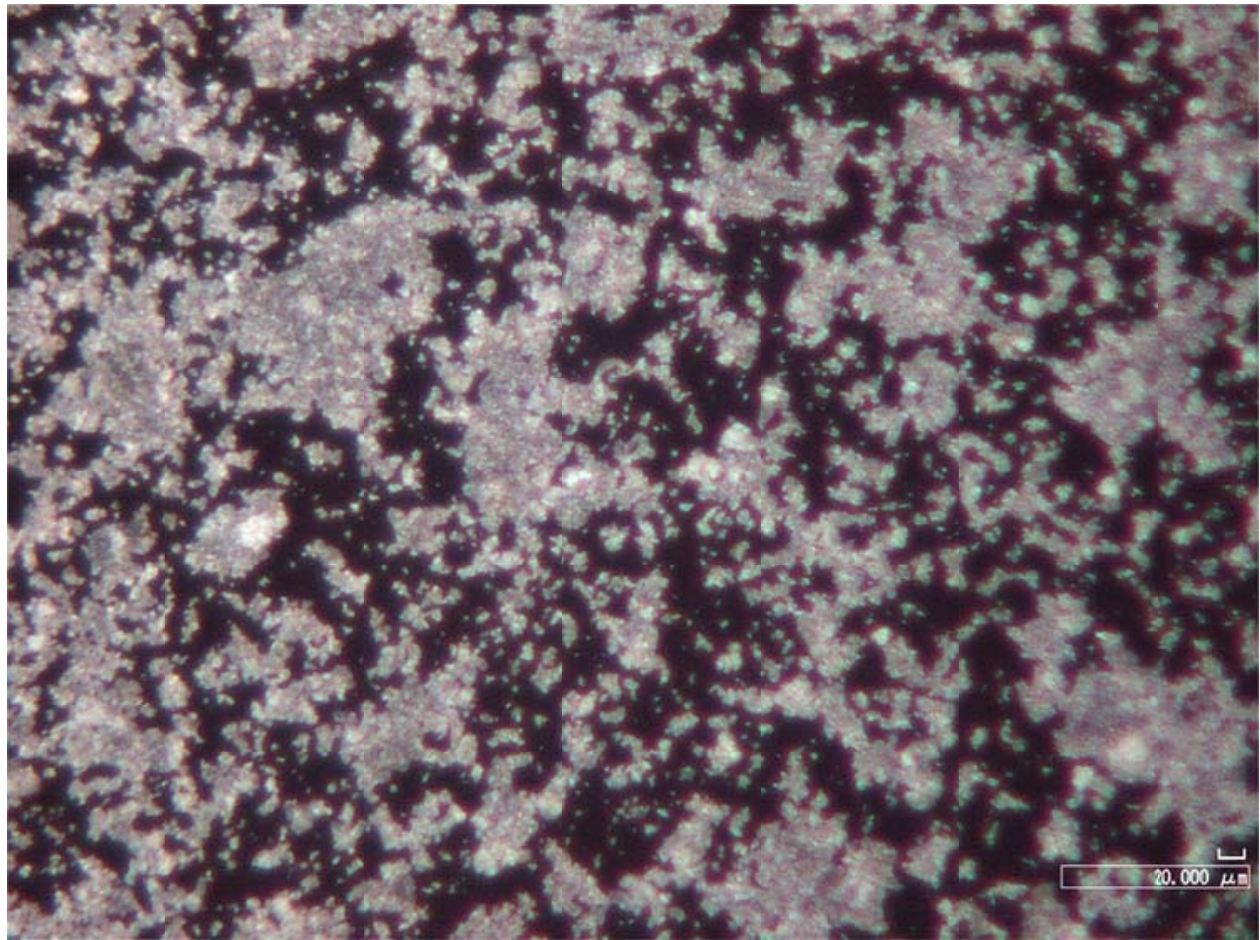

(b) LST powder after ball milling

Figure 12. LST powders using ethylene glycol - nitrate method 


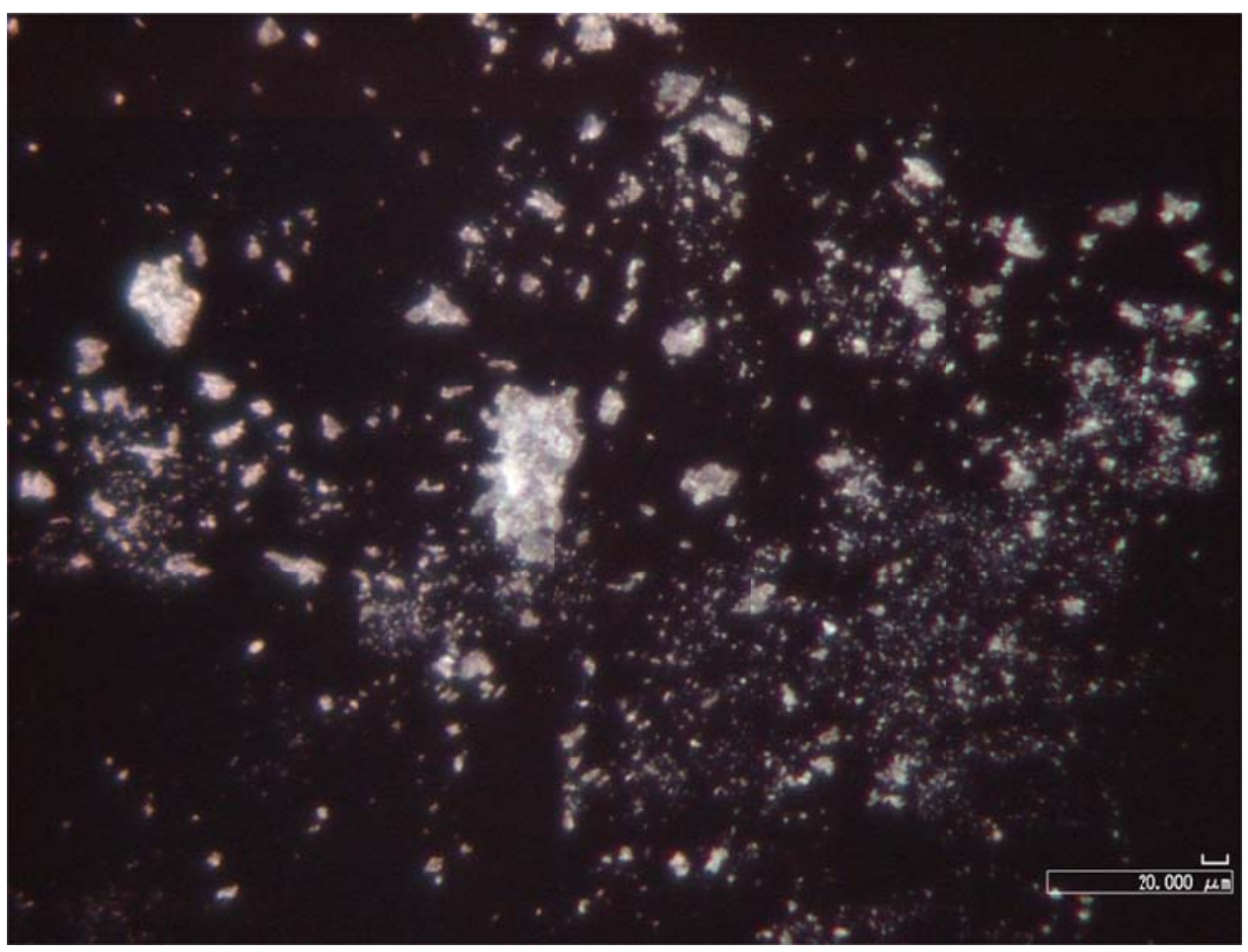

(a) As prepared LSCM annealed at $600^{\circ} \mathrm{C}$

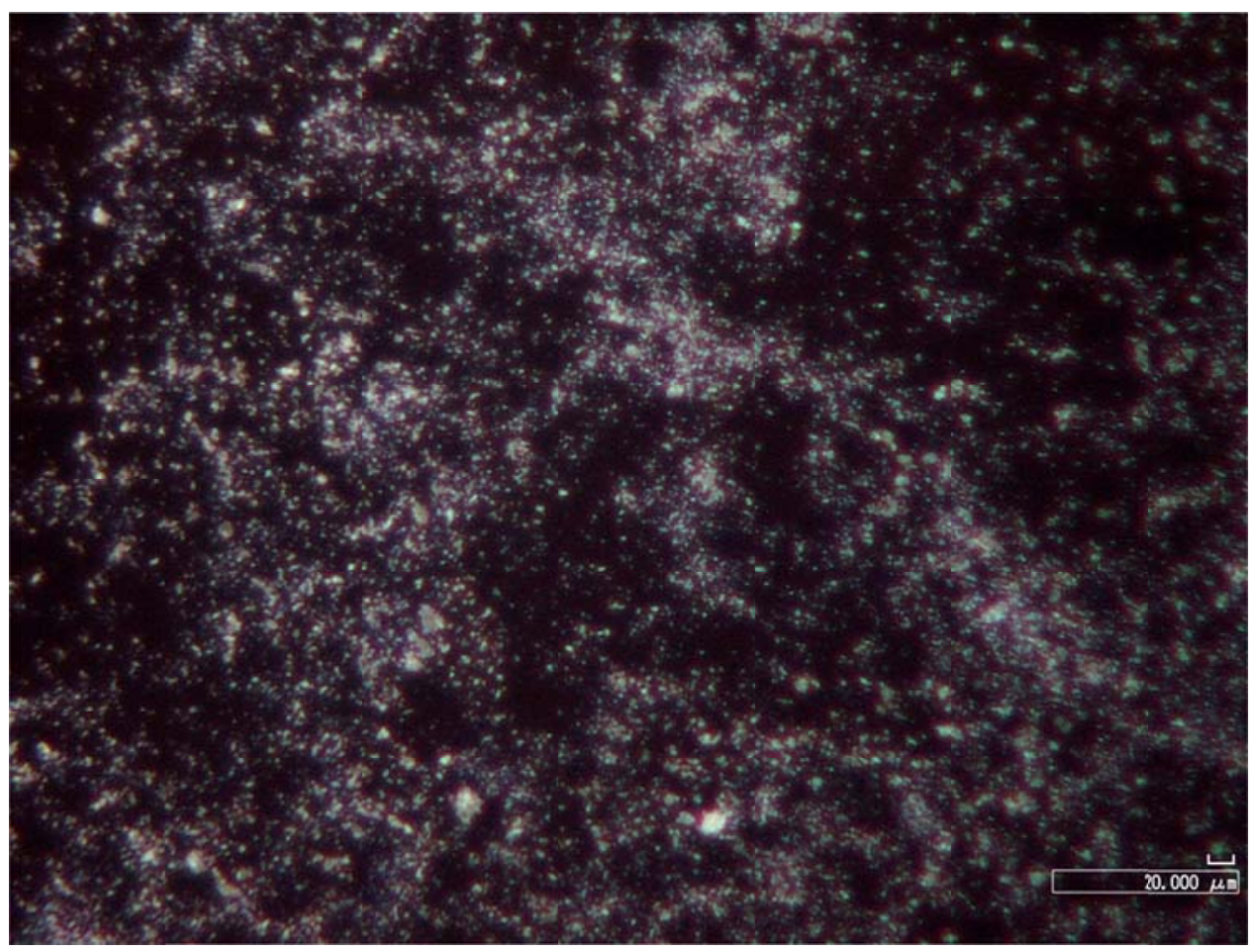

(b) LSCM powder after ball milling

Figure 13. LSCM powders using ethylene glycol - nitrate method 


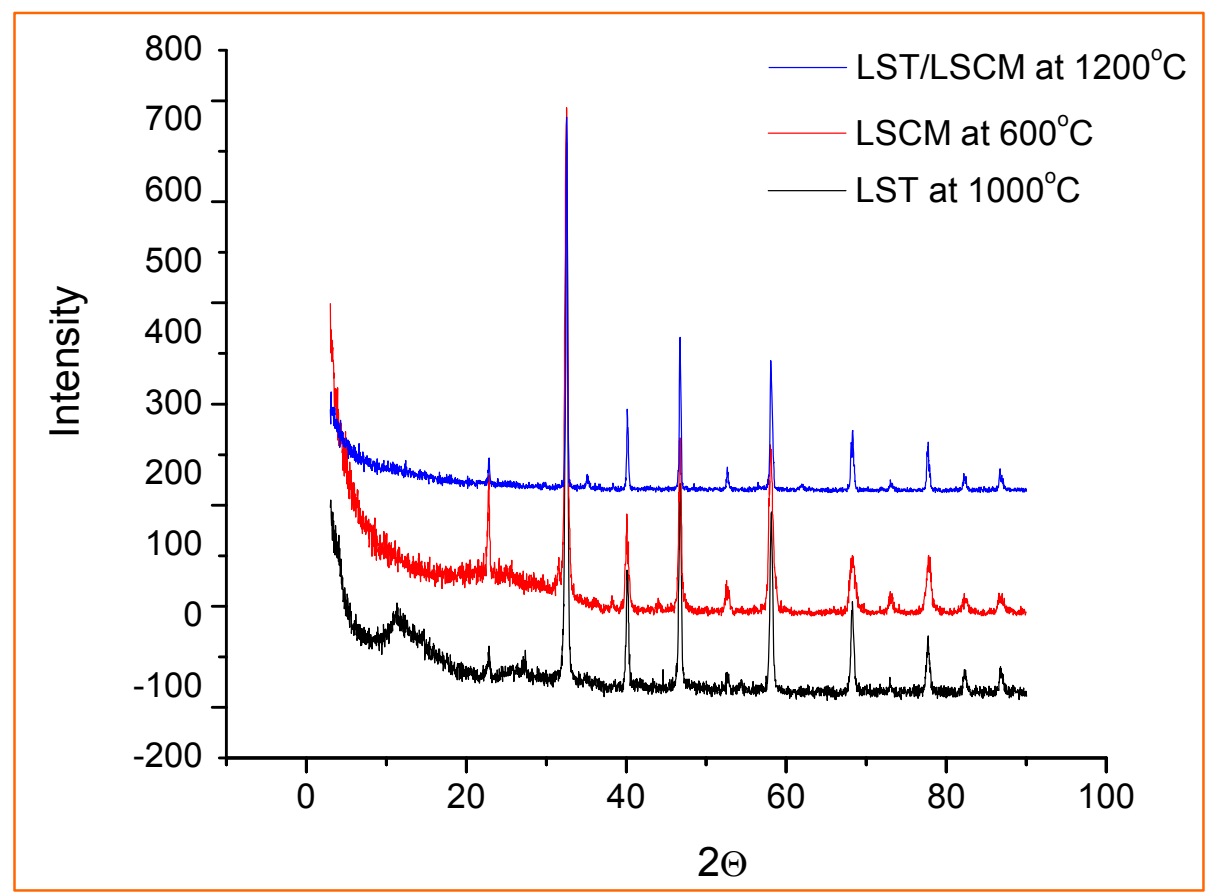

Figure 14. XRD of LST, LSCM and 50wt $\%$ LST $-50 \mathrm{wt} \% \mathrm{LSCM}$ mixture annealed at 600,1000 and $1200^{\circ} \mathrm{C}$, respectively.

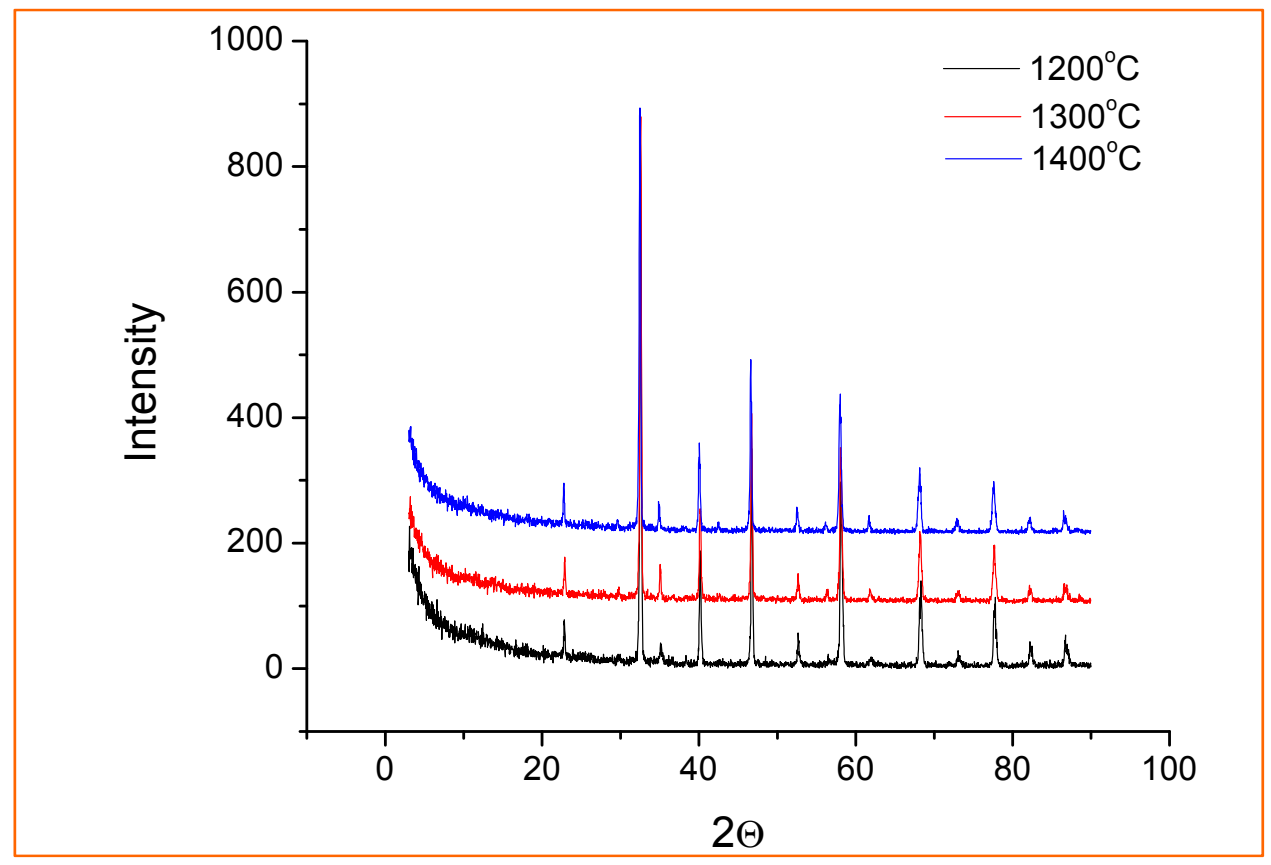

Figure 15. XRD of 50wt $\%$ LST $-50 \mathrm{wt} \% \mathrm{LSCM}$ sintered at 1200,1300 and $1400^{\circ} \mathrm{C}$

SEM micrographs of LST/LSCM mixture: After powder preparation, a mixture of n-type and ptype oxides was prepared by mixing LST and LSCM powders $50 \%$ by weight. Discs were pressed and sintered at $900^{\circ} \mathrm{C}, 1000^{\circ} \mathrm{C}, 1100^{\circ} \mathrm{C}, 1200^{\circ} \mathrm{C}, 1300^{\circ} \mathrm{C}$ and $1400^{\circ} \mathrm{C}$ in air to investigate a plausible sintering temperature at which there was minimum inter-diffusion between the two 
phases. The microstructural characterizations of the sintered samples at different temperatures were shown in Figure 16.
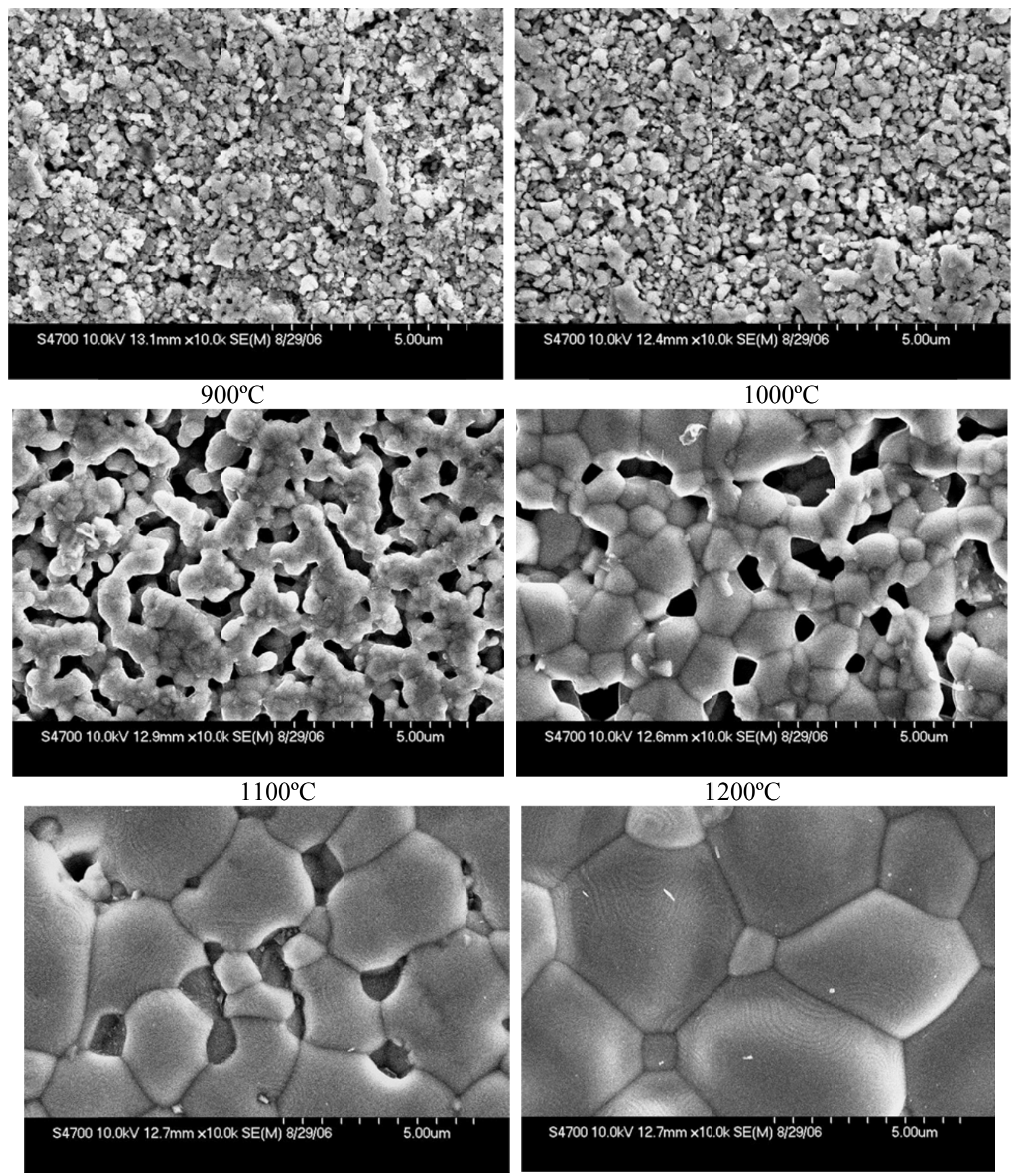

$1300^{\circ} \mathrm{C}$

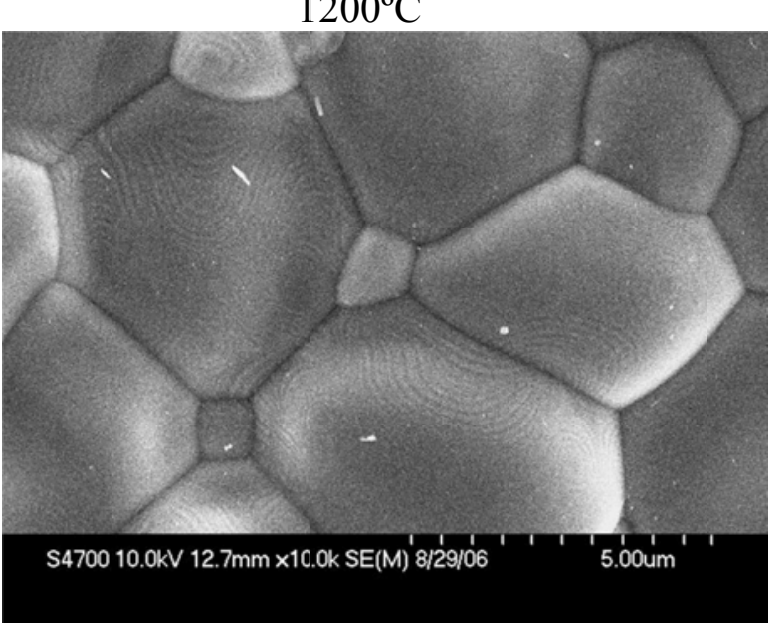

$1400^{\circ} \mathrm{C}$

Figure 16. SEM micrographs at $10 \mathrm{KX}$ for $\mathrm{LST} / \mathrm{LSCM}$ sintered between $900^{\circ} \mathrm{C}, 1000^{\circ} \mathrm{C}, 1100^{\circ} \mathrm{C}, 1200^{\circ} \mathrm{C}$, $1300^{\circ} \mathrm{C}$ and $1400^{\circ} \mathrm{C}$. 
As shown in the figure, LST and LSCM remained as separate particles if the sintering temperature was below $1000^{\circ} \mathrm{C}$. The densification or inter-diffusion process commenced at temperatures above $1100^{\circ} \mathrm{C}$, though distinct LST and LSCM phases remained at temperatures up to $1200^{\circ} \mathrm{C}$. Significant inter-diffusion between LST and LSCM was observed as the sintering temperature neared $1300^{\circ} \mathrm{C}$ and continued up to $1400^{\circ} \mathrm{C}$. The degree of inter-diffusion at each sintering temperature will be discussed below. Grain growth and well-defined grains/grain boundaries were observed at $1200^{\circ} \mathrm{C}$ and growth increased as the temperature increased to $1400^{\circ} \mathrm{C}$. The space between two phases (such as LST and LSCM) due to low sintering temperature at 900 and $1000^{\circ} \mathrm{C}$ became large pores at $1100^{\circ} \mathrm{C}$. The size of pores decreased to 2 micron at $1200^{\circ} \mathrm{C}$ and about 1 micron at $1300^{\circ} \mathrm{C}$ as densification progressed. The pores completely disappeared at $1400^{\circ} \mathrm{C}$.

Electrical conductivity of LST/LSCM mixture: The electrical conductivities of the corresponding samples were measured as a function of oxygen activity at $900^{\circ} \mathrm{C}$. As shown in Figure 17 , the electrical conductivity of LST/LSCM (50/50 by weight) exhibited p-type characteristics in the high oxygen activity regime $\left(10^{-1}-10^{-10} \mathrm{~atm}\right)$ and n-type behavior in the low oxygen activity regime below $10^{-10} \mathrm{~atm}$. The electrical conductivity of LSCM was p-type and didn't exhibit any n-type behavior even at very low oxygen activity below $10^{-20} \mathrm{~atm}$, as shown Figure 1. Therefore, the n-type conductivity in the low oxygen activity area resulted from the LST phase. In fact, the overall characteristics of the composite were dominated by the low electrical conductivity of the LST.

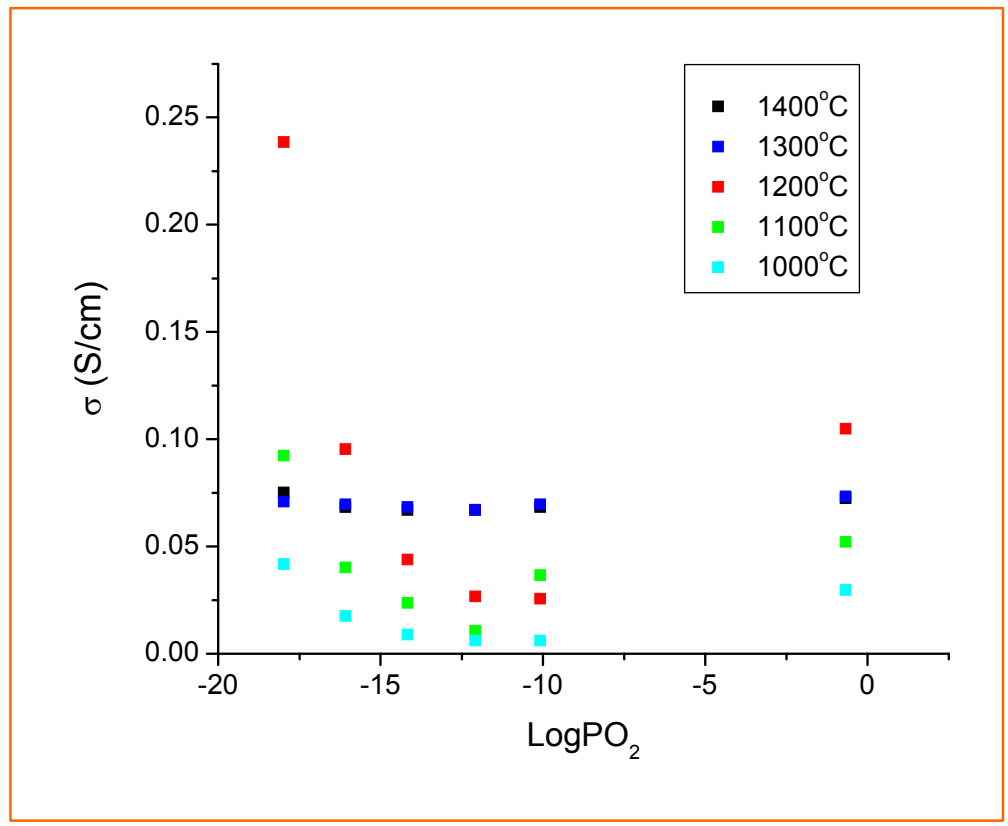

Figure 17. Conductivities of $\operatorname{LST}(0.8 / 0.2 / 1) / \operatorname{LSCM}(0.8 / 0.2 / 0.5 / 0.5)$ sintered at $1000-1400^{\circ} \mathrm{C}$ were measured as a function of oxygen activity at $900^{\circ} \mathrm{C}$

It is important to notice that even though the electrical conductivity of LSCM in air was $25 \mathrm{~S} / \mathrm{cm}$ at $800^{\circ} \mathrm{C}$, the conductivity of the LST/LSCM composite was between about $0.1 \mathrm{~S} / \mathrm{cm}$ in the highest oxygen activity area and $0.25 \mathrm{~S} / \mathrm{cm}$ in the lowest oxygen activity area. Figure 18 shows the LST electrical conductivity measurement as a function of oxygen activity at $900^{\circ} \mathrm{C}$. The LST 
sample was sintered at $1200^{\circ} \mathrm{C}$ in air. As shown in the figure, at $900^{\circ} \mathrm{C}$ the electrical conductivity of LST was only $5 \times 10^{-4} \mathrm{~S} / \mathrm{cm}$ at the highest oxygen activity and $0.9 \mathrm{~S} / \mathrm{cm}$ at the lowest oxygen activity, indicating that LST was not a suitable cathode for the SOFEC applications, and leading to the consideration of other n-type oxides.

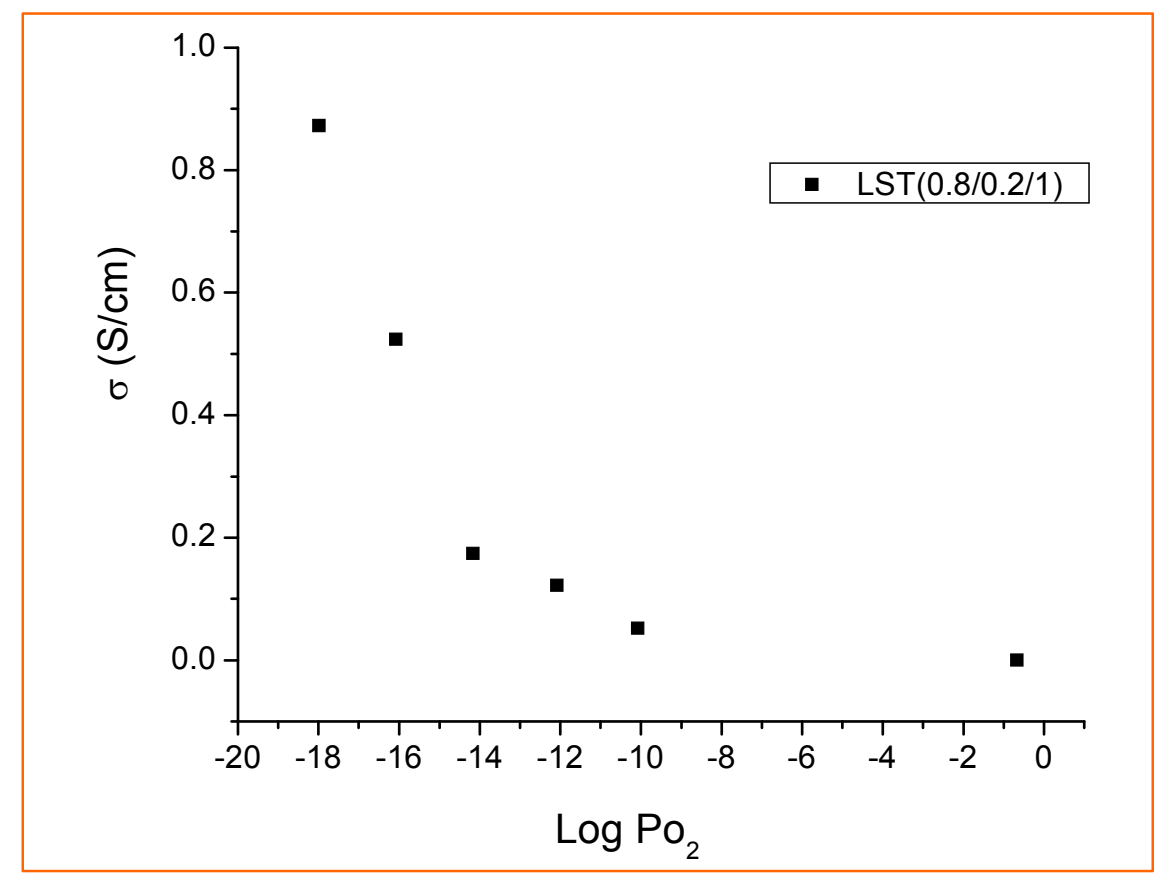

Figure 18. Electrical conductivity of $\operatorname{LST}(0.8 / 0.2 / 1)$ sintered at $1200^{\circ} \mathrm{C}$ as a function of oxygen activity at $900^{\circ} \mathrm{C}$

Chemical Analysis of LST/LSCM using SEM-EDAX: Chemical analyses of LST/LSCM were carried out using SEM-EDAX (Hitachi S4700 FE-SEM). Even though SEM-EDAX did not provide precise information as to the material's composition, it provided information regarding the compositional variation on the desired area of materials. According to the conductivity data shown in Figure 17, LST/LSCM sintered at 1100 and $1200^{\circ} \mathrm{C}$ were of interest because the mixture exhibited distinct $\mathrm{p}$-type to n-type transition characteristics and had higher conductivities than those sintered at other temperatures. The characteristics proved that the LST/LSCM performed as an n-type conductor in a low oxygen activity regime as well as a p-type conductor in a high oxygen activity regime. Therefore, in addition to the results from the electrical conductivity and microstructural analysis, the results from the chemical analyses could be very helpful to determine the optimum sintering temperature of LST/LSCM for minimizing the interdiffusion process and maximizing the electrical conductivity. Figure 19 shows that the chemical analysis of the LST/LSCM samples sintered at $1100^{\circ} \mathrm{C}$ and $1200^{\circ} \mathrm{C}$. The chemical analyses were performed at the light and dark-colored areas of the LST/LSCM sintered at $1100^{\circ} \mathrm{C}$, as shown in Figure 19 (a) and (b), because the grain boundary was not fully developed to distinguish grains and grain boundaries at this level of sintering temperature. On the other hand, the grains and grain boundaries were fully developed at $1200^{\circ} \mathrm{C}$. Therefore, as shown in Figure 19 (c) and (d), the chemical analysis was carried out on the grains and grain boundaries for the LST/LSCM sintered at $1200^{\circ} \mathrm{C}$. 


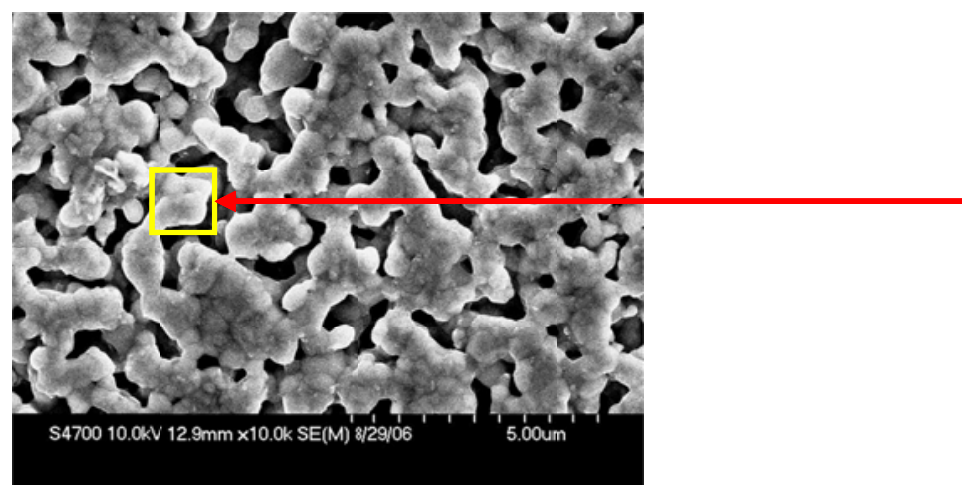

\begin{tabular}{lrr} 
Element & Wt \% & \multicolumn{1}{c}{ At \% } \\
O K & 30.57 & 70.08 \\
SrL & 10.31 & 4.32 \\
TiK & 12.07 & 9.24 \\
LaL & 37.72 & 9.96 \\
CrK & 4.95 & 3.49 \\
MnK & 4.37 & 2.92 \\
Total & 100 & 100
\end{tabular}

(a) EDAX profile on light colored area on LST/LSCM (sintered at $1100^{\circ} \mathrm{C}$ )

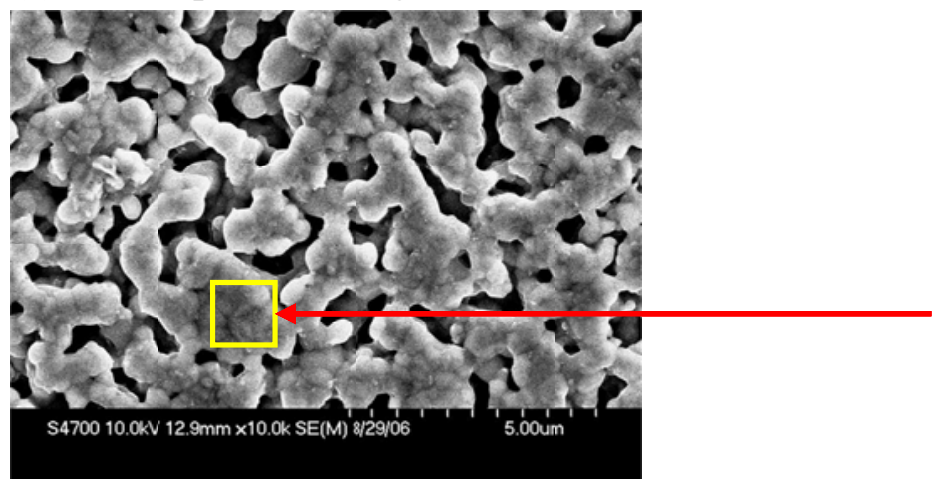

\begin{tabular}{lrr} 
Element & Wt \% & \multicolumn{1}{l}{ At \% } \\
O K & 22.83 & 54.92 \\
SrL & 5.16 & 2.27 \\
TiK & 7.07 & 5.68 \\
LaL & 21.42 & 5.94 \\
CrK & 17.47 & 12.93 \\
MnK & 26.06 & 18.26 \\
Total & 100 & 100
\end{tabular}

(b) EDAX profile on dark colored area on LST/LSCM (sintered at $1100^{\circ} \mathrm{C}$ )

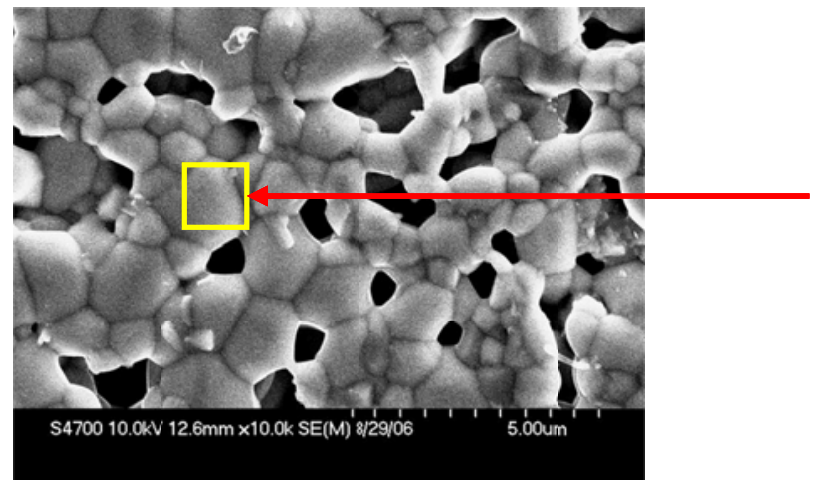

\begin{tabular}{lrr} 
Element & Wt \% & \multicolumn{1}{l}{ At \% } \\
O K & 15.29 & 49.09 \\
SrL & 10.82 & 6.35 \\
TiK & 15.89 & 17.05 \\
LaL & 47.83 & 17.69 \\
CrK & 5.96 & 5.89 \\
MnK & 4.21 & 3.93 \\
Total & 100 & 100
\end{tabular}

(c) EDAX profile on light colored area on LST/LSCM (sintered at $1200^{\circ} \mathrm{C}$ )

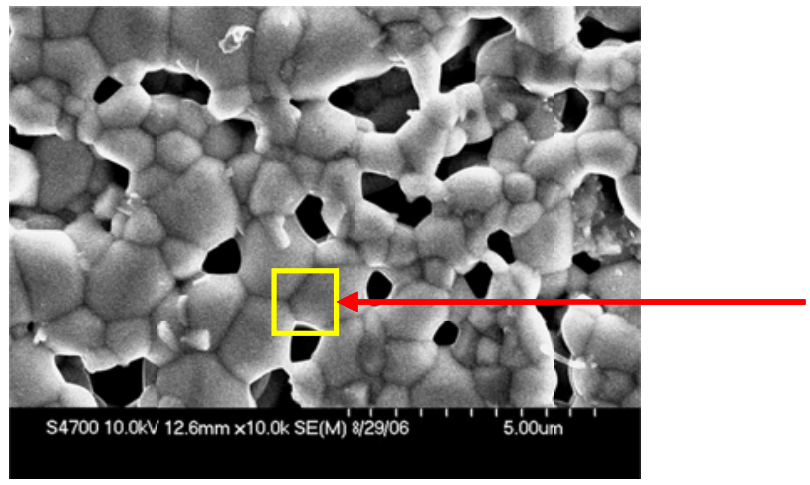

\begin{tabular}{lrr} 
Element & Wt \% & \multicolumn{1}{l}{ At \% } \\
& & \\
O K & 24.16 & 63.03 \\
SrL & 11.06 & 5.27 \\
TiK & 13.68 & 11.92 \\
LaL & 41.97 & 12.61 \\
CrK & 5.35 & 4.29 \\
MnK & 3.8 & 2.89 \\
Total & 100 & 100
\end{tabular}

(d) EDAX profile on dark colored area on LST/LSCM (sintered at $1200^{\circ} \mathrm{C}$ )

Figure 19. Chemical analysis of LST/LSCM sintered at $1100^{\circ} \mathrm{C}(\mathrm{a}, \mathrm{b})$ and at $1200^{\circ} \mathrm{C}(\mathrm{c}, \mathrm{d})$ 
As shown in the Figure 19 (a) and (b), the area with light-color was rich in LST while the area with dark color was rich in LSCM, suggesting that a diffusion process between LST and LSCM was limited or slow at $1100^{\circ} \mathrm{C}$. As shown in Figure 19 (c) and (d), the LST/LSCM sintered at $1200^{\circ} \mathrm{C}$ had no significant composition variation between grain and grain boundary. Therefore, the active diffusion process seemed to start around $1100 \sim 1200^{\circ} \mathrm{C}$. The apparent density of $\mathrm{LST} / \mathrm{LSCM}$ sintered at $1200^{\circ} \mathrm{C}$ was also much higher than that sintered at $1100^{\circ} \mathrm{C}$. Since the electrical conductivity of LST/LSM sintered at $1200^{\circ} \mathrm{C}$ was higher than that of sintered at $1100^{\circ} \mathrm{C}$, it could be possibly attributed to (1) a higher density when sintering at $1200^{\circ} \mathrm{C}$; (2) a relatively early stage of active inter-diffusion process at which n-type LST and p-type LSCM coexisted without losing the original material properties completely. The electrical conductivity of LST/LSCM sintered at the temperatures higher than $1200^{\circ} \mathrm{C}$ was much lower than that of $\mathrm{LST} / \mathrm{LSCM}$ sintered at $1200^{\circ} \mathrm{C}$, suggesting that once the inter-diffusion process was progressed, the overall conductivity was dominated by the LST which had a low electrical conductivity. Therefore, a sintering temperature higher than $1200^{\circ} \mathrm{C}$ was not recommended.

Task 1.5 Characterization of SDC- and GDC- based n-type perovskites

In addition to LST, Gd- and Sm- doped ceria (GDC and SDC respecitvely) were also investigated as potential n-type candidates, and samples (both dense and porous) were made for electrical conductivity study as a function of temperature and oxygen activity. The chemical and mechanical stabilities of the GDC and SDC were evaluated via the electrical conductivity measurements during reduction/oxidation processes from $500^{\circ} \mathrm{C}$ and $800^{\circ} \mathrm{C}$.

Electrical conductivity of $G d$ doped Ceria $(G D C)$ : The electrical conductivity measurements of Gd-doped Ceria $\left(\mathrm{Gd}_{0.2} \mathrm{Ce}_{0.8} \mathrm{O}_{2}\right)$ were carried out to investigate whether the GDC can be a candidate material for a redox stable cathode. The GDC powder used in this experiment was prepared by Praxair (purity: 99.9\%) using the combustion spray pyrolysis method. GDC powders were pressed $(10 \mathrm{kpsi})$ and sintered respectively at $1100^{\circ} \mathrm{C}$ and $1400^{\circ} \mathrm{C}$ for porous and dense pellets in air over 4 hours before the electrical conductivity measurement. A four-probe method was used to measure the GDC electrical conductivity. The prepared porous and dense GDC samples had $\sim 75 \%$ and $>90 \%$ of theoretical density, respectively. Figure 20 shows the electrical conductivities of the porous and dense GDC pellets as a function of temperatures. The conductivity of the dense GDC samples was higher than the porous one by a factor of two. In a low temperature range $\left(300-500^{\circ} \mathrm{C}\right)$, the conduction activation energies of the porous and dense GDC's were found $\sim 0.86 \mathrm{eV}$ and $0.74 \mathrm{eV}$, respectively, while in a high temperature range (600 $-900^{\circ} \mathrm{C}$ ), both activation energies were about $0.68 \mathrm{eV}$. The activation energy differences between the porous and dense samples were related to a grain boundary resistance increase in the lower temperature range, and impedance spectroscopy was used for the investigation. 


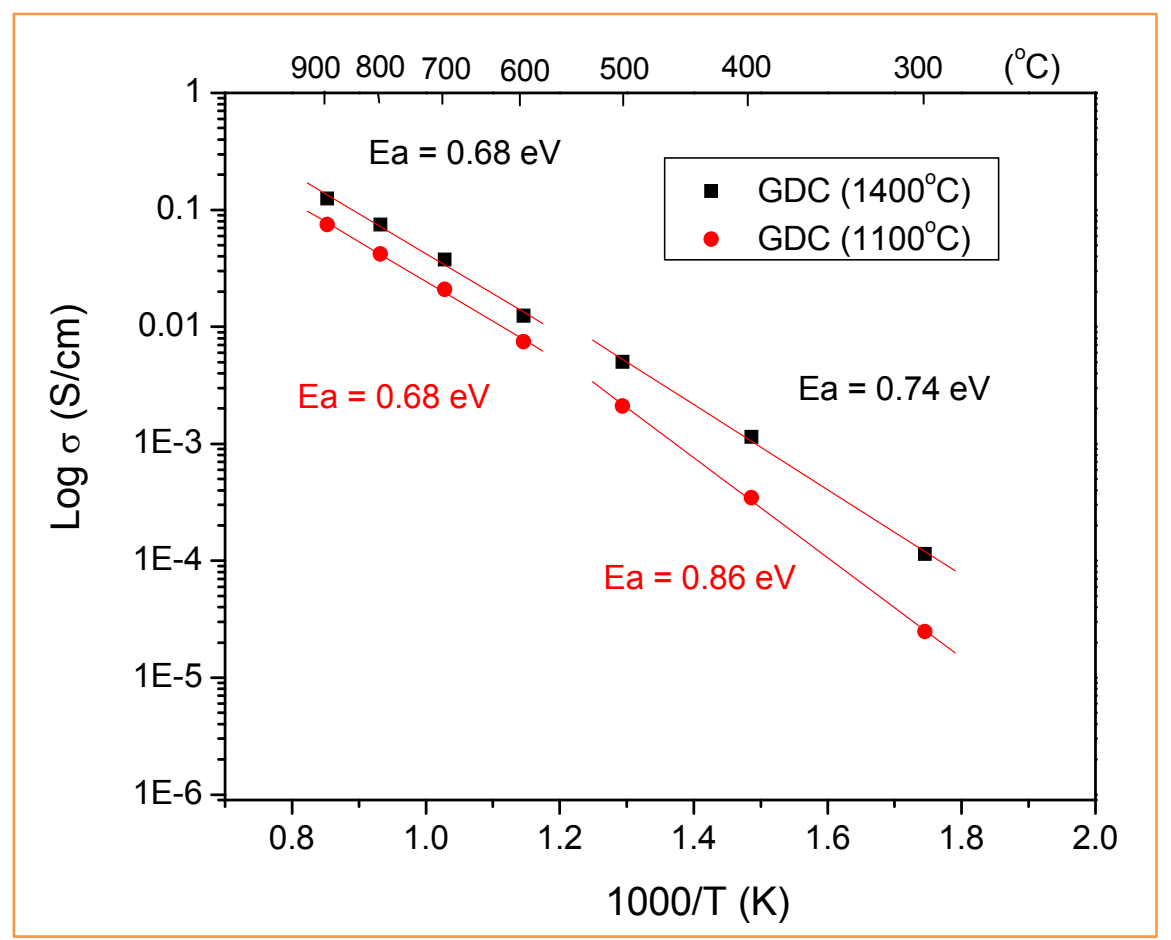

Figure 20. Conductivity of $\mathrm{Gd}_{0.2} \mathrm{Ce}_{0.8} \mathrm{O}_{2-\delta}$ discs sintered at $1100^{\circ} \mathrm{C}$ and $1400^{\circ} \mathrm{C}(\sim 75$ and $>90 \%$ of theoretical density, respectively) measured as a function of temperature in air

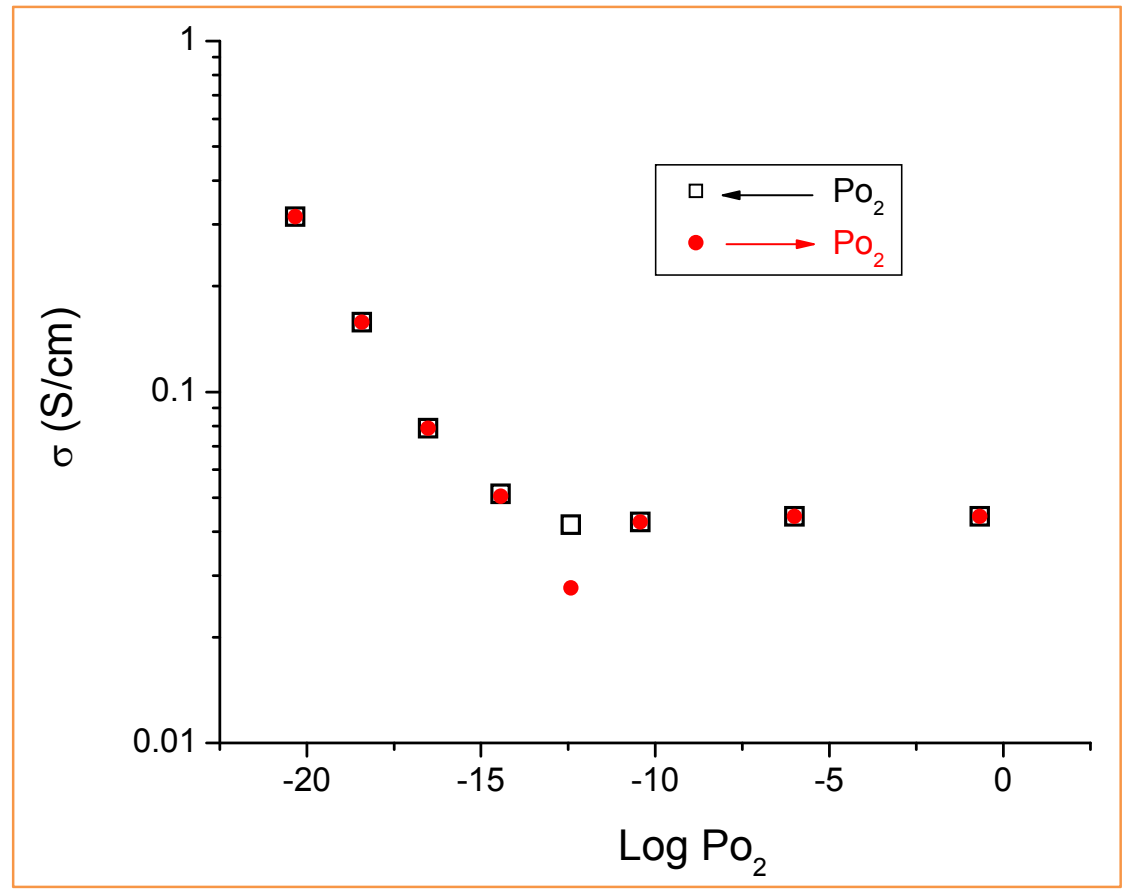

Figure 21. Conductivity of a porous $\mathrm{Gd}_{0.2} \mathrm{Ce}_{0.8} \mathrm{O}_{2-\delta}$ pellet (sintered at $1100^{\circ} \mathrm{C}, \sim 75 \%$ of theoretical density) as a function of oxygen activity at $800^{\circ} \mathrm{C}$

The electrical conductivity of porous GDC discs was also measured as a function of oxygen activity at $800^{\circ} \mathrm{C}$. As mentioned above, the porous ceramic samples were used because they 
equilibrated to changes in temperature and oxygen activity much faster than that in the case of dense samples. This was especially true at lower temperatures and in a reducing atmosphere. As shown in Figure 21, the electrical conductivity was about $0.04 \mathrm{~S} / \mathrm{cm}$ in air and did not change significantly until the oxygen activity reduced to $1 \times 10^{-12}$ atm. Beyond that point, the electrical conductivity began to increase, which was due to the reduction of the ceria and reached about $0.35 \mathrm{~S} / \mathrm{cm}$ at $1 \times 10^{-20} \mathrm{~atm}$.

Impedance Spectroscopy of SDC: Impedance spectroscopy was measured as a function of temperature and frequency $\left(1\right.$ to $\left.1 \times 10^{6} \mathrm{~Hz}\right)$. SDC powder was purchased from DKKK Co., Ltd (Japan). After pressing and sintering at $1400^{\circ} \mathrm{C}$, a typical thickness of a dense SDC disc was around $220 \mu \mathrm{m}$ with a density $>95 \%$ of the theoretical density. Silver (Ag) paint was used as the electrode and current collector on both sides. The results were plotted in Figure $22(\mathrm{a})-(\mathrm{h})$ for the temperatures from $100^{\circ} \mathrm{C}$ to $800^{\circ} \mathrm{C}$. As shown in Figure 20 (a) - (e), the impedance spectra in the low temperature range from $100^{\circ} \mathrm{C}$ to $400^{\circ} \mathrm{C}$ exhibited distinct grain and grain boundary contributions to the electrical conductivity (first two semi-circles from the high frequency range). However, when the temperature increased above $400^{\circ} \mathrm{C}$, the relative grain and grain boundary contributions to the electrical conductivity were no longer distinguishable. Above $500^{\circ} \mathrm{C}$, the total conductivity was determined at the intersection between impedance spectrum and $\mathrm{x}$-axis at high frequency range. The impedance spectrum associated with the low frequency range for temperatures between $200^{\circ} \mathrm{C}-500^{\circ} \mathrm{C}$ and the only spectrum observed for temperatures higher than $600^{\circ} \mathrm{C}$ were assumed to be resulted from the contact and interfacial resistance between the Ag electrode and SDC.

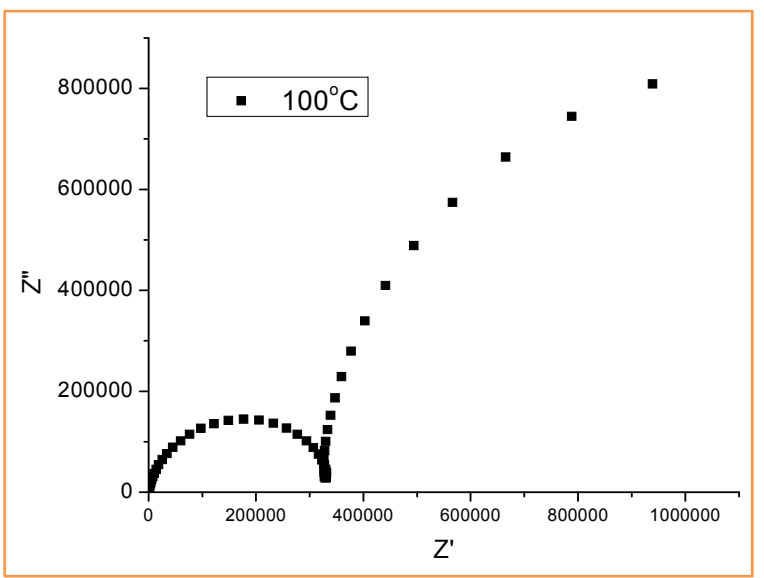

(a) at $100^{\circ} \mathrm{C}$

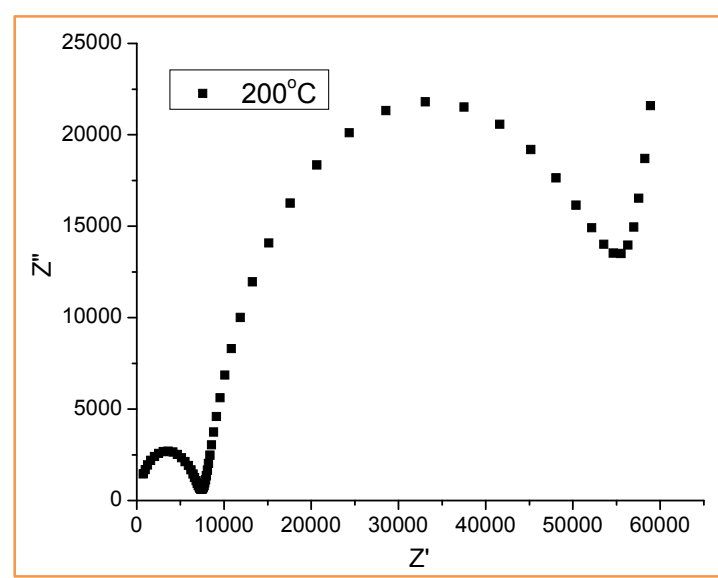

(b) at $200^{\circ} \mathrm{C}$ 


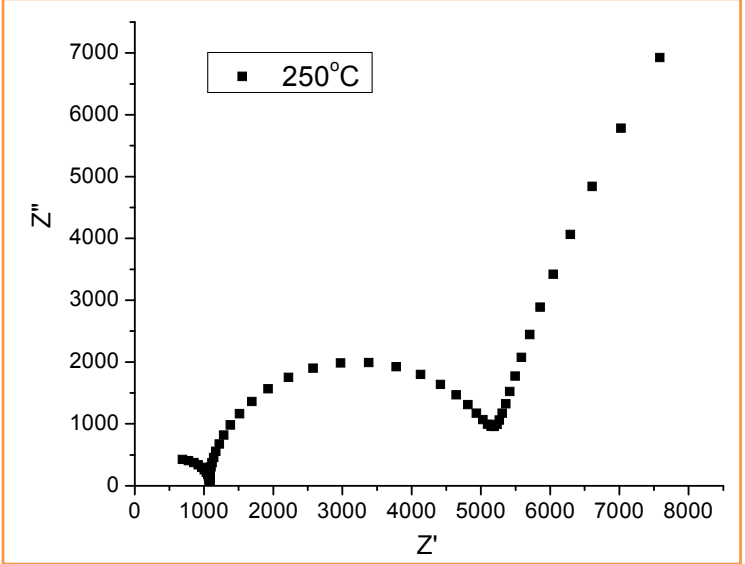

(c) at $250^{\circ} \mathrm{C}$

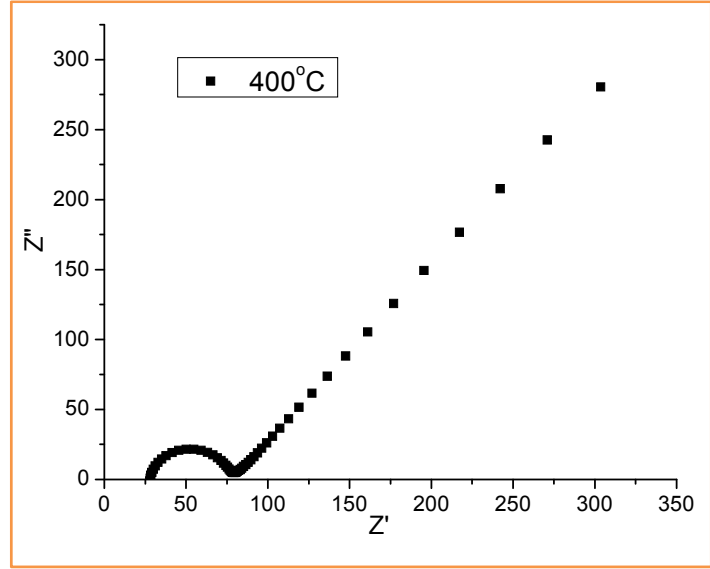

(e) at $400^{\circ} \mathrm{C}$

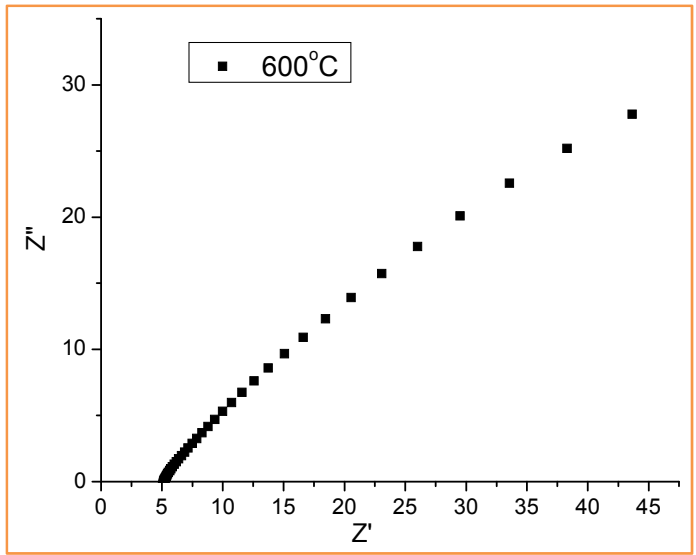

(g) at $600^{\circ} \mathrm{C}$

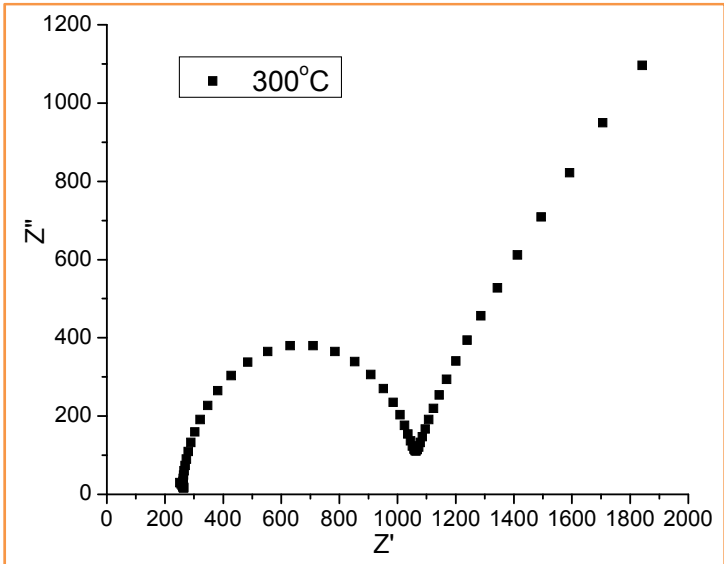

(d) at $300^{\circ} \mathrm{C}$

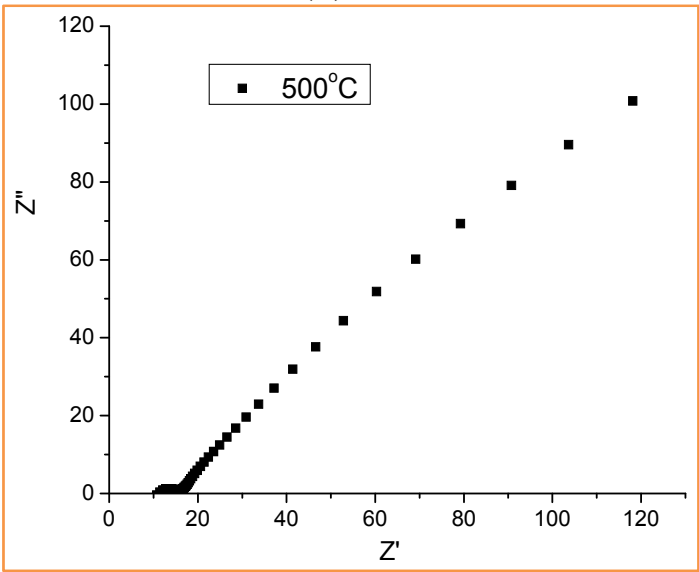

(f) at $500^{\circ} \mathrm{C}$

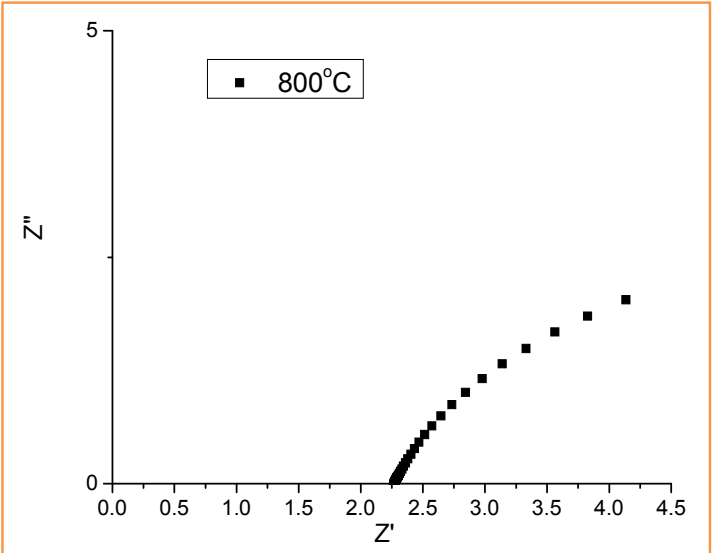

(h) at $800^{\circ} \mathrm{C}$

Figure 22. Impedance spectroscopy of SDC discs as a function of temperature with frequency range between $1-1 \mathrm{e}^{6} \mathrm{~Hz}$ (surface area of the electrode was $0.5 \mathrm{~cm}^{2}$ )

Activation Energy of SDC: The SDC electrical conductivities were calculated using the impedance spectroscopy measurements as a function of temperature, and shown in Figure 23. It was observed that the SDC conductivity was limited by the grain boundaries when the temperature was below $400^{\circ} \mathrm{C}$. As the temperature increased above $400^{\circ} \mathrm{C}$, the conductivity was controlled by the conductivity of the grains. The activation energy was also estimated and is 
shown in Figure 23. When the temperature was below $400^{\circ} \mathrm{C}$, the activation energy was about $0.9 \mathrm{eV}$ for the grain boundary and $0.8 \mathrm{eV}$ for the grain of the SDC. The activation energy for the total conduction was also about $0.9 \mathrm{eV}$ which agreed well with the activation energy of the grain boundary below $400^{\circ} \mathrm{C}$. This again suggested that the total conductivity was limited by the grain boundary below $400^{\circ} \mathrm{C}$. However, above $400^{\circ} \mathrm{C}$ the activation energy for grain conduction was about $0.6 \mathrm{eV}$, and about $0.7 \mathrm{eV}$ for the total conduction (includes grain and grain boundary), suggesting that for the operation temperature above $400^{\circ} \mathrm{C}$, the total conductivity of SDC was limited by the conductivity of the grain. When the activation energy of SDC was compared with that of the reference values of SDC (about $0.6 \mathrm{eV}$ ), the cells have higher activation energy by 0.1 $\mathrm{eV}$ than that of the reference values.

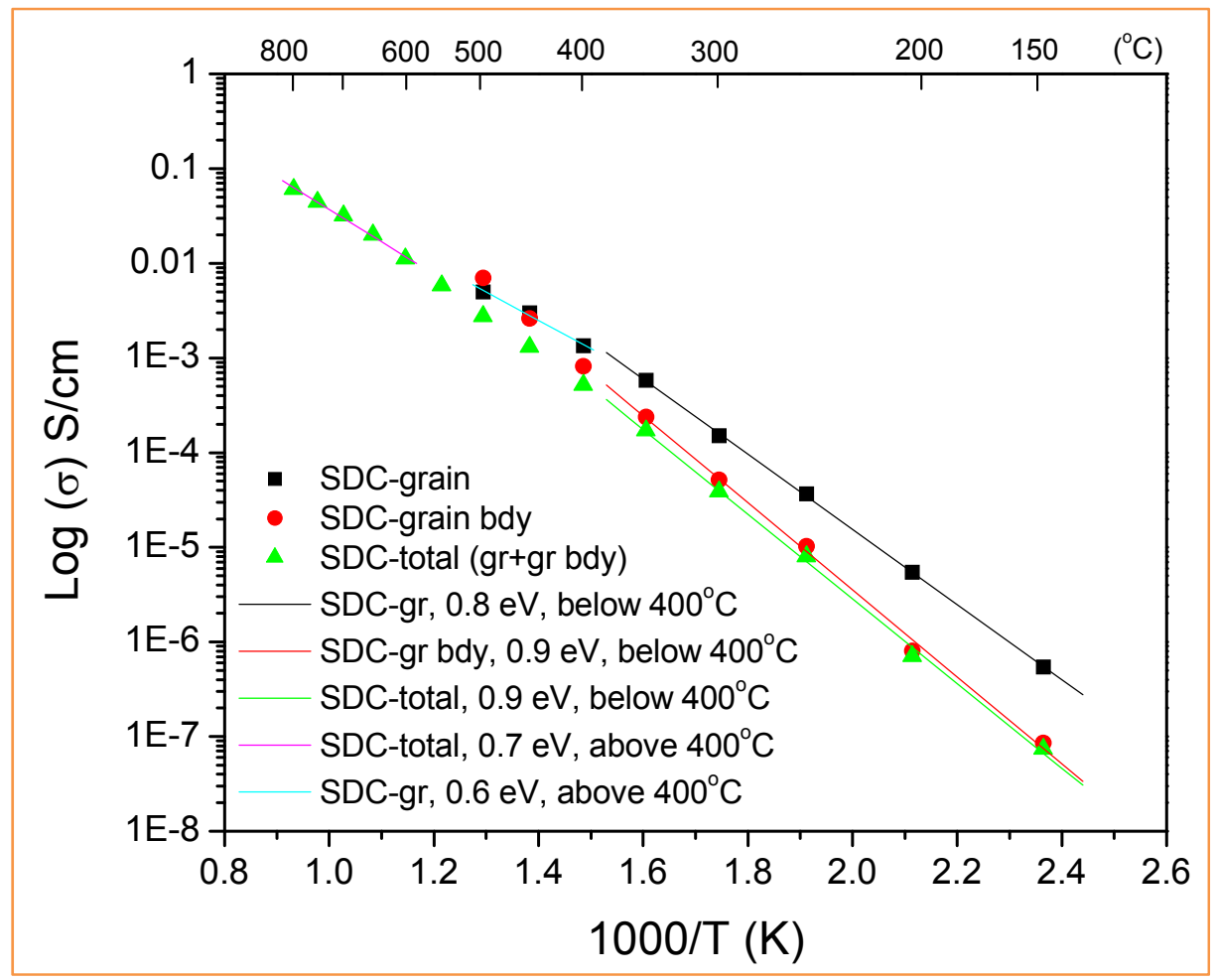

Figure 23. Activation energy of SDC discs as a function of temperature.

Redox stability of GDC and SDC: The redox stability of porous GDC and SDC sintered at $1100^{\circ} \mathrm{C}$ and $1200^{\circ} \mathrm{C}$ was tested in air and wet-forming gas $\left(10 \% \mathrm{H}_{2}\right.$ bal. $\left.\mathrm{N}_{2}\right)$ at various temperatures. Figure 24 and Figure 25 show the redox stability test results of GDC and SDC, respectively. As shown in the figures, reversible redox characteristics were observed for both materials. In another redox stability test (as shown in the Figure 25), the SDC sample was redox-cycled at $100^{\circ} \mathrm{C}$ intervals, starting from $500^{\circ} \mathrm{C}$ to $800^{\circ} \mathrm{C}$. Although the sample was subjected to several redox cycles at each temperature, it exhibited great redox stability. From the studies above, doped-ceria (both SDC and GDC) exhibited good conductivity in reducing/oxidizing atmopsheres and good redox stability, and ceria was thus choosen for the reversible SOFEC/SOFC application. 


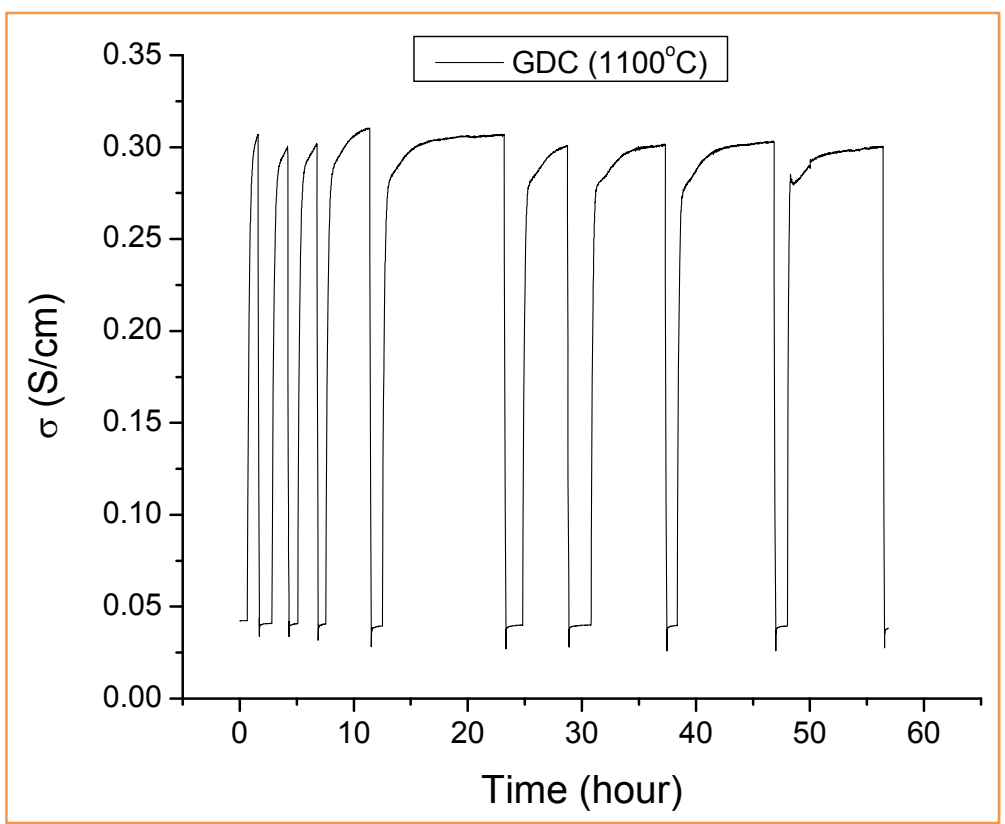

Figure 24. Redox stability of GDC tested in air and wet-forming gas $\left(10 \% \mathrm{H}_{2}\right.$ bal. $\left.\mathrm{N}_{2}\right)$ at $800^{\circ} \mathrm{C}$

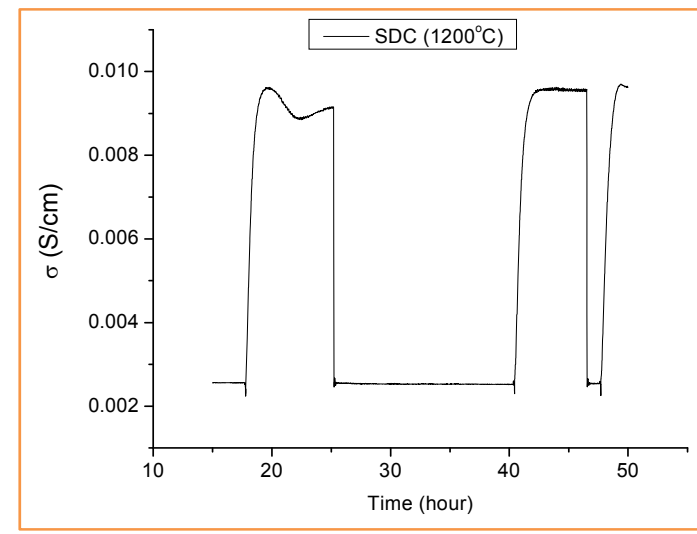

(a) $\mathrm{SDC}$ at $500^{\circ} \mathrm{C}$

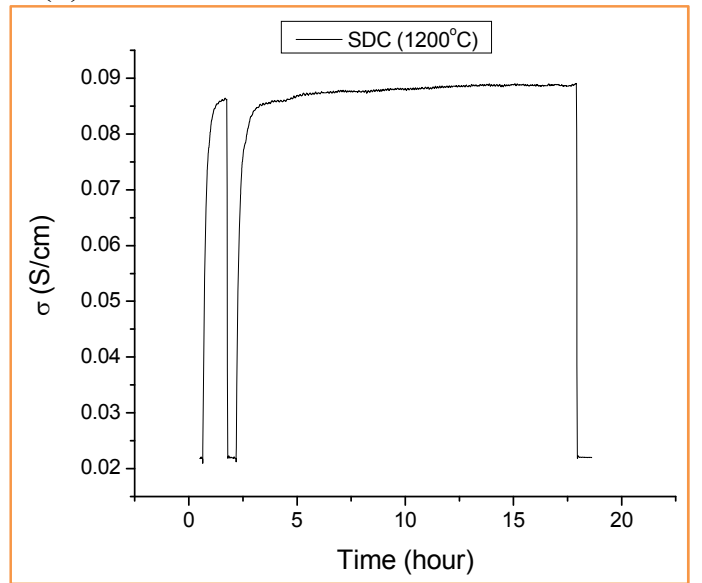

(c) $\mathrm{SDC}$ at $700^{\circ} \mathrm{C}$

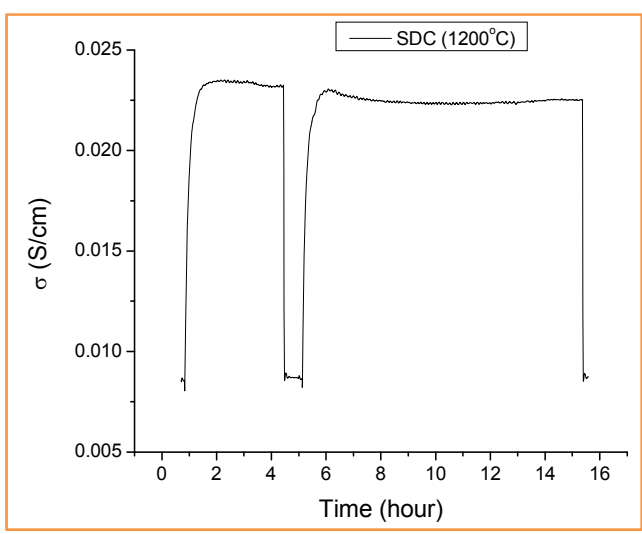

(b) $\quad \mathrm{SDC}$ at $600^{\circ} \mathrm{C}$

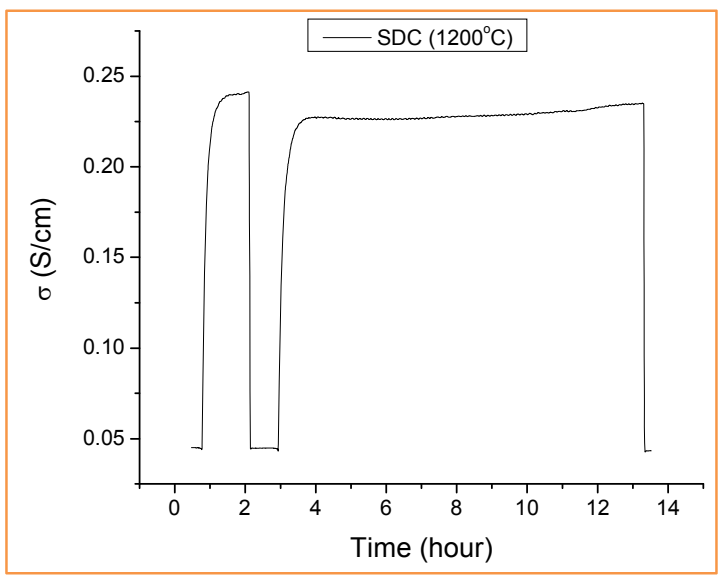

(d) $\quad \mathrm{SDC}$ at $800^{\circ} \mathrm{C}$

Figure 25. Redox stability of SDC tested in air and wet-forming gas $\left(10 \% \mathrm{H}_{2}\right.$ bal. $\left.\mathrm{N}_{2}\right)$ between 500 and $800^{\circ} \mathrm{C}$ 
Task 1.6 Composite LSCM and SDC cathode development

Doped-ceria (GDC \& SDC) and LSCM have been separately investigated above as n-type and ptype materials, and sufficient experimental results showed that their conductivity and chemical stability in reducing atmospheres ensured their use as the cathode. Figure 26 shows the conductivity of the SDC and LSCM composite as a function of oxygen activity. The ratio of LSCM/SDC and the optimum sintering temperature maintaining both SDC and LSCM phases separately without inter-diffusion were investigated. Mixtures of LSCM $\left(\mathrm{La}_{0.75} \mathrm{Sr}_{0.25} \mathrm{Cr}_{0.5} \mathrm{Mn}_{0.5} \mathrm{O}_{3}\right)$ and $\mathrm{SDC}\left(\mathrm{Sm}_{0.2} \mathrm{Ce}_{0.8} \mathrm{O}_{2}\right)$ were prepared with LSCM compositing varying from $10 \mathrm{wt} \%$ to $50 \mathrm{wt} \%$. The mixtures were sintered in air at $1300^{\circ} \mathrm{C}$ over 2 hours. The chemical and structural analyses of the mixtures were carried out using XRD to verify if SDC and LSCM phases were separately synthesized. As shown in Figure 27, the XRD results verified that no evidence of $2^{\text {nd }}$ phases formation was detected for both mixtures. According to the XRD peaks, the LSCM phase was not observed in $10 \mathrm{wt} \%$ of LSCM $-90 \mathrm{wt} \%$ of SDC mixture. However, the LSCM phase was clearly observed in $20 \mathrm{wt} \%$ of LSCM $-80 \mathrm{wt} \%$ of SDC sample. This implied that the n-type SDC and p-type LSCM phases were separately formed when LSCM was over $20 \mathrm{wt} \%$. Electrical conductivity measurements were carried out as a function of oxygen activity, and showed that the composite LSCM/SDC had the best performance characteristics.

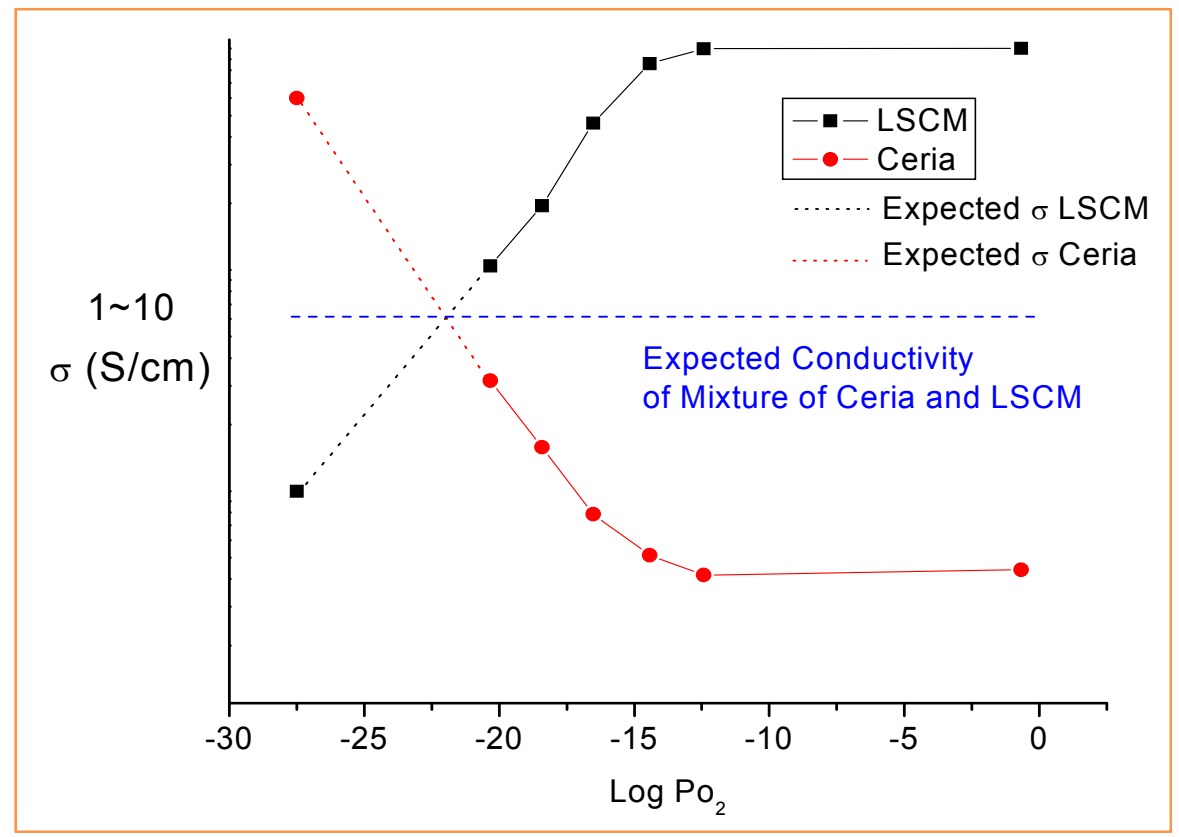

Figure 26. Conductivity of a mixture of n-type $\mathrm{Sm}_{0.2} \mathrm{Ce}_{0.8} \mathrm{O}_{2}$ and p-type $\mathrm{La}_{0.75} \mathrm{Sr}_{0.25} \mathrm{Cr}_{0.5} \mathrm{Mn}_{0.5} \mathrm{O}_{3}$ as a function of oxygen activities at $800^{\circ} \mathrm{C}$ 


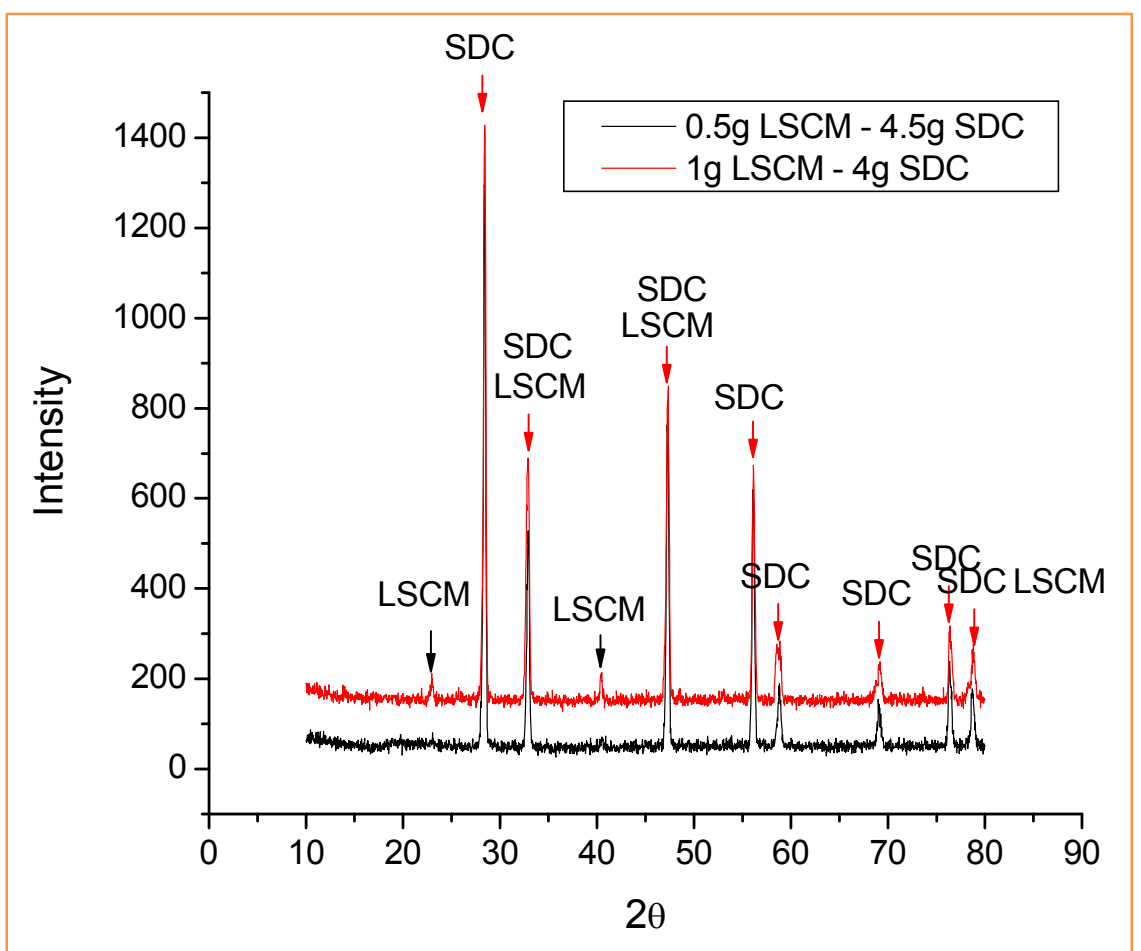

Figure 27. XRD pattern of a mixture of $50 \mathrm{wt} \%$ of $\mathrm{Sm}_{0.2} \mathrm{Ce}_{0.8} \mathrm{O}_{2}$ and $50 \mathrm{wt} \%$ of $\mathrm{La}_{0.75} \mathrm{Sr}_{0.25} \mathrm{Cr}_{0.5} \mathrm{Mn}_{0.5} \mathrm{O}_{3}$ sintered at $1300^{\circ} \mathrm{C}$

Task 2 Fabrication of Anode-Supported, Thin Film YSZ-based Solid Oxide Electrochemical Cell

MSRI has been developing and optimizing anode-supported solid-oxide devices for many years, and has made significant strides in increasing longevity and performance, with the anodesupported SOFCs developed by MSRI showing exceptionally high power density. The tapecasting method, extensively used in the ceramic industry, was used in this project to fabricate anode-supported SOFECs/SOFCs with large active areas and flat substrates. The method uses a mixture of $\mathrm{NiO}$ and YSZ powders with binders and solvents, which is ball-milled to form a slurry. The slurry is then cast over a precision casting surface, forming a tape with desired thickness. The tape is then cut into the preferred shape by a laser machine after an air drying process, following a bisquing process, graded anode functional layers and electrolyte layer are applied by a spray-coating technique. After co-sintering the multiple layers, cells have a cathode functional layer and a cathode current collecting layer deposited by screen-printing. Figure 28 shows MSRI's testing vehicles varying from button-sized cells to square cells with per-cell active area of $400 \mathrm{~cm}^{2}$. 


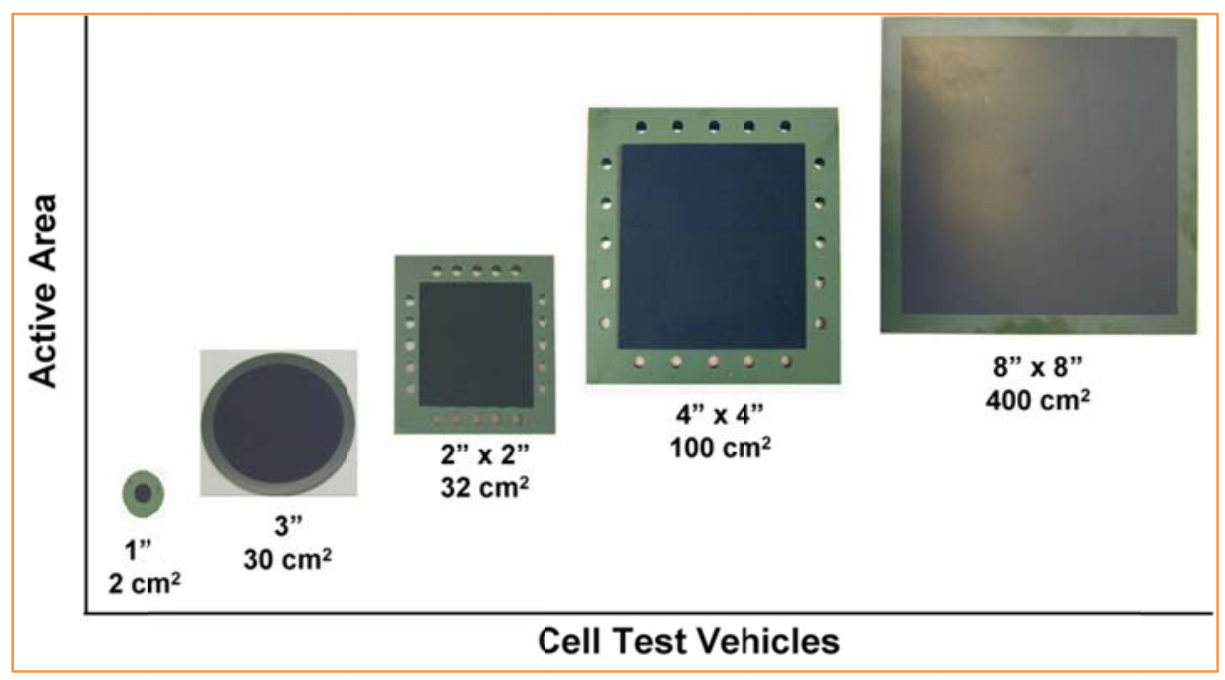

Figure 28. MSRI anode-supported SOFCs.

\section{Task 2.1 Fundamental studies of anode substrates}

Five loss mechanisms can be associated with electrochemical reactions of the SOFC/SOFEC: (1) ohmic polarization, which is the voltage loss due to the intrinsic resistivity of the electrolyte and electrode materials and also non-capacitive losses associated with the interfaces between the electrodes and the electrolyte, and between the electrodes and the current collectors (contact resistance). (2) Concentration polarization at the cathode, associated with the transport of the oxygen-bearing gas (air \& steam) through the porous cathode to the active sites in the cathode interlayer. (3) Activation polarization at the cathode, which is associated with the oxygenbearing gas reduction reaction. (4) Concentration polarization at the anode, which is associated with the transport of fuel through the anode to the active sites in the anode interlayer and the transport of the reaction products away from the active sites and back through the anode. (5) Activation polarization at the anode, associated with the fuel oxidation reaction(s). Optimizing SOFEC/SOFC performance requires that all of these losses be as small as possible. Researchers in SOFC industry commonly assume that most of the ohmic loss was due to the electrolyte. Therefore, an electrolyte with high ionic conductivity and small thickness were all that were required to minimize the ohmic polarization. This assumption ignored the effect of the ionic and electronic conductivity of the electrodes, the linear contribution of the strong coupling between concentration and activation polarization, and possible ohmic resistances associated with interfaces. Higher conductivity electrodes and lower sheet resistance were also important in lowering the ohmic contribution of the total polarization. Significant efforts of developing and optimizing the anode substrates were made in this project.

The goals of the anode substrate development were to minimize the polarization losses (including the concentration overpotential and ohmic losses) introduced by the anode substrates while keeping a high level of mechanical strength. In addition, the cost of the anode substrates was also under consideration to meet the cost target of hydrogen production set by DOE. Various approaches were undertaken, including the raw materials consideration (particle size, $\mathrm{NiO} / \mathrm{YSZ}$ ratio, etc.), pore former additives (types of pore formers and percentage of the 
additives), fabrication process modifications (milling ratio, substrate bisquing and sintering profiles, etc.).

$\mathrm{NiO}$ and YSZ ratio consideration: A composition of $80 \% \mathrm{NiO}$ and $20 \% \mathrm{YSZ}$ by weight $(80 / 20$ cell) was typically used to make the anode substrates as the standard cells. In process, the powder mixture was milled to fine microstructures. This resulted in a strong anode with a high level of mechanical toughness, the drawbacks to this composition being the reduction of $\mathrm{NiO}$ to $\mathrm{Ni}$ results in porosity of only about 33\% (about 10\% lower than desired) and with submicron pores size of very high tortuosity. Both of these led to high anode polarization losses. Much work was done so far on determining the ideal level of $\mathrm{NiO}$ and also finding a pore former that led to low anode polarization. Figure 29 provided a calculation matrix for the NiO-YSZ system as a guideline to develop the anode substrate with desired porosity and composition. Based on the percolation theory, at least $30 \% \mathrm{Ni}$ by volume would be required to maintain a good electrical conductivity. Consequently, a value of $67 \% \mathrm{NiO}$ and $33 \% \mathrm{YSZ}$ by volume (or 70/30 by weight, or called as 70/30 cells) was selected to increase the YSZ level, meanwhile the substructure of YSZ was continuous, as indicated in Figure 29. As was studied previously, 80/20 did not provide this characteristic, because the anode strength and mechanical toughness of the $80 / 20$ cells was provided only by $\mathrm{Ni}$ metal (after reduction) with the YSZ precipitated throughout. Upon reduction, such $80 / 20$ cells only had $22 \%$ YSZ and trended to change their shapes and/cambers. Figure 30 and Figure 31 are SEM micrographs of the 80/20 cells and 70/30 cells, respectively, exhibiting distinct microstructure characteristics between the two. Both cells were fabricated by the tape-casting method. Batches of 67/33 cells were provided to UAF for the thermo-mechanical property investigations.

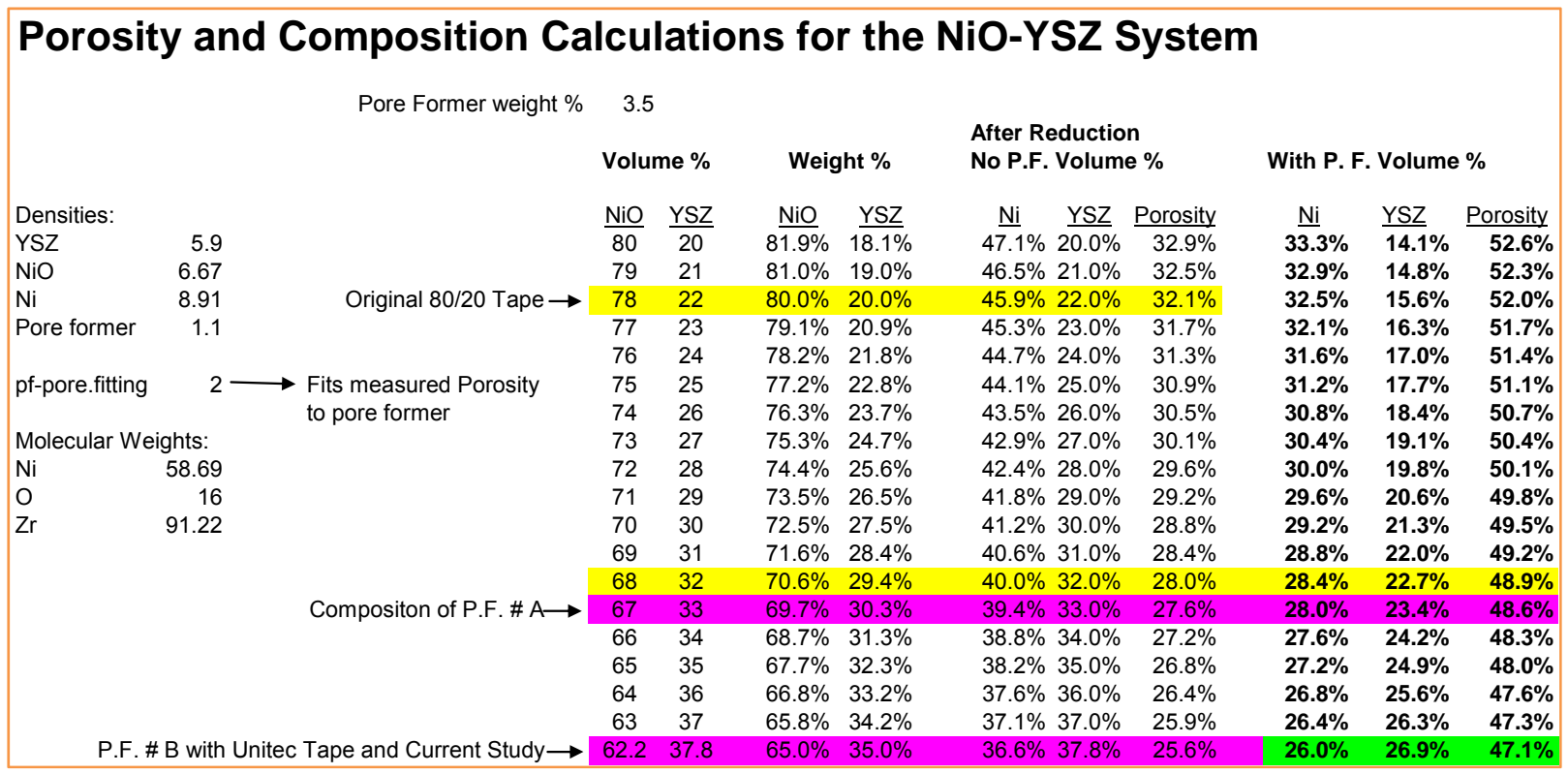

Figure 29. Porosity and composite matrix for the NiO-YSZ system 


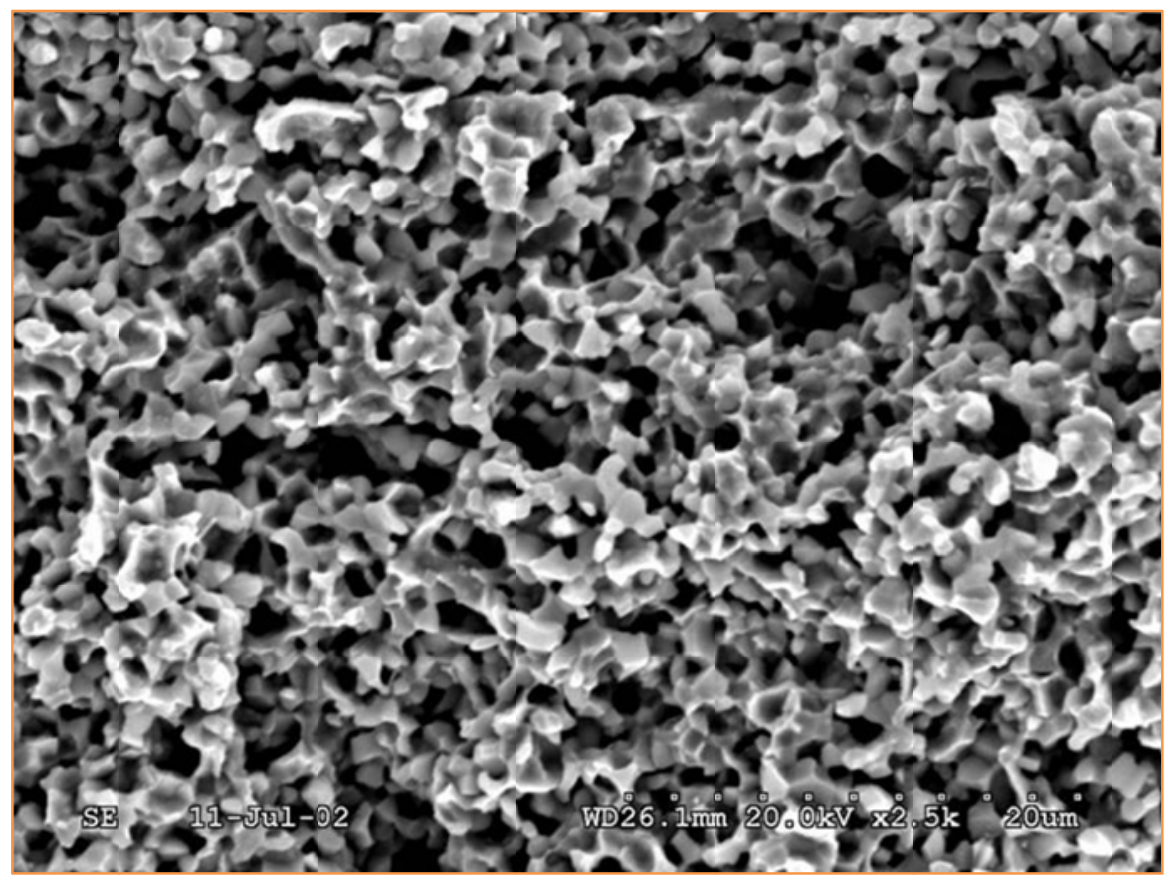

Figure 30. SEM micrograph of a 80/20 cell with no pore former additive

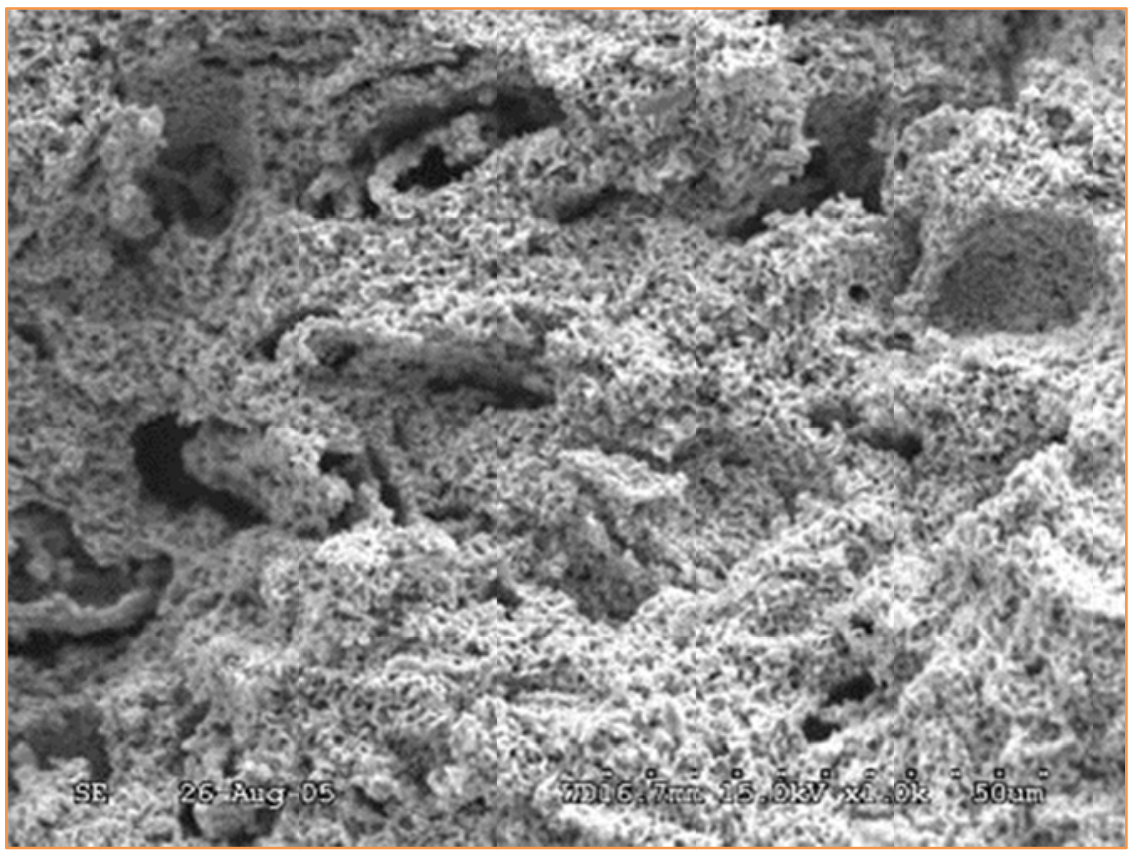

Figure 31. SEM micrograph of a 70/30 cell with type A pore former additive

Pore forming additive: Pore forming additives were also investigated to optimize the anode substrate microstructures, including the porosity, tortuosity, number of open pores, and pore sizes. It was discovered previously that a desired porosity was around $40 \% \sim 45 \%$, with a significant number of open pores, and balanced for mechanical strength. The amount of pore former added was adjusted to control the cell mechanical strength and green tape sinterbility. Figure 32 and Figure 33 show the SEM micrographs of the 70/30 cell with Type A pore-former 
additive before and after polish, respectively. The porosity was about $42 \%$ upon reduction. Cells with this type of anode substrate were constructed and experimentally characterized. The results showed reduced polarization losses, resulted from the increased porosity and pores sizes. Notwithstanding, elongated pores were also present and degraded the mechanical strength. The studies of the mechanical strength of the anode substrates were carried out by UAF, and will be reported in next task (Task 3 ).

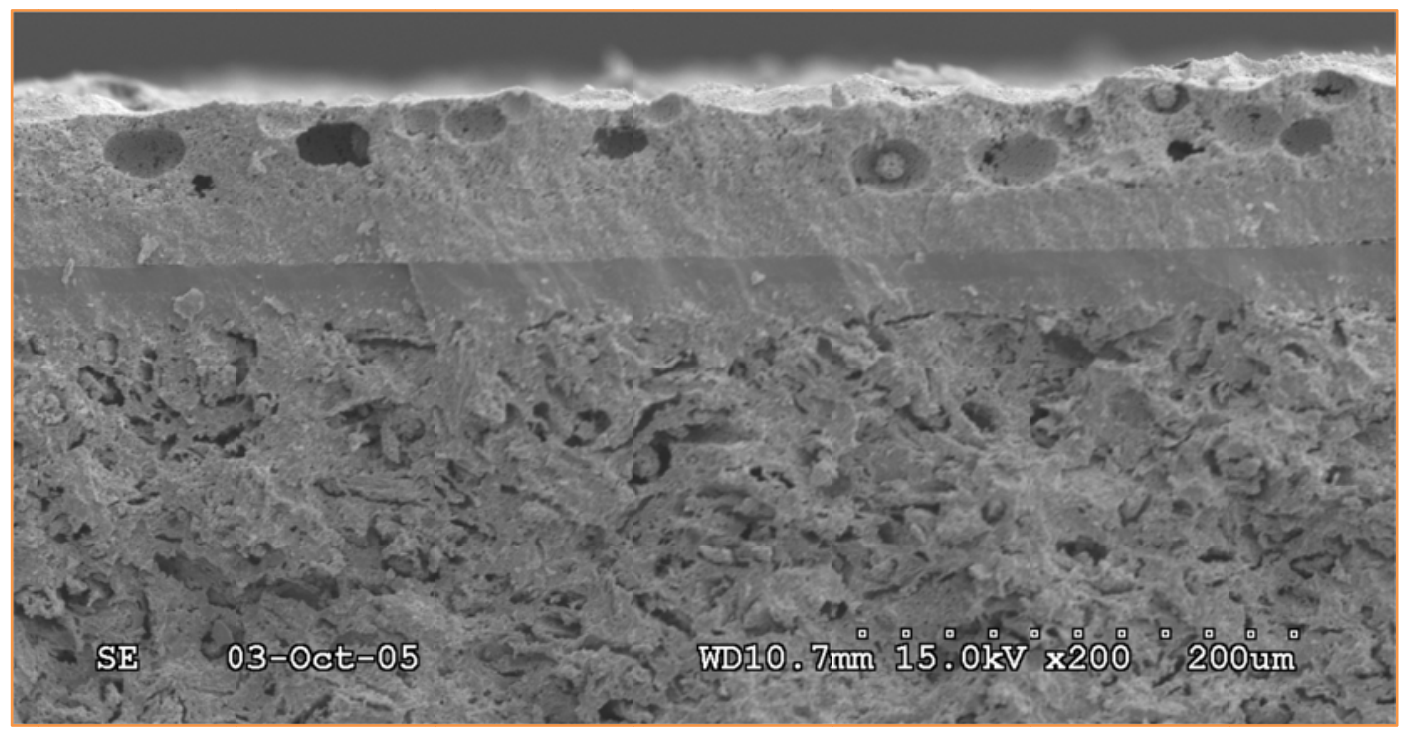

Figure 32. SEM micrograph of a 70/30 cell type A pore former

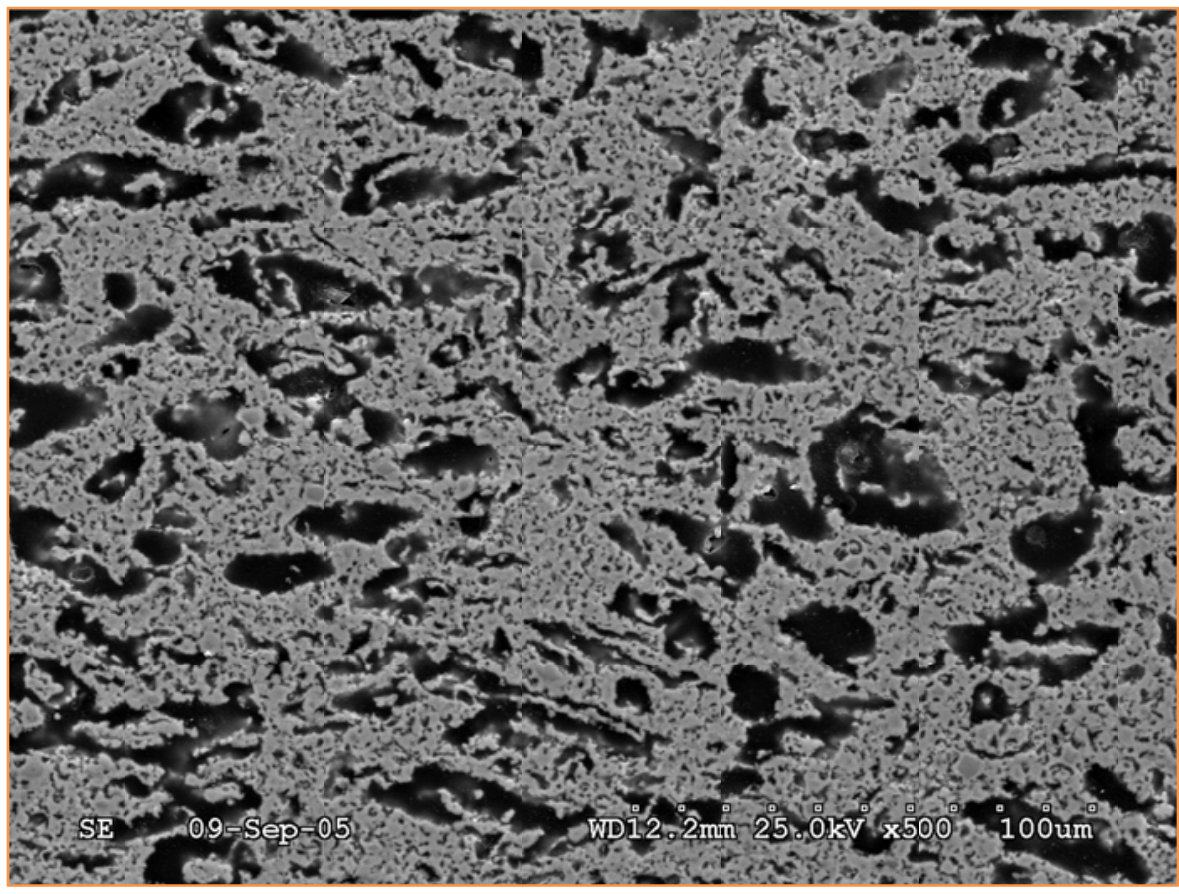

Figure 33. SEM micrograph of a 70/30 cell type A pore former polished 
Other types of pore former (Type B \& C) were also under investigation to modify the porosity, while maintaining the mechanical strength. Figure 34 is a SEM of a cell using Type B pore former. The porosity was measured to be $42 \%$ after reduction, as shown in the figure, the pores were spherical which should reduce the polarization losses and improve mechanical strength (compared to Type A). Efforts were made to engineer the tape casting method to make high quality tapes. During fabrication, it was noticed that an additional advantage of using Type B pore-former was that after sintering, cells were flat enough that no extra creep-flattening process was needed, thus reducing costs associated with production time and cell losses. The type B pore-former, however, was significantly more expensive and thus precluded from current use. Bulk purchase/production may allow its use in future.

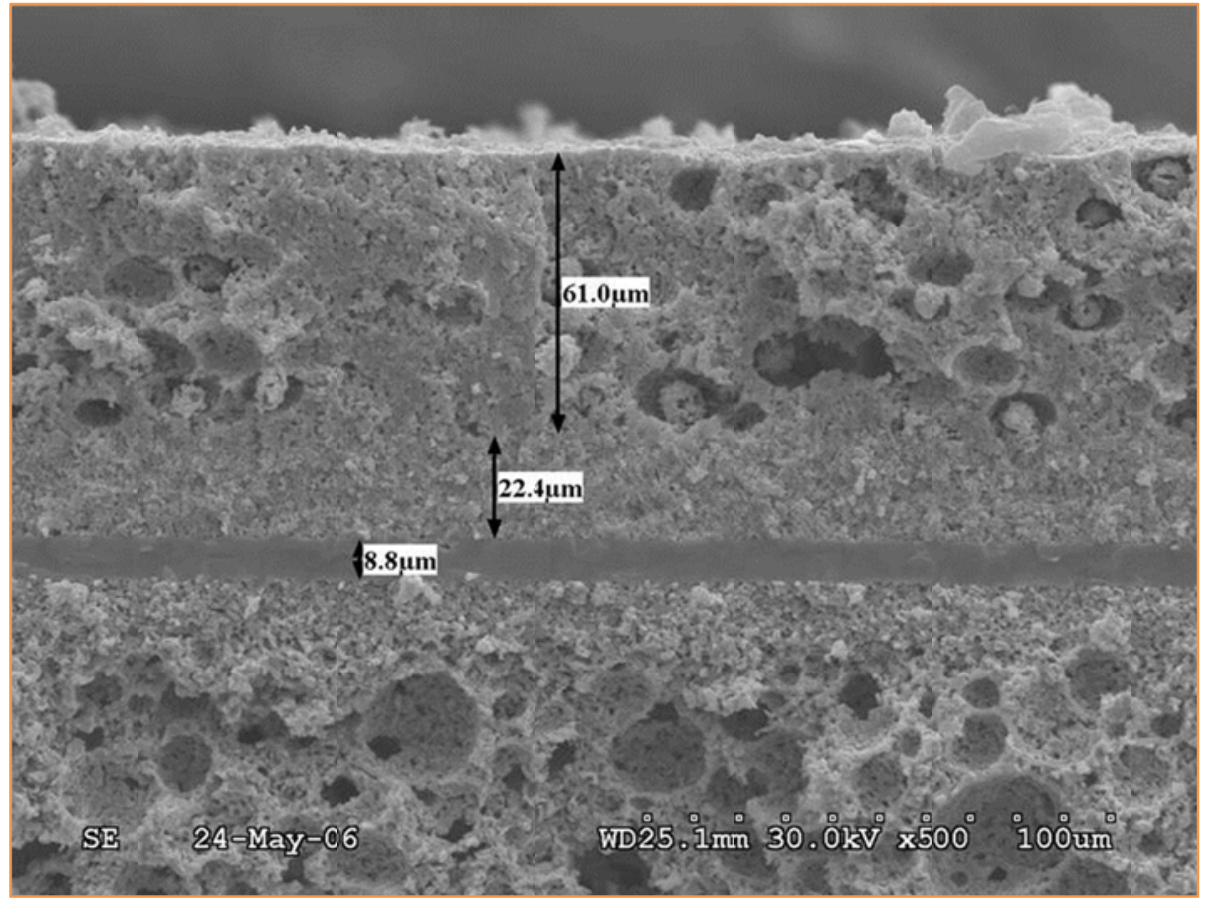

Figure 34 SEM micrograph of a 70/30 cell type B pore former

Type C pore former, which was purchased from the same vendor as Type B but with different particle sizes, was also investigated as a possible candidate. Preliminary results showed similar microstructures as Type A pore former.

\section{Task 2.2 Anode substrate fabrication protocol}

Solvent system, dispersant and plasticizer were developed for each types of pore former for the tape-casting method. A fine microstructure of the powder was provided by a milling ratio of media to powder. It was discovered that 10:1 ratio leads to a well sintered microstructure with a porosity provided by the pore former added. In addition, work was also done on a coarser microstructure based on $65 \% \mathrm{NiO}$ and $35 \%$ YSZ milled at a 5:1 ratio. The conductivity was maintained because the Ni closely followed the YSZ and remained contiguous. In this project, besides the Tosoh (Japan) powder, relatively inexpensive 8YSZ powders provided by other vendors were also investigated in order to reduce the cost of cell materials (subsequent hydrogen 
production cost). Particularly, the $8 Y$ YSZ powder provided by Unitec showed much promise. Unlike the Tosoh YSZ powder which was prepared by chemical means, the Unitec powder was made from a melt followed by extensive milling, thus providing much rougher morphology. It was expected that using Unitec powder was able to maintain sufficient strength while providing for the desired open porosity for the anode substrates. Figure 35is a SEM of an anode substrate using Unitec powder with Type B pore former. Tape casting formula was developed to cope with the powder characteristics. Batches of 4" $\mathrm{x} 4$ "cells were fabricated and delivered to UAF for thermo-mechanical studies.

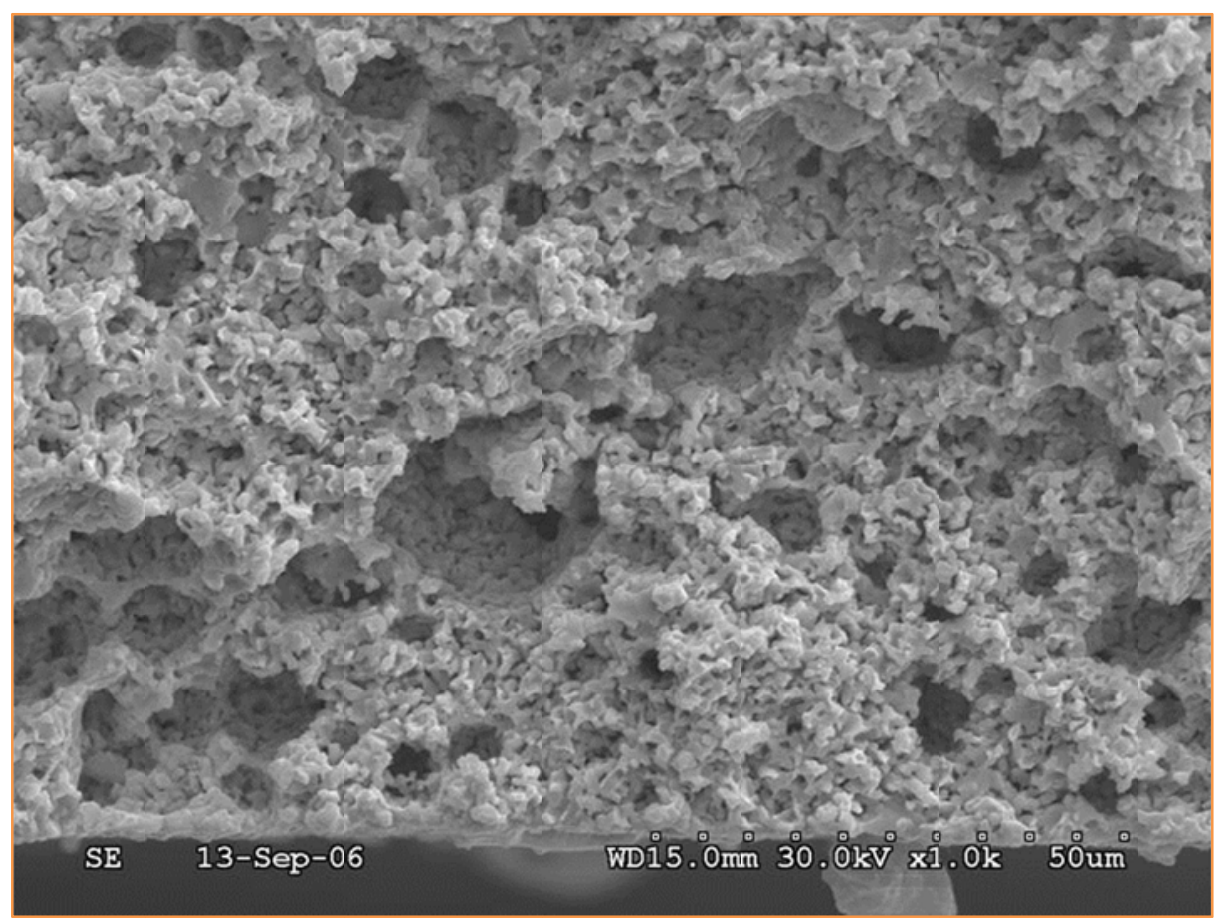

Figure 35. A SEM micrograph of an anode substrate using Unitec powder with Type B pore former additive

\section{Task 2.3 SOFEC/SOFC production}

After the fundamental studies on the anode substrate and development of fabrication protocols for optimum cell structures, large batches of cells were were produced for the $5 \mathrm{~kW}$ demonstration system's needs. As designed, the $5 \mathrm{~kW}$ system required three SOFEC-SOFC hybrid stacks for hydrogen production and three dedicated SOFC stacks for power generation. Each modular stack had 40 60 cells with either square or hexagonal designs. Figure 36 shows a picture of the completed 360 cells (with 60 extra cells) to be assembled into six modules. 


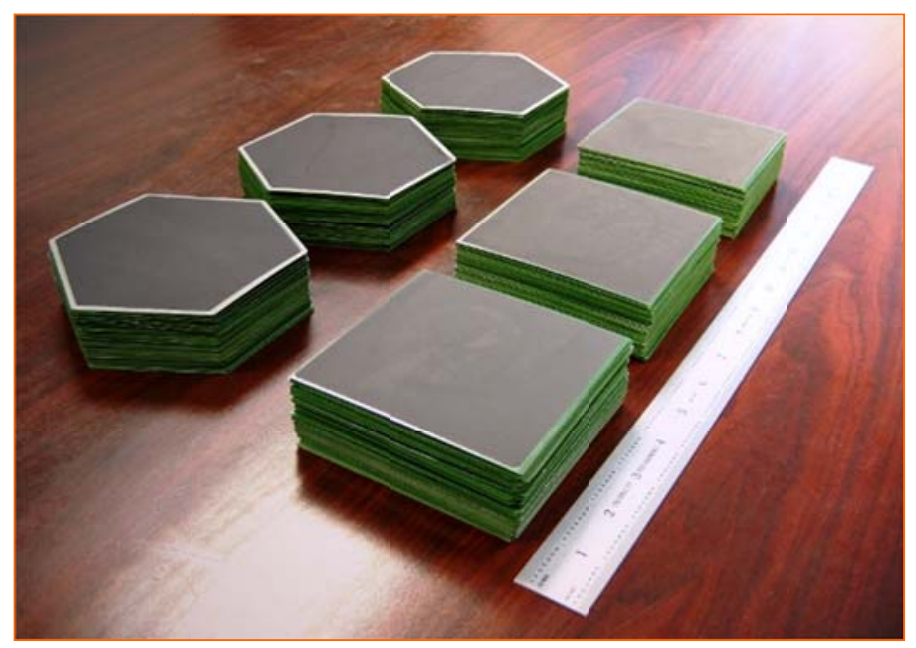

Figure 36. a picture of cells fabricated for the $5 \mathrm{~kW}$ hybrid system

Task 3 Anode Substrate Thermo-mechanical Properties Investigation

Successful commercialization of SOFCs/SOFECs depends not only on the electrochemical efficiency of cell/stack components but also on their ability to endure the mechanical stresses which arise during fabrication, stack assembly or the extensive servicing period when the solidoxide cells are susceptible to external impacts and internal thermomechanical stresses. To provide such robustness, at least one of cell component layers should have adequate thickness and mechanical robustness to give sufficient structural support. Although conventional electrolyte-supported designs offer mechanical strength, thick electrolytes deleteriously affects the performance of the cell by increasing the ohmic losses, operating temperature, start-up time and overall $\operatorname{costs}^{1,2}$. Another option, Ni+YSZ-based porous anode-supported cells have been successfully developed in both tubular and planar type designs. Since the electrolyte is kept as thin as possible to decrease ohmic losses through it and to lower the cell operating temperature, the cathode is a weak and compliant material ${ }^{3,4,5,6}$, and the anode becomes exclusively responsible for the structural integrity and reliability of the cell ${ }^{7,8}$. Therefore, a study of the mechanical properties of SOFC/SOFEC components is essential to comprehend reliability issues, which depend on several factors, including residual stresses, chemical stresses arising due to reduction-oxidation reactions, assembly stresses, stresses generated by thermal cycling, etc.

\footnotetext{
${ }^{1}$ Haile, S. M., Fuel cell materials and components. Acta Mater., 2003, 51, 5981-6000

${ }^{2}$ Wang, Y., Walter, M. E., Sabolsky, K. and Seabaugh, M. M., Effects of powder sizes and reduction parameters on the strength of Ni-YSZ anodes. Solid State Ionics, 2006, 177, 1517-1527

${ }^{3}$ Atkinson, A. and Selcuk, A., Mechanical behaviour of ceramic oxygen ion-conducting membranes. Solid State Ionics, 2000, 134, 59-66

${ }^{4}$ Selcuk, A., Merere, G. and Atkinson, A., The influence of electrodes on the strength of planar zirconia solid oxide fuel cells. J. Mater. Sci., 2001, 36, 1173-1182

${ }^{5}$ Dokiya, M., SOFC system and technology. Solid State Ionics, 2002, 152/153, 383-392

${ }^{6}$ Gaudon, M., Menzler, N. H., Djurado, E. and Buchkremer, H. P., YSZ electrolyte of anode-supported SOFCs prepared from sub micron YSZ powders. J. Mater. Sci., 2005, 40, 3735-3743

${ }_{7}$ Primdahl, S., Sorensen, B. F. and Mogensen, M., Effect of nickel oxide/yttria-stabilized zirconia anode precursor sintering temperature on the properties of solid oxide fuel cells. J. Am. Ceram. Soc., 2000, 83, 489-494

${ }^{8}$ Singhal, S. C., Solid oxide fuel cells for stationary, mobile, and military applications. Solid State Ionics, 2002, 152$153,405-410$
} 
In this task, several important issues were identified as potential contributors and detractors from cell strength and reliability; these issues, were addressed on a fundamental level to evaluate their importance in the cell optimization process. These studies included:

- Evaluation of the porosity, composition and thickness dependent elastic properties, hardness, and fracture toughness of as-received and reduced NiO-YSZ anode samples.

- Determining the equibiaxial flexural strength of as-received NiO-YSZ and reduced NiYSZ anode-supported bi-layer SOFC membrane structures at room temperature in ambient air and at elevated temperatures in air/reducing environments.

- Studying the effects of crystallographic and micro structural changes after reduction on fracture mechanisms.

- Characterization of the elastic properties of Ni-YSZ anodes at elevated temperatures and reducing environments, simulating the actual operating conditions in SOFCs.

- Evaluation of the thermal expansion properties and the effects of thermal cycling on the microstructure, porosity, hardness, elastic properties and strength of as-received NiOYSZ anode samples.

- Studying the effects of anode layer thickness on the probability of failure $(\mathrm{P})$ of the SOFC membrane electrolyte assembly using Weibull plots to optimize the anode design.

- Modeling of stress distributions in the SOFC component layers by finite element analysis. Based on the model, stresses generated in the different component layers will be predicted, allowing comparisons of the theoretical predictions with the experimental results.

\section{Task 3.1 Experiemntal preparation}

As shown in Figure 37 and Table 1, three different sets of half-cell samples, which were comprised of a thin and dense electrolyte layer of YSZ supported by a thick and porous NiOYSZ anode precursor structure, were studied in this investigation.

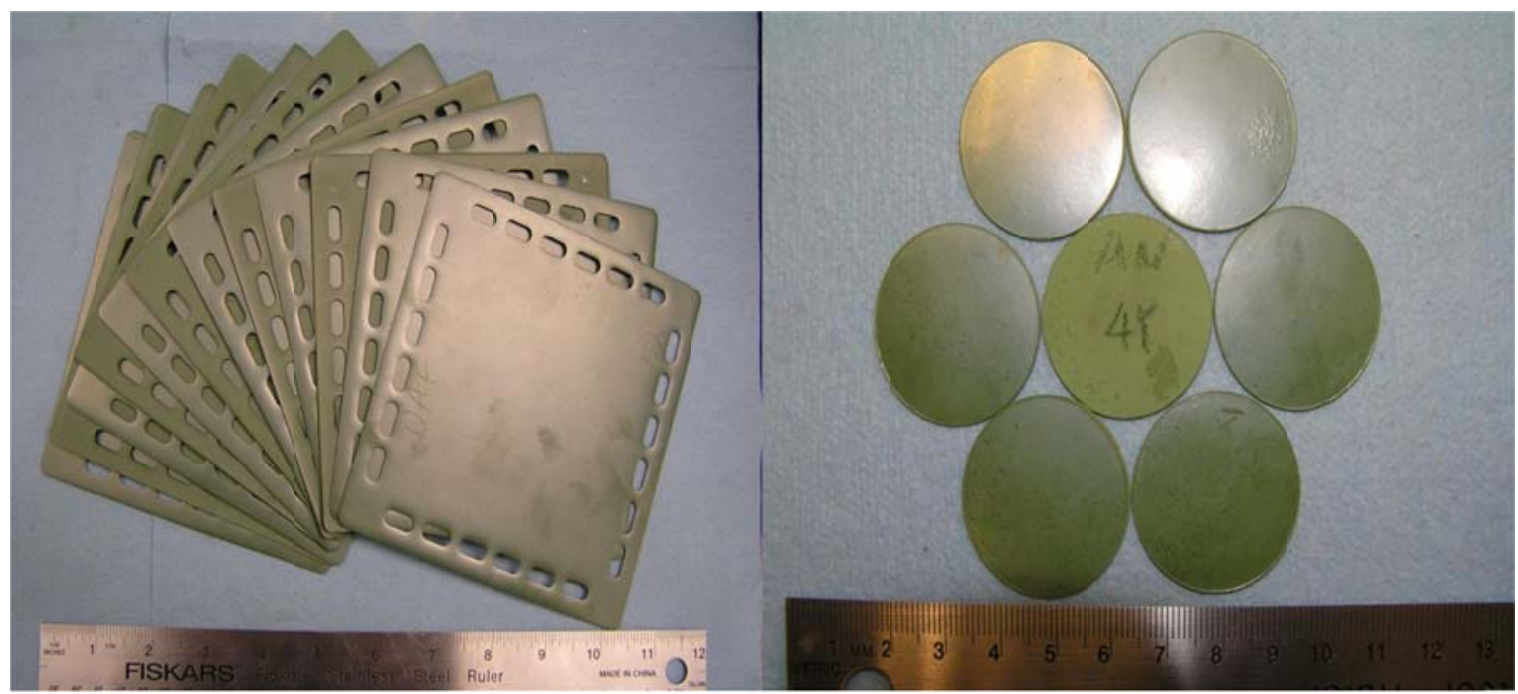

Figure 37. Photographs of the NiO-8YSZ (4"x4") and NiO-4YSZ (1" dia) as-received samples 
Table 1. Samples studied and characterized

\begin{tabular}{|c|c|c|}
\hline Sample dimensions & Anode & Electrolyte \\
\hline Button cells ( $1 "$ diameter) & $\mathrm{NiO}+4 \mathrm{~mol} \% \mathrm{Y}_{2} \mathrm{O}_{3}$ stabilized & $4 \mathrm{~mol} \% \mathrm{Y}_{2} \mathrm{O}_{3}$ \\
\hline Rectangular cells (4" x 4")--- & $\mathrm{ZrO}_{2}(4 \mathrm{YSZ})(70 / 30)$ & $(4 Y S Z)$ \\
\hline Batch I $(600 \mu \mathrm{m}$ thick $)$ & $\begin{array}{l}\mathrm{NiO}+8 \mathrm{~mol} \% \mathrm{Y}_{2} \mathrm{O}_{3} \text { stabilized } \\
\mathrm{ZrO}_{2}(8 \mathrm{YSZ})(70 / 30)\end{array}$ & $\begin{array}{l}8 \mathrm{~mol}^{\%} \mathrm{Y}_{2} \mathrm{O}_{3} \text { stabilized } \mathrm{ZrO}_{2} \\
(8 \mathrm{YSZ})\end{array}$ \\
\hline $\begin{array}{l}\text { Rectangular cells (4" x 4")--- } \\
\text { Batch II }(900 \mu \mathrm{m} \text { thick })\end{array}$ & $\begin{array}{l}\mathrm{NiO}+8 \mathrm{~mol} \% \mathrm{Y}_{2} \mathrm{O}_{3} \text { stabilized } \\
\mathrm{ZrO}_{2}(8 \mathrm{YSZ})(70 / 30)\end{array}$ & $\begin{array}{l}8 \mathrm{~mol} \% \mathrm{Y}_{2} \mathrm{O}_{3} \text { stabilized } \mathrm{ZrO}_{2} \\
\text { (8YSZ) }\end{array}$ \\
\hline
\end{tabular}

A number of the as-received samples from MSRI were cut into suitable sizes and exposed to elevated temperatures $\left(800,1000,1250\right.$ and $1500^{\circ} \mathrm{C}$ for 60 minutes) and the effect of temperature on the microstructure, hardness and the fracture toughness was evaluated. Vickers micro hardness method was used to estimate the hardness and to calculate the fracture toughness from originated cracks. The samples were carefully polished prior to the indentation experiments with diamond pastes without destroying the layers involved. The electrolyte was polished with 6 and $3 \mu \mathrm{m}$ diamond pastes while the anode layer was polished using $\mathrm{SiC}$ (400 grade) paper prior to the diamond polishing. The fracture toughness values $\left(\mathrm{K}_{\mathrm{IC}}\right)$ were calculated using the following formula suggested by Evans and Charles?,

where,

$$
\mathrm{K}_{\mathrm{IC}}=0.16 \mathrm{H}_{\mathrm{v}} \mathrm{a}^{1 / 2}(\mathrm{c} / \mathrm{a})^{-3 / 2}
$$

$$
\begin{aligned}
& \mathrm{K}_{\mathrm{IC}}=\text { Mode I critical stress intensity factor }\left(\mathrm{MPa} \mathrm{m}^{1 / 2}\right) \\
& \mathrm{H}_{\mathrm{V}}=\text { Vickers hardness }(\mathrm{GPa}) \\
& \mathrm{c}=\text { radius of the surface crack (median) }(\mathrm{m}) \text { and } \\
& \mathrm{a}=\text { half diagonal of the Vicker's indent }(\mathrm{m})
\end{aligned}
$$

More of the as-received NiO-8YSZ samples (Batch I \& II) were cut into suitable sizes and reduced in a gas mixture of $5 \% \mathrm{H} 2-95 \% \mathrm{Ar}$ at $800^{\circ} \mathrm{C}$. The reduction reaction was carried out in an autoclave set-up, where the samples were kept at the above temperature for $1 \mathrm{~h}$ prior to the reduction so that they could attain thermal equilibrium before the reaction started. Then the gas mixture was introduced in the chamber at a constant flow rate of 3.2 SLPM and the temperaturechemical environment condition was maintained for selected time periods of $10 \mathrm{~min}, 30 \mathrm{~min}, 1 \mathrm{~h}$, $2 \mathrm{~h}$ and $8 \mathrm{~h}$. After that the samples were cooled down to room temperature without any changes in the reducing environment.

The porosity and density values in the as-received and the reduced half-cell samples were estimated by Archimedes principle as given in ASTM Standard C20-00. Since the electrolyte layer was very thin in comparison to the anode, these values were near approximation of the true values of porosity/density in the anode. The fraction of $\mathrm{NiO}$ reduced in the samples was determined by thermogravimetric analysis (TGA) carried out in air with Perkin-Elmer model DT-40, Shimadzu Co., Japan. The crystal structure of the as-received and the reduced samples

\footnotetext{
${ }^{9}$ Evans, A. G. and Charles, E. A., Fracture toughness determination by indentation. J. Am. Ceram. Soc., 1976, 59, $371-372$
} 
were analyzed using X-ray diffraction (XRD), using a Rigaku diffractometer and $0.15418 \mathrm{~nm} \mathrm{Cu}$ $\mathrm{K}_{\alpha}$ radiation. The microstructures were also studied using a JEOL JSM-7000 scanning electron microscope (SEM), an accelerating voltage of $10 \mathrm{kV}$ was used to resolve the images of the NiYSZ cermet structure. Hardness of the samples was measured by Vickers indentation method on the anode surface with a load of $500 \mathrm{gm}$ for $15 \mathrm{~s}$. Thermal expansion behavior of the as-received NiO-8YSZ samples was evaluated in air up to $1000^{\circ} \mathrm{C}$ with a NETZSCH DIL 402 PC dilatometer at a heating/cooling rate of $3 \mathrm{~K} / \mathrm{min}$. The correction runs for the sample support and the push rods were done prior to the actual experiment with a standard sapphire sample. Elastic properties (Young's and shear moduli) of the as-received, partially and fully reduced samples at elevated temperatures were determined by the impulse excitation technique using the Buzz-osonic software (BuzzMac, Glendale, WI) by measuring the fundamental vibration frequencies and a custom made experimental design, as shown in Figure 38. A cylindrical alumina base was used as a stage on which the test specimen $(50 \times 15 \times 0.6 / 0.9 \mathrm{~mm})$ was suspended on a thin wire support. An impulse tool was used to give mechanical impulse at the bottom of the rectangular bar and the vibration frequencies were transferred to a microphone through a sound guide. Delivery of the mechanical impulse in a definite time interval $(1 \mathrm{~min})$ and the data acquisition was managed by the software and the entire experimental design was housed inside a furnace and the temperature was controlled by a programmable controller.

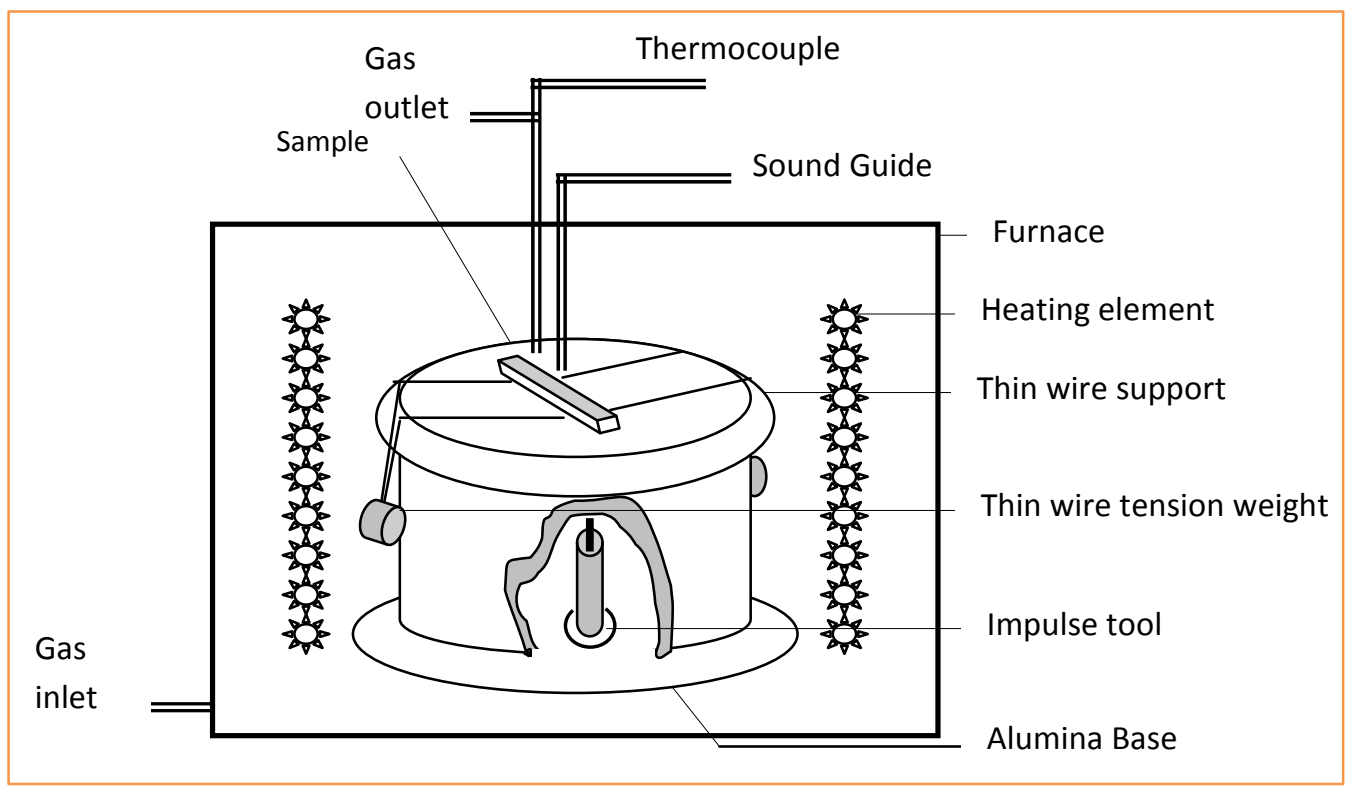

Figure 38. Schematic diagram of the experimental design used for evaluating Young's modulus as a function of temperature

Flexural and equibiaxial strength of the as-received, partially and fully reduced NiO-8YSZ halfcell samples (Batch I \& II) was determined at ambient and elevated temperatures. A four point fixture was used to determine the flexural strength of the samples. A concentric ring-on-ring configuration was fabricated using alumina and used to determine in-plane biaxial strength according to ASTM C1499-05. In this configuration, test specimens with diameter $(D)$ of $\approx 26$ $\mathrm{mm}$ were spaced concentrically between a loading ring with a diameter $\left(D_{L}\right)$ of $5.5 \mathrm{~mm}$ and a supporting ring with a diameter $\left(D_{S}\right)$ of $20 \mathrm{~mm}$. The load was applied to the samples at a 
constant cross-head displacement rate of $1.2 \mathrm{~mm} / \mathrm{min}$ and equibiaxial strength was calculated using the following equation:

$$
\sigma_{f}=\frac{3 . F}{2 \pi h^{2}}\left[(1-v) \frac{D_{S}{ }^{2}-D_{L}{ }^{2}}{2 D^{2}}+(1+v) \ln \frac{D_{S}}{D_{L}}\right]
$$

where, $F, h$ and $v$ are failure load $(\mathrm{N})$, sample thickness $(\mathrm{mm})$ and Poisson's ratio, respectively. For a rectangular test specimen, the value of $D$ for calculations with Eq. 2 is:

$$
D=0.54\left(l_{1}+l_{2}\right)
$$

where, $l_{1}$ and $l_{2}$ are the lengths of the edges. The edge lengths should be within $0.98 \leq l_{1} / l_{2} \geq$ 1.02. Since the test specimen thickness was unchangable, the values for $D_{S}$ and $D_{L}$ were chosen according to the following condition:

$$
2 \leq \frac{D-D_{S}}{h} \leq 12
$$

The load was applied from direction of electrolyte and the anode was kept in the tensile side. Graphite sheets were used as compliant layers and the whole specimen arrangement is shown schematically in Figure 39. At least six specimens were tested and average of the strength values was reported. The post fracture microstructure analysis was carried out using SEM to study the fracture originating flaws.

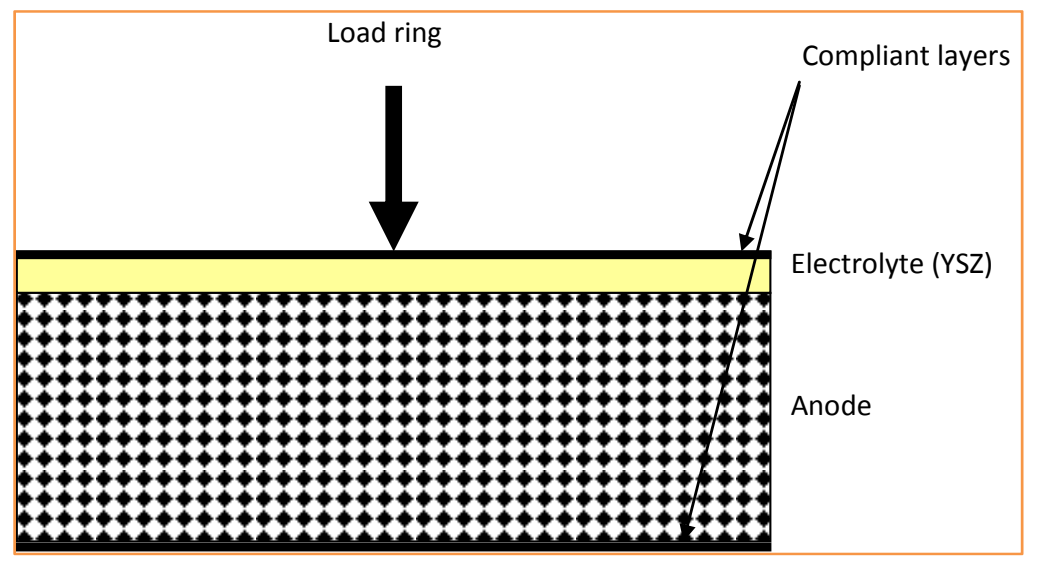

Figure 39. A schematic of the specimen and loading configuration in the ring-on-ring test

The failure probability $(\mathrm{P})$ of as-received samples at room temperature and fully reduced samples ( $8 \mathrm{~h}$ reduced) at $800^{\circ} \mathrm{C}$ in $\mathrm{H}_{2}$ atmosphere were estimated and the resulting data was fitted to the two-parameter Weibull equation to determine the Weibull parameter $(\mathrm{m})$ and characteristic strength $\left(\sigma_{0}\right)$. The fractured surfaces were examined with SEM.

The as-received NiO-8YSZ (batch II) samples were cut into suitable sizes for the thermal cycling studies in a high temperature thermal cycling set-up of Carbolite Inc. The thermal cycling tests 
were performed by cooling the samples from $800^{\circ} \mathrm{C}$ to $100^{\circ} \mathrm{C}$ in air environment. Each cycle consisted of an hour immersion in the furnace followed by a natural cooling to $100^{\circ} \mathrm{C}$ by taking out the sample outside the furnace. As soon as the sample was cooled down to $100^{\circ} \mathrm{C}$, it was again introduced in the furnace kept at the constant temperature of $800^{\circ} \mathrm{C}$. Three sets of samples of 1,50 and 250 number of cycles treated were characterized.

\section{Task 3.2 Experimental results and discussions}

\section{Task 3.2.1 Microstructural analysis of as-received, heat treated and reduced half-cell samples}

The optical micrographs in Figure 40 show the cross sectional view of the as-received NiO8 YSZ rectangular half cell samples (both batches).
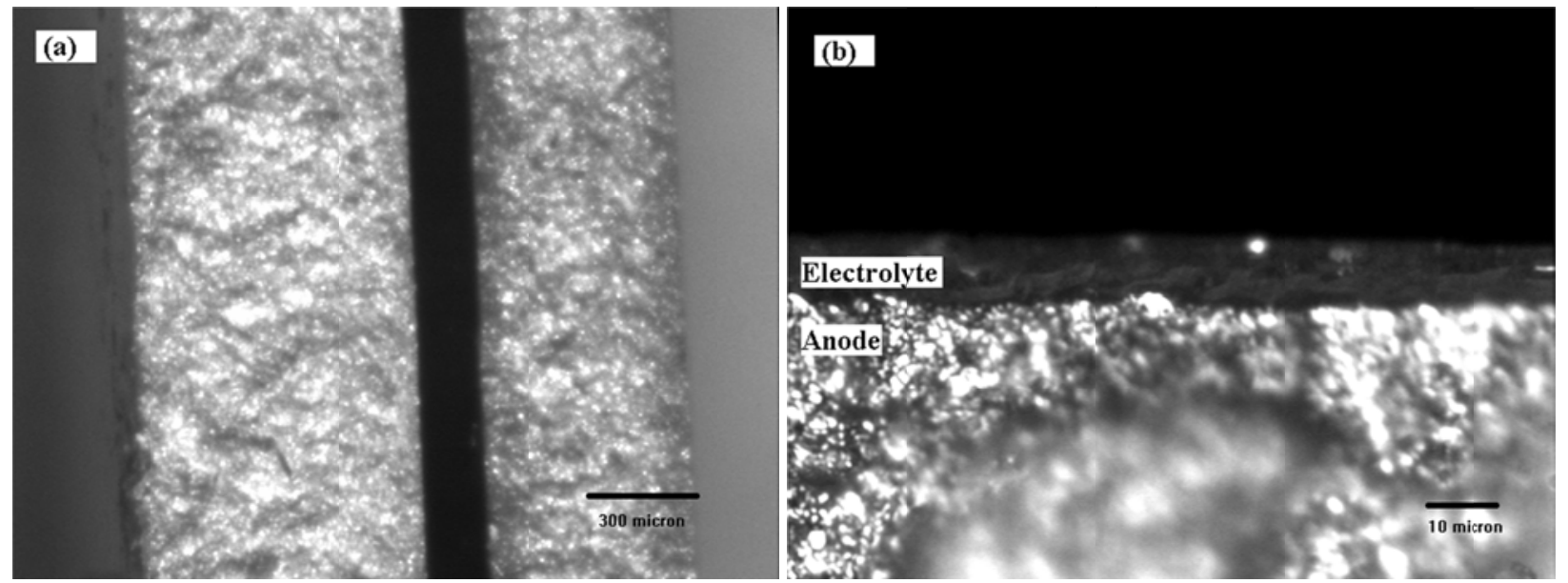

Figure 40. (a) Optical micrographs showing the cross sectional view of the as-received NiO-8YSZ halfcell samples (Batch I : $600 \mu \mathrm{m}$ thick; batch II : $900 \mu \mathrm{m}$ thick); (b) Electrolyte and anode layers observed in as-received NiO-8YSZ batch II samples at a higher magnification

The rectangular half-cell samples of batch I \& II had a thickness of $\sim 600$ and $900 \mu \mathrm{m}$, respectively. The electrolyte layer had a thickness of $8 \sim 10 \mu \mathrm{m}$ in both batches. The anode (NiO-8YSZ) was porous and the pores were partly interconnected. Figure 41 compares the optical micrographs of the anode surface of as-received and the heat-treated NiO-8YSZ (Batch I) samples. The samples were allowed to remain for $60 \mathrm{~min}$ at the maximum temperatures before cooling. Very slow heating and cooling rates were used in order to avoid any possible thermal shock and associated delamination of layers. It was observed from the micrographs that the pore size and geometry were modified by the heat treatment of the anodes at the high temperatures. At elevated temperatures, particularly at $1500^{\circ} \mathrm{C}$, the pores were spherical in shape. This showed that the sintering of $\mathrm{YSZ}$ at $1500^{\circ} \mathrm{C}$ was very active in closing the pores. 

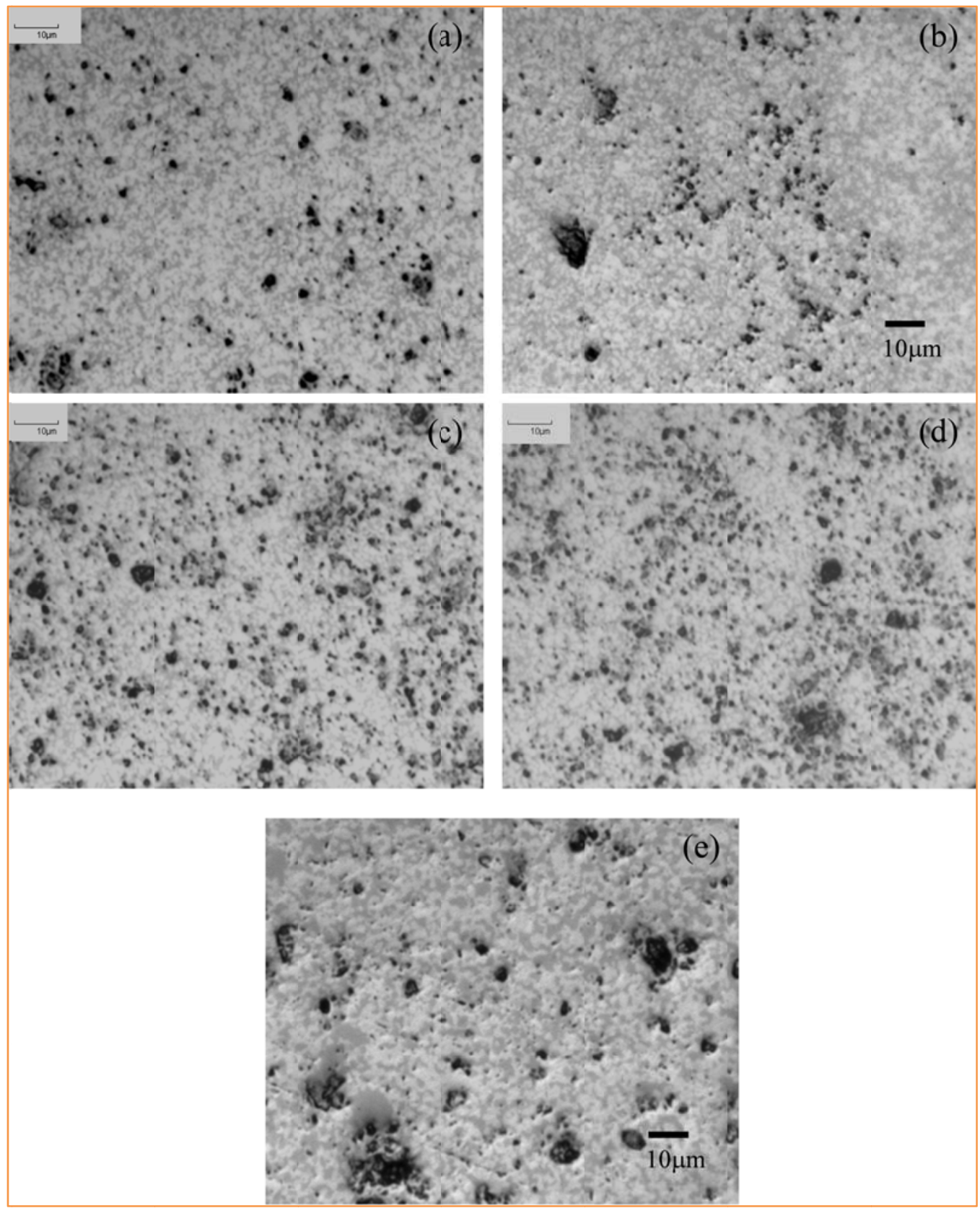

Figure 41. Optical micrographs of the anode surface of as-received and the heat treated NiO-8YSZ samples (Batch I) : (a) as-received, (b) $800^{\circ} \mathrm{C}$, (c) $1000^{\circ} \mathrm{C}$, (d) $1250^{\circ} \mathrm{C}$, and (e) $1500^{\circ} \mathrm{C}$. Note that the pore distribution was not uniform and the pores were mostly interconnected.

Also $\mathrm{NiO}$ diffused out over YSZ surface at $1300^{\circ} \mathrm{C}$. It was reported that less than $1 \mathrm{~mol} \% \mathrm{NiO}$ acts as a sintering aid for YSZ at high temperatures ${ }^{10}$. The solubility of $\mathrm{NiO}$ in YSZ depended on both the sintering temperature and $\mathrm{Y}_{2} \mathrm{O}_{3}$ content. The maximum solubility of $2.5 \mathrm{~mol} \%$ in

\footnotetext{
${ }^{10}$ Linderoth, S. and Kuzjukevics, A., NiO in yttria-doped zirconia; pp. 1076-1085 in Solid Oxide Fuel Cells V, Proceedings of the Fifth International Synposium on Solid Oxide Fuel Cells (Aachen, Germany, June 1997), Vol. PV 97-40. Edited by U. Stimming, S. C. Singhal, H. Tagawa and W. Lehnert. The Electrochemical Society, Pennington, NJ, 1997
} 
YSZ with 8 YSZ existed at $1200^{\circ} \mathrm{C}^{10,11}$, as reported. Probably, this could be a reason for the densification of $\mathrm{YSZ}$ at $1500^{\circ} \mathrm{C}$. A detail analysis was needed in order to study the segregation of $\mathrm{Ni}$ in YSZ at high temperatures and the solubility of Ni or NiO in YSZ. The XRD analysis coupled with TGA could help in understanding the sintering mechanism of the NiO-YSZ cermets.
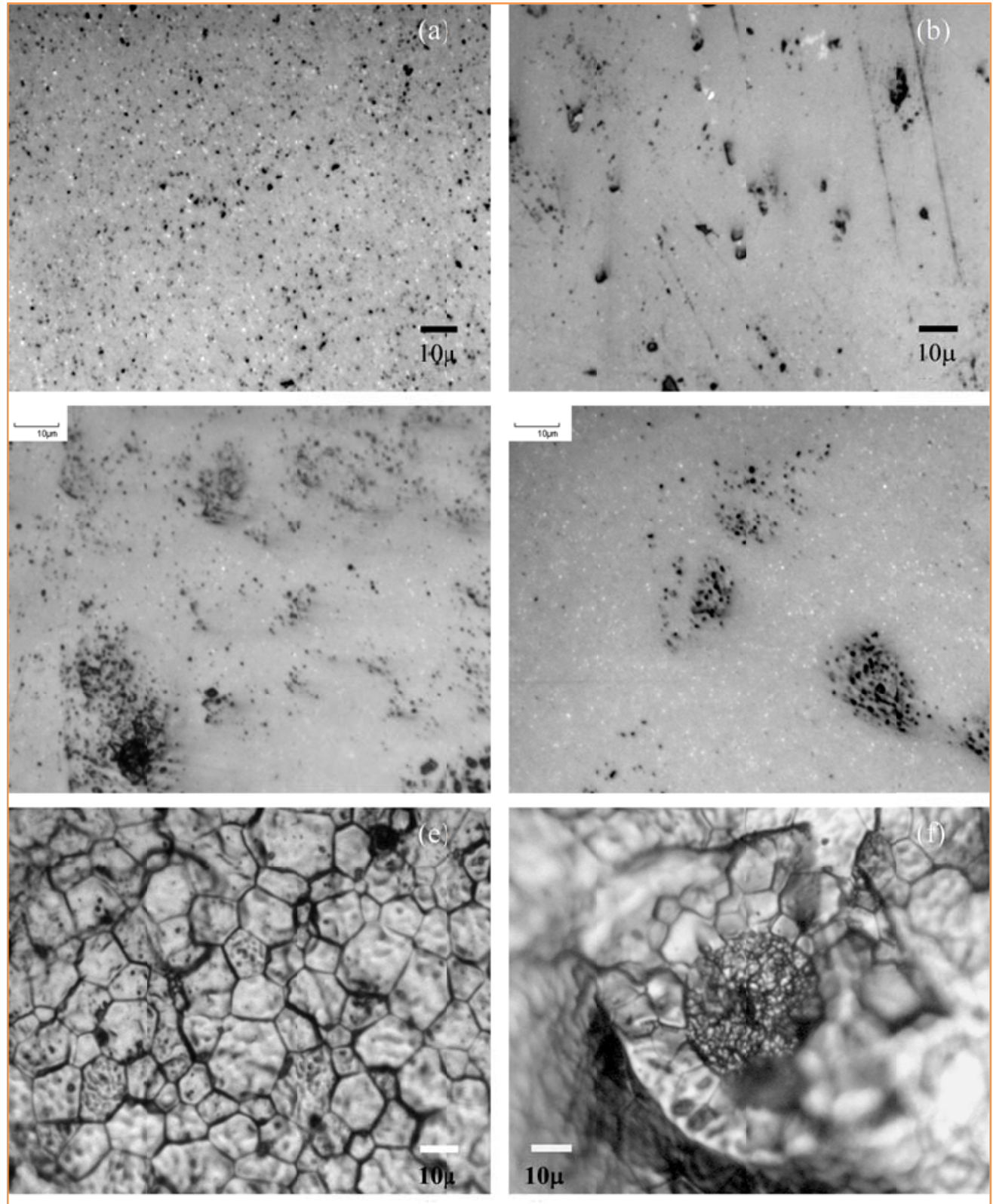

Figure 42. Optical micrographs of the electrolyte surface of as-received and the heat treated NiO-8YSZ samples (Batch I) : (a) as-received, (b) $800^{\circ} \mathrm{C}$, (c) $1000^{\circ} \mathrm{C}$, (d) $1250^{\circ} \mathrm{C}$, and (e \& f) $1500^{\circ} \mathrm{C}$.

\footnotetext{
${ }^{11}$ Kuzjukevics, A., Linderoth, S. and Grabis, J., Plasma produced ultrafine YSZ-NiO powders; pp. 319-330 in High Temperature Electrochemistry : Ceramics and Metals, Proceedings of the 17th Risø International Symposium on Materials Science (Roskilde, Denmark, Sep. 1996). Edited by F. W. Poulsen, N. Bonanos, S. Linderoth, M. Mogensen and B. Zachau-Christiansen. Risø National Laboratory, Roskilde, Denmark, 1996.
} 
It is essential to know the mechanical properties and microstructure of the electrolyte in order to understand the mechanical properties of the bi-layer structure. Since, the thickness of the electrolyte layer was less $(<10 \mu \mathrm{m})$, it was polished with great care. Figure 42 shows the optical micrographs of the electrolyte surfaces of as-received and heat treated NiO-8YSZ samples (Batch I). It was observed that the polishing has removed the electrolyte layer in some places and has exposed the porous anode layer. Particularly, in Figure $42 \mathrm{e} \& \mathrm{f}$, the anode layers were visible. The heat treatment or the exposure to the high temperature facilitated the grain growth in the YSZ electrolyte as can be seen in Figure 42 e. The grain growth was largely uniform as shown in the grain size distribution in Figure 43 which plots the grain size distribution in 8YSZ electrolytes (Batch I) after heat treating at $1500^{\circ} \mathrm{C}$. The average grain size was about $10 \mu \mathrm{m}$. It was interesting to note that the grain growth in the anode at $1500^{\circ} \mathrm{C}$ was comparatively less than in the electrolyte. This could be due to the presence of $\mathrm{Ni}$ in the anode or the porosity or both. Figure $42 \mathrm{f}$ shows a pore in the electrolyte through which the anode was visible. The grains in the anode were comparatively smaller than the electrolyte. It can be observed in Figure 42 e that the grain boundaries of YSZ were widened or cleaved. It may be due to the tensile forces acting on the YSZ grains as the shrinkage of the anode was comparatively higher. This differential shrinkage exerted a tensile force on the YSZ grains and formed the grain boundary cleavages. It also caused delamination of the layers when the SOFC was exposed to high temperatures or generate new flaws which would reduce the mechanical reliability of the cells.
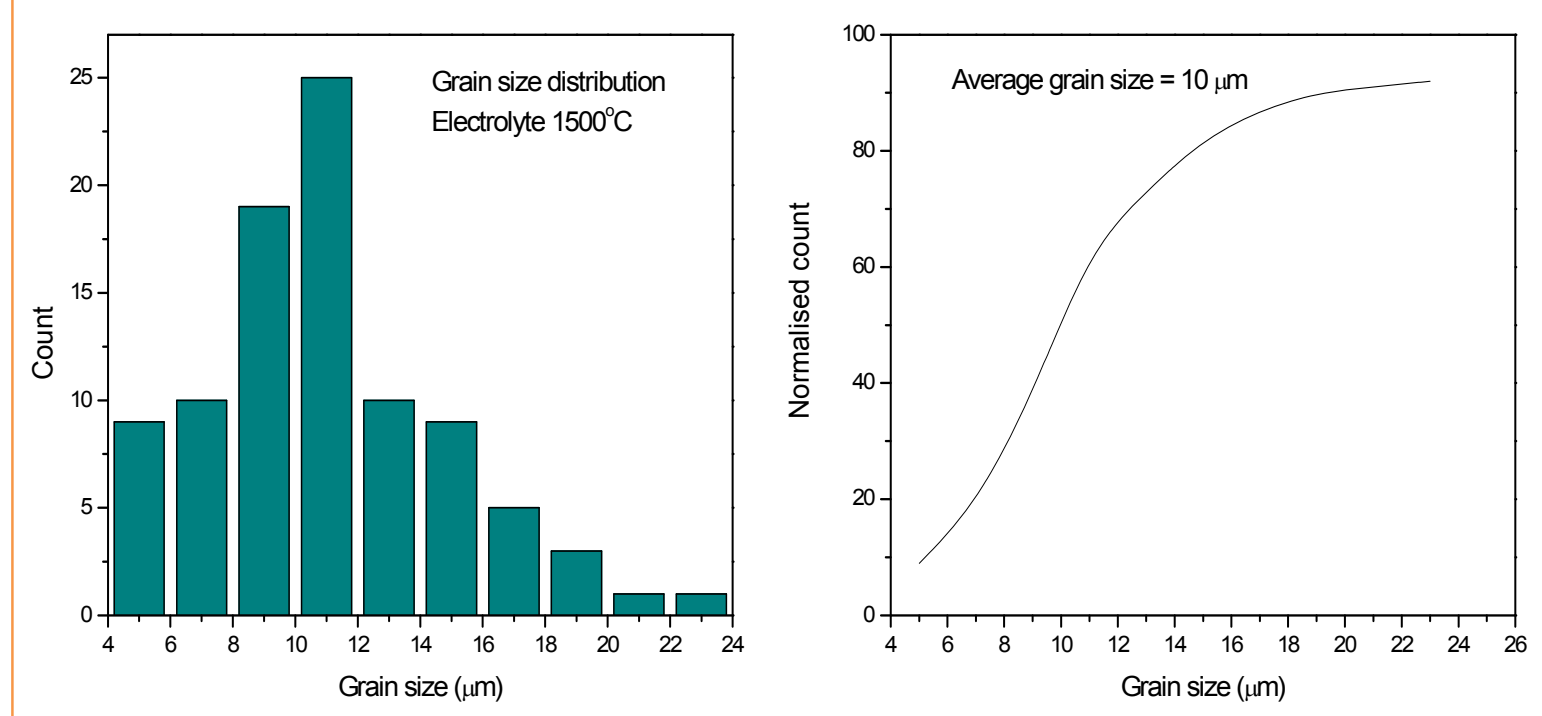

Figure 43. Grain size distribution in $8 \mathrm{YSZ}$ electrolytes (Batch I) after heat treating at $1500^{\circ} \mathrm{C}$. The average grain size was $\sim 10 \mu \mathrm{m}$.

The processes of the hydrogen oxidation reaction in Ni-YSZ cermet electrodes have been investigated by many researchers and the results revealed that the reaction was indeed limited by the length of the TPB region ${ }^{12,13}$. The possible electrochemical process in the hydrogen/water

\footnotetext{
${ }^{12}$ Jiang, S. P. and Badwal, S. P. S., Hydrogen oxidation at the nickel and platinum electrodes on yttria-tetragonal zirconia electrolyte. J. Electrochem. Soc., 1997, 144, 3777-3784

${ }^{13}$ Kim, S. J., Lee, W., Lee, W. J., Park, S. D. and Song, J. S., Preparation of nanocrystalline nickel oxide-yttriastabilized zirconia composite powder by solution combustion with ignition of glycine fuel. J. Mater. Res., 2001, 16, $3621-3627$
} 
reaction at the TPB regions were due to solid state diffusion, surface diffusion and adsorption in the electrode/electrolyte surfaces and interface. High electrical power was obtained for high conversion rates (electrochemical reaction rates) leading to high current densities at low overpotentials. High conversion rate requires highly active anodes (high electro-catalytic activity) or high numbers of TPB contacts. The number of triple phase boundary contact points was determined by the porous microstructure of the electrode. Small particles and pore sizes were essentials for obtaining high TPB length. The thermo-mechanical properties of the fuel cell were also highly dependent on the microstructure of the membrane. The distribution of the metal ions controled the thermal expansion coefficient (TEC) and determined the structural stability of the electrochemical system during operation.

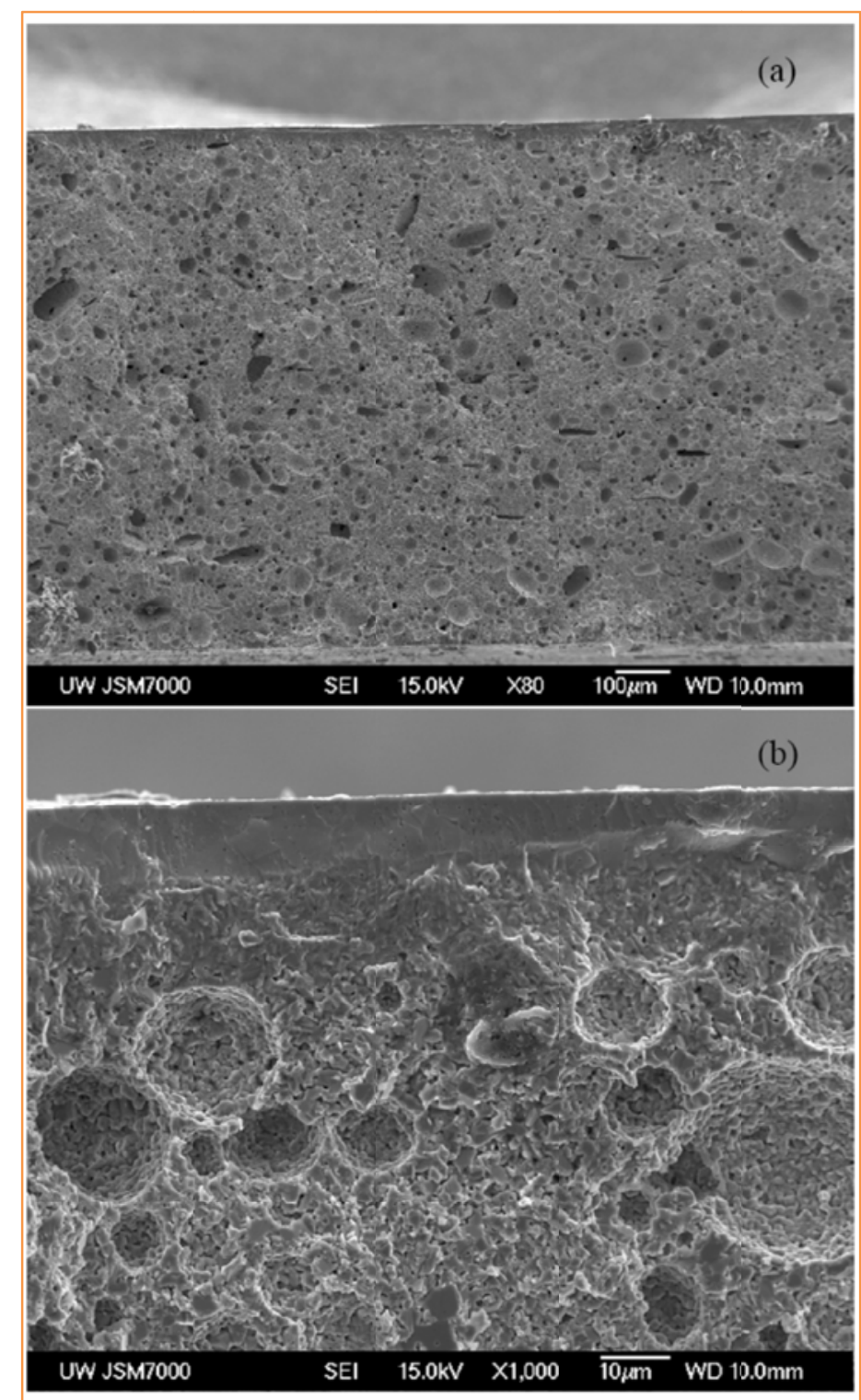

Figure 44. SEM micrographs of NiO-4YSZ button cell samples (cross sectional view). 
In Figure 44, the SEM micrographs show the cross sectional view of the NiO-4YSZ button cell samples. The fracture surface showed uniform distribution of the pores in the anode section. An open porous structure was very much required in the anode to reduce the loss of electrical conductivity caused by the gas transport. The counter diffusion of the gas and the water vapor during the polarization of the cells limits the performance of the fuel cell under test conditions. The mixtures of the electronic conducting anode material $(\mathrm{Ni})$ with an oxygen ion conductor (YSZ) dispersed the reaction zones in the volume of the porous electrode. Spreading out the reaction zones away from the anode/electrolyte interface was likely to increase the electrochemical conversion rate. In the pores, gaseous reactants and products had to be transported to and from the reaction zones (TPB zones). As can be seen more clearly in Figure 45 , the pore formers produced spherical pores which were interconnected and dispersed in the anode uniformly. The uniform distribution of the spherical pores in the anode provided unbroken percolation paths for electrons, oxide ions and gaseous species.

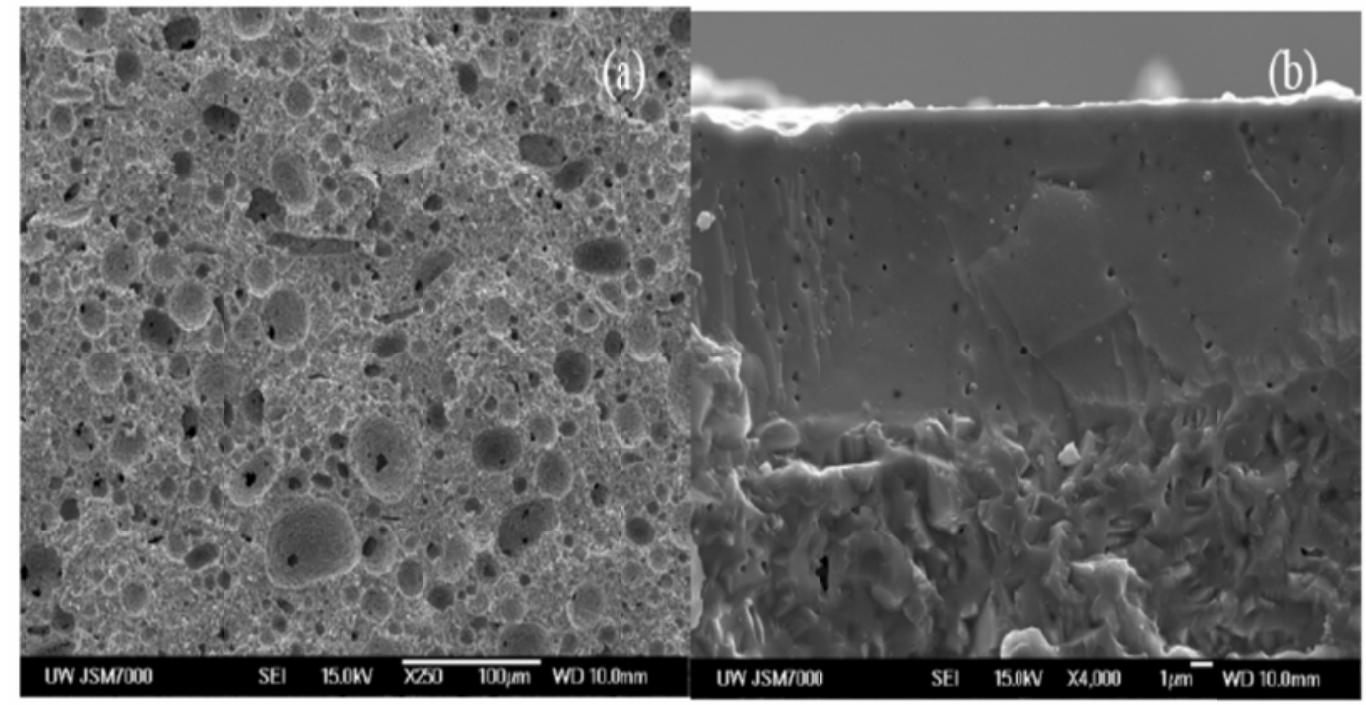

Figure 45. SEM micrograph of the NiO-4YSZ (a) anode and (b) electrolyte layer.

It was observed that sintering of the anode tapes resulted in the uniform distribution of pores. The electrolyte was fairly dense. It was also observed that the fracture of the electrolyte was transgranular in nature and the fracture mode in the anode layer was intergranular, as shown in Figure $45 \mathrm{~b}$. The anode support layer was well sintered and no de-lamination of electrolyte was observed throughout the cell. Vickers indentations given at the anode support layer produced no visible crack at the interface or any delamination of the electrolyte. The porosity of the anode support layer was expected to increase $40 \%$ upon reduction. 


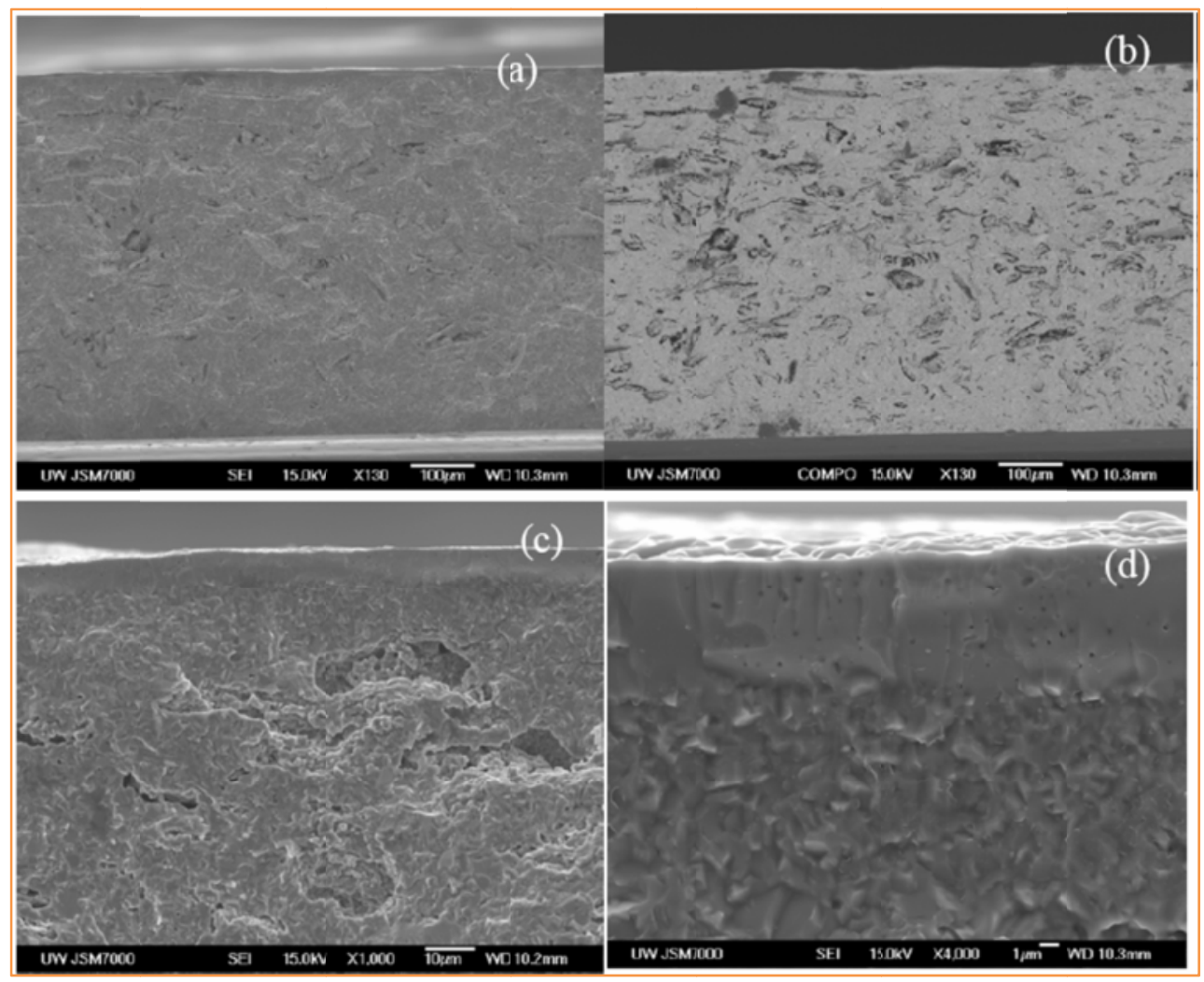

Figure 46. SEM micrographs of NiO-8YSZ samples (Batch I) in cross section. Low magnifications : (a) secondary electron image and (b) back scattered electron image. (c \& d) high magnifications. Note the irregular shaped pores dispersed in the anode structure. The electrolyte was dense and showed no delamination or cracks at the interface.

Figure 46 shows the SEM microstructure of the cross section of the NiO-8YSZ samples (Batch I). The anode layer produced by tape casting of NiO-8YSZ powders was relatively denser than the NiO-4YSZ samples and there was no evidence of spherical pores in the microstructure. In addition, the few large pores which visibly seemed to be interconnected as shown in Figure $46 \mathrm{c}$, were neither uniformly distributed nor had any regular shape. The electrolyte layer was $\sim 10 \mu \mathrm{m}$ thick and had very few closed pores, as shonw in Figure $46 \mathrm{~d}$. The anode layer was well sintered and showed no evidence of delamination at the interface. 


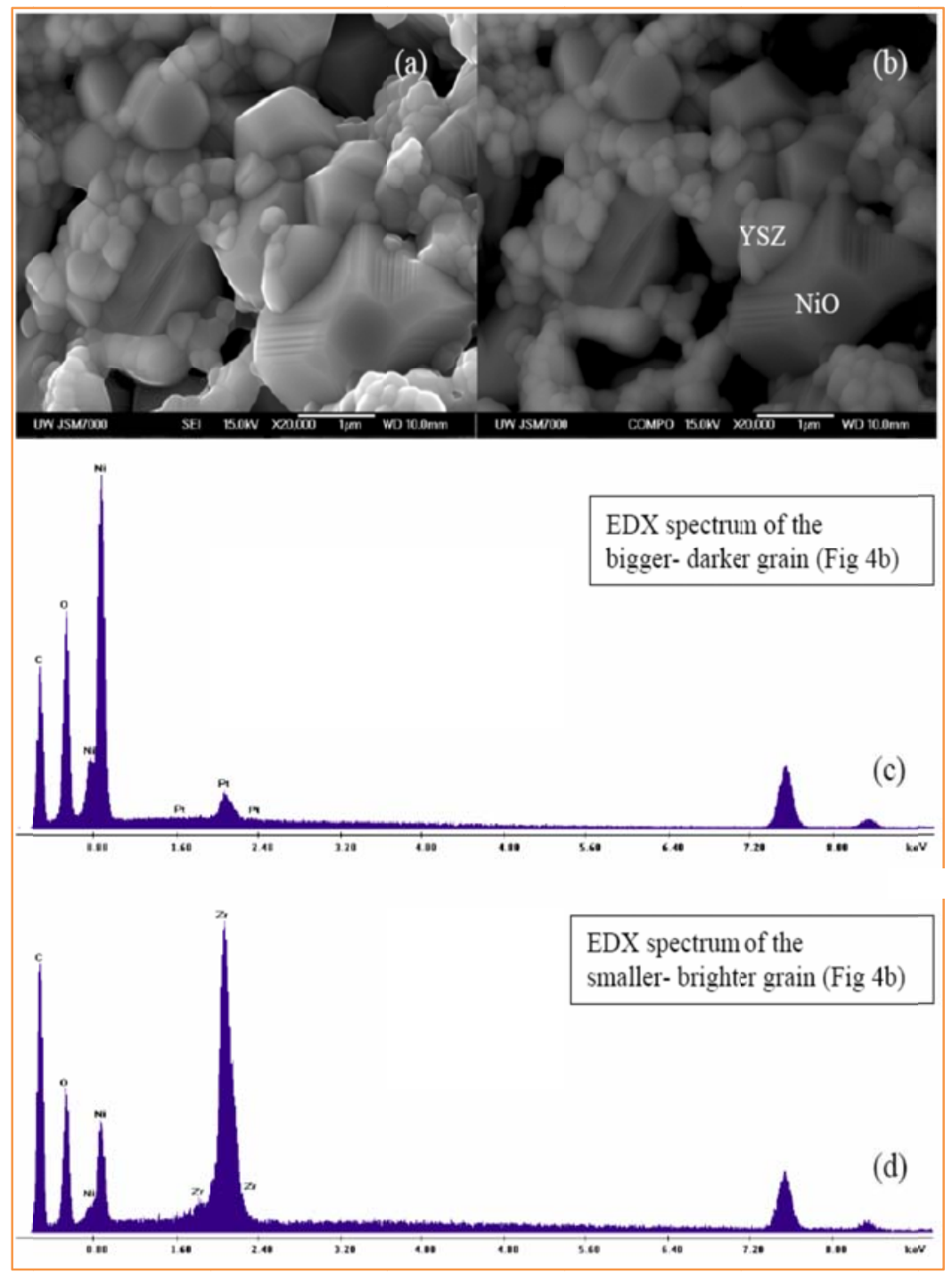

Figure 47. Secondary electron image (a) and back scattered electron image (b) of the NiO-4YSZ button cell anode, (c \& d) EDX spectra taken from the NiO and YSZ grains respectively.

High resolution SEM images of the NiO-4YSZ anodes along with the corresponding EDX spectra are shown in Figure 47. It was clearly visible that the $\mathrm{NiO}$ grains were surrounded by the submicron 4YSZ grains. The NiO has acted as sintering aid; hence there were no visible micro cracks or strain at the NiO-4YSZ interface. The EDX spectra taken from the NiO and 4YSZ grains are shown in Figure $47 \mathrm{c} \& \mathrm{~d}$. The sample was coated with Pt prior to the SEM analysis. The presence of carbon in the fuel cells was possibly due to the remnants of the pore formers that were used to produce the interconnected pores. 


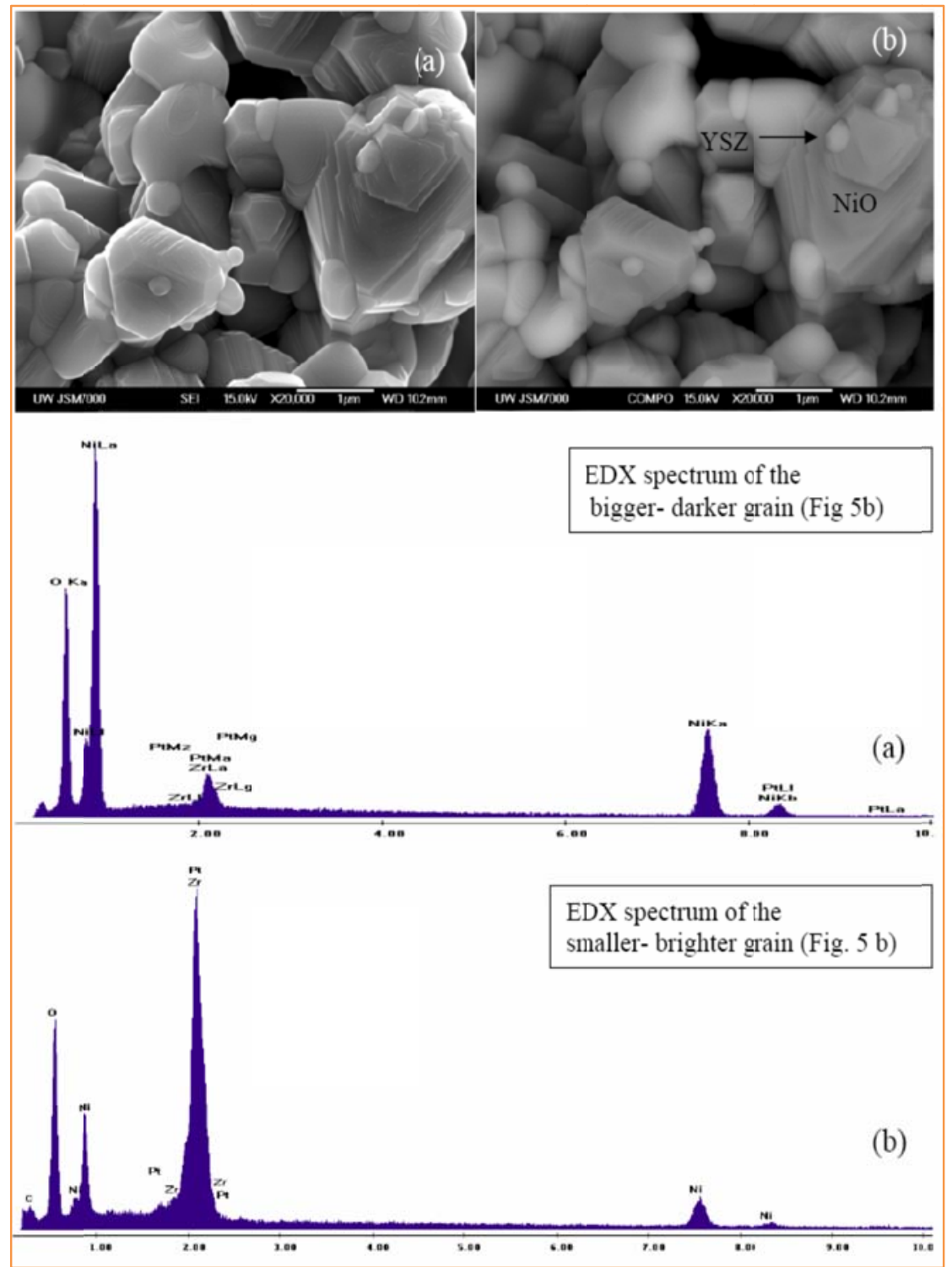

Figure 48. Secondary electron image (a) and back scattered electron image (b) of the NiO-8YSZ anode (Batch I). EDX spectra taken from the NiO and YSZ grains respectively.

Similarly, Figure 48 shows the high resolution SEM images of the as-received NiO-8YSZ anode (Batch I). Analogous to the NiO-4YSZ system, the larger NiO grains were surrounded by the submicron 8 YSZ gains and there were no visible microcracks at the NiO-8YSZ interface. The EDX spectra taken from the $\mathrm{NiO}$ and $8 \mathrm{YSZ}$ grains were shown in Figure $48 \mathrm{c} \& \mathrm{~d}$. The interconnected pores were clearly visible in both cells. Further shrinkage in the volume of the phases due to the reduction enhanced the porosity; as a result, the TPB increased significantly.

Task 3.2.2 Effect of reduction on the microstructure development in the NiO-8YSZ half-cells

In Figure 49, the SEM micrographs illustrate a systematic study of the effect of reduction on the microstructure development in forming the anode in the NiO-8YSZ half-cells (Batch II). The asreceived NiO-8YSZ anode precursor shown in Figure 49a, was relatively dense with small 
number irregularly shaped pores which were distributed randomly. As the exposure period to the reducing atmosphere increased, the $\mathrm{NiO}$ reduced to $\mathrm{Ni}$ gradually from the edge of the anode side and after $8 \mathrm{~h}$ of exposure it became fully reduced. Figure $49 \mathrm{~b}$ shows the unreduced part of the anode closer to the electrolyte after $10 \mathrm{~min}$ of reduction. Further exposures completely reduced the $\mathrm{NiO}$, as exhibited by the changes in the microstructure in the 2 or $8 \mathrm{~h}$ reduced samples, as shown in Figure $49 \mathrm{c} \& d$. The electrolyte remained unaffected and no delamination of electrolyte was visible after complete reduction.

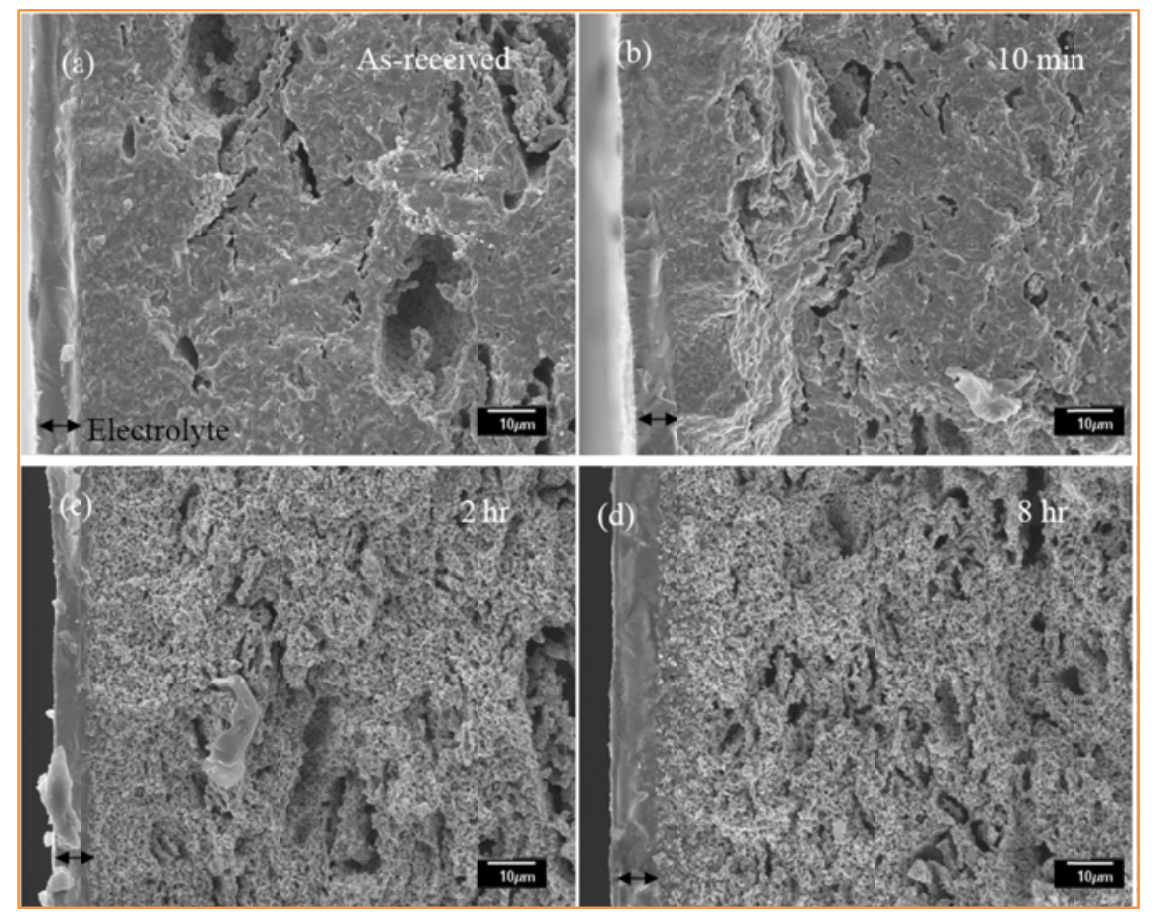

Figure 49. Effect of reduction on development of microstructure in NiO-8YSZ half-cells (Batch II). NiO gradually reduced from the edge of the anode and spread across the half-cell towards the electrolyte layer as the time of exposure increases.

Figure 50 shows the microstructural changes in details. The exposure to the reducing conditions for $10 \mathrm{~min}$ or $30 \mathrm{~min}$ formed a thin layer of $\mathrm{Ni}$ on the $\mathrm{NiO}$ particles. Further exposure to the reducing conditions has reduced the volume of $\mathrm{NiO}$ considerably which led to the development of a typical porous cermet microstructure comprising homogeneous dispersion of Ni particles in 8 YSZ with interconnected pores. 

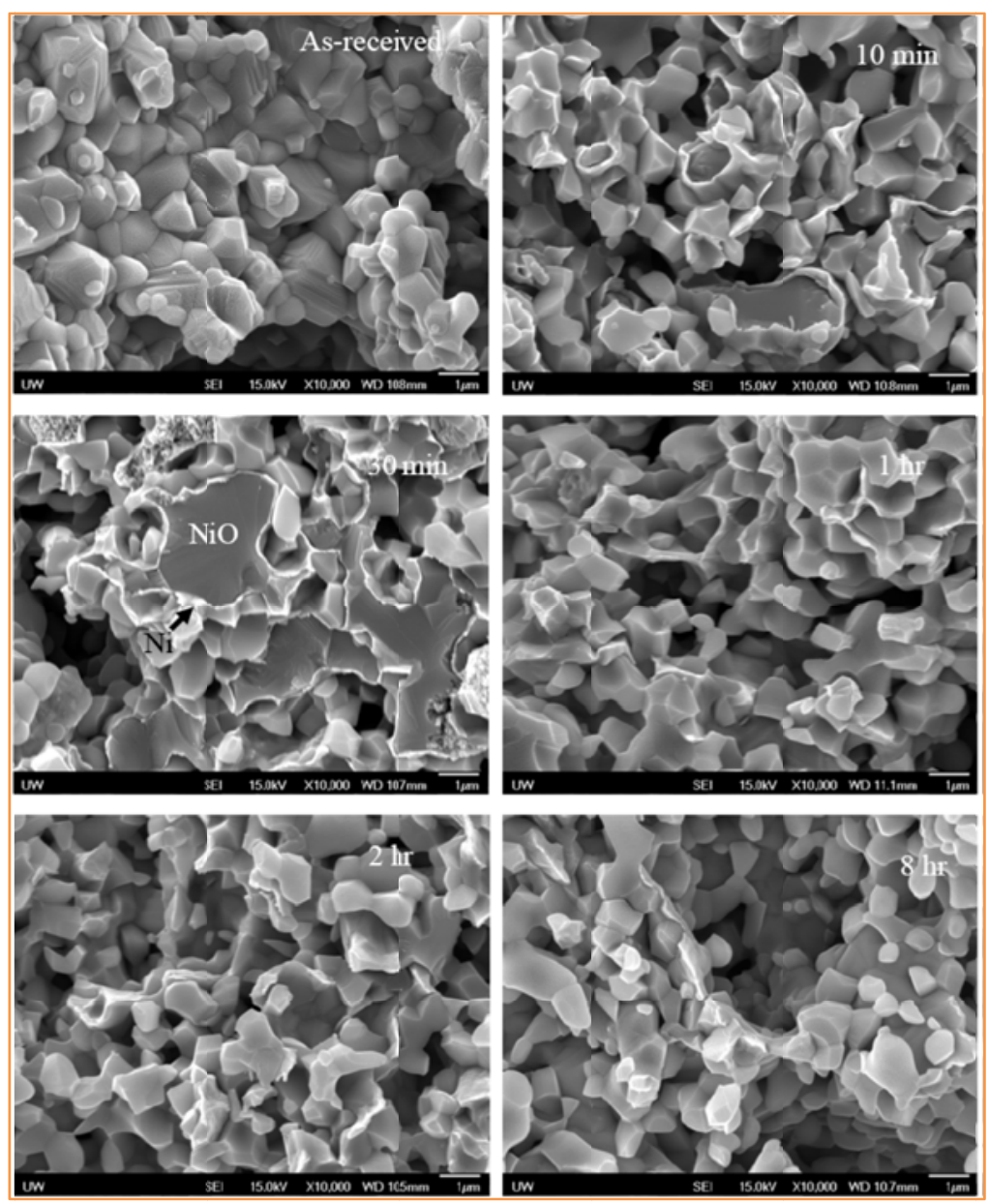

Figure 50. Development of Ni-8YSZ microstructure (Batch II) in details. The reducing atmosphere formed a thin layer of $\mathrm{Ni}$ on the $\mathrm{NiO}$ grains, which gradually growed until the whole $\mathrm{NiO}$ grain was reduced to $\mathrm{Ni}$.

Similarly, in Figure 51, the SEM micrographs show the effects of reduction on microstructure development in the anode of the batch I samples. 

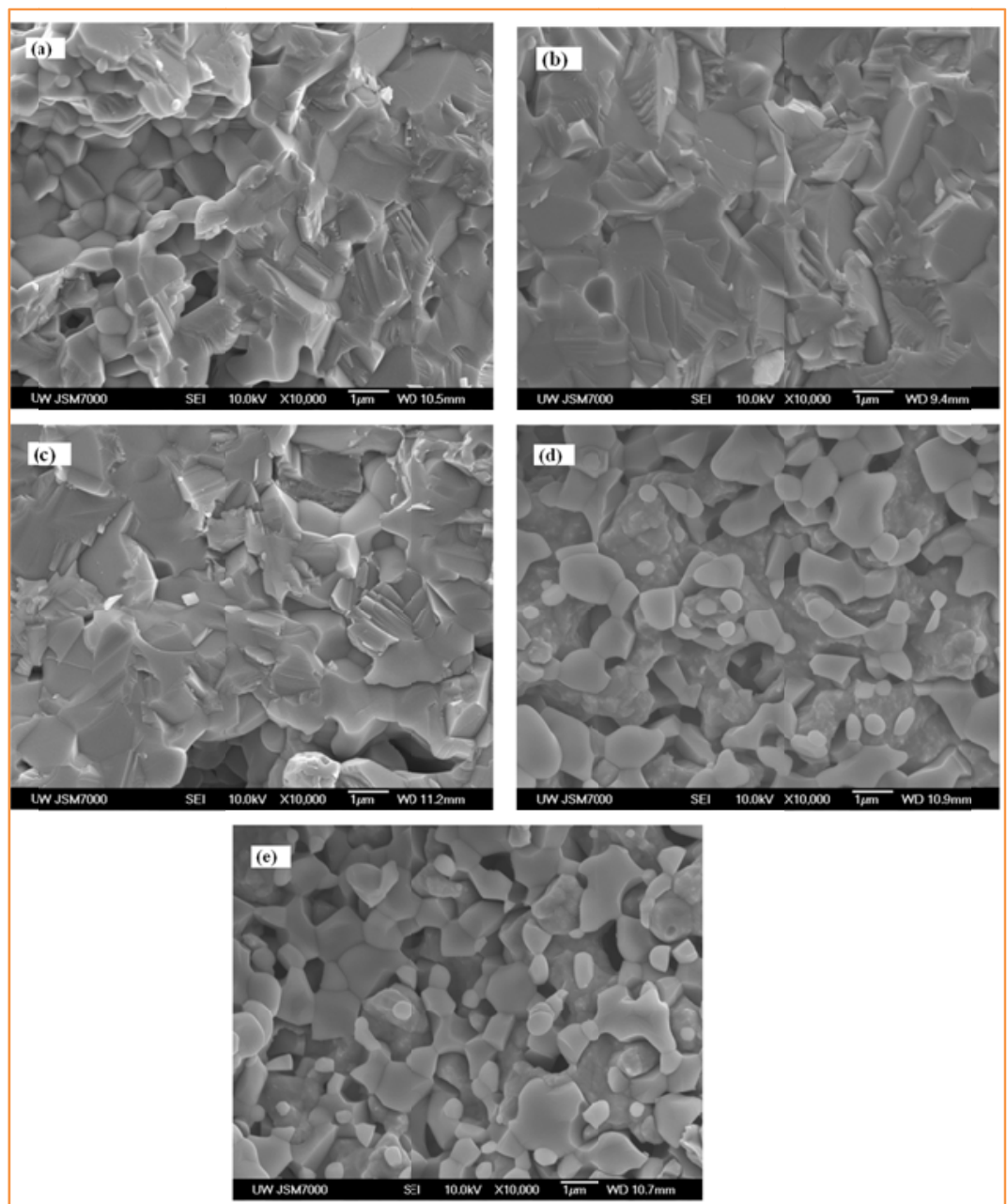

Figure 51. SEM micrographs in the anode surface of (a) as-received, (b) $10 \mathrm{~min}$, (c) $30 \mathrm{~min}$, (d) $2 \mathrm{~h}$ and (e) $8 \mathrm{~h}$ reduced NiO-8YSZ samples (Batch I).

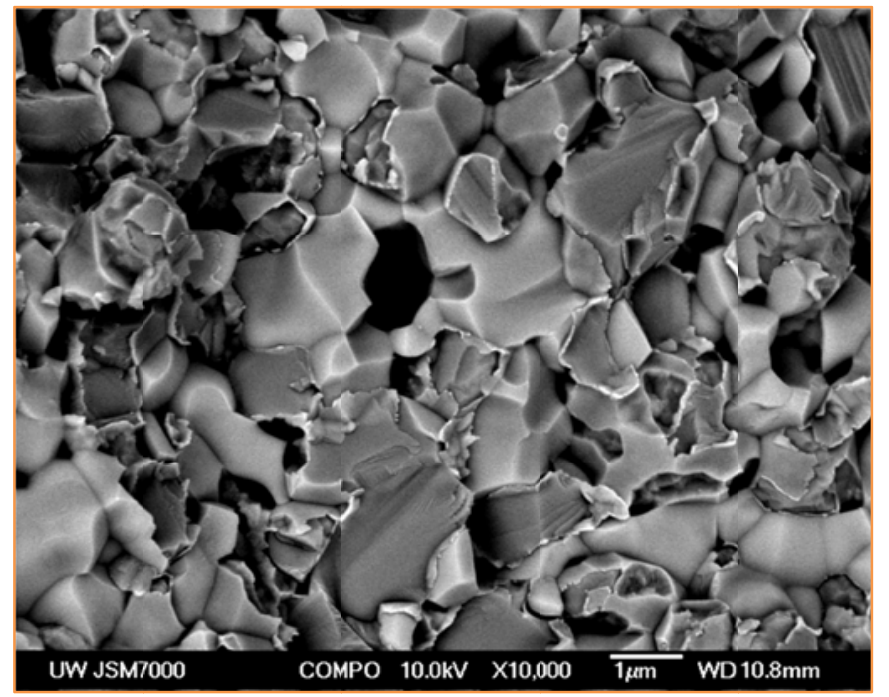

Figure 52. A back scattered image of the NiO-8YSZ anode reduced at $800^{\circ} \mathrm{C}$ in $5 \% \mathrm{H}_{2}$ for $10 \mathrm{~min}$. (Note the formation of $\mathrm{Ni}$ layers on the $\mathrm{NiO}$ particles) 
The as-received anode was relatively dense and the pores were not interconnected. The exposure to the reducing conditions for $10 \mathrm{~min}$ or $30 \mathrm{~min}$ formed a layer of $\mathrm{Ni}$ on the $\mathrm{NiO}$ particles. The formation of Ni layers was distinguishably visible in the back scattered SEM images in Figure 52. Further exposure to the reducing conditions has reduced the volume of the $\mathrm{NiO}$ considerably, leading to the development of the desired microstructure with interconnected pores and Ni particles.

Task 3.2.3 Evaluation of porosity and crystalline phase in the as-received and reduced halfcell samples

Bulk density and apparent porosity values in the as-received and the reduced half-cell samples were estimated using Archimedes principle as given in ASTM standard C20-00. The samples were cut into small pieces and their dry weights were measured. Then the sample pieces were boiled in distilled water for $2 \mathrm{~h}$ and kept immersed in water for $12 \mathrm{~h}$ to cool to room temperature before weighing. The suspended weights of the samples were measured. The samples were then taken out and all drops of water from the surfaces were cleaned with a moistened smooth linen or wet cloth. Then the water saturated weights of the samples were measured. Density and porosity values of the samples were calculated from the different weights of the samples. The results obtained in the as-received NiO-YSZ samples are given in Table 2. Since the electrolyte layer was very thin comparing to the anode, these values were near approximation of the true values of porosity/density in the anode.

Table 2. Bulk density and apparent porosity of the as-received half-cell samples

\begin{tabular}{|c|c|c|c|c|}
\hline Samples & $\begin{array}{c}\text { Apparent } \\
\text { porosity, } \\
(\%)\end{array}$ & $\begin{array}{c}\text { Density, B } \\
(\mathrm{g} / \mathrm{cc})\end{array}$ & $\begin{array}{c}\text { Average P } \\
(\%)\end{array}$ & $\begin{array}{c}\text { Average B } \\
(\mathrm{g} / \mathrm{cc})\end{array}$ \\
\hline $\begin{array}{c}\text { NiO-4YSZ } \\
\text { button cells }\end{array}$ & $\begin{array}{c}36.7866 \\
35.4974\end{array}$ & $\begin{array}{c}3.9986 \\
4.0161\end{array}$ & 36.1471 & 4.0013 \\
& 36.1573 & 3.9891 & & \\
NiO-8YSZ & 11.8753 & 5.4706 & 12.0006 & 5.4668 \\
$\begin{array}{c}\text { (Batch I, } \\
600 \mu \mathrm{m}\end{array}$ & 11.6563 & 5.4755 & & \\
thick) & 12.4701 & 5.4543 & & 3.9262 \\
$\begin{array}{c}\text { NiO-4YSZ } \\
\text { (electrolyte } \\
\text { portion }\end{array}$ & 39.0547 & 3.7985 & 38.7523 & \\
removed) & 39.1220 & 3.9980 & & \\
\hline
\end{tabular}

The NiO-4YSZ cells had a porosity of $36.15 \%$ with a bulk density of $4.0 \mathrm{~g} / \mathrm{cc}$, while the NiO8 YSZ (Batch I) cells had a lower value of average porosity of $12.0 \%$ and an enhanced density of $5.47 \mathrm{~g} / \mathrm{cc}$. The major contribution to the porosity of the samples was from the thick layer of the anode. In order to have an idea of the porosity in the anode portions only, the porosity of the anode was measured exclusively. These samples were made by simply removing the electrolyte 
portion of the cells by polishing in a BUELER grinder using 240 grade $\mathrm{SiC}$ paper for $1 \mathrm{~min}$. at $150 \mathrm{rpm}$. The average porosity and density measured in the NiO-4YSZ anode were found to be $38.75 \%$ and $3.93 \mathrm{~g} / \mathrm{cc}$, respectively.
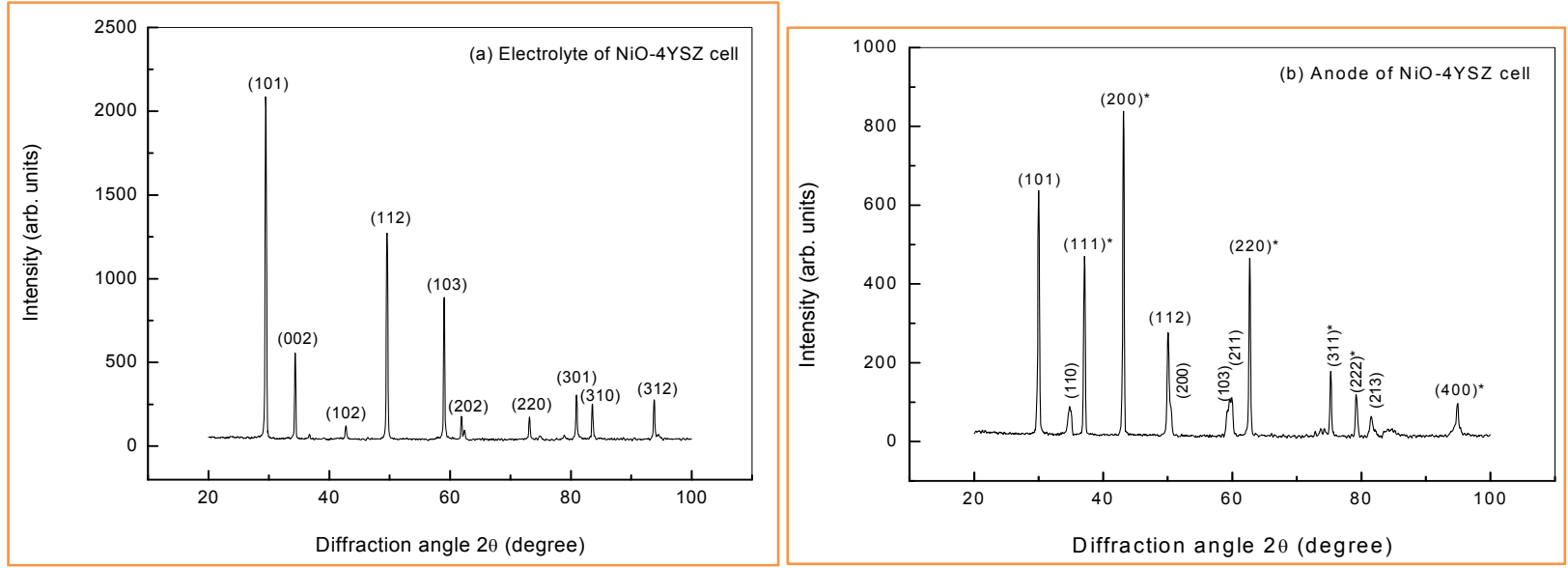

Figure 53. X-ray diffractograms of (a) electrolyte and (b) anode of a NiO-4YSZ button cell. “*” denotes $\mathrm{NiO}$ peaks.

X-ray diffraction studies of both the anode and electrolyte surfaces of the as-received NiO-4YSZ and NiO-8YSZ cells were performed in order to study their crystalline structure. Figure 53 shows typical X-ray diffractograms in (a) electrolyte and (b) anode surfaces of the as-received NiO-4YSZ cells. The electrolyte, composed of 4YSZ, showed well resolved strong peaks (Figure 53a) of $\mathrm{ZrO}_{2}$ in the $\mathrm{O}^{15}{ }_{4 \mathrm{~h}}: \mathrm{P}_{2} / \mathrm{nmc}$ tetragonal $(t)$ phase with lattice parameters $a=0.3655$ $\mathrm{nm}$ and $c=0.5195 \mathrm{~nm}$ and a lattice volume $\mathrm{V}_{\mathrm{o}}=0.0694 \mathrm{~nm}^{3}$. In contrast, the anode which consisted of heavily doped $\mathrm{NiO}$ in $4 \mathrm{YSZ}$ (70/30) showed strong reflection peaks (Figure 53b) from cubic $\mathrm{NiO}\left(a=0.4185 \mathrm{~nm}\right.$ and $\left.\mathrm{V}_{\mathrm{o}}=0.0733 \mathrm{~nm}^{3}\right)$ and relatively weaker peaks from $t-\mathrm{ZrO}_{2}$ planes with $a=0.3620 \mathrm{~nm}, c=0.5212 \mathrm{~nm}$ and $\mathrm{V}_{\mathrm{o}}=0.0683 \mathrm{~nm}^{3}$. Nevertheless, $t-\mathrm{ZrO}_{2}$ in both electrolyte and anode, showed the most intense peak from the (101) reflections, with the second and third most intense peaks in the (112) and (103) reflections, respectively.
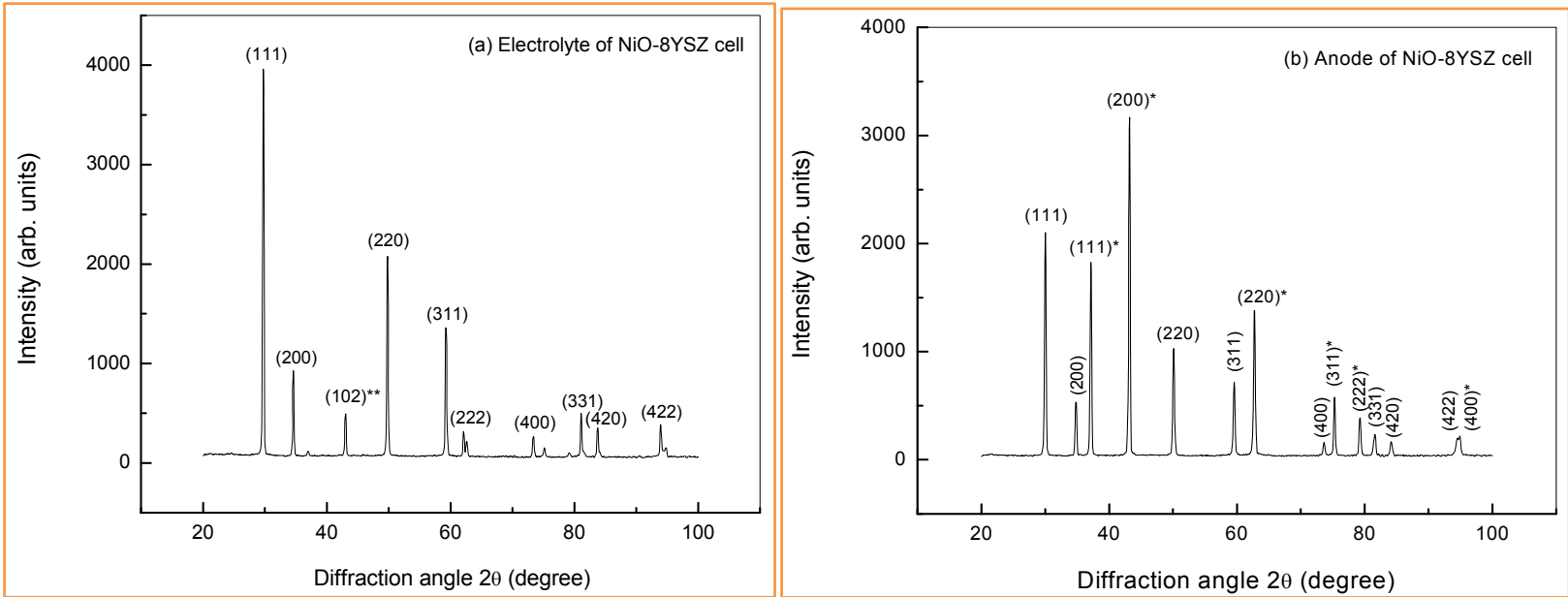

Figure 54. X-ray diffractograms of (a) electrolyte and (b) anode of a NiO-8YSZ cell (Batch I, $600 \mu \mathrm{m}$ thick). "***" and "**" denoted $t-\mathrm{ZrO}_{2}$ and $\mathrm{NiO}$ peaks respectively. 
Similarly, Figure 54 shows the X-ray diffractograms in the (a) electrolyte and (b) anode surfaces of the as-received NiO-8YSZ cells (Batch I). The electrolyte showed strong peaks of $\mathrm{ZrO}_{2}$ in the $\mathrm{O}_{\mathrm{h}}^{5}$ : Fm3m cubic (c) fluorite phase with a small peak from (102) planes of $t-\mathrm{ZrO}_{2}$, confirming the presence of a minute amount of $t-\mathrm{ZrO}_{2}$. However, according to the phase diagram, $8 \mathrm{YSZ}$ is in the cubic phase. The $c-\mathrm{ZrO}_{2}$ involved a value $\mathrm{V}_{\mathrm{o}}=0.1378 \mathrm{~nm}^{3}$ with $a=0.5165 \mathrm{~nm}$ and the tetragonal peak revealed a $\mathrm{V}_{\mathrm{o}}$ value of $0.0674 \mathrm{~nm}^{3}$ with $a=0.3615 \mathrm{~nm}$ and $c=0.5160 \mathrm{~nm}$. The XRD pattern of the anode showed strong peaks of $\mathrm{NiO}$ with $a=0.4183 \mathrm{~nm}\left(\mathrm{~V}_{\mathrm{o}}=0.0732 \mathrm{~nm}^{3}\right)$ and relatively weaker peaks from $\mathrm{c}-\mathrm{ZrO}_{2}$ with $a=0.5140 \mathrm{~nm}$ and $\mathrm{V}_{\mathrm{o}}=0.1358 \mathrm{~nm}^{3}$. No peak from $t-\mathrm{ZrO}_{2}$ was observed in the anode.

As shown in Figure 55, the relative porosity values in the batch I samples (600 $\mu \mathrm{m}$ thick) after reduction increased (with an obvious decreased in density) with the reduction time, i.e., with the fraction of reduced $\mathrm{NiO}$. The porosity increased from $12 \%$ (density, $\rho=5.47 \mathrm{~g} / \mathrm{cc}$ ) in the asreceived samples to $36.68 \%(\rho=4.69 \mathrm{~g} / \mathrm{cc})$ for the $8 \mathrm{~h}$ reduced samples. This type of behavior was expected, since, the specific volume of metallic Ni was significantly smaller than that of $\mathrm{NiO}$. Earlier studies of the $\mathrm{NiO}$ reduction with shrinking core models [27] have shown good correlation with experimental results which suggested that YSZ had little effect on the reduction process at that temperature and the change in mass was assumed to be only from the reduction of $\mathrm{NiO}$ to $\mathrm{Ni}^{14}$.

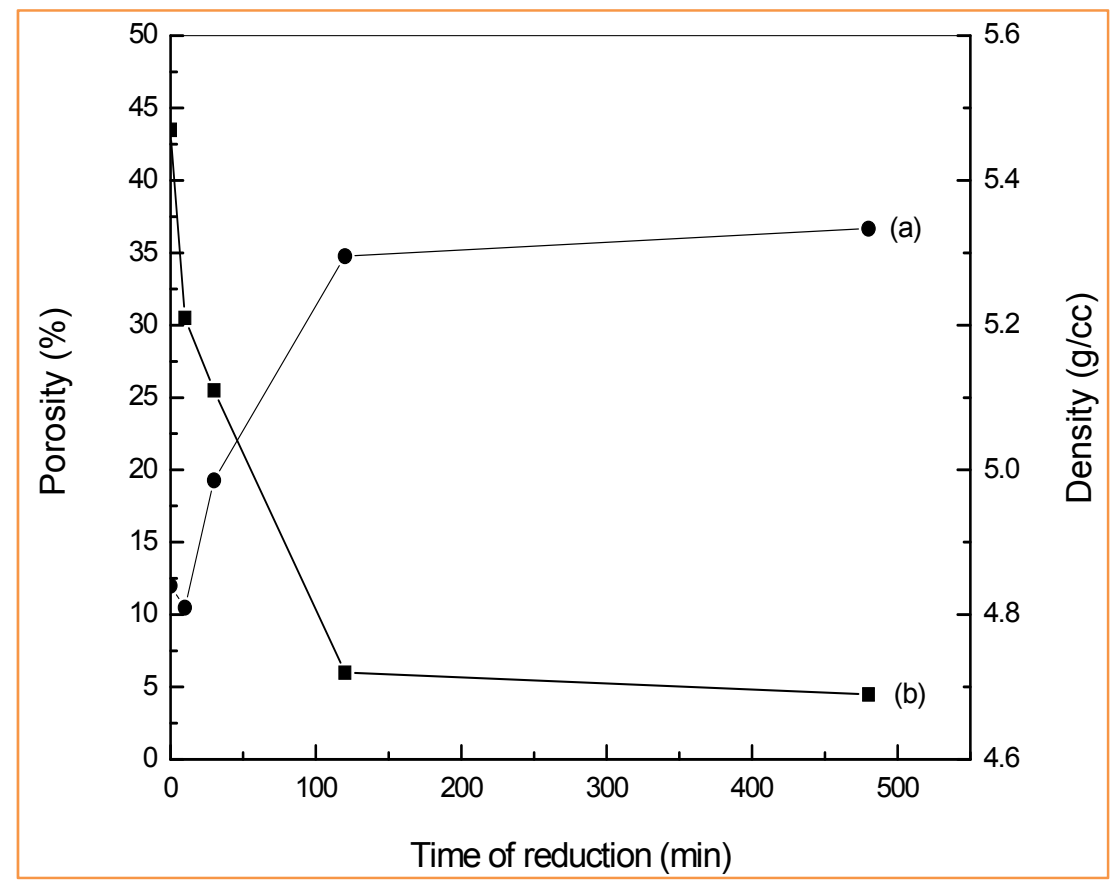

Figure 55. Measured values of (a) porosity and (b) density in the reduced NiO-8YSZ (Batch I) half-cell samples as a function of reduction time

\footnotetext{
${ }^{14}$ Radovic, M. and Lara-Curzio, E., Mechanical properties of tape cast nickel-based anode materials for solid oxide fuel cells before and after reduction in hydrogen. Acta Mater., 2004, 52, 5747-5756.
} 
The high temperature sintering (generally, $1100^{\circ} \mathrm{C}$ to $1500^{\circ} \mathrm{C}$ ) of the green anode precursor structure after its deposition resulted in the essential densification and neck formation between the particles in the anode, which is necessary for the formation of percolation paths. The NiO phase which contracted $\sim 25 \mathrm{vol} \%$ after the reduction to Ni, didn't wet YSZ very well with a wetting angle of $\sim 120^{\circ 15}$. Moreover, Ni had high surface mobility at higher temperature with a strong propensity to agglomerate ${ }^{16}$. As a result, the performance and durability of the anode highly depended on the sintering of a well-packed green structure to obtain a rigid YSZ network capable of restricting the Ni phase from agglomeration. It was observed that the fracture strength of electrolyte-supported cells decreased with the increased sintering temperature of the deposited NiO-YSZ anode precursor due to the formation of channel cracks in the electrode layers, originating in a mismatch in the thermal expansion coefficient between the layers.

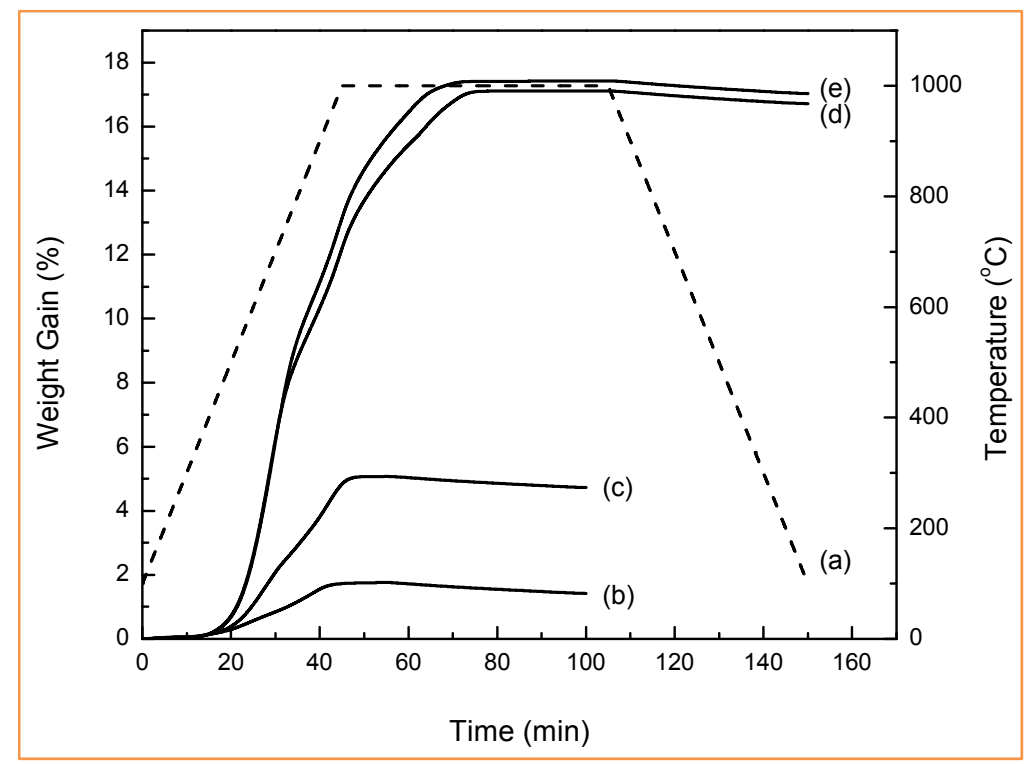

Figure 56. TG thermograms, showing the oxidation of Ni in the NiO-8YSZ (Batch I) samples reduced for (b) $10 \mathrm{~min}$, (c) $30 \mathrm{~min}$, (d) $2 \mathrm{~h}$ and (e) $8 \mathrm{~h}$ when subjected to a temperature profile (a) in air.

Since the half-cells had an electrolyte layer, it was difficult to estimate the remaining mass of $\mathrm{NiO}$ in the partially reduced anodes from the weight of the test samples. Hence, a TGA study, as shown in Figure 56, was carried out in air in order to determine the fraction of reduced $\mathrm{NiO}$ in the half-cell samples reduced for various time periods. From the weight gain due to the oxidation of the reduced $\mathrm{Ni}$ in the samples, the initial fractions of reduced $\mathrm{NiO}(\%)$ in the samples were calculated as shown in Figure 57. It appeared that the first few hours in reducing the $\mathrm{NiO}$ in the anode were decisive as $2 \mathrm{~h}$ of exposure to the reducing conditions $\left(800^{\circ} \mathrm{C}\right.$ in $5 \%$ $\mathrm{H}_{2}$ environment) was enough to reduce $\sim 80 \%$ of NiO. Further exposure to the reducing conditions could only cause a very marginal increase in the reduced amount of $\mathrm{NiO}$. The amount of reduced $\mathrm{NiO}$ after $8 \mathrm{~h}$ of exposure to the reducing conditions was $\sim 81.3 \%$.

\footnotetext{
${ }^{15}$ Nikolopoulos, P. and Sotiropoulou, D., Wettability between zirconia ceramics and the liquid metals copper, nickel, and cobalt. J. Mater. Sci. Lett., 1996, 6, 1429-30

${ }^{16}$ Murphy, M. M., Van herle, J., McEvoy, A. J. and Thampi, K. R., Electroless deposition of electrodes in solidoxide fuel cells. J. Electrochem. Soc., 1994, 141, L94-L96
} 


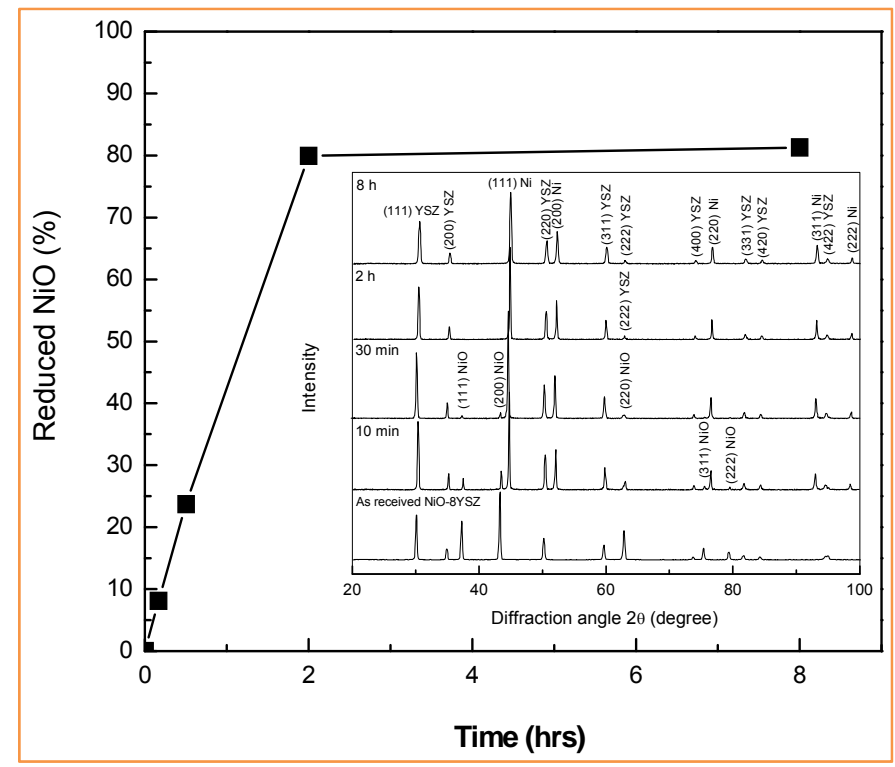

Figure 57. The fraction of reduced $\mathrm{NiO}(\%)$ in the NiO-8YSZ (Batch I) samples as a function of reduction time. The inset figure showed the x-ray diffractograms in the anode surface of the as-received and the reduced samples.

The inset figure compared the x-ray diffractograms in the anode surface of the as-received NiO$8 \mathrm{YSZ}$ (Batch I) half-cells with that of the samples reduced for $10 \mathrm{~min}, 30 \mathrm{~min}, 2 \mathrm{~h}$ and $8 \mathrm{~h}$, respectively. The as-received sample showed strong peaks of $\mathrm{NiO}$ with lattice parameter, $a=$ $0.4183 \mathrm{~nm}$ (lattice volume, $\mathrm{V}_{\mathrm{o}}=0.0732 \mathrm{~nm}^{3}$ ) and relatively weaker peaks of cubic- $\mathrm{ZrO}_{2}$ with $a=$ $0.5140 \mathrm{~nm}$ and $\mathrm{V}_{\mathrm{o}}=0.1358 \mathrm{~nm}^{3}$. Upon reduction, the NiO transformed to cubic Ni with $a=$ $0.3516 \mathrm{~nm}\left(\mathrm{~V}_{\mathrm{o}}=0.0435 \mathrm{~nm}^{3}\right)$. The $\mathrm{NiO}$ peaks gradually diminished with the increase in reduction time with a modified value of $a=0.4170 \mathrm{~nm}\left(\mathrm{~V}_{\mathrm{o}}=0.0725 \mathrm{~nm}^{3}\right)$ in the samples reduced for 10 or 30 minutes, however, the lattice parameter of $\mathrm{Ni}$ remained more or less unchanged with reduction time. Although, as par TGA measurements a part of $\mathrm{NiO}$ remained unreduced in the samples even after reduction for $8 \mathrm{~h}$, no $\mathrm{NiO}$ peaks were observed in their x-ray diffractograms. Furthermore, a very slow scan XRD studies $\left(0.01^{\circ}\right.$ step size, $2 \mathrm{~s}$ dwell time $)$ after pulverizing the half-cells have been done in order to trace any residual NiO peak, as shown in Figure 58. As expected, the relative intensity of the YSZ peaks increased due to contributions from the electrolyte part; however, there was no trace of $\mathrm{NiO}$ in the samples reduced for $\geq 2 \mathrm{~h}$ or any $\mathrm{Ni}$ in the as-received samples. 


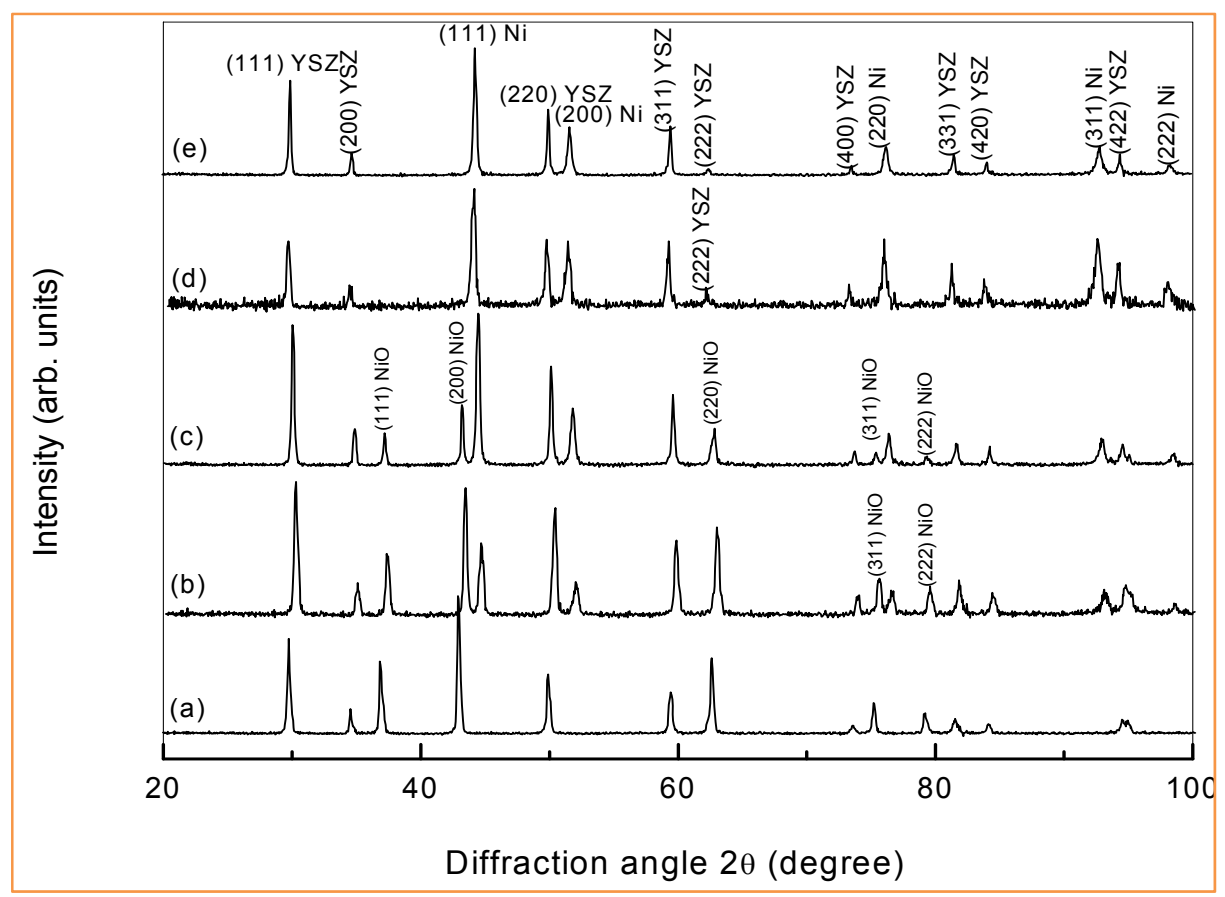

Figure 58. X-ray diffractograms of pulverized half-cell samples of (a) as-received NiO-8YSZ (Batch I) and after reducing at $800{ }^{\circ} \mathrm{C}$ in $5 \% \mathrm{H}_{2}-95 \%$ Ar atmosphere for (b) $10 \mathrm{~min}$, (c) $30 \mathrm{~min}$, (d) $2 \mathrm{~h}$ and (e) 8 h.

Similarly, the porosity/density and crystal structure of the reduced NiO-8YSZ (Batch II) samples have been analyzed. As observed in Batch I samples, the relative porosity value in the reduced samples increased (with decrease in density) with the reduction time, i.e., with the fraction of reduced $\mathrm{NiO}$, as shown in Figure 59. The porosity increased from $11.76 \%(\rho=5.24 \mathrm{~g} / \mathrm{cc})$ in the as-received samples to $39.66 \%(\rho=4.50 \mathrm{~g} / \mathrm{cc})$ after $8 \mathrm{~h}$ reduction.

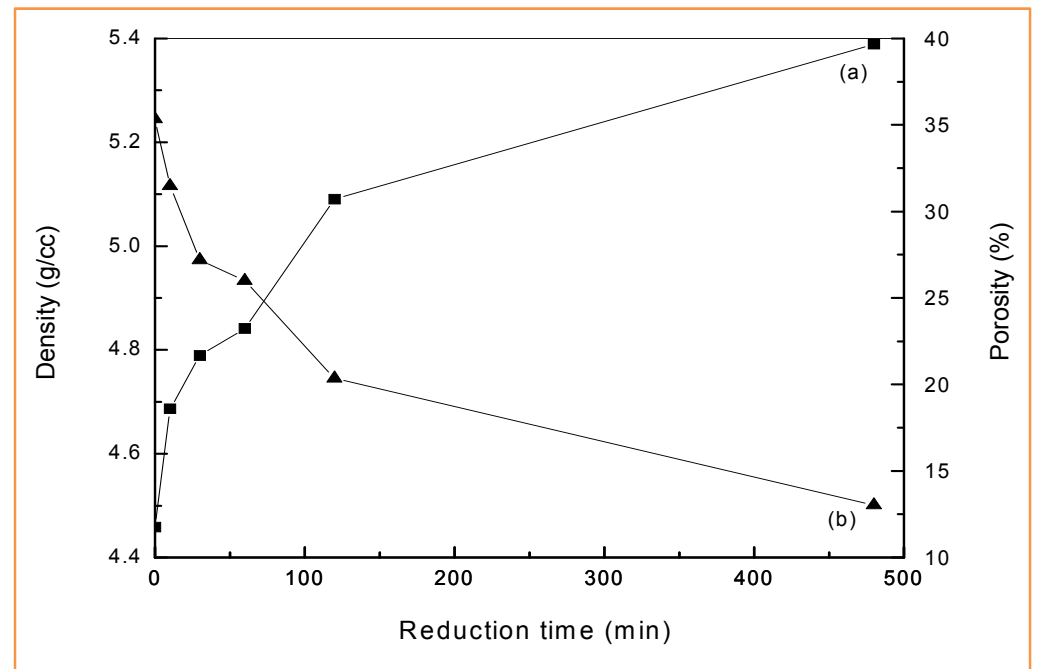

Figure 59. Measured values of (a) porosity and (b) density in the reduced NiO-8YSZ (Batch II) half-cell samples as a function of reduction time 
Figure 60a shows the total weight loss in the half-cell samples as a result of the reduction. As discussed earlier, due to the presence of the electrolyte layer in the half-cells, it was difficult to estimate the remaining mass (\%) of $\mathrm{NiO}$ in the partially reduced anodes from the weight loss of the test samples. However, the weight loss was solely attributed to the reduction of $\mathrm{NiO}$ to $\mathrm{Ni}$ since YSZ had little effect on the reduction process at that temperature. Similar to the Batch I samples, the reduced amount of $\mathrm{NiO}(\%)$ was estimated using TGA analysis and plotted in Figure $60 \mathrm{~b}$.

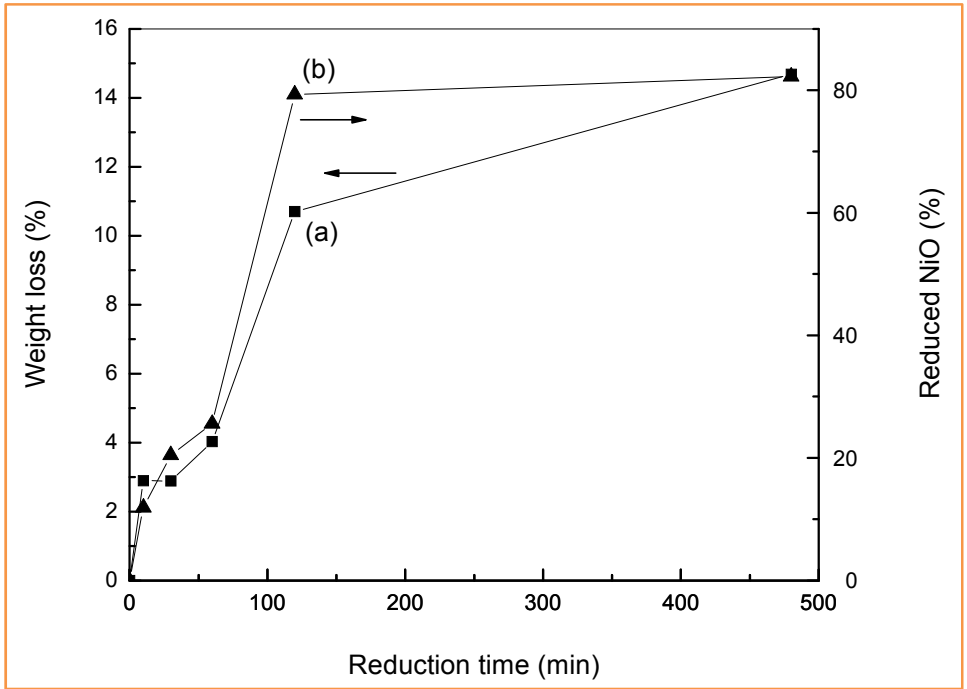

Figure 60. (a) Weight loss (\%) and (b) reduced $\mathrm{NiO}(\%)$ observed in the reduced NiO-8YSZ (Batch II, $900 \mu \mathrm{m}$ thick) half-cell samples as a function of reduction time.

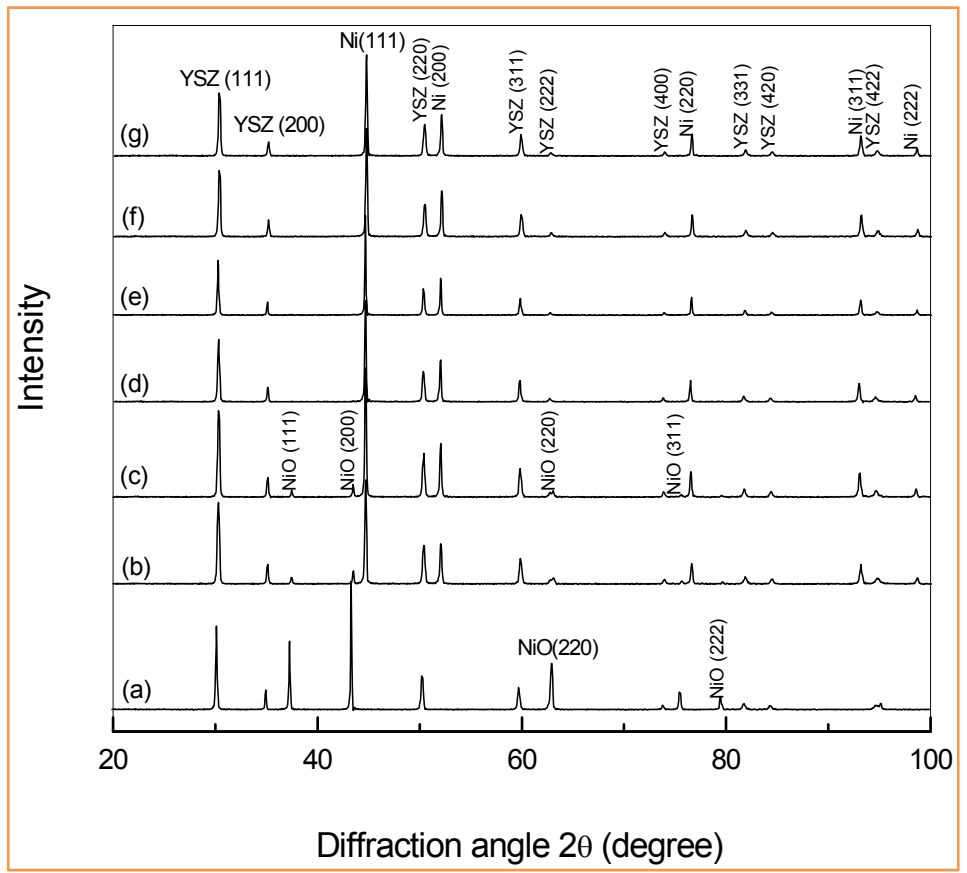

Figure 61. X-ray diffractograms of the anode surface of (a) as-received ( $900 \mu \mathrm{m}$ thick, batch II) half-cells and the samples reduced for (b) $10 \mathrm{~min}$, (c) $30 \mathrm{~min}$, (d) $1 \mathrm{~h}$, (e) $2 \mathrm{~h}$, (f) $8 \mathrm{~h}$ and the samples (g) boiled in water for $2 \mathrm{~h}$ after reducing for $8 \mathrm{~h}$. 
As observed in the Batch I samples, the first few hours in reducing the $\mathrm{NiO}$ in the anode were decisive as $2 \mathrm{~h}$ of exposure to the reducing condition $\left(800^{\circ} \mathrm{C}\right.$ in $5 \% \mathrm{H}_{2}$ environment) was enough to generate $\sim 10.70 \%$ mass loss $(79.29 \%$ reduced $\mathrm{NiO})$. Further exposure to the reducing conditions only introduced a very marginal increase in the reduced amount of $\mathrm{NiO}$. The amount of mass loss after $8 \mathrm{~h}$ of exposure to the reducing conditions was $\sim 14.68 \%$ (82.24\% reduced $\mathrm{NiO}$ ). Figure 61 compared the x-ray diffractograms of the anode surface of the as-received halfcells with samples reduced for $10 \mathrm{~min}, 30 \mathrm{~min}, 1 \mathrm{~h}, 2 \mathrm{~h}$ and $8 \mathrm{~h}$, respectively. The measured values of lattice parameter, $a$ and lattice volume, $\mathrm{V}_{\mathrm{o}}$ in the as-received and reduced samples were given in Table 3 below.

Table 3 Lattice parameters and lattice volumes observed in as-received and reduced NiO-8YSZ (Batch II) samples.

\begin{tabular}{|c|c|c|c|c|c|c|}
\hline \multirow{2}{*}{ Samples } & \multicolumn{2}{|c|}{$\mathrm{NiO}$} & \multicolumn{2}{c|}{$\mathrm{Ni}$} & \multicolumn{2}{c|}{ YSZ } \\
\cline { 2 - 7 } & $a(\mathrm{~nm})$ & $\mathrm{V}_{\mathrm{o}}\left(\mathrm{nm}^{3}\right)$ & $a(\mathrm{~nm})$ & $\mathrm{V}_{\mathrm{o}}\left(\mathrm{nm}^{3}\right)$ & $a(\mathrm{~nm})$ & $\mathrm{V}_{\mathrm{o}}\left(\mathrm{nm}^{3}\right)$ \\
\hline As-received & 0.4170 & 0.0725 & - & - & 0.5126 & 0.1347 \\
10 min reduced & 0.4165 & 0.0723 & 0.3516 & 0.0435 & 0.5123 & 0.1345 \\
30 min reduced & 0.4162 & 0.0721 & 0.3515 & 0.0434 & 0.5123 & 0.1345 \\
1 h reduced & - & - & 0.3517 & 0.0435 & 0.5126 & 0.1347 \\
2 h reduced & - & - & 0.3518 & 0.0435 & 0.5128 & 0.1348 \\
8 h reduced & - & - & 0.3515 & 0.0434 & 0.5122 & 0.1344 \\
8 h reduced and \\
boiled for 2 h
\end{tabular}
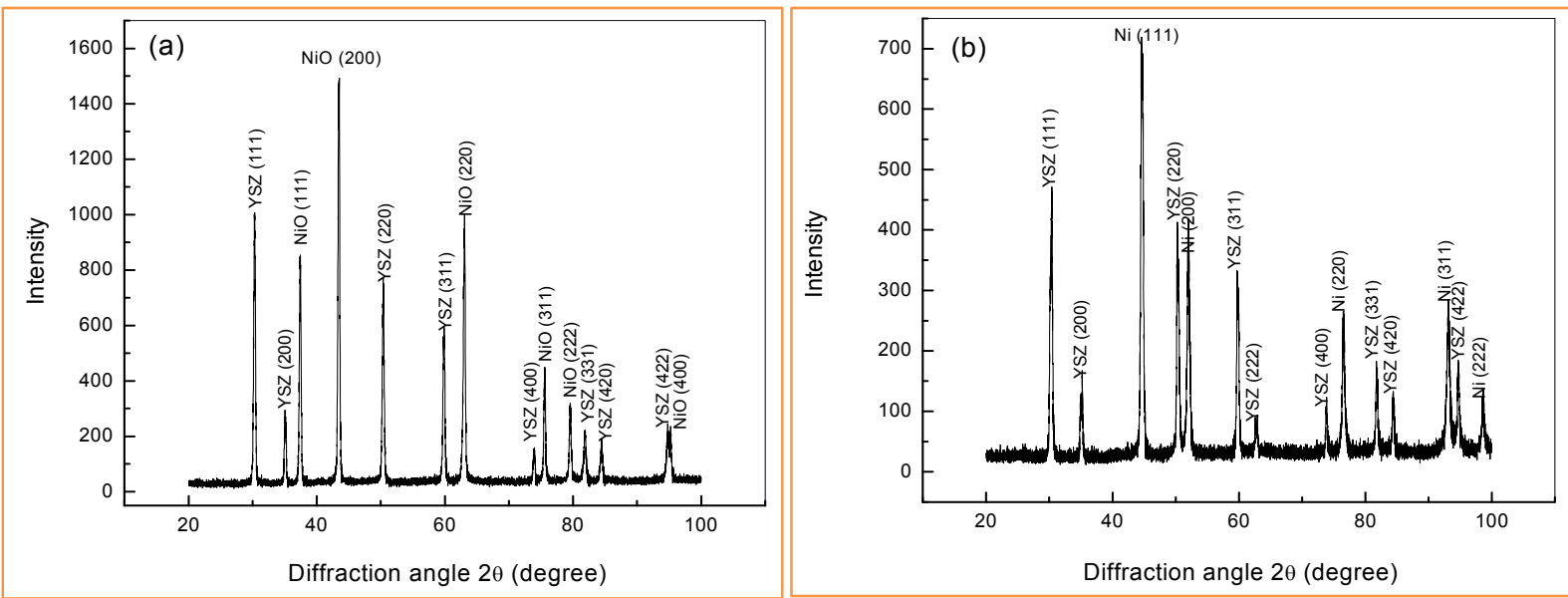

Figure 62. XRD patterns of pulverized (a) as-received and (b) $8 \mathrm{~h}$ reduced NiO-8YSZ (900 $\mu \mathrm{m}$ thick, Batch II) half-cell samples.

The as-received NiO-8YSZ (900 $\mu$ m thick batch II) samples showed strong peaks of NiO with $a$ $=0.4170 \mathrm{~nm}\left(\mathrm{~V}_{\mathrm{o}}=0.0725 \mathrm{~nm}^{3}\right)$ and relatively weaker peaks of cubic- $\mathrm{ZrO}_{2}$ with $a=0.5126 \mathrm{~nm}$ and $\mathrm{V}_{\mathrm{o}}=0.1347 \mathrm{~nm}^{3}$. upon reduction, the NiO transformed to cubic Ni with $a=0.3516 \mathrm{~nm}\left(\mathrm{~V}_{\mathrm{o}}\right.$ $=0.0435 \mathrm{~nm}^{3}$ ). The $\mathrm{NiO}$ peaks gradually diminished with the increase in reduction time with a modified value of $a=0.4162 \mathrm{~nm}\left(\mathrm{~V}_{\mathrm{o}}=0.0721 \mathrm{~nm}^{3}\right)$ in the samples reduced for 30 minutes, however, the lattice parameter of Ni remained more or less unchanged with reduction time. No 
peaks of $\mathrm{NiO}$ were observed in the samples reduced for $\geq 1 \mathrm{~h}$. In order to study the crystalline stability, the $8 \mathrm{~h}$ reduced samples were boiled in water for $2 \mathrm{~h}$. XRD pattern of the boiled samples, as shown in Figure 61g, was identical with that of the un-boiled $8 \mathrm{~h}$ reduced samples. Furthermore, a very slow scan $\left(0.01^{\circ}\right.$ step size, $2 \mathrm{~s}$ dwell time) XRD study, as shown in Figure 62 , after pulverizing the half-cells, left no trace of $\mathrm{NiO}$ in the samples reduced for $8 \mathrm{~h}$ or any $\mathrm{Ni}$ in the as-received samples.

Task 3.2.4 Mechanical properties of as-received, heat treated and reduced NiO-YSZ half-cell samples

Task 3.2.4.1 Evaluation of hardness and elastic moduli in as-received, heat treated and reduced $\mathrm{NiO}-\mathrm{YSZ}$ samples at room temperature

Hardness of as-received, heat treated and the reduced NiO-YSZ half-cells was estimated using Vickers indenter. Since the samples had high interconnected porosity, the preparation of samples for an indentation test was critical. Heat treatment was done prior to grinding and polishing of the heat treated samples.

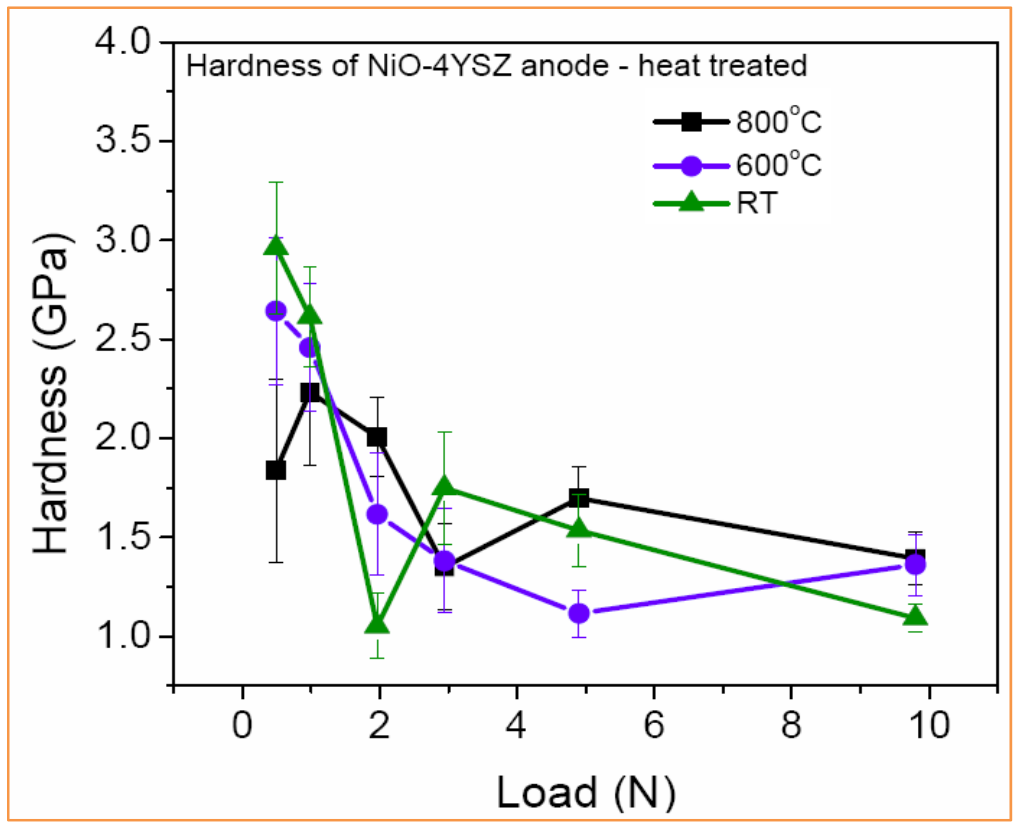

Figure 63. Hardness values measured in the anode surface of the heat treated NiO-4YSZ samples.

Figure 63 shows the effect of heat treatment on the hardness of the anode of the NiO-4YSZ cells. A reduction in the hardness values was observed with increasing indentation loads for all the three samples. The reduction in the hardness values was attributed to the underlying porosity of the anode. The high scattering in the hardness values at lower loads was also due to the high porosity of the anode. It was not possible to get a reasonable fracture toughness value from the indentation method due to the high porosity levels of the anodes. 


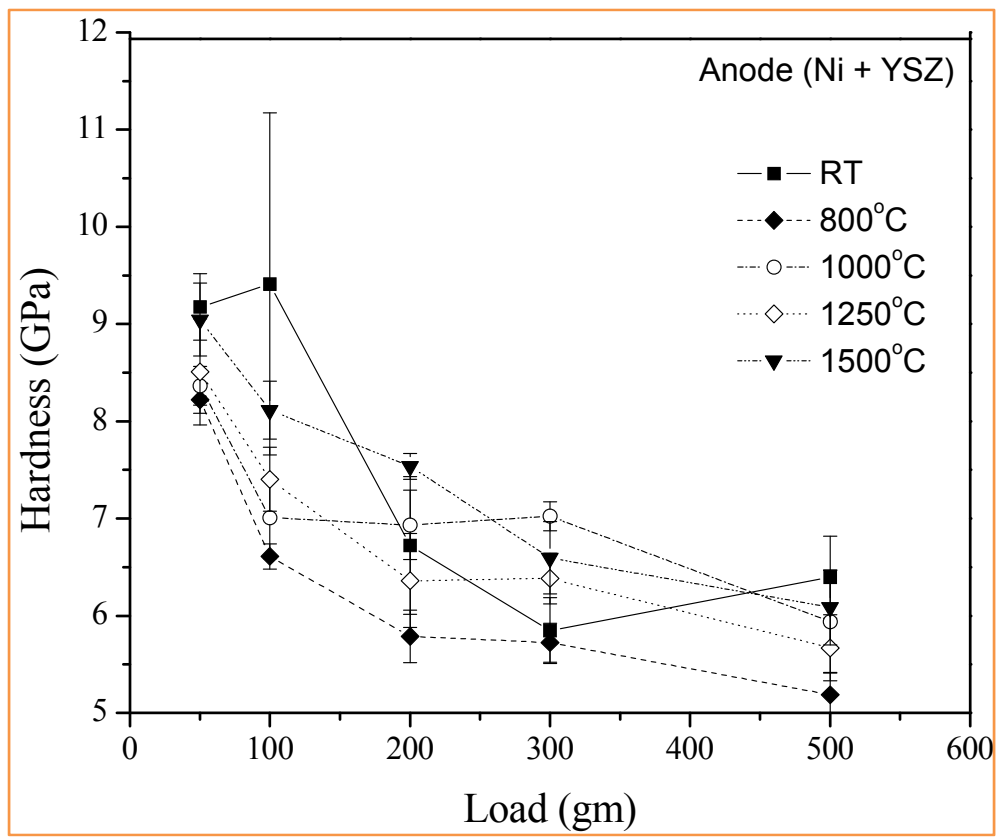

Figure 64. The effect of heat treatment on the hardness of the NiO-8YSZ anode.

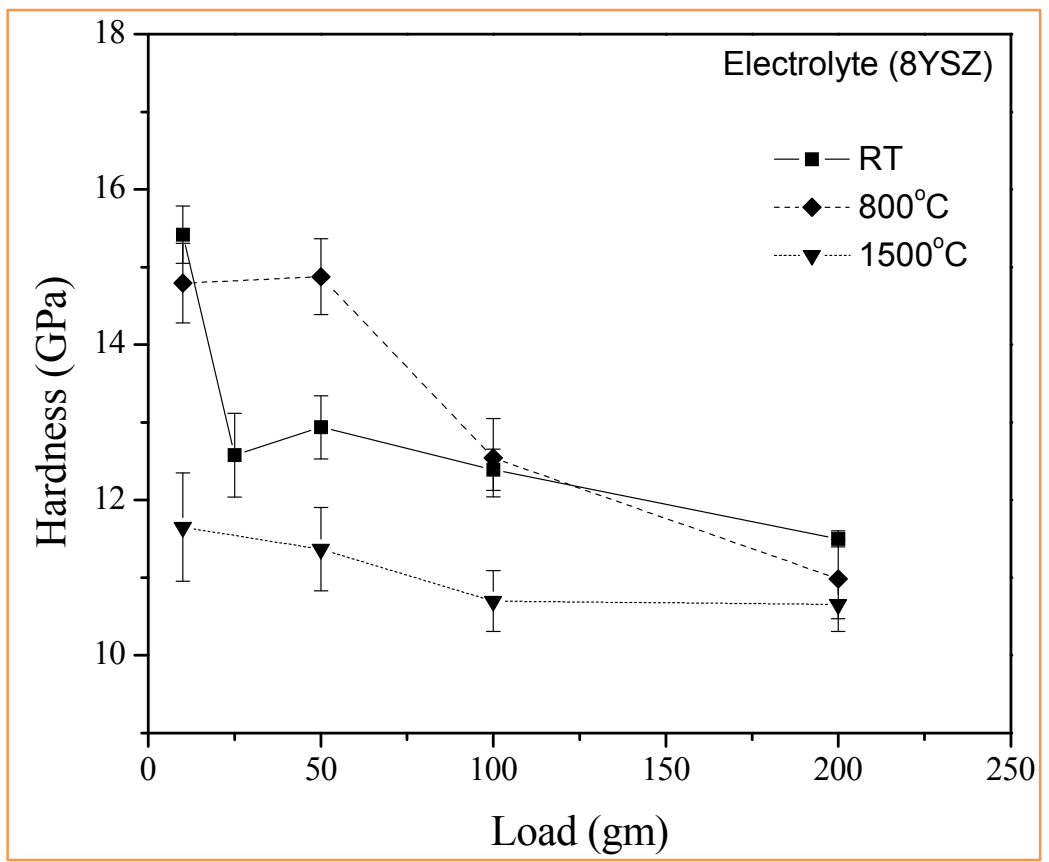

Figure 65. The effect of heat treatment on the hardness of the electrolyte.

Figure 64 shows the hardness values measured from the anode surface of the heat-treated NiO8YSZ (Batch I) samples. Similar to the NiO-4YSZ samples, the hardness values decreased with increasing indentation load. In general, for all the heat-treated anodes, the hardness decreased with an increasing indentation load. The porosity of the anode contributed more to this phenomenon. A closer observation of Figure 64 revealed that the hardness of the anodes which were heat treated at $800-1250^{\circ} \mathrm{C}$ was inferior in comparison to as-received anodes. It was 
attributed to the possible changes in the residual stresses in the half-cells caused by the heat treatment. Figure 65 shows the effect of heat treatment on the hardness of the $8 \mathrm{YSZ}$ electrolytes (600 $\mu \mathrm{m}$ thick, batch I samples). The electrolyte heat treated at $1500^{\circ} \mathrm{C}$ exhibited a consistent value of hardness at higher loads. This confirms the densification of anode was at $1500^{\circ} \mathrm{C}$. The hardness values for the loads less than $50 \mathrm{gm}$ were significantly higher. This may be due to some artifact rather than the material property.

Fracture toughness of the NiO-8YSZ (600 $\mu \mathrm{m}$ thick) anodes heat treated at various temperatures is plotted in Figure 66. The fracture toughness value was above $1.8 \mathrm{MPa} \cdot \mathrm{m}^{1 / 2}$ for all the anodes. The sharp increase in the $\mathrm{K}_{\mathrm{IC}}$ for the $1500^{\circ} \mathrm{C}$ heat treated sample was due to the densification or crack deflection caused by the weak grain boundaries resulted by the differential shrinkage.

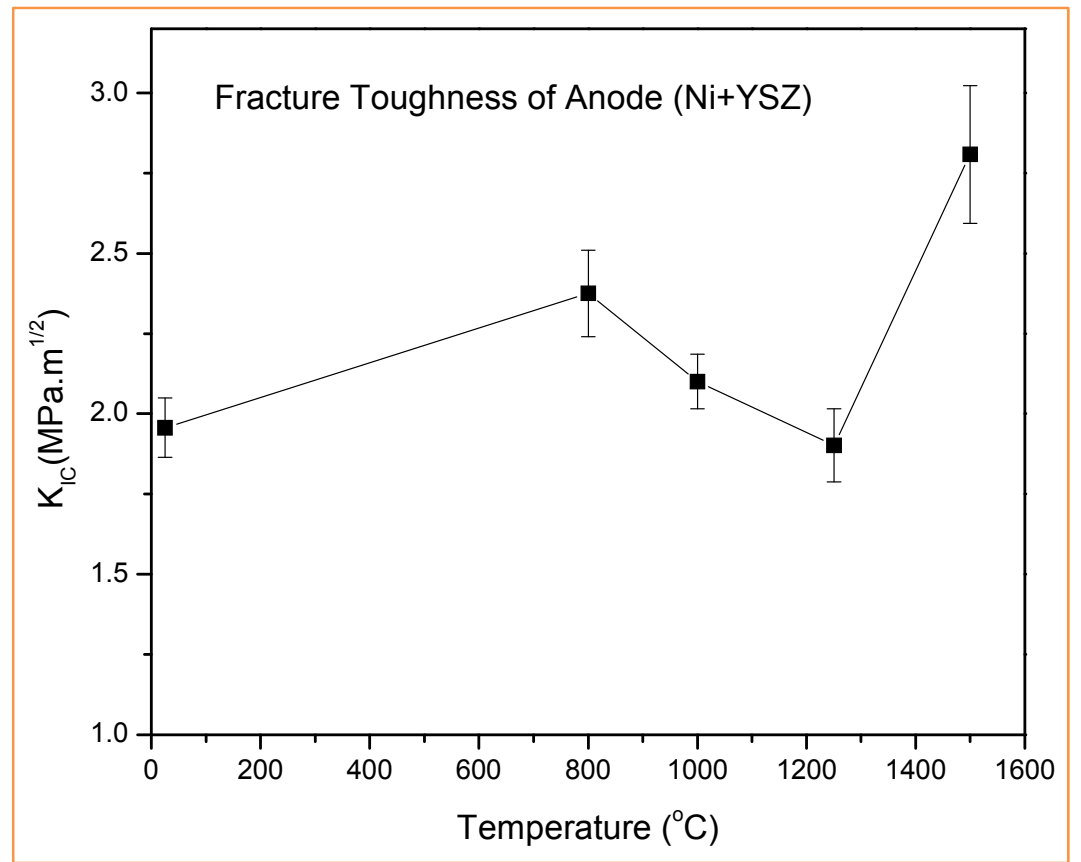

Figure 66. The effect of heat treatment on the fracture toughness of the NiO-8YSZ anodes.

Figure 67 shows the Vickers hardness values of as-received and the reduced NiO-8YSZ (600 $\mu \mathrm{m}$ thick) anode samples at room temperature plotted as a function of porosity. The as-received precursor sample which had a high density $(5.47 \mathrm{~g} / \mathrm{cc})$ and low porosity $(12 \%)$ showed a hardness value of $5.5 \mathrm{GPa}$. After reduction, the hardness value reduced to less than $1 \mathrm{GPa}$ in the $8 \mathrm{~h}$ reduced samples with an increased porosity of $37 \%$. The increase in porosity as a result of the reduction severely affected the hardness of the anode. It was interesting to note that the scattering in the hardness values also decreased with increasing porosity. Even though they were highly porous, the $2 \mathrm{~h}$ or $8 \mathrm{~h}$ reduced anode samples had negligible scattering in their hardness values in comparison to the as-received samples. This type of behavior was attributed to the higher metal content present in the highly reduced porous anodes. 


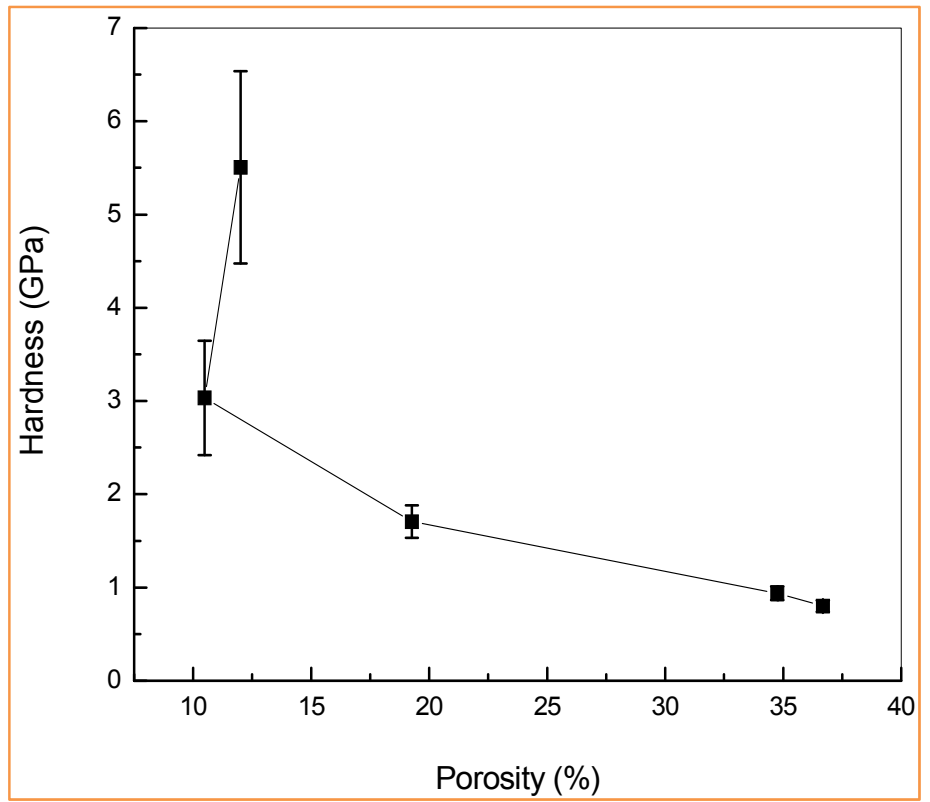

Figure 67. Hardness values plotted as a function of porosity in the as-received and the reduced NiO8 YSZ (600 $\mu \mathrm{m}$ thick, batch I) samples.

Similarly, Figure 68 shows the room temperature Vickers hardness values of as-received and the reduced NiO-8YSZ (900 $\mu \mathrm{m}$ thick, batch II) anode samples plotted as a function of porosity. The as-received precursor sample which had a low porosity $(11.76 \%)$ showed a hardness value of $3.13 \mathrm{GPa}$. After reduction, the hardness value has reduced to $0.40 \mathrm{GPa}$ in the $8 \mathrm{~h}$ reduced samples having as high as $39.66 \%$ porosity.

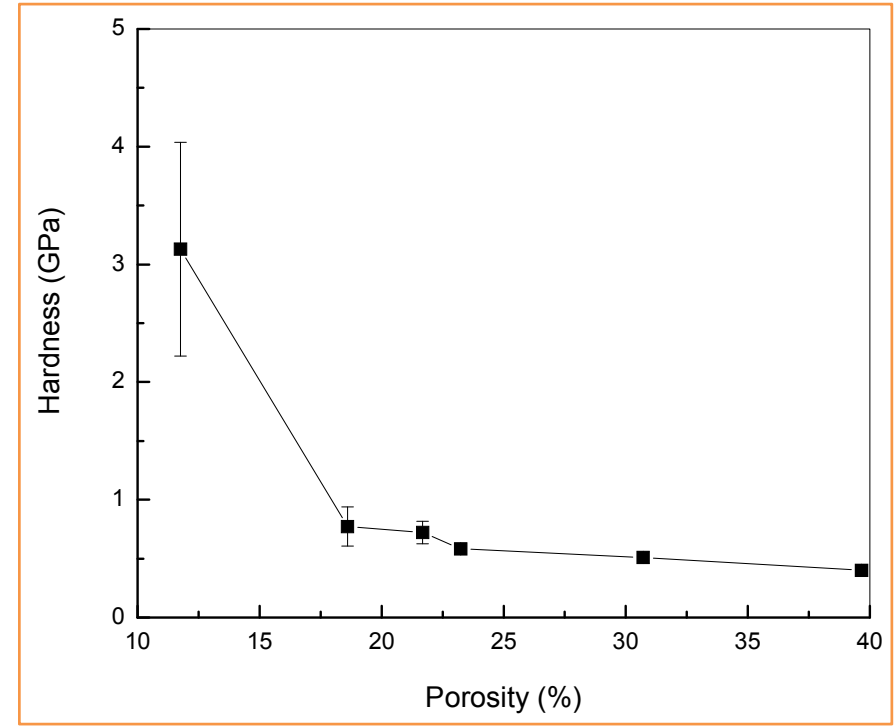

Figure 68. Hardness values plotted as a function of porosity in the as-received and the reduced NiO8 YSZ (900 $\mu \mathrm{m}$ thick, batch II) anode samples. 


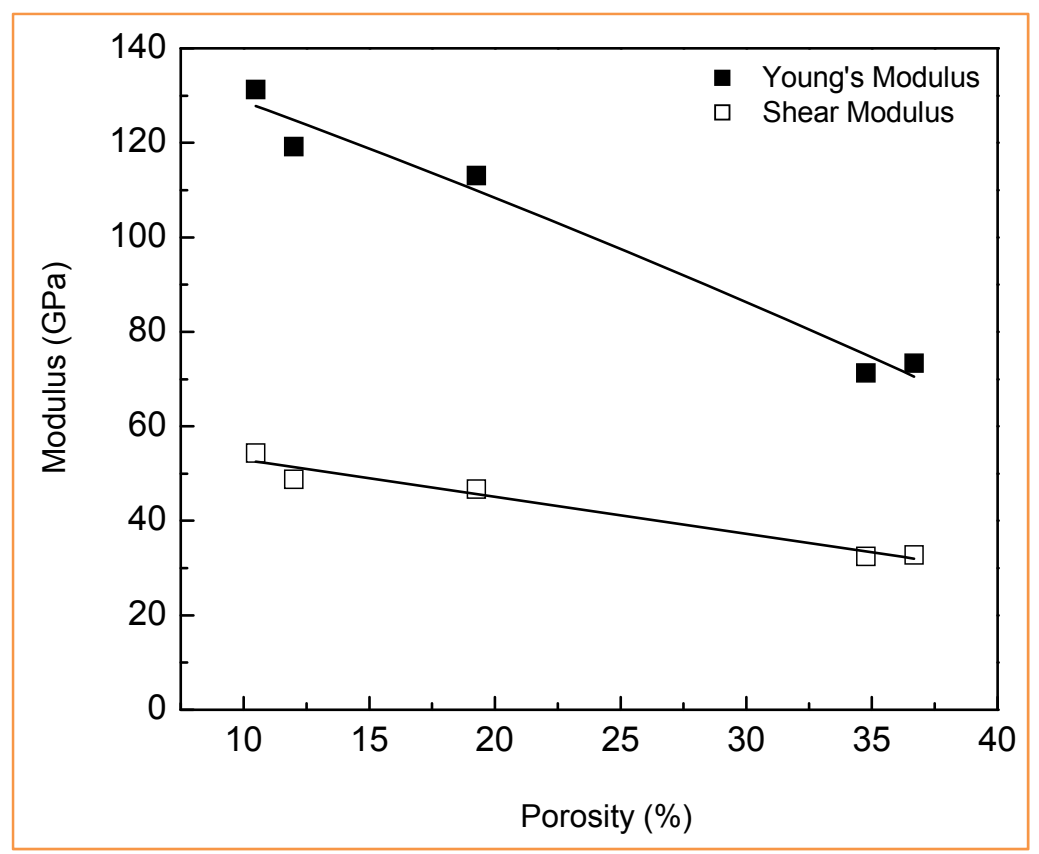

Figure 69. Room temperature Young's and shear moduli values plotted as a function of porosity in the as-received and the reduced NiO-8YSZ (Batch I) anode samples.

In Figure 69, the Young's $(E)$ and shear $(G)$ moduli of as-received and the reduced NiO-8YSZ (Batch I) anodes, characterized with the impulse excitation technique at room temperature, are plotted as a function of volume fraction of porosity in the samples. The measured values of Young's and shear moduli in the as-received samples were found to be 119.2 and $48.8 \mathrm{GPa}$, respectively. The elastic moduli values diminished significantly with the increase in the volume fraction of porosity. The observed decrease in elastic moduli was evidently a result of changes in the composition of the anode and/or increase in porosity. Since the elastic moduli of fully dense $\mathrm{Ni}(E=200 \mathrm{GPa} \text { and } G=77 \mathrm{GPa})^{17}, \mathrm{NiO}(E=220 \mathrm{GPa}$ and $G=84 \mathrm{GPa})$ and $8 \mathrm{YSZ}(E=$ $220 \mathrm{GPa}$ and $G=83.3 \mathrm{GPa})^{18}$ were comparable to each other, the changes in the chemical composition of the anode after reduction was expected to have trivial effects on the magnitude of the effective elastic moduli of the anode material. Therefore, the observed decrease of $\sim 38 \%$ in the Young's modulus ( $\sim 33 \%$ in shear modulus) after $8 \mathrm{~h}$ of reduction of the anode samples was predominantly due to the significant increase in porosity in the samples.

The room temperature Young's and shear moduli of as-received and the reduced NiO-8YSZ (Batch II) anodes are plotted as a function of volume fraction of porosity in Figure 70. The measured values of Young's and shear moduli in the un-reduced NiO-8YSZ samples were found to be 107.1 and $74.2 \mathrm{GPa}$, respectively. Similar to the Batch I samples, the elastic moduli values decreased significantly with the increase in the volume fraction of porosity. As explained before, the observed decrease of $\sim 52 \%$ in the Young's modulus ( $~ 54 \%$ in shear modulus) after $8 \mathrm{~h}$ of

\footnotetext{
${ }^{17}$ Liu, C., Lebrun, J. L. and Huntz, A. M., Origin and development of residual stresses in Ni-NiO system : In-situ studies at high temperature by x-ray diffraction. Mater. Sci. Eng. A, 1993, 160, 113-126

${ }^{18}$ Selcuk, A. and Atkinson, A., Elastic properties of ceramic oxides used in solid oxide fuel cells (SOFC). J. Eur. Ceram. Soc., 1997, 17, 1523-1532
} 
reduction of the anode samples was predominantly due to the significant increase in porosity in the samples.
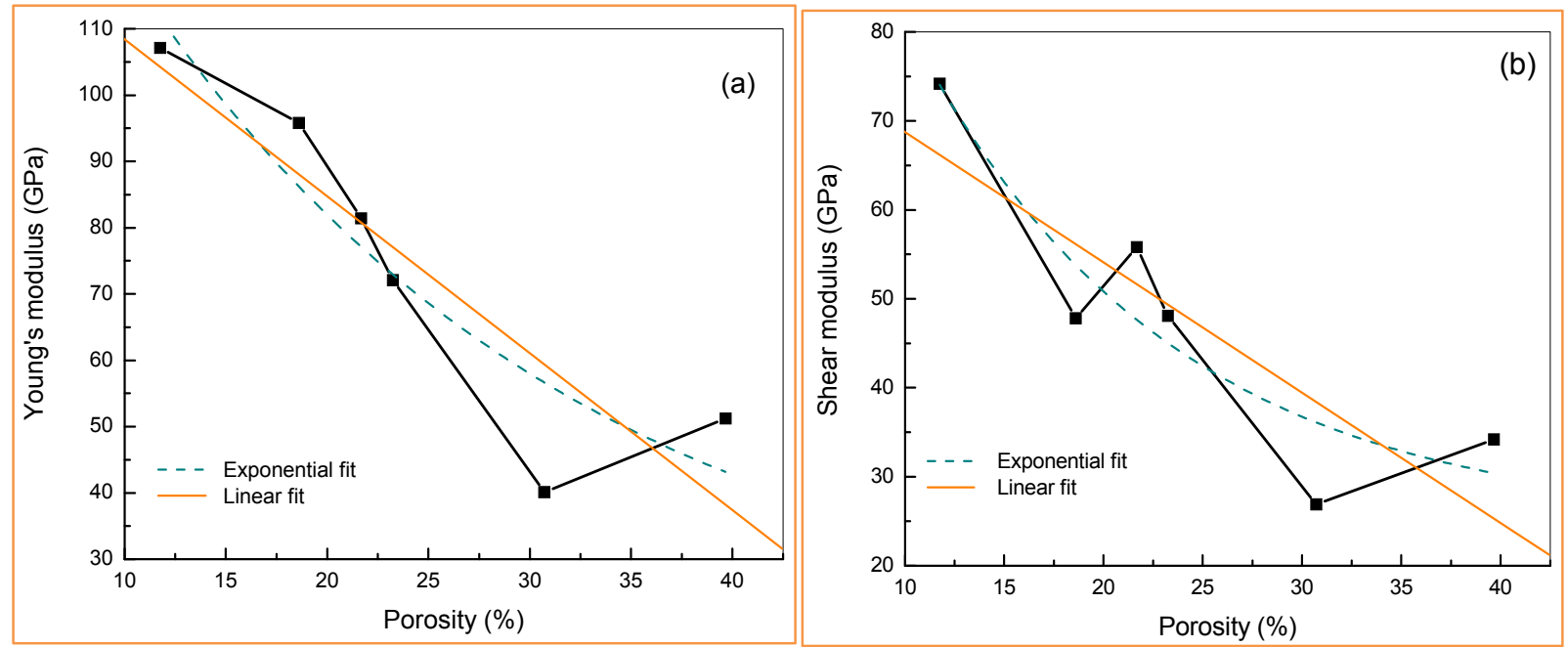

Figure 70. Room temperature (a) Young's and (b) shear moduli values plotted as a function of porosity in the as-received and the reduced NiO-8YSZ (Batch II) anode samples.

Selcuk and Atkinson ${ }^{18}$ reported a similar type of porosity dependence of elastic moduli at room temperature in $75 \mathrm{~mol} \% \mathrm{NiO}-\mathrm{YSZ}$ anode samples with as much as $14 \%$ initial porosity. They found that the Young's modulus of fully dense NiO-YSZ $(E=205-218 \mathrm{GPa})$ decreased significantly with the increase in the volume fraction of porosity. Analogous results were also obtained by Radovic and Lara-Curzio ${ }^{19}$ in 75 mol. \% NiO-YSZ samples (23\% porosity) with a lower value of $E$ and $G$ in the range of 93.6-103.3 GPa and 36.2-40.3 GPa, respectively. Based on their proposed empirical model, they predicted that the difference in the elastic moduli between hypothetical fully dense NiO-YSZ and Ni-YSZ was $\sim 4 \%$. Therefore, the observed large decrease in elastic moduli was primarily due to the significant increase in porosity with the reduction of $\mathrm{NiO}$.

From the comparison of hardness and elastic properties in the two sets of NiO-8YSZ samples, it could be stated that, with microstructure and porosity approximately the same, a $50 \%$ increase in the anode layer thickness would significantly reduce the hardness and Young's modulus of the samples. However, the shear moduli values remained approximately the same in the fully reduced samples irrespective of their thickness. The changes in hardness and elastic moduli after reduction in this type of Ni-based anode materials resulted in a re-distribution in the residual stresses in the SOFC component layers. A detail analysis of the effects in correlation with microstructure was necessary in order to predict the conditions for optimal performance and reliability of the SOFCs.

Task 3.2.4.2 Evaluation of thermal expansion coefficient and Young's modulus of as-received and the reduced NiO-8YSZ samples at elevated temperatures

\footnotetext{
${ }^{19}$ Radovic, M. and Lara-Curzio, E., Elastic properties of nickel-based anodes for solid oxide fuel cells as a function of the fraction of reduced NiO. J. Am. Ceram. Soc., 2004, 87, 2242-2246.
} 


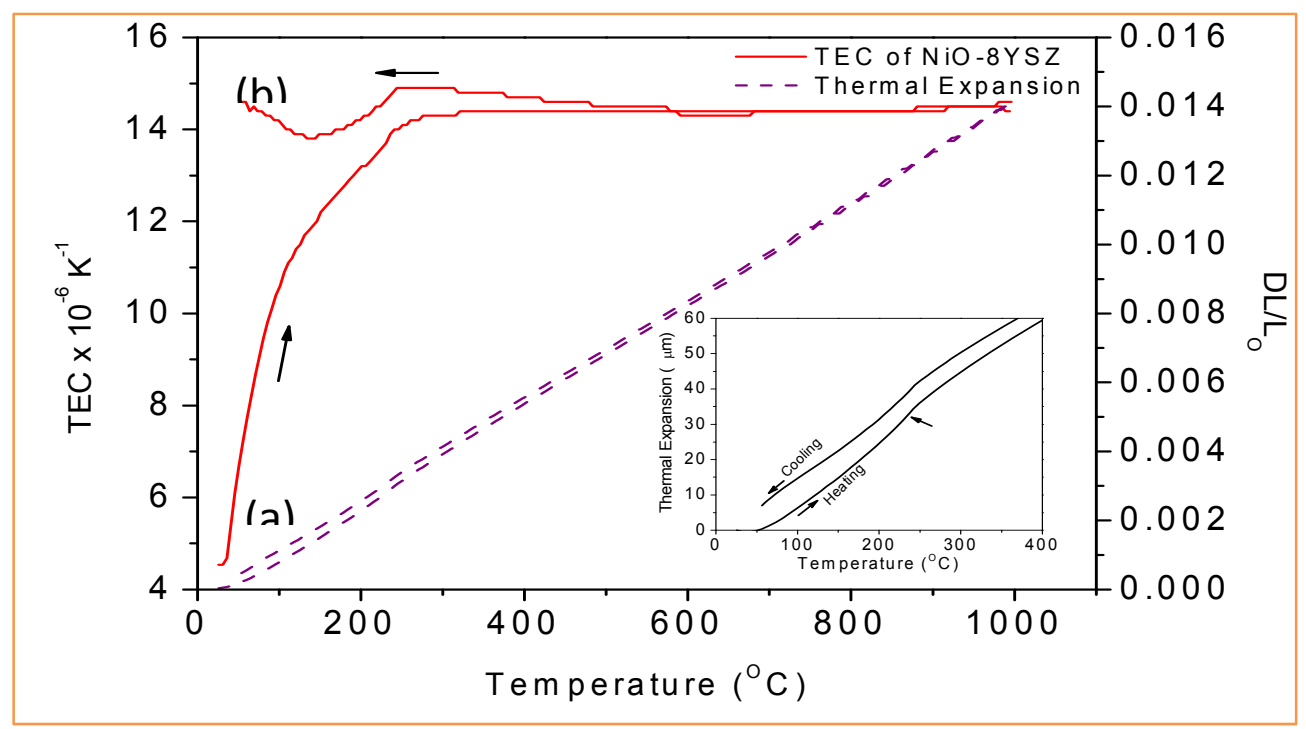

Figure 71. The variation of the total expansion coefficients of as-received NiO-8YSZ $(600 \mu \mathrm{m}$ thick, batch I) samples on heating (a) and cooling (b) in air at $3 \mathrm{~K} / \mathrm{min}$. The insert showed the change in thermal expansion behavior at the vicinity of the temperature at which structural/magnetic transition of $\mathrm{NiO}$ occurs during heating and cooling.

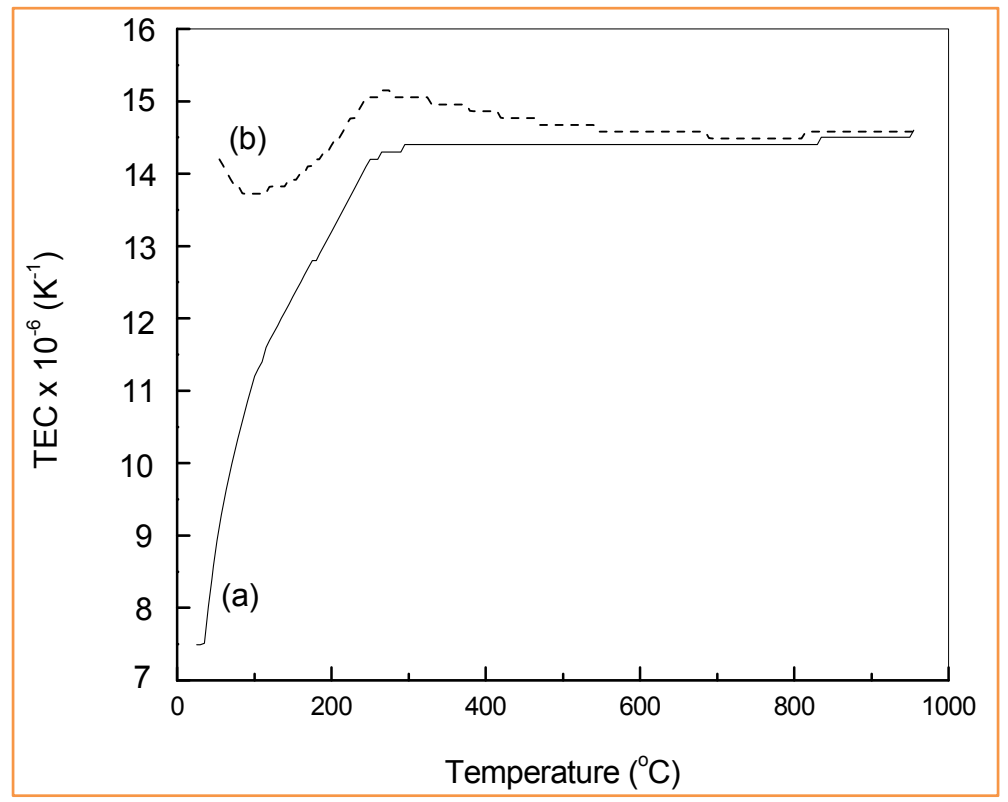

Figure 72. The thermal expansion coefficient values of as-received NiO-8YSZ (900 $\mu \mathrm{m}$ thick, batch II) samples on (a) heating and (b) cooling in air at $3 \mathrm{~K} / \mathrm{min}$.

In addition to porosity, the high operating temperature significantly influenced the elastic moduli of the Ni-8YSZ anodes. At elevated temperatures, the onset of oxidation in the Ni-8YSZ cermets changed the elastic moduli considerably. Although there were few reports in the published literature on the effects of porosity on elastic properties of the anodes, no information was available on the elastic properties of NiO-8YSZ anodes as a function of temperature. Along with the other material properties such as density, the TEC of the anode played an essential role 
in determining the elastic moduli as a function of temperature. Here, we reported the thermal expansion behavior and temperature dependent elastic properties of as-received and the reduced NiO-8YSZ anodes evaluated in ambient air environment. Figure 71 shows the measured TEC in the as-received NiO-8YSZ $\left(600 \mu \mathrm{m}\right.$ thick, Batch I) samples. A TEC value of $14.4 \times 10^{-6} \mathrm{~K}^{-1}$ was determined at $1000^{\circ} \mathrm{C}$ in air for the samples. This value was used to calculate the Young's modulus at elevated temperatures.

Figure 72 shows the measured TEC in the as-received NiO-8YSZ (900 $\mu \mathrm{m}$ thick, batch II) samples. The expansion behavior during heating was monotonic in nature and reaches a value of $\sim 14.4 \times 10^{-6} \mathrm{~K}^{-1}$ at $295^{\circ} \mathrm{C}$ and remains nearly constant up to $1000^{\circ} \mathrm{C}$. However, during cooling, the TEC slightly increased and reached a value of $15.1 \times 10^{-6} \mathrm{~K}^{-1}$ at $265^{\circ} \mathrm{C}$. This increment in the TEC value around $250^{\circ} \mathrm{C}$ was also observed in the Batch I samples, as shown in Figure 71. This small hump in the TEC curve was related to the structural transition of NiO from distorted facecentered rhombohedral to cubic rock salt structure near its Neel temperature of $250^{\circ} \mathrm{C}^{20,21}$. Below that temperature, it started decreasing and attained a value of $13.6 \times 10^{-6} \mathrm{~K}^{-1}$ at $100^{\circ} \mathrm{C}$.

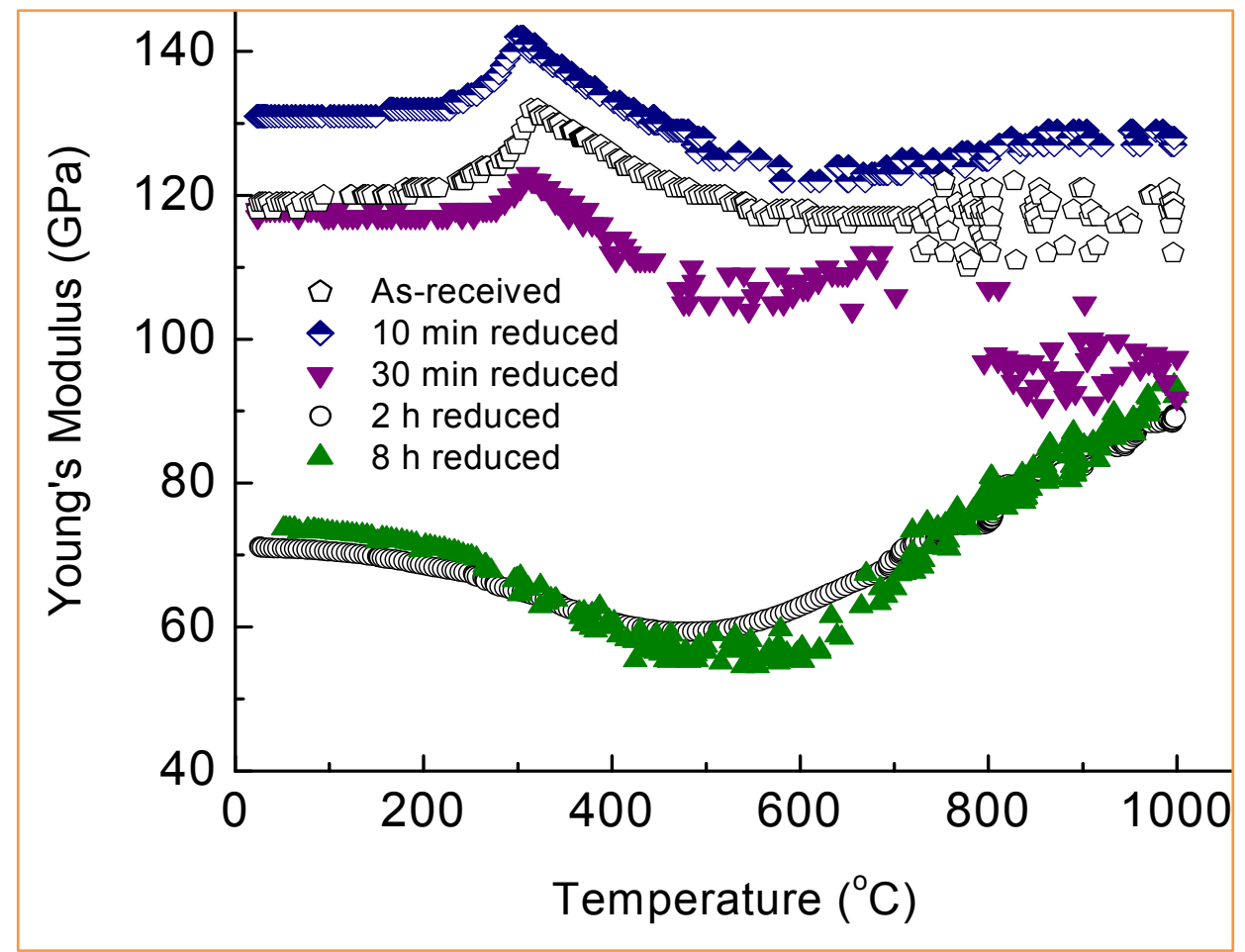

Figure 73. Young's moduli values plotted as a function of temperature in the as-received and the reduced NiO-8YSZ (600 $\mu \mathrm{m}$ thick, batch I) anode samples

Figure 73 shows the Young's moduli values of as-received and the reduced NiO-8YSZ anode samples $(600 \mu \mathrm{m}$ thick, batch I) as a function of temperature in air. The temperature dependence of Young's modulus in air could be discussed based on the composition of the half cells. The

\footnotetext{
${ }^{20}$ Samuel Smart, J. and Greenwald, S., Crystal structure transitions in antiferromagnetic compounds at the Currie temperature. Phys. Rev., 1951, 82, 113-114

${ }^{21}$ Toussaint, C. J., A high-temperature X-ray diffraction study of the NiO-Li2O system. J. Appl. Cryst., 1971, 4, 293-297
} 
half cells which had $\mathrm{NiO}$ as one of the major constituents (as-received, 10 or 30 min reduced) showed a distinctively different elastic behavior throughout the temperature profile from the cermets which had no or negligible amount of $\mathrm{NiO}(2 \mathrm{~h}$ or $8 \mathrm{~h}$ reduced samples). At the outset, the high $\mathrm{NiO}$ containing half cells had significantly higher moduli at room temperature since they had comparatively less porosity than the reduced Ni-YSZ cermets. As temperature increased, an increase in moduli was observed over the temperature range $200-500^{\circ} \mathrm{C}$, with a maximum value at around $325^{\circ} \mathrm{C}$. This well-defined peak in the Young's modulus vs. temperature curve at $\sim 325^{\circ} \mathrm{C}$ moght be related to the structural transition of $\mathrm{NiO}$ from rhombohedral to cubic or magnetic transition of $\mathrm{NiO}$ at this temperature. These structural/magnetic transitions affected several material properties of $\mathrm{NiO}$ including the thermal expansion coefficient. A change in the thermal expansion data at around $250^{\circ} \mathrm{C}$ was revealed in the as-received half cells during heating as well as cooling and shown in Figure 71. Therefore, it was highly necessary to study the structural transition-assisted stresses in the whole cell or in the membrane electrolyte assembly.

No such structural/magnetic transition assisted change in the modulus curve was observed in other partially or fully reduced cermets $(2 \mathrm{~h}$ or $8 \mathrm{~h}$ reduced $)$ that had no or very negligible amount of $\mathrm{NiO}$ in their composition. The observed behavior was rather different and could be divided into three separate regions. From room temperature to $\sim 250^{\circ} \mathrm{C}$, Young's moduli values decreased slowly, and then more strongly from 250 to $550^{\circ} \mathrm{C}$, finally the values increased monotonically with the increase in temperature. The decrease in Young's moduli values with temperature up to $550^{\circ} \mathrm{C}$ was presumably as a result of the mechanical losses due to enhanced atomic motion $^{22,23}$. The mechanical losses were often responsible for large scattering in $E$ values at higher temperatures.

These effects were also present in the as-received NiO-8YSZ samples, but the overlapping of the effects due to the structural transition of $\mathrm{NiO}$ made them dormant. Above $500^{\circ} \mathrm{C}$, the decreasing moduli of the $\mathrm{NiO}$ rich half cells reached a steady state and remain almost unchanged till $1000^{\circ} \mathrm{C}$. However, the reason for the observed sharp decrease after $\sim 800^{\circ} \mathrm{C}$ in the $30 \mathrm{~min}$ reduced batch I samples was not yet clear. In contrast, the Ni-rich reduced cermets showed a monotonically increasing tendency in the elastic moduli values above $550^{\circ} \mathrm{C}$. This was reasonably due to the oxidation of $\mathrm{Ni}$ in air atmosphere. The formation of $\mathrm{NiO}$ scales over the $\mathrm{Ni}$ grains increased the elastic modulus of the anode samples. TGA studies of pure Ni revealed that the oxidation started at $\sim 600^{\circ} \mathrm{C}$ in air. However, in actual operations of SOFCs with hydrogen fuels, the Ni-8YSZ cermet anodes didn't undergo the oxidation reaction.

\footnotetext{
${ }^{22}$ Shimada, M., Matsushita, K., Kuratani, S., Okamoto, T., Koizumi, M., Tsukuma, K. and Tsukidate, T., Temperature dependence of Young's modulus and internal friction in alumina, silicon nitride, and partially stabilized zirconia ceramics. J. Am. Ceram. Soc., 1984, 67, C23-C24

${ }^{23}$ Lakki, A., Herzog, R., Weller, M., Schubert, H., Reetz, C., Gorke, O., Kilo, M. and Borchardt, G., Mechanical loss, creep, diffusion and ionic conductivity of $\mathrm{ZrO} 2-8$ mol. \% Y2O3 polycrystals. J. Eur. Ceram. Soc., 2000, 20, 285-296
} 


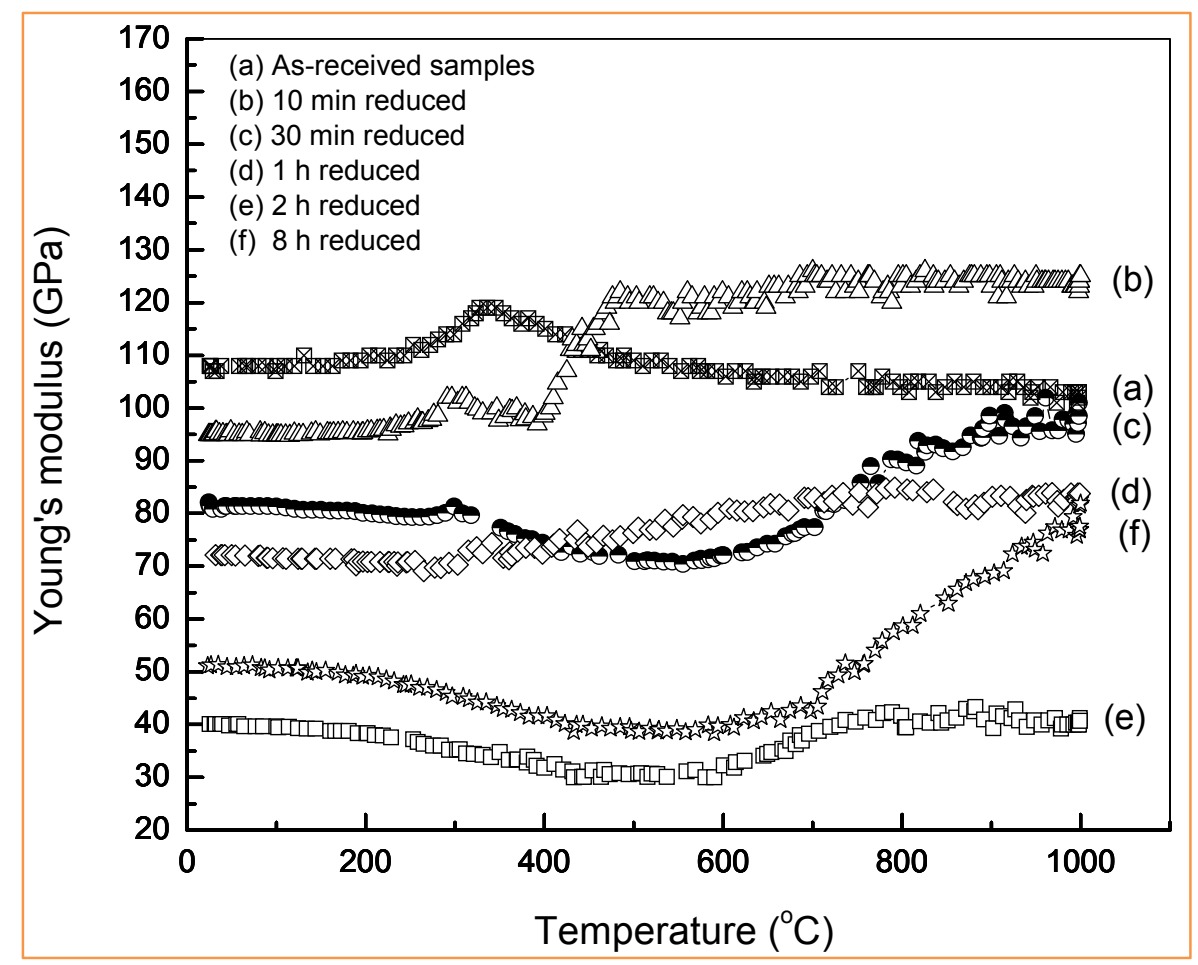

Figure 74. The variation of Young's modulus with temperature in (a) as-received, (b) $10 \mathrm{~min}$, (c) $30 \mathrm{~min}$, (d) $1 \mathrm{~h}$, (e) $2 \mathrm{~h}$ and (f) $8 \mathrm{~h}$ reduced NiO-8YSZ (900 $\mu \mathrm{m}$ thick, batch II) samples.

Figure 74 shows the temperature dependent variations in the Young's moduli values of (a) asreceived, (b) $10 \mathrm{~min}$, (c) $30 \mathrm{~min}$, (d) $1 \mathrm{~h}$, (e) $2 \mathrm{~h}$ and (f) $8 \mathrm{~h}$ reduced NiO-8YSZ (900 $\mu \mathrm{m}$ thick, batch II) samples. The as-received samples showed a Young's modulus value of $108 \mathrm{GPa}$ at room temperature. The changes in the Young's moduli values at the elevated temperatures in air were almost similar to the Batch I half-cells in general. After heating in air, an increase in the value was observed over $200-500^{\circ} \mathrm{C}$ with a peak value of $119 \mathrm{GPa}$ at $336^{\circ} \mathrm{C}$ due to the structural transition in $\mathrm{NiO}$. It was interesting to note that the $1 \mathrm{~h}$ reduced half-cells showed no peak around $300^{\circ} \mathrm{C}$ which implied that the half-cells reduced for $1 \mathrm{~h}$ at $5 \% \mathrm{H}_{2}$ were left with no or negligible amount of $\mathrm{NiO}$. The cermets $(2 \mathrm{~h}$ and $8 \mathrm{~h}$ reduced half cells) underwent an oxidation around $600^{\circ} \mathrm{C}$ that caused an increment in their Young's moduli values with temperature.

Task 3.2.4.3 Effects of reducing atmosphere on the Young's modulus of the fully reduced halfcells

In order to characterize the effects of reducing atmosphere on the elastic properties of the reduced Ni-8YSZ anodes at elevated temperatures, we further analyzed the samples (both batches) in 5\% $\mathrm{H}_{2}-95 \%$ Ar environment. The Young's moduli of the anodes were dependent on the initial porosity, composition and thickness of the half-cells. Figure 75 shows the effects of reducing atmosphere on the Young's moduli of the half-cells at elevated temperatures. The Young's modulus of the $8 \mathrm{~h}$ reduced Ni-8YSZ batch I, half-cells (600 $\mu \mathrm{m}$ thick) at room temperature was $\sim 73 \mathrm{GPa}$, as shown in Figure 75a. This was significantly higher than the Young's modulus of the batch II, half-cells (900 $\mu \mathrm{m}$ thick) which was $\sim 52 \mathrm{GPa}$ at the same temperature, as shown in Figure $75 \mathrm{~b}$. 

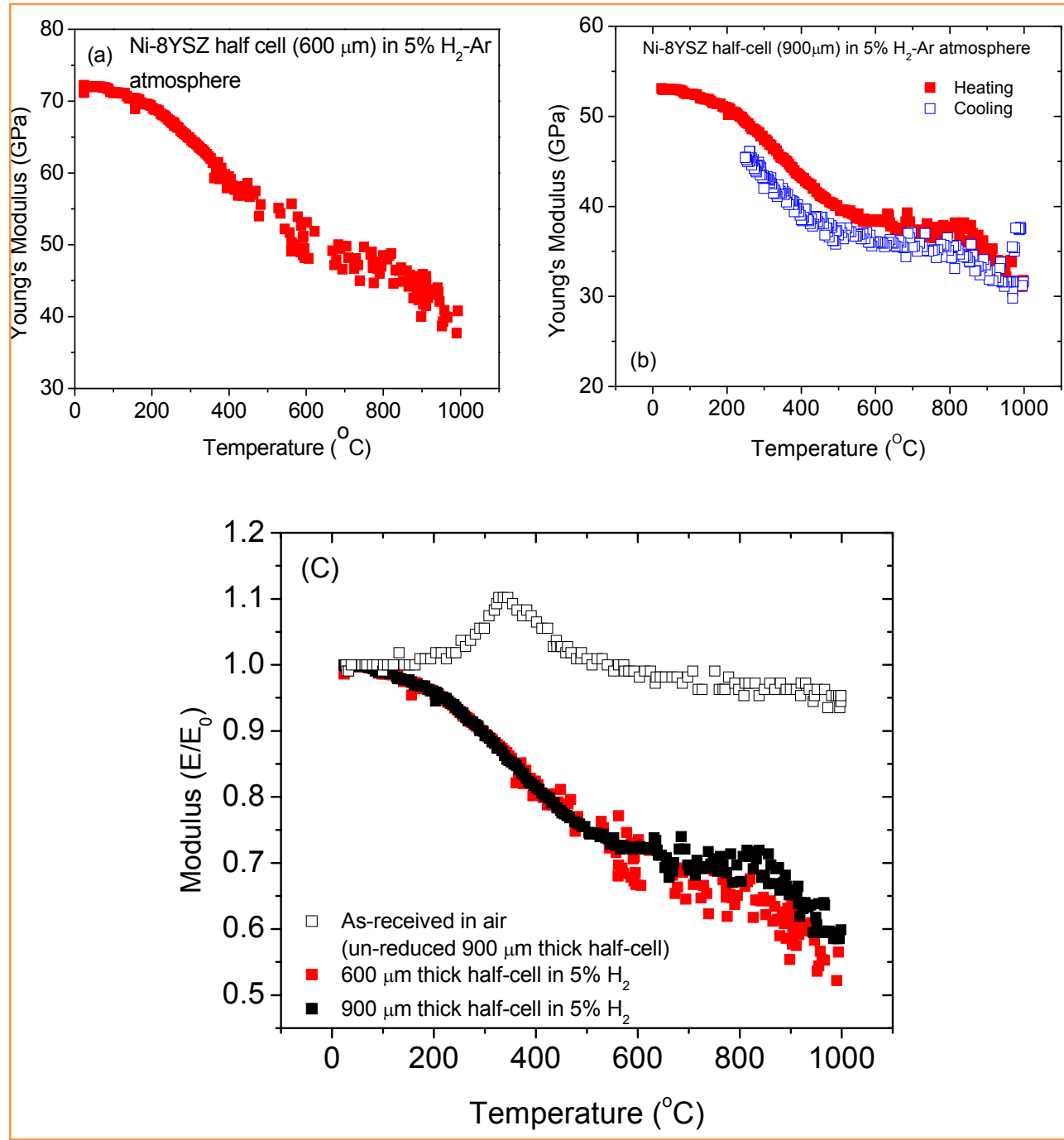

Figure 75. Young's moduli values of the as-received and $8 \mathrm{~h}$ reduced Ni-8YSZ half-cells as a function of temperature.

For both cells the modulus decreased as the temperature increased. The $600 \mu \mathrm{m}$ thick samples exhibited a sharp decrease in the modulus values as the temperature increased from 200 to $1000^{\circ} \mathrm{C}$ whereas in the $900 \mu \mathrm{m}$ thick half-cells, this avalanche in the modulus values reached a plateau at $550^{\circ} \mathrm{C}$ and remained stable up to $800^{\circ} \mathrm{C}$. Then a sharp decrease in the modulus was observed till the temperature reached $1000^{\circ} \mathrm{C}$.

The total decrease in the Young's modulus as the temperature increased from room temperature to $1000^{\circ} \mathrm{C}$ in reducing atmosphere was $\sim 44 \%$ for $600 \mu \mathrm{m}$ thick batch $\mathrm{I}$, half-cells and $\sim 40 \%$ for $900 \mu \mathrm{m}$ thick batch II, half-cells, respectively, as shown in Figure 75c. It was interesting to note that the unreduced half-cells exhibited no significant change in the modulus as the temperature increased after $450^{\circ} \mathrm{C}$ in air whereas the fully reduced half-cells exhibited continuous decrease in the modulus. The weights of the half-cells were measured after the evaluation of Young's 
moduli in the reducing atmosphere to detect any possible oxidation at the elevated temperatures. No oxidation was observed.

Task 3.2.4.4 Effects of reduction on the equibiaxial strength of as-received and reduced NiO8 YSZ half-cells

Figure 76 shows the photographs of the ring-on-ring fixture and a typical fractured specimen after the strength test. Most of the specimens fractured into 3 pieces and the fracture originated within in the load ring diameter. Figure 77 shows the effect of reduction on the biaxial strength of the $900 \mu \mathrm{m}$ thick (batch II) Ni-8YSZ half-cells at room temperature in ambient air. The strength of the as-received cell was $275 \mathrm{MPa}$ and it increased suddenly to $399 \mathrm{MPa}$ in the $10 \mathrm{~min}$ reduced samples, even though the porosity increased. This was due to the formation of Ni layer on the surface of the $\mathrm{NiO}$ grains in the anode. The Ni layer acted as a metallic coating layer and increased the strength of the half-cell. However, the strength of the cell started to decrease as the porosity increases and reached a value of $290 \mathrm{MPa}$ at a porosity value of $23.24 \%$ (after $1 \mathrm{~h}$ reduction). After $2 \mathrm{~h}$ of reduction, the anode was mostly of $\mathrm{Ni}$ and the porosity increased to $30.71 \%$. Hence, the half-cell exhibited a steady state in the strength values after $2 \mathrm{~h}$ of reduction. The scattering has also reduced with the increase of $\mathrm{Ni}$ in the anode structure. Although the porosity was considered as an important criterion in determining the strength of materials, the amount of metallic Ni present in the anode surpassed the deleterious effect of porosity and enhanced the strength. The half-cell exhibited a $23 \%$ increase in strength value after $8 \mathrm{~h}$ reduction even though the porosity increased from $11.76 \%$ to $39.66 \%$.

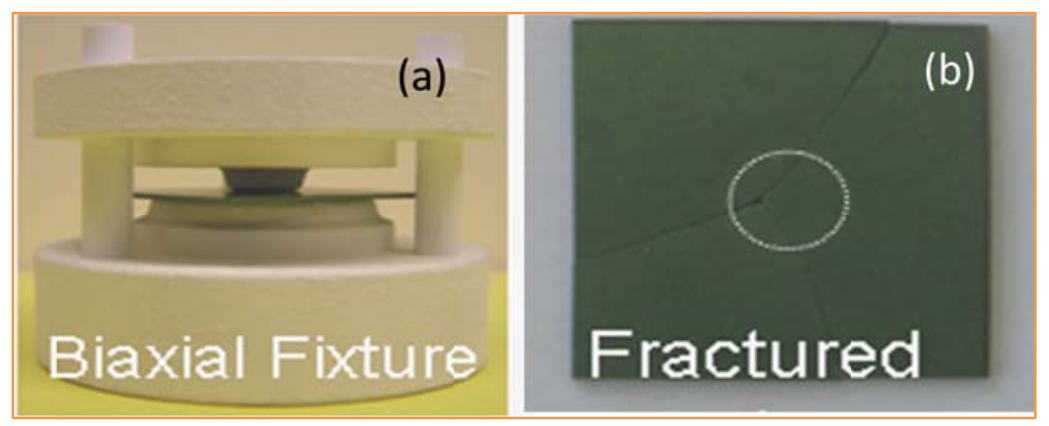

Figure 76. Photographs of biaxial fixture (a) and fractured half-cell (b). 


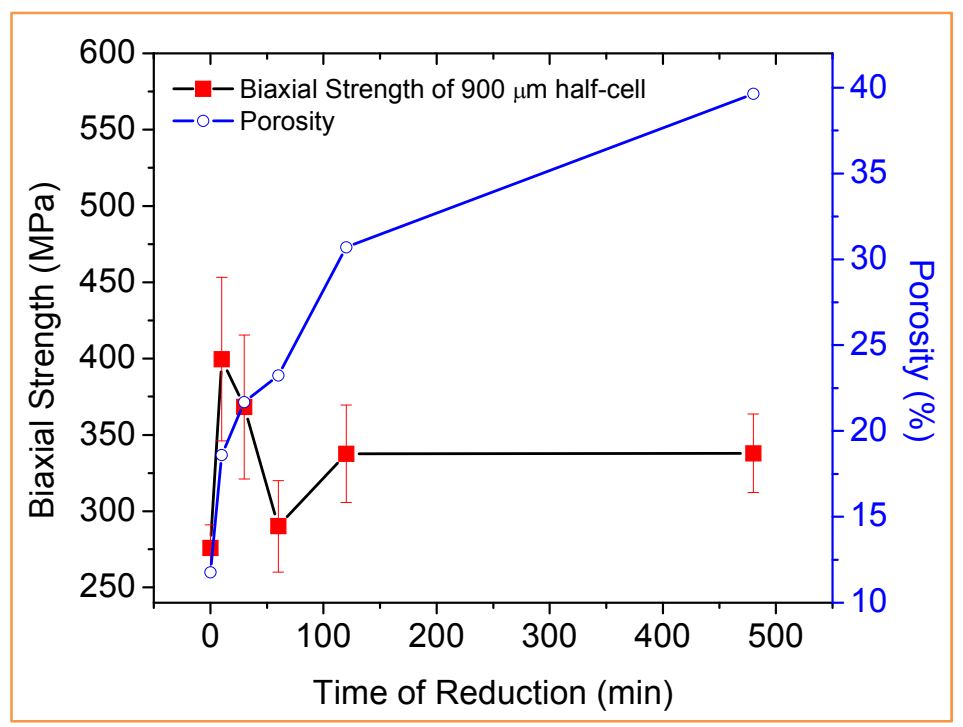

Figure 77. Effect of reduction on the biaxial strength (measured at room temperature in ambient air) and development of porosity in the $900 \mu \mathrm{m}$ thick, batch II samples.

Figure 78 shows the effect of reduction and porosity on the strength of the $600 \mu \mathrm{m}$ thick halfcells (batch I) at room temperature. The strength value increased to $\sim 530 \mathrm{MPa}$ after $2 \mathrm{~h}$ of reduction and remained constant thereafter. Similar to the batch II samples, the high value of porosity in the reduced samples didn't reduce the strength of the samples.

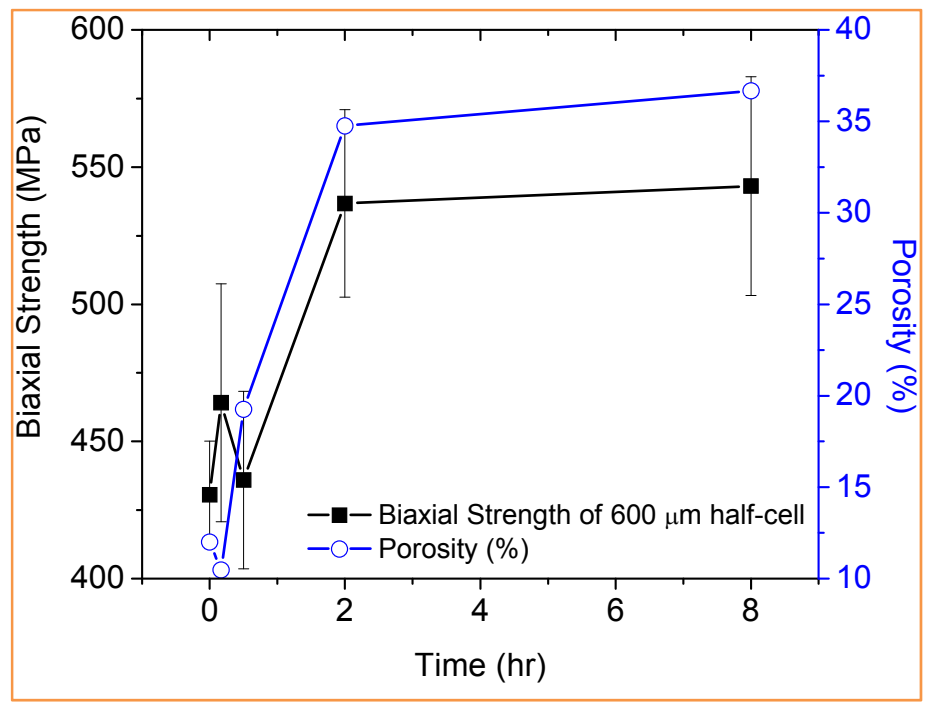

Figure 78. Effect of reduction on the equibiaxial strength of the reduced NiO-8YSZ (batch I) half-cells at room temperature. The influence of reduction on porosity was also given for comparison.

Fractured surfaces were also studied using SEM and the fracture origin was identified. In most of the cases the fracture originating flaws were volume flaws. The micrographs are shown in Figure 79. Fracture origins wer either agglomerates of YSZ (a) or the agglomerates of NiO (b) or cavities formed during casting (c, d, e and f). 

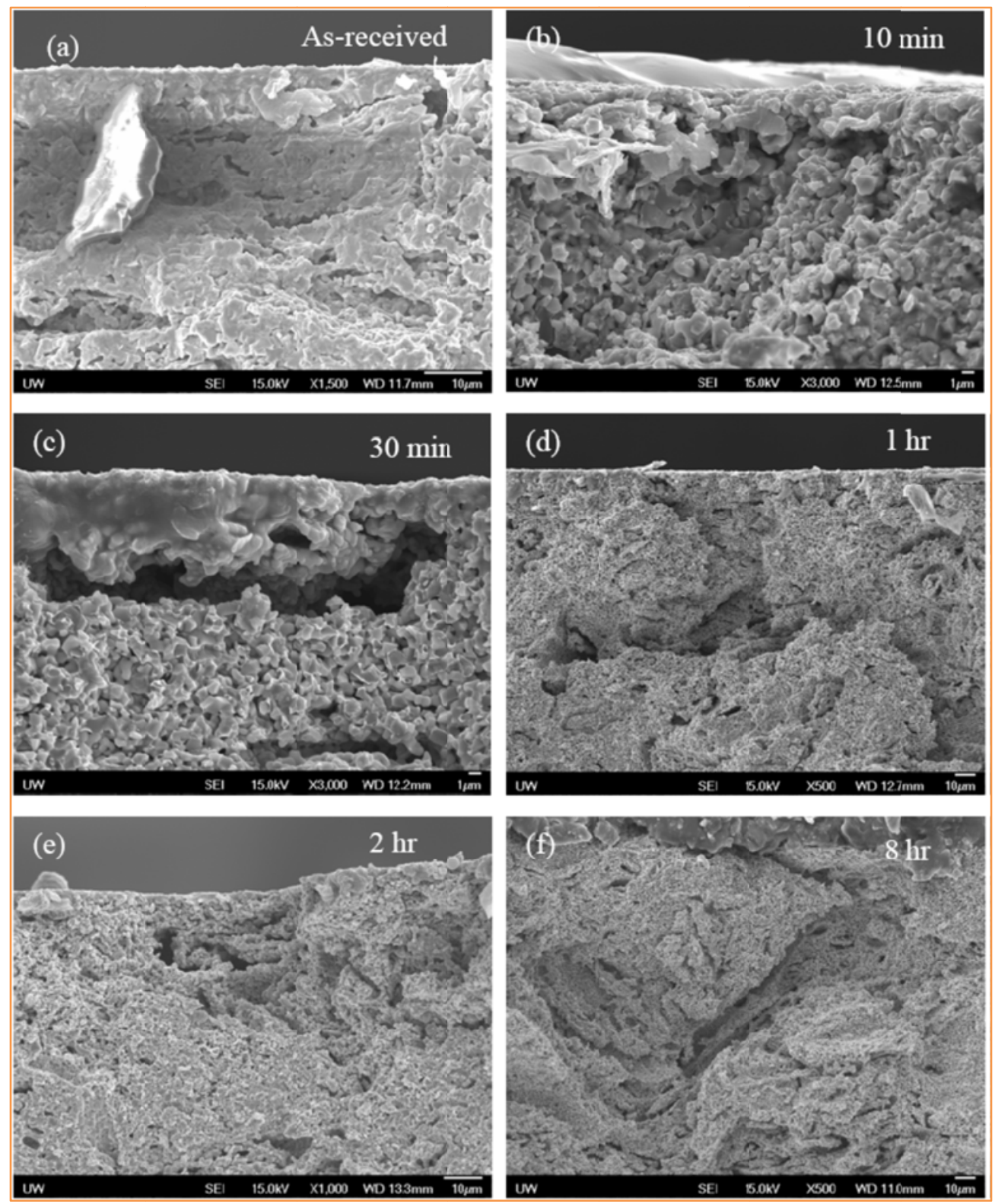

Figure 79. Typical failure origined closer to the tensile surface (batch I samples): (a) agglomerate of YSZ; (b) pull out of $\mathrm{NiO}$ agglomerate; (c, d, e and f) cavities formed during casting.

Table 4. Equibiaxial strength of the half-cells at $800{ }^{\circ} \mathrm{C}$ in ambient air and reducing atmosphere

\begin{tabular}{|c|c|c|}
\hline $\begin{array}{c}\text { Half-cell } \\
\text { thickness }\end{array}$ & Strength at $800^{\circ} \mathrm{C}$ in air $(\mathrm{SD})^{\mathrm{a}}$ & Strength at $800^{\circ} \mathrm{C}$ in $5 \% \mathrm{H}_{2}(\mathrm{SD})^{\mathrm{b}}$ \\
\hline $600 \mu \mathrm{m}$ & $217.0(41.2)$ & $301.4(31.8)^{\mathrm{c}}$ \\
\hline $900 \mu \mathrm{m}$ & $200.5(5.5)$ & $120.8(12.2)$ \\
\hline
\end{tabular}

${ }^{\mathrm{a}}$ - As-received half-cell; ${ }^{\mathrm{b}}$ - fully reduced half-cell; ${ }^{\mathrm{c}}$ - This value can not be considered as the strength of the cell due to extensive ductile nature of the sample at this test condition.

Table 4 shows the strength values of the half-cells in ambient air and 5\% $\mathrm{H}_{2}-95 \% \mathrm{Ar}$ environment at $800^{\circ} \mathrm{C}$. As shown in the table, there was a $40-50 \%$ reduction in strength values 
when the samples were evaluated at $800^{\circ} \mathrm{C}$. The high temperature significantly reduced the strength even for the fully reduced samples in reducing environment.

Figure 80 shows the typical fracture behavior of the fully reduced half-cells at $800^{\circ} \mathrm{C}$ in $5 \% \mathrm{H}_{2}$ atmosphere. A graceful failure was expected due to the presence of large metal contents as observed from the load-displacement curves, as shown in Figure 81. The fully reduced half-cells deformed due to the ductile nature of the $\mathrm{Ni}$ and eventually failed due to the crack-growth. However, the unreduced half-cells displayed a catastrophic failure (brittle fracture) as the load was applied in room temperature as well as at $800^{\circ} \mathrm{C}$ (in air).
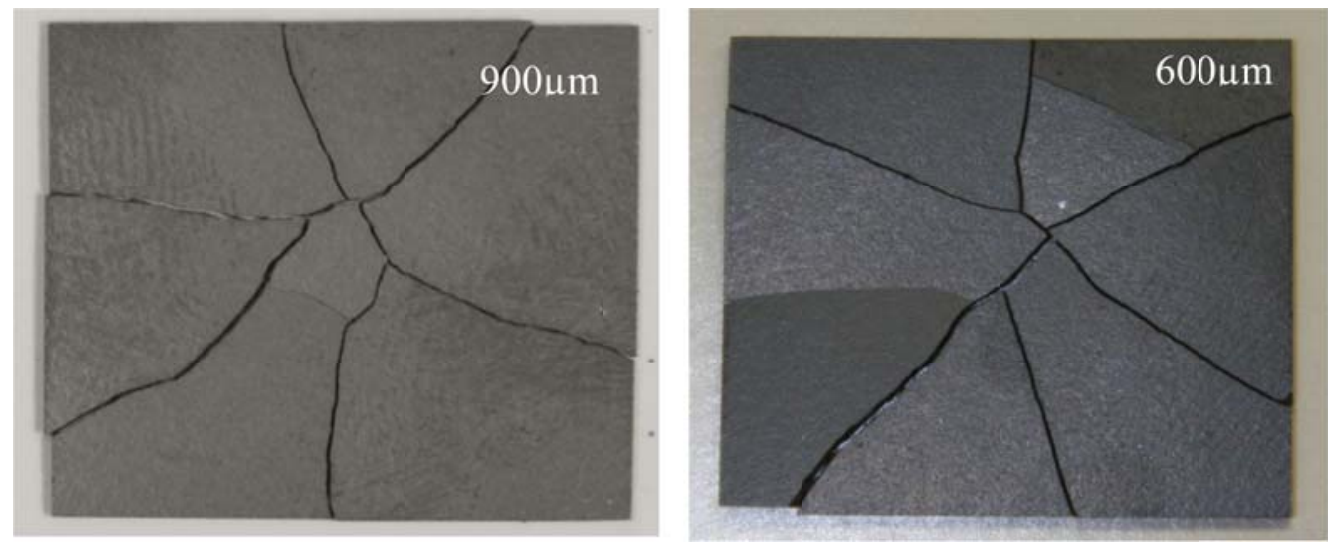

Figure 80. The typical fracture behavior of the fully reduced half-cells at $800{ }^{\circ} \mathrm{C}$ in $5 \% \mathrm{H}_{2}$ atmosphere.

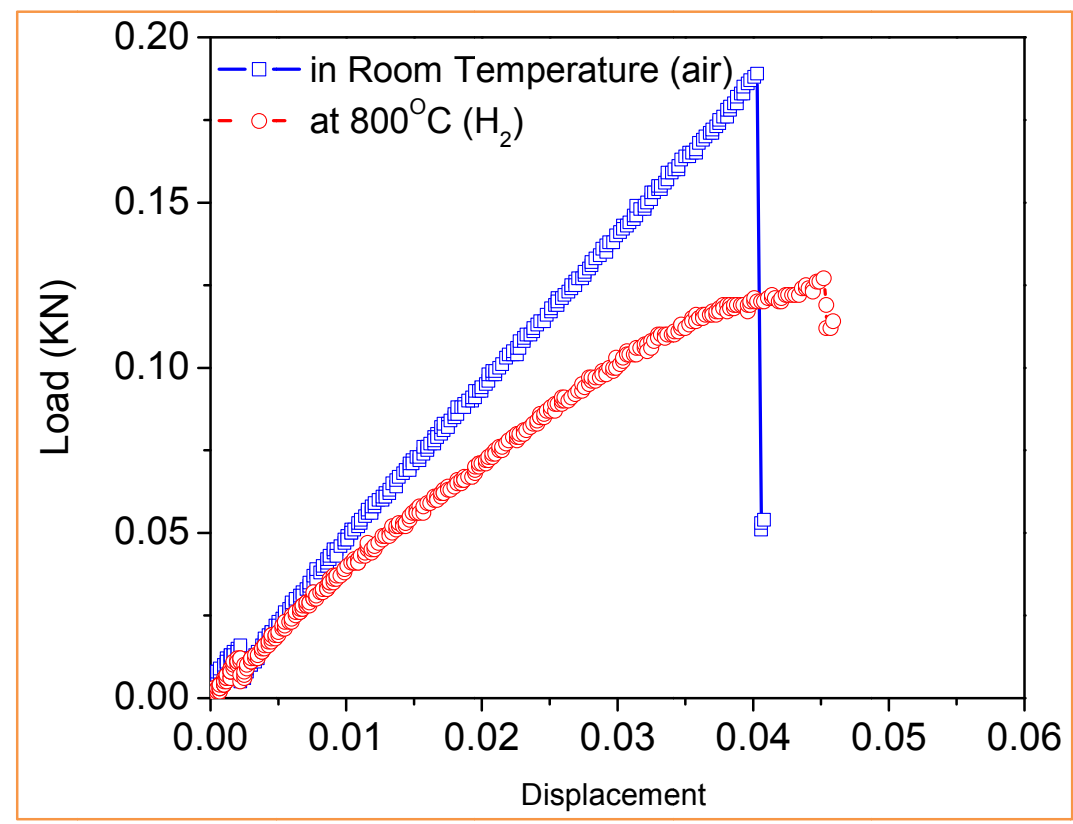

Figure 81. Typical load-displacement curves of the half-cells at room temperature in air and $800^{\circ} \mathrm{C}$ in reducing atmosphere.

As given in Table 4, the strength values of the $900 \mu \mathrm{m}$ thick, as-received half-cells decreased significantly after they were exposed to $800^{\circ} \mathrm{C}$ in air. Although the fully reduced half-cells exhibited a slightly higher strength value at room temperature than their precursor (as-received 
half-cells), the strength value decreased to more than $60 \%$ when exposed to reducing conditions at $800^{\circ} \mathrm{C}$. Microscopic analysis indicates that the near-surface volume flaws were controlling the fracture, as shown in Figure 82. Figure 83 shows the fracture surface of a fully reduced half-cell with a volume flaw. The as-received half-cells showed significantly higher Weibull parameter $(\mathrm{m}=9.02)$ as compared to the fully reduced half-cells at $800^{\circ} \mathrm{C}$ in $5 \% \mathrm{H}_{2}$ atmosphere $(\mathrm{m}=4.69)$. The observed variations in the strength for these two sets of half-cells were plotted on Weibull graphs as shown in Figure 84 a \& b. The decreased Weibull modulus and the strength values could be attributed mainly to the increased porosity. The volume flaws that governed the strength value of the as-received half-cells at room temperature were formed during processing. The flaws were mostly generated due to the agglomeration of $\mathrm{NiO}$ or YSZ particles or cavities formed due to the organic removal as shown in Figure 82. These volume flaws remained same even after the reduction of the half-cells. Figure 83 shows a volume flaw in the fracture surface of a fully reduced half-cell. In addition to the volume flaws generated during the processing, the porosity developed during the reduction process reduced the strength when evaluated in the reducing conditions at $800^{\circ} \mathrm{C}$. Hence, it was essential to control the volume flaw population generated during anode processing.
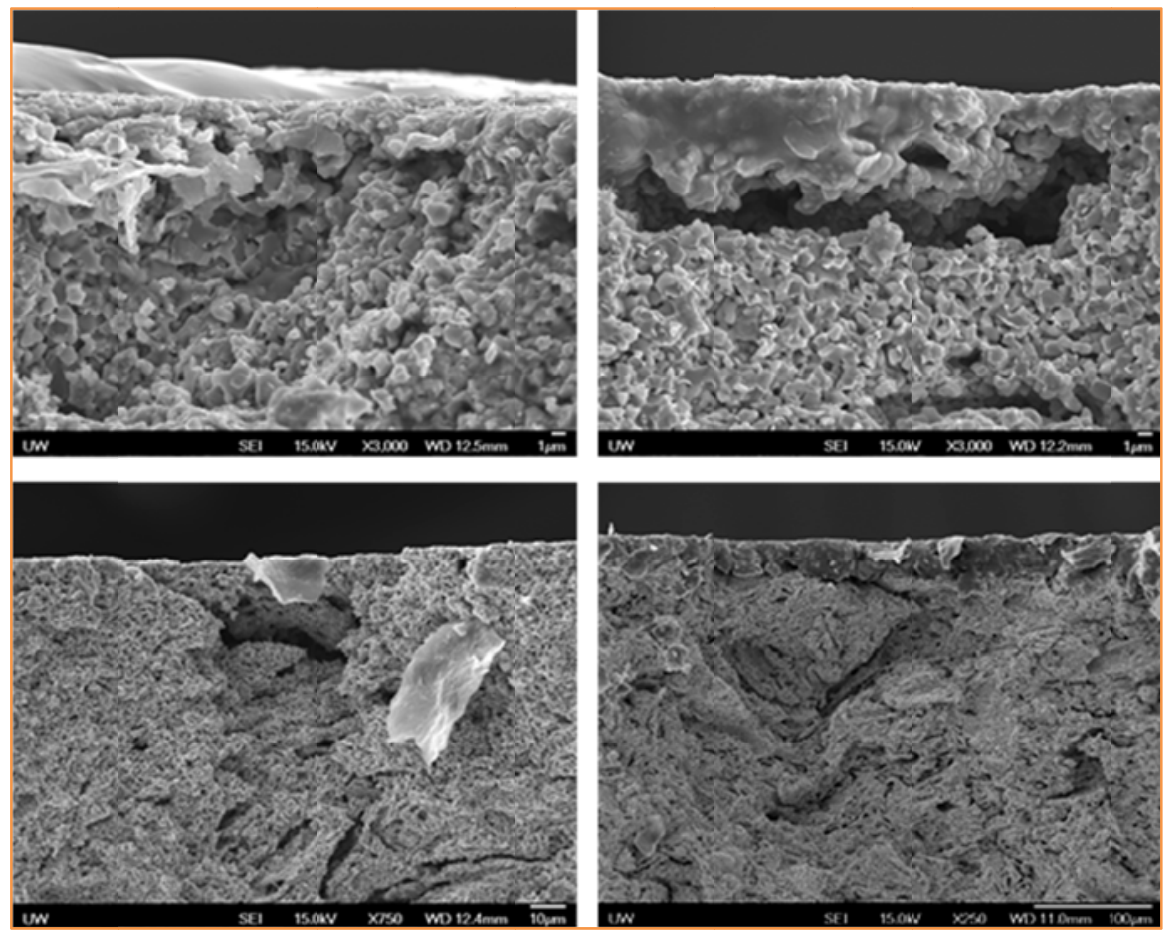

Figure 82. The near-surface volume flaws observed in the as-received $900 \mu \mathrm{m}$ thick, batch II half-cells. 


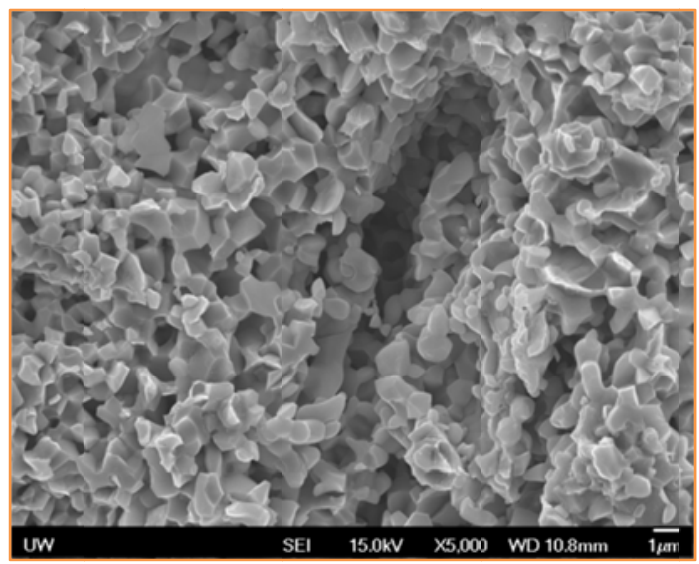

Figure 83. Fracture surface of a fully reduced half-cell with a volume flaw.
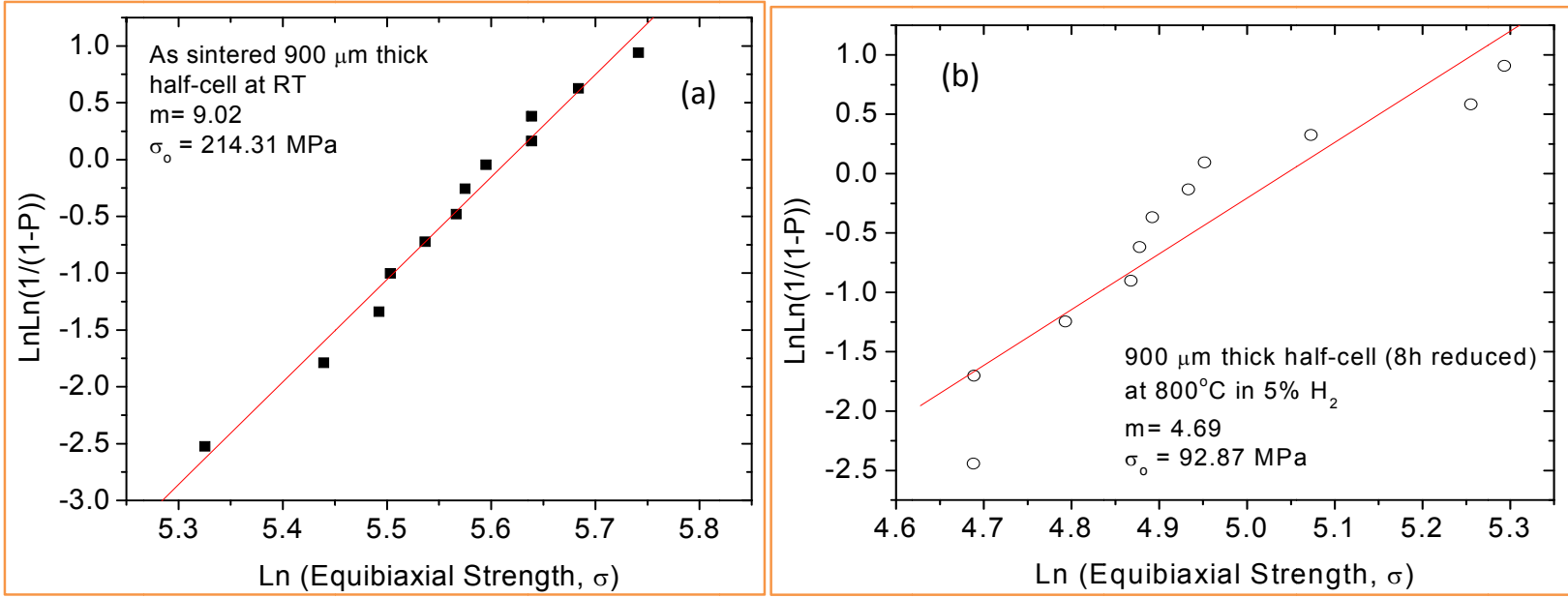

Figure 84. Weibull plots for equibiaxial tests at (a) room temperature and (b) at reducing conditions $\left(800^{\circ} \mathrm{C}\right.$ in $\left.5 \% \mathrm{H}_{2}\right)$ for as-received half-cells (batch II)

Task 3.2.4.5 Effects of thermal cycling on the microstructure and mechanical properties of NiO-8YSZ anodes

Figure 85 shows the measured values of porosity and density in the unreduced NiO-8YSZ samples (batch II) as a function of the number of thermal cycles treated. The as-received samples with a porosity of $11.76 \%($ density $=5.24 \mathrm{~g} / \mathrm{cc})$ showed an increased porosity $=13.63 \%$ $($ density $=5.20 \mathrm{~g} / \mathrm{cc})$ after 250 thermal cycles. 


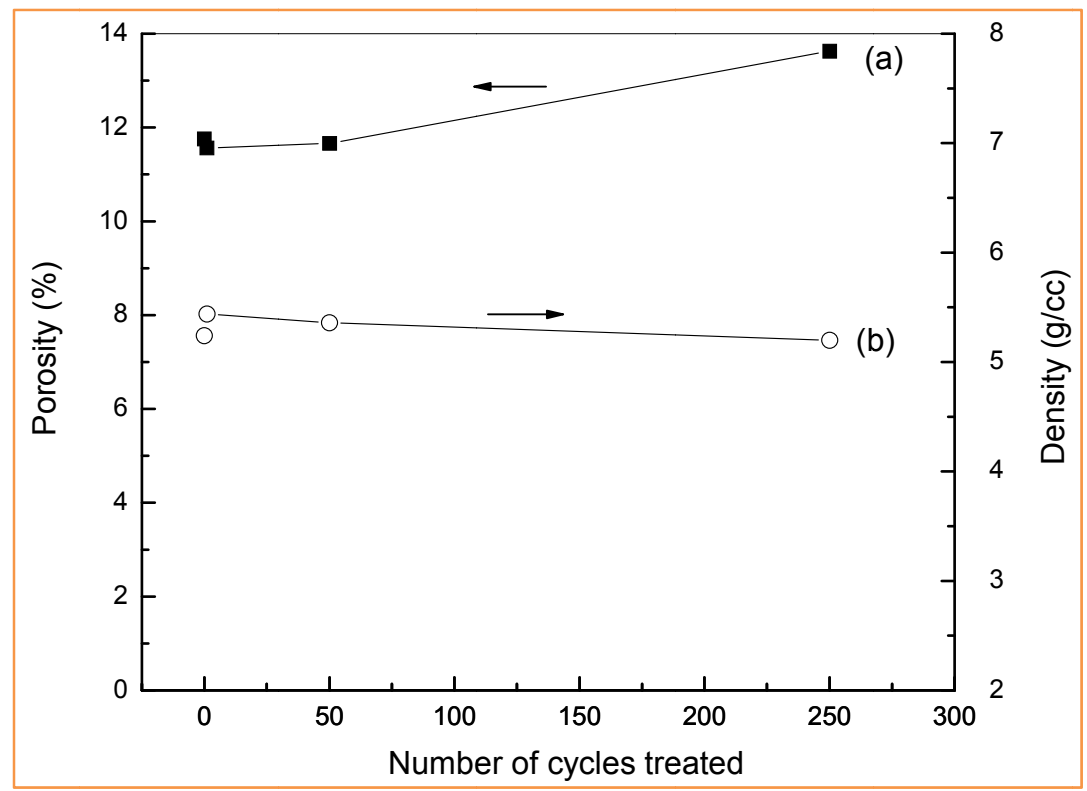

Figure 85 . The variation of porosity (a) and density (b) with the number of thermal cycles treated to the $900 \mu \mathrm{m}$ thick, unreduced NiO-8YSZ samples.

After thermal cycling, most of the samples were found to be fractured due to the rapid thermal shock. Optical microscope studies were performed in the fracture surface of the samples to detect any trace of delaminations or other types of deformations at the anode-electrolyte interface. Figure 86 shows a cross sectional view of the fracture surface of a sample treated for 50 cycles. No cracks or delaminations were found at the interface of the two layers.

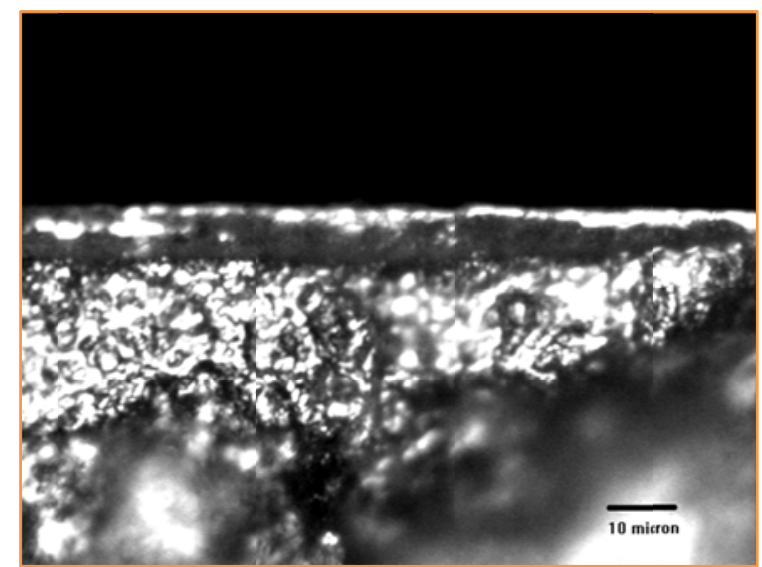

Figure 86. Cross sectional view of a fractured NiO-8YSZ sample treated for 50 cycles.

The rapid thermal shocks had considerable effects on the hardness and elastic properties of the NiO-8YSZ samples. As can be seen in Figure 87, a hardness of $3.13 \mathrm{GPa}$ in the anode surface of the as-received samples was reduced to $2.74 \mathrm{GPa}$ after 250 cycles. However, the scattering in the hardness values remained almost the same. 


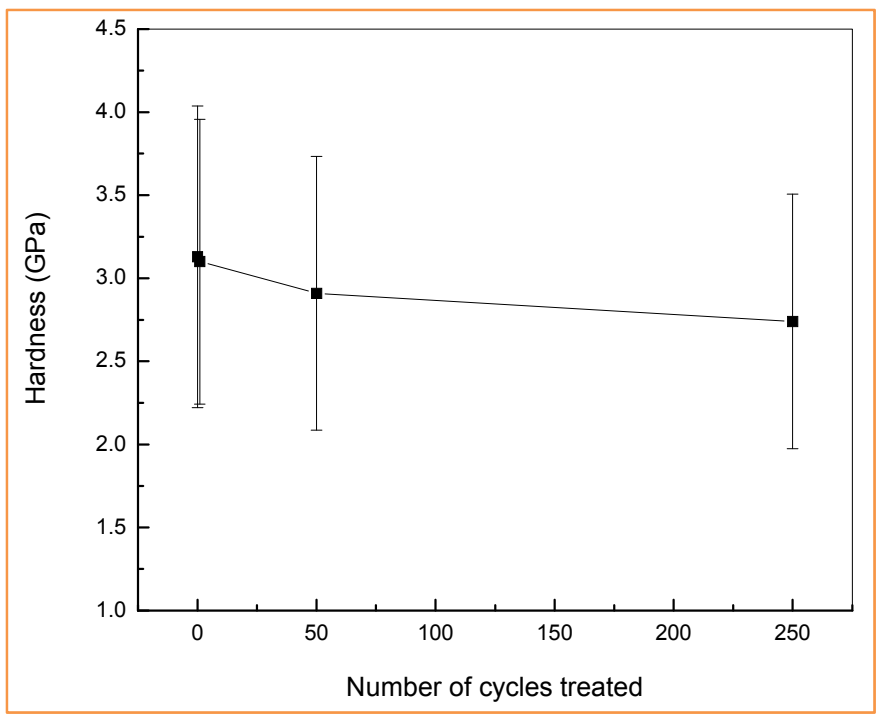

Figure 87. Hardness values in the anode surface of the thermal cycled NiO-8YSZ samples.

Figure 88 shows the reduction in the Young's and shear moduli values in the NiO-8YSZ samples with the increase in the number of thermal cycles. The Young's and shear moduli values of 107.1 and $74.2 \mathrm{GPa}$ in the as-received samples became 94.5 and $63.7 \mathrm{GPa}$, respectively after 250 cycles.

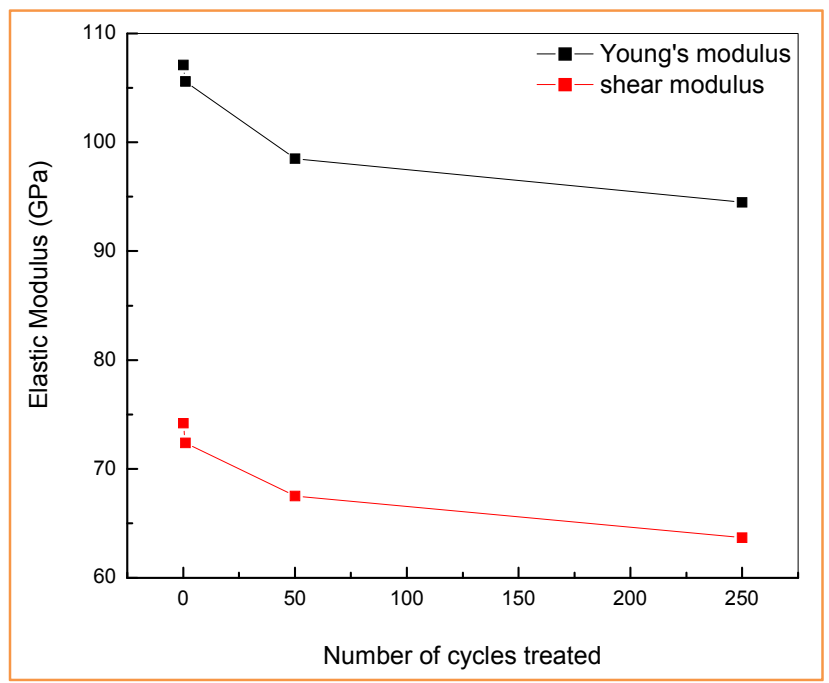

Figure 88. Room temperature Young's and shear moduli values in the NiO-8YSZ samples plotted as a function of the number of thermal cycles treated.

Task 3.3 Finite element analyses of stress fields in Vickers indentation on NiO-8YSZ anode/8YSZ electrolyte structures

In this section, we presented a finite element model to simulate the indentation processes in the $\mathrm{NiO}-8 \mathrm{YSZ}$ anode /8YSZ electrolyte bi-layer structures for solid oxide fuel cell applications. The model focused on the study of mechanical integrity of the structure when subjected to a mechanical load. Simulations showed that brittle cracks start to form within the anode due to 
high von Mises stresses. Residual stresses in reduced NiO-8YSZ anode/8YSZ electrolyte structures were estimated. Simulated indentation data were also discussed with experimental observations.

The mechanical strength of porous $8 \mathrm{YSZ} / \mathrm{NiO}$ composite support was affected by the processinginduced residual stresses in the SOFC component layers (NiO-8YSZ/8YSZ). The residual stresses may lead to fracture or curvature of the cells, which affected the stack assembly. NiO$8 \mathrm{YSZ}$ anode/8YSZ electrolyte structure was reported to suffer from relatively poor mechanical strength which reduced its performances, particularly in planar SOFCs. Therefore, it was important to understand the residual stresses and improving the mechanical properties of the cells. Three possible modes of damage during indentation are summarized in Figure 89, i.e., cracks in the electrode, interfacial delamination, and the substrate yielding. A finite element model was capable to capture these major features. Therefore, a finite element model was developed to investigate the indentation fracture behavior of the NiO-8YSZ anode/8YSZ electrolyte structures. Stress distributions were simulated using finite element analyses.

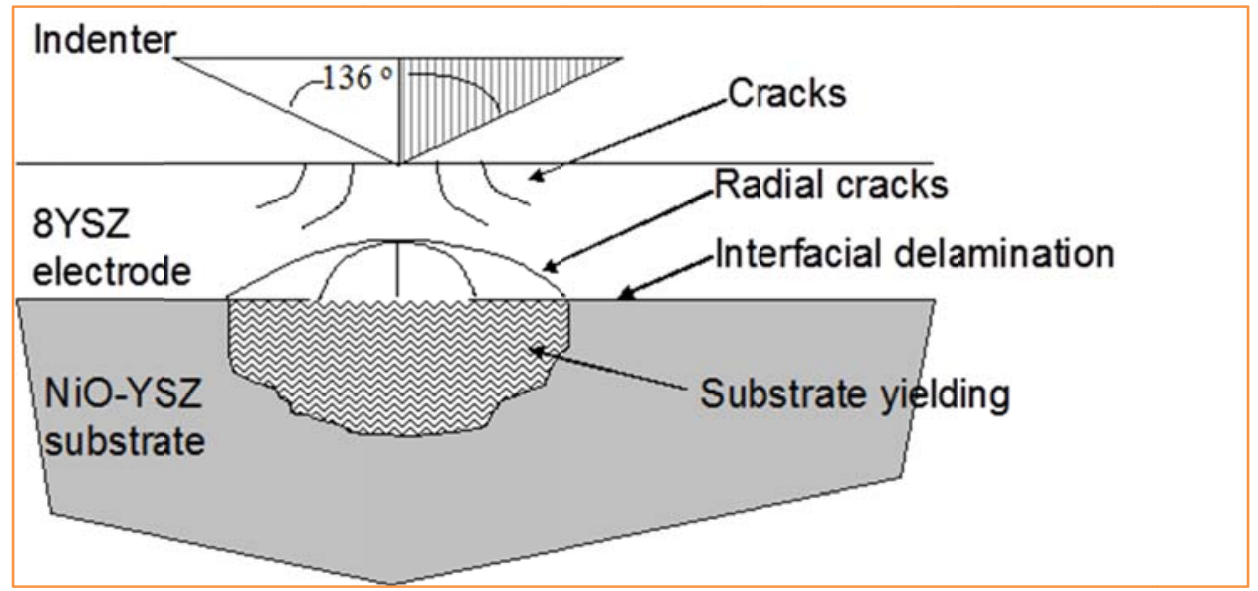

Figure 89. Damage modes that may be observed in a bi-layer system subjected to an indentation loading.

\section{Task 3.3.1 Finite element model}

The finite element model was developed with a commercial package ABAQUS. The mesh of model was shown in Figure 90. Due to the symmetry of the indentation, only one quarter of the volume was simulated. In the model, there were 2432 three-dimensional solid elements. The indenter was modeled as a rigid plane with an apex angle of $136^{\circ}$ between opposite faces. All of the nodes on the bottom surface were constrained in the direction of indentation, $\mathrm{Y}$ axis in the figure. The symmetric boundary conditions were applied on the symmetric planes. The friction between the indenter and the specimen was assumed to be zero since a previous study showed that the friction had no significant effect in indentation simulations. A static analysis was applied to remove the inertia effects. In the simulations, the initial increment size was kept at $0.001 \mathrm{~s}$ with a minimum step size of $10^{-5} \mathrm{~s}$. In order to improve the convergence of the results, a nonlinear geometric algorithm was used. 


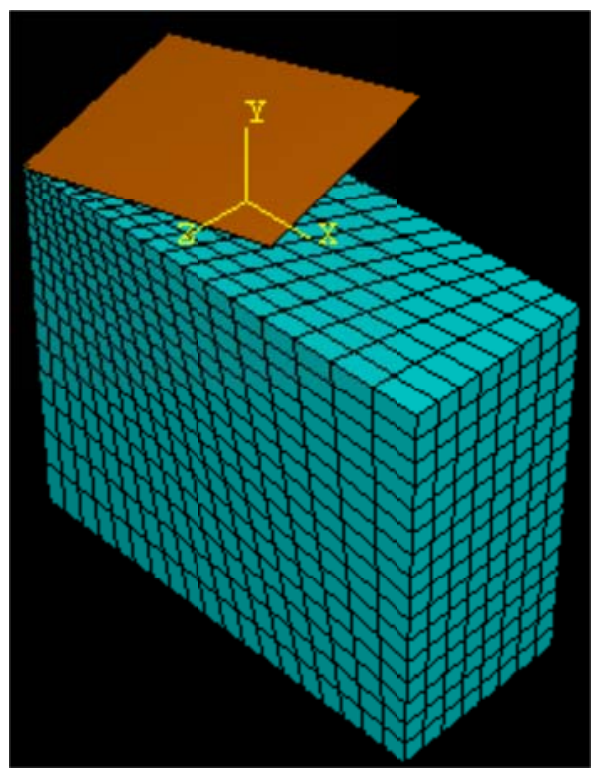

Figure 90. The finite element model used in the simulations.

The materials properties used in the simulation are as follows. The Young's modulus of NiO8YSZ (Batch I samples) was $119 \mathrm{GPa}$ determined by the impulse method. The Poisson's ratio was assumed to be 0.3 . Density was taken as $5500 \mathrm{~kg} / \mathrm{m}^{3}$. The very thin electrolyte layer was not included in the model. Both experiments and simulations showed that the indentations didn't seem to be affected by the inclusion of the very thin electrolyte layer. This work represented an effort to solve efficiently a complex indentation problem using finite element method. The simulation was performed in a quasi-static analysis to avoid any inertia effects. The indentation is achieved by increasing the indentation depth.

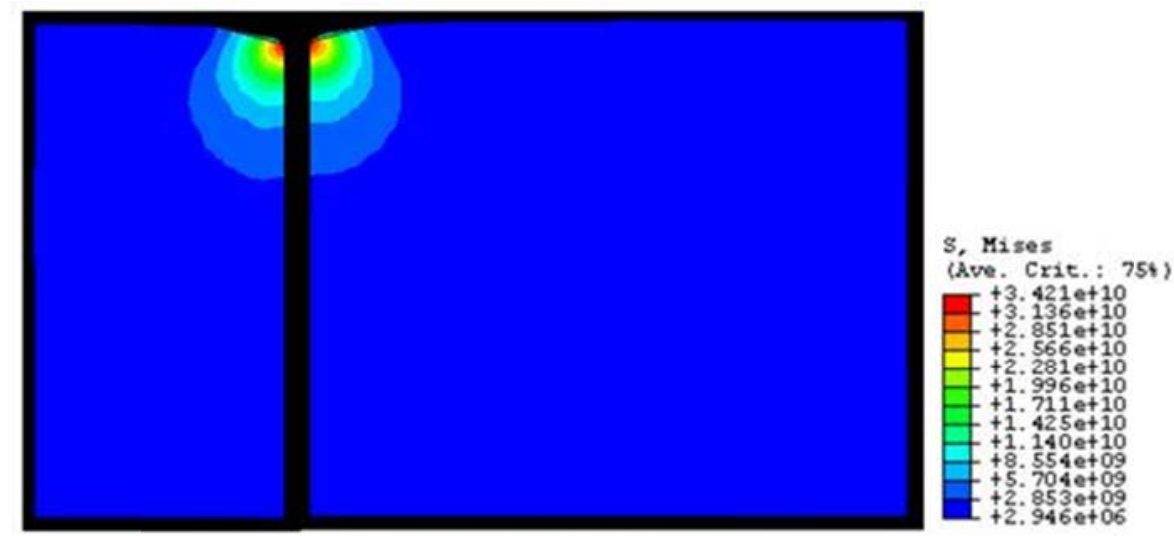

Figure 91. Plane views of stress distributions in as-received NiO-8YSZ (Batch I) samples.

Figure 91 shows the plane side view of stresses around the indentation mark after full loading. Cracks initiation in brittle materials were mainly caused by tensile stresses. The region of highest tensile stress was identified as the location where cracks were most likely to nucleate. Experiments showed that radical cracks formed at the corners of the indentation mark. In the simulations, stress distributions suggested that the radial cracks nucleated at the bottom and the corner of the indentation mark. The radial cracks propagated linearly along the diagonal of the 
indentation marks. Based on the available material data, the residual stresses of NiO-8YSZ anode/8YSZ electrolyte structures were estimated in the order of $1 \mathrm{GPa}$ right below the indentation mark.

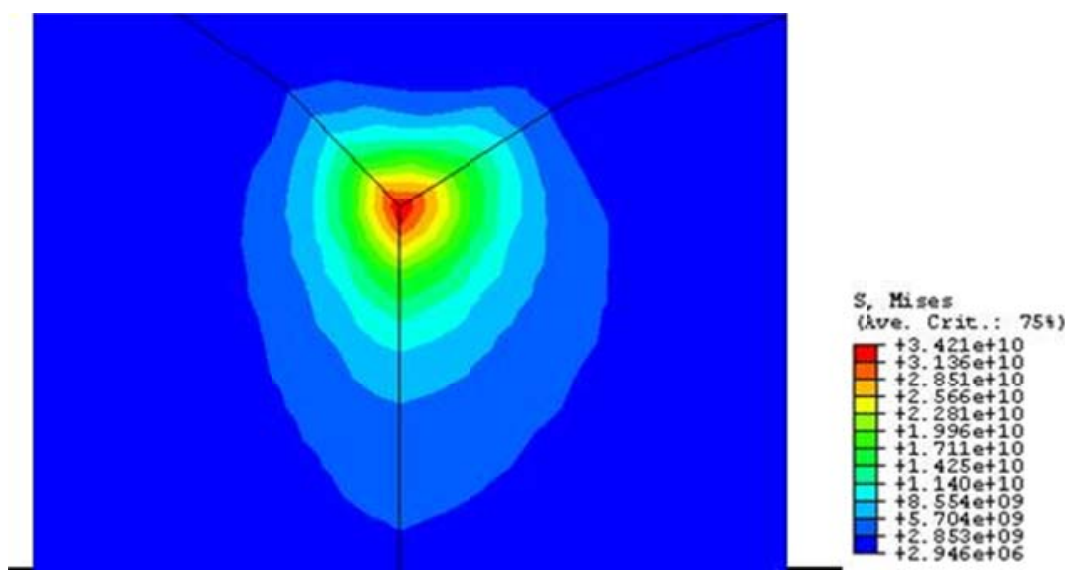

Figure 92. Three-dimensional simulation of stress distributions in as-received NiO-8YSZ (Batch I) samples.

Figure 92 shows the three-dimensional simulation of the stress distributions in the as-received NiO-8YSZ (Batch I) samples. The stress distribution showed that high stresses developed on the surface of the samples as the indenter moved into the specimens. From the stress contour, the crack therefore formed around the shoulder of the indentation marks. If the stresses exceeded the fracture strength of the specimen, cracks generated radially on the top surface and form the radial cracks.

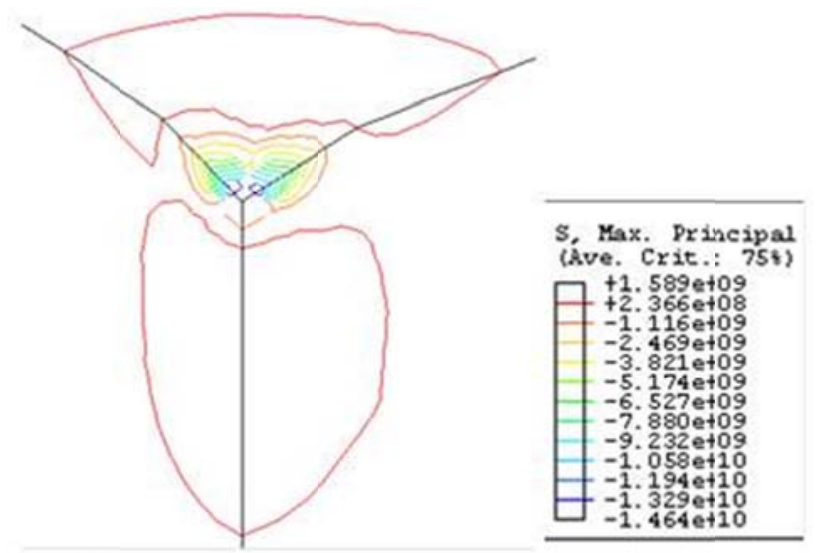

Figure 93. The 3D contour of the maximum principal stress.

Figure 93 shows the 3D view of the contour of the maximum principle stress. It was noted that the maximum principal stresses were mainly beneath the indentation mark. It showed that the maximum principal stress distribution developed on the surface of the indentation mark and became circular. The maximum principal stress existed at the shoulder of the indentation marks, suggesting that the radial cracks propagated along the diagonal of the indentation marks. The figure also showed that a compressive stress developed beneath the contact surface of the tip of the indenter. However, a large tensile stress region existed beneath the indentation region, which 
created a plastic zone. The transition from compression to tension below the indenter could cause a lateral crack initiation. With the improved material property model, the simulated indentation force versus depth curve is shown in Figure 94. The nonlinearity of the curve has been observed experimentally in the literature, which is due to the Poisson effect during indentations.

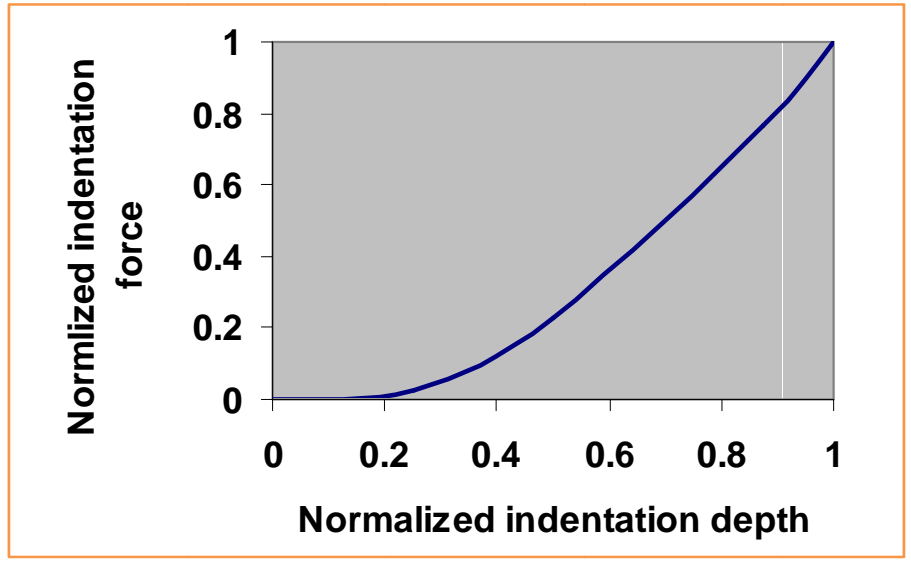

Figure 94. Simulated indentation force versus depth curve. The force and depth are normalized by their maximum values.

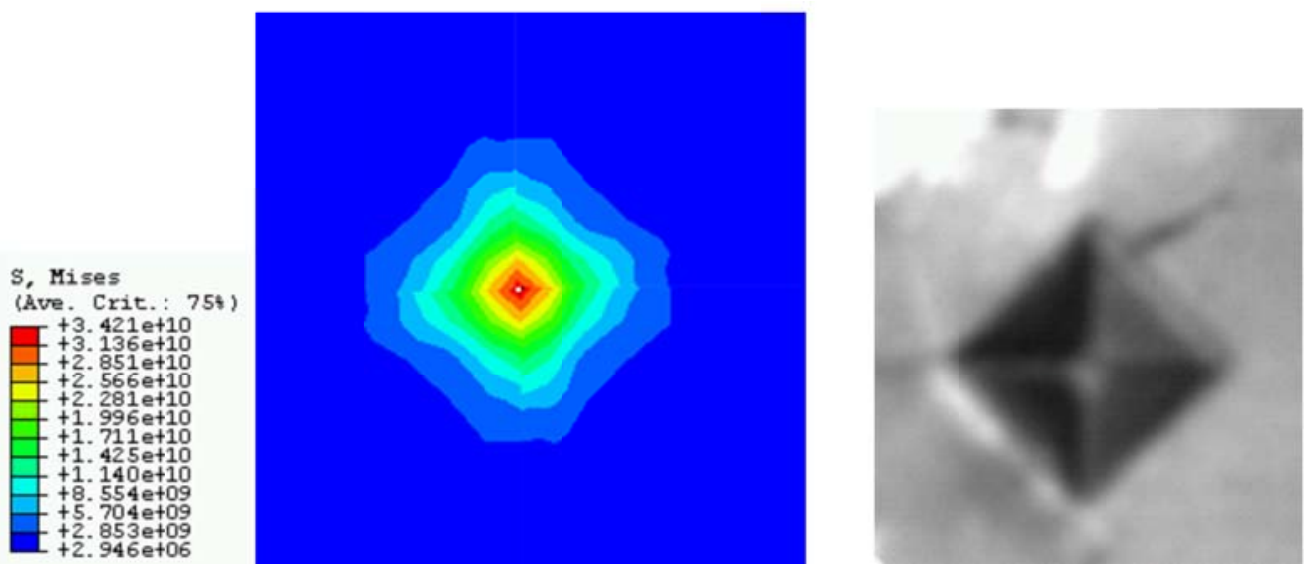

Figure 95. (a) Simulated indentation mark on electrolyte side. Colors represent different stress levels on the indented samples. (b) Optical image of indentation mark on the electrolyte (Load $50 \mathrm{gm}$ at 500x).

Figure 95 shows the indentation mark comparison between the simulation and the experimental observations. The stresses were directly related to the indentation depth. Similar to the discussion before, the patterns were well demonstrated in the simulations.

\section{Task 4 Hermetic Seal Development}

Reliable hermetic sealing technologies must be developed in order to achieve the maximum performance possible for SOFC/SOFEC stacks. For the past decade, considerable effort has gone into the development of glasses and glass-ceramics for these seals ${ }^{24}$. Compositions with

${ }^{24}$ J.W. Fergus, J. Power Sources, 147 46-57 (2005) 
the requisite thermal properties for seals have been developed, but questions about long-term property stability, deleterious interfacial reactivity, and component volatility madd the development of new, reliable sealing materials a priority.

\section{Task 4.1 Thermo-mechanical stability and electrical conductivity}

The glasses developed at MS\&T had relatively low silica contents ( $<45$ mole $\%$ ) and possessed molecular-level structures that were much less connected than conventional silicate glasses. These depolymerized structures contributed to desirably low viscosities at the sealing temperatures $\left(850-900^{\circ} \mathrm{C}\right)$, and led to the formation of crystalline phases that possessed relatively high CTEs and good thermal stabilities when the seals were crystallized to form glass-ceramics. Two compositions, called glass \#50 and G\#81, were promising compositions that possessed the requisite thermal properties for SOFC seals. Glasses $\mathrm{G} \# 50$ and $\mathrm{G} \# 81$ formed a $\mathrm{CaSrSiO}_{4}$ and $\mathrm{Sr}_{2} \mathrm{SiO}_{4}$-based glass-ceramic, respectively, that could be sealed at $850^{\circ} \mathrm{C}-900^{\circ} \mathrm{C}$, typically for one hour. Figure 96 shows that the CTE of glasses $\# 50$ and $\# 81$ remains around $11-11.5 \times 10^{-6} /{ }^{\circ} \mathrm{C}$ after four months at $800^{\circ} \mathrm{C}$. Figure 97 shows the electrical conductivity measurement of G\#81 sealing glass-ceramics as a function of time in air and $\mathrm{H}_{2}$ at $800^{\circ} \mathrm{C}$. The electrical conductivity for glasses $\# 50^{25}$ and G\#81 likewise didn't change with time under SOFC operational conditions. These glass compositions were intended to crystallize during sealing to form glass-ceramics with the requisite thermal and chemical properties.

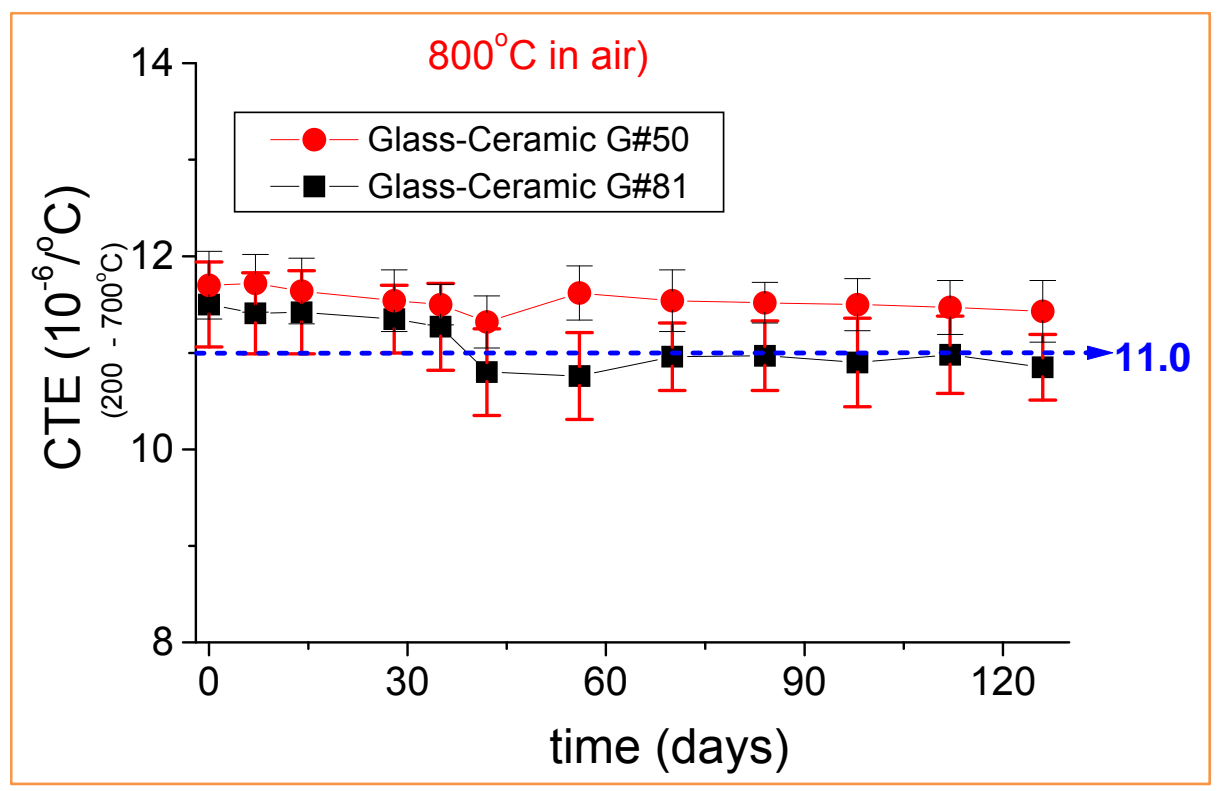

Figure 96. Thermal expansion coefficient for sealing glass compositions after heating to $800^{\circ} \mathrm{C}$ in air for over an extended period

\footnotetext{
${ }^{25}$ Yang, S. B., "Silicate based bioactive glass fiber scaffolds for bone tissue regeneration”, Masters' Thesis in Ceramic Engineering, University of Missouri-Rolla, 2007C. S. Ray, T. Zhang, S. T. Reis, and R. K. Brow, "Determining Kinetic Parameters for Isothermal Crystallization of Glasses," Journal of the American Ceramic Society, 90[3], 769-773 (2007).
} 


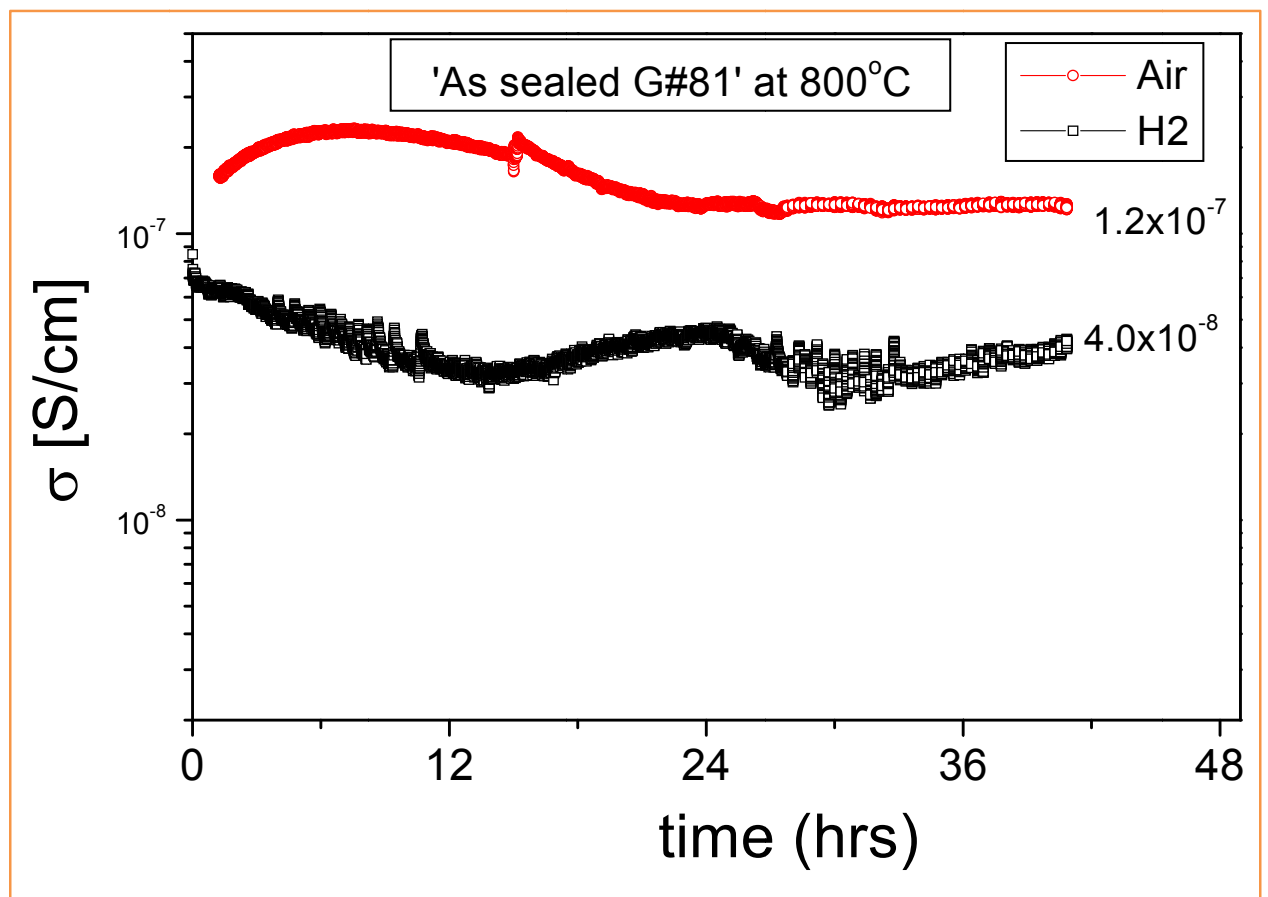

Figure 97. Electrical conductivity for $\mathrm{G} \# 81$ sealing glass-ceramics as a function of time in air and $\mathrm{H}_{2}$ at $800^{\circ} \mathrm{C}$

Task 4.2 Influence of glass particle size on crystallization behavior

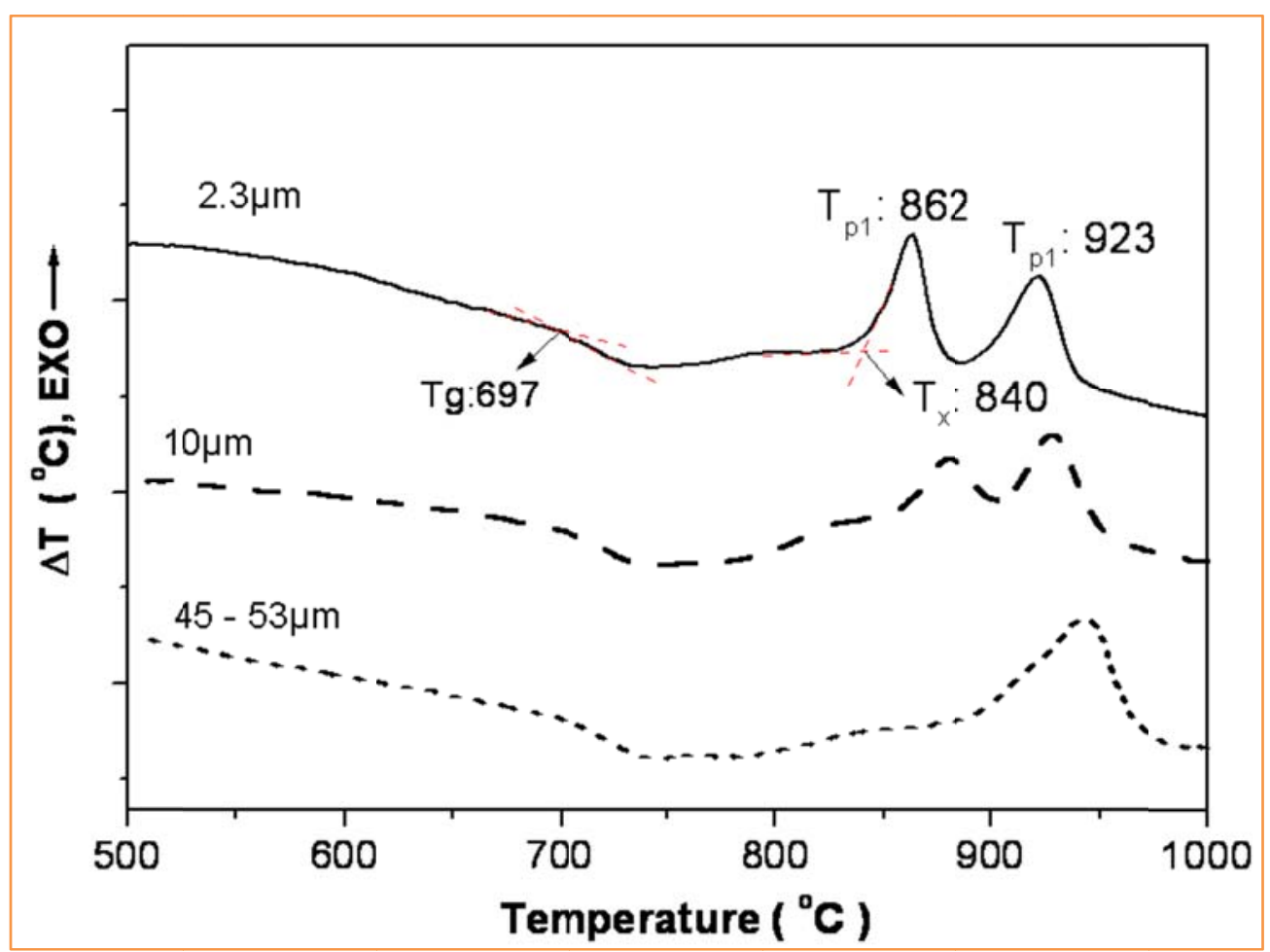

Figure 98. Differential thermal analyses of glass \#50 powders with different average particle sizes, at a heating rate of $10^{\circ} \mathrm{C} / \mathrm{min}$ 
Figure 98 shows differential thermal analyses (DTA) of different particle sizes of a commercially-provided glass $\# 50$, collected at $10^{\circ} \mathrm{C} / \mathrm{min}$. The glass transition temperature $\left(\mathrm{T}_{\mathrm{g}}\right)$, the temperature of the onset of crystallization, $T_{x}$, and the crystallization peak temperature, $T_{p}$, were indicated in the figure for particle size of $2.3 \mu \mathrm{m}$. Table 5 summarizes the particle-size dependence of these characteristic temperatures. The parameter $\Delta \mathrm{T}_{\mathrm{x}}=\left(\mathrm{T}_{\mathrm{x}} \mathrm{T}_{\mathrm{g}}\right)$ was an indication of glass stability against crystallization, as shown in Table 5; larger particle sizes had greater values of $\Delta T_{x}$, indicating a greater resistance to immediate crystallization ${ }^{26}$. The effect of particle size on crystallization behavior was also characterized using a hot-stage microscopic technique described in reference ${ }^{26}$. In this technique, glass powder compacts were heated and the densification processes were monitored using a camera to record changes in sample profiles. Table 6 summarizes the experiments on glass \#50 powders with different particle sizes. In this table the parameter $\mathrm{S}_{\mathrm{C}}$ meant the competition between sintering and crystallization of glass powders of different particle sizes during the heating. Negative values for $\mathrm{S}_{\mathrm{C}}$ for glass powders with average particle sizes of 2.3 and $10 \mu \mathrm{m}$ indicated that crystallization could impede the sintering process, leading to poorly sintered and porous materials.

Table 5. Characteristic temperature for G\#50 glasses with different particle sizes

\begin{tabular}{|lccccc|}
\hline Glass ID & Particle size $(\mu \mathrm{m})$ & $\mathrm{Tg} \pm 3$ & $\mathrm{Tx} \pm 4$ & $\mathrm{Tp} \pm 4$ & $\Delta \mathrm{Tx}$ \\
\hline \multirow{2}{*}{ G50-06110170127 } & 2.3 & 697 & 768 & $789-862-923$ & 71 \\
& 10 & 697 & 779 & $806-876-926$ & 82 \\
& $45-53$ & 690 & 792 & $815-936$ & 102 \\
\hline
\end{tabular}

Table 6. DTA and HSM data for G\#50 with different average particle sizes, at heating rate of $5^{\circ} \mathrm{C} / \mathrm{min}$.

\begin{tabular}{|c|c|c|c|}
\hline $\begin{array}{c}\text { Particle } \\
\text { size, } \mu \mathrm{m}\end{array}$ & $\mathrm{T}_{\mathrm{MS}}$ & $\mathrm{T}_{\mathrm{X}}$ & $\begin{array}{c}\mathrm{T}_{\mathrm{X}}-\mathrm{T}_{\mathrm{MS}} \\
\left(\mathrm{S}_{\mathrm{C}}\right)\end{array}$ \\
\hline 2.3 & 770 & 756 & -14 \\
\hline 10 & 790 & 779 & -11 \\
\hline 45 & 790 & 798 & 8 \\
\hline
\end{tabular}

$\mathrm{T}_{\mathrm{g}}$ : glass transition temperature from DTA;

$\mathrm{T}_{\mathrm{FS}}$ : first shrinkage temperature from HSM;

$\mathrm{T}_{\mathrm{MS}}$ : maximum shrinkage temperature from HSM;

$\mathrm{T}_{\mathrm{X}}$ : onset of crystallization from DTA ;

$\mathrm{S}_{\mathrm{C}}:\left(\mathrm{T}_{\mathrm{X}}-\mathrm{T}_{\mathrm{MS}}\right)$ : parameter for sinterability;

$\mathrm{T}_{\mathrm{D}}$ : softening Temperature from (HSM);

$\mathrm{T}_{\mathrm{HB}}$ : Half ball Temperature from (HSM);

$\mathrm{T}_{\mathrm{F}}$ : flow Temperature from (HSM)

Task 4.3 Tape-casting and hermetic seals

\footnotetext{
${ }^{26}$ C. Lara, M.J. Pascual, and A. Duran, J. Non-Crystalline Solids, 348, 149-155 (2004).

${ }^{27}$ Glass prepared by a commercial vendor.
} 
Glass powders with particle sizes in the range of $10-12 \mu \mathrm{m}, 25-53 \mu \mathrm{m}$, and $45-53 \mu \mathrm{m}$ for tape casting experiments were prepared from commercially-supplied versions of glasses G\#50 and

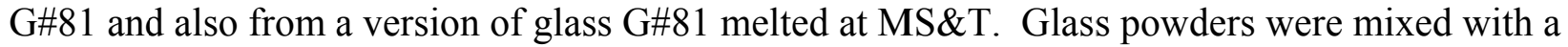
solution of PVB binder and acetone and the mixture was applied between substrates of materials used in SOFC stacks, including SS430, YSZ electrolyte and Ni-YSZ anode materials. Sealing samples were then heated in air at $2^{\circ} \mathrm{C} /$ minute to $450^{\circ} \mathrm{C}$ and held for 1 hour to remove the binder. The samples were then heated to $850^{\circ} \mathrm{C}(\mathrm{G} \# 81)$ or $900^{\circ} \mathrm{C}(\mathrm{G} \# 50)$ for thirty minutes to allow the glass to melt and flow to the edges of the sealed packages, whereupon the samples were then cooled at $2^{\circ} \mathrm{C} /$ minute to $800^{\circ} \mathrm{C}$ and held for two hours to form the desired glass-ceramic material. Sealed samples were held at $800^{\circ} \mathrm{C}$ in either forming gas or air for 24 hours and then were checked for leaks using a 4 psig differential in the testing gas. Figure 99a shows the experimental set-up for these tests and Figure 99b shows examples of the seals that were fabricated and tested. After 24 hours at $800^{\circ} \mathrm{C}$, the seals were cooled to room temperature ($10^{\circ} \mathrm{C} / \mathrm{min}$ ) and retested for hermeticity. Samples that did not leak (i.e. held 4 psig pressure for two hours) were reheated to $800^{\circ} \mathrm{C}$ and held for another 24 hour heat treatment/hermeticity cycle. Table 7 summarizes the results of these tests. It was significant to note that in general for the samples described in the table, hermeticity was lost when the ceramic component of the seal fractured, sometimes as a result of handling. However a color change was noted for the Ni-YSZ ceramics, from green to gray, which could be related to the reduction of $\mathrm{NiO}$ during the thermal treatment under forming gas, and the expected volume change would also contribute to the interfacial stresses that developed for these samples. Also the glass-ceramic layer on the 430SS/G502 $(10-12 \mu \mathrm{m}) / \mathrm{Ni}-Y S Z$ sample sealed using the commercial version of G\#502 with particle size below $45 \mu \mathrm{m}$ appeared with more porosity that could be related with the leakage of 1.5 psi shown in Table 7. Even though G\#81, the evolution of G\#50 with lower sealing condition, was more indicated as a sealant for materials as $8 \%$ YSZ as shown in Figure 100, the seals using this glass with particle size around $25 \mu \mathrm{m}$ showed hermeticity acceptable in forming gas at $800^{\circ} \mathrm{C}$.

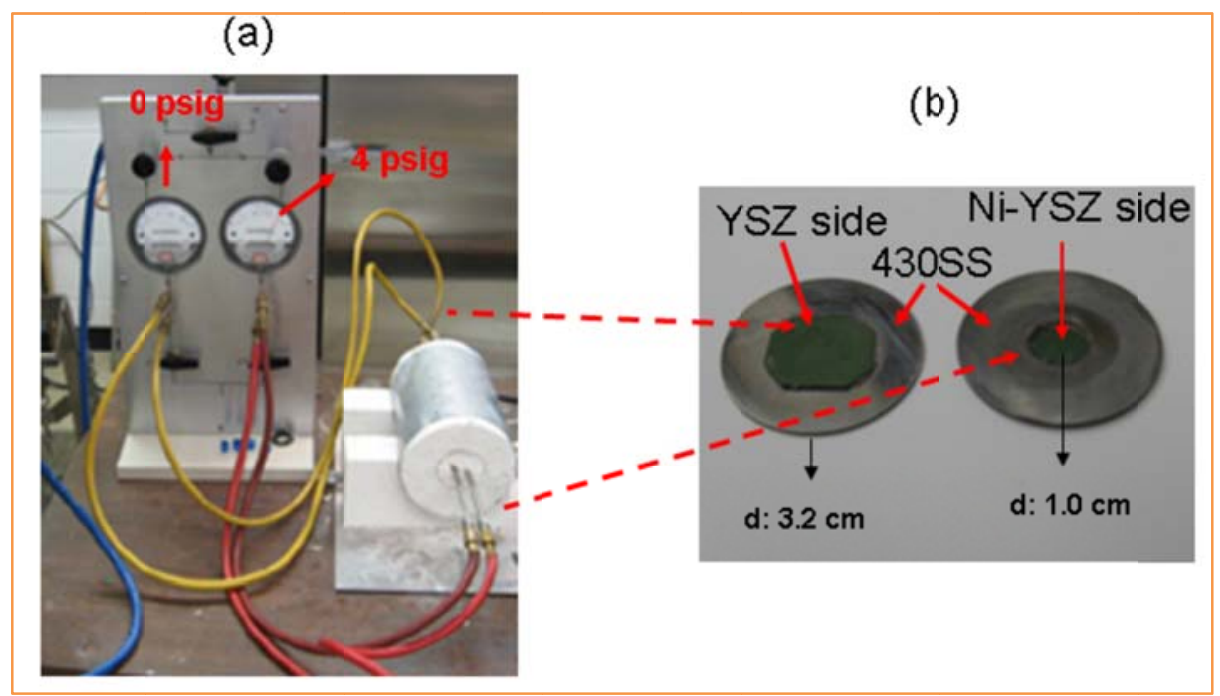

Figure 99. Pictures of the hermeticity test showing in (a) tubular furnace and the apparatus used for the test and in (b) seals between 430SS discs and Ni-YSZ used during the test 


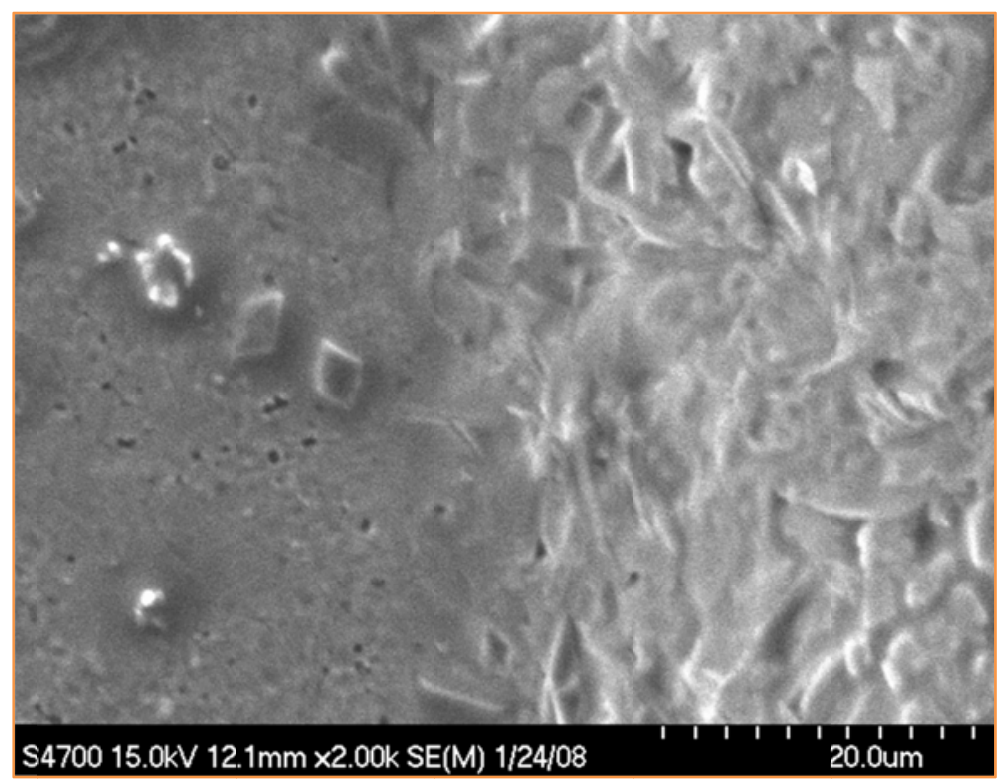

Figure 100. SEM picture of a seal between $8 \% \mathrm{YSZ}$ (left) and G\#81 (right) with $25 \mu \mathrm{m}$ particle size treated at $850^{\circ} \mathrm{C}$ for 1 hour in air

Table 7. Summary of recent thermal cycling tests of glass seals.*

\begin{tabular}{|c|c|c|}
\hline Sealing materials & Test conditions & Notes \\
\hline $\begin{array}{l}430 \mathrm{SS} / \mathrm{G} 50^{28}(10- \\
12 \mu \mathrm{m}) / \mathrm{Ni}-\mathrm{YSZ}\end{array}$ & wet forming gas & Failed after 4 cycles; Ni-YSZ fracture \\
\hline $\begin{array}{l}430 \mathrm{SS} / \mathrm{G} 50^{25}(10- \\
12 \mu \mathrm{m}) / \mathrm{Ni}-\mathrm{YSZ}\end{array}$ & wet forming gas & Leakage of 1.5 psi after 2 cycles \\
\hline $\begin{array}{l}430 \mathrm{SS} / \mathrm{G} 50^{25}(45- \\
53 \mu \mathrm{m}) / \mathrm{Ni}-\mathrm{YSZ}\end{array}$ & wet forming gas & Failed after 20 cycles; Ni-YSZ fracture \\
\hline $\begin{array}{l}430 \mathrm{SS} / \mathrm{G} 50^{25}(45- \\
53 \mu \mathrm{m}) / \mathrm{YSZ}\end{array}$ & air & Failed after 10 cycles; YSZ fracture \\
\hline $\begin{array}{l}430 \mathrm{SS} / \mathrm{G} 50^{25}(45- \\
53 \mu \mathrm{m}) / \mathrm{YSZ}\end{array}$ & air & Failed after 60 cycles; YSZ fracture \\
\hline $\begin{array}{l}430 \mathrm{SS} / \mathrm{G} 81^{25}(20- \\
45 \mu \mathrm{m}) / \mathrm{Ni}-\mathrm{YSZ}\end{array}$ & forming gas & 10 cycles; Ni-YSZ fracture \\
\hline $\begin{array}{l}430 \mathrm{SS} / \mathrm{G} 81^{29}(45 \mu \mathrm{m}) / \mathrm{Ni}- \\
\mathrm{YSZ}\end{array}$ & forming gas & Failed after 30 cycles; Ni-YSZ fracture \\
\hline $\begin{array}{l}430 \mathrm{SS} / \mathrm{G} 81^{26}(25 \mu \mathrm{m}) / \mathrm{Ni}- \\
\text { YSZ }\end{array}$ & forming gas & 32 cycles without failure \\
\hline
\end{tabular}

*Samples were held for 24 hours at $800^{\circ} \mathrm{C}$ under forming gas or compressed air, and tested for hermeticity.

${ }^{28}$ Glass prepared by a commercial vendor (MOSci)

${ }^{29}$ Glass prepared at MS\&T. 


\section{Task 5 Single Cell Testing and Characterization}

Cathode materials developed for the SOFEC/SOFC were evaluated in cells first on button-sized cells, followed by large cells with per-cell active areas of $100 \mathrm{~cm}^{2}$. The one-inch button cells were screen-printed with $2 \mathrm{~cm}^{2}$ active areas. A test fixture, shown in Figure 101 in an exploded view, was modified and built using a design developed for SOFC evaluations. The fixture was spring loaded to ensure constant loading and to minimize contact resistance. No metallic interconnects, such as used in typical planar SOFC stacks, were used, thus eliminating the effects of oxidation and metallic interconnects resistance from the testing. Silver mesh was used as a current collector on both the anode and cathode side. A 4-point configuration was adopted in this setup so that the resistance of the lead wires was removed from the measurements. This type of fixture eliminates many of the secondary losses that occur in planar stacks, and thus allows for an accurate measurement of the performance of the SOFEC/SOFC cells. Both anode and cathode had a closed gas chamber that allowed for the use of a range of gases.

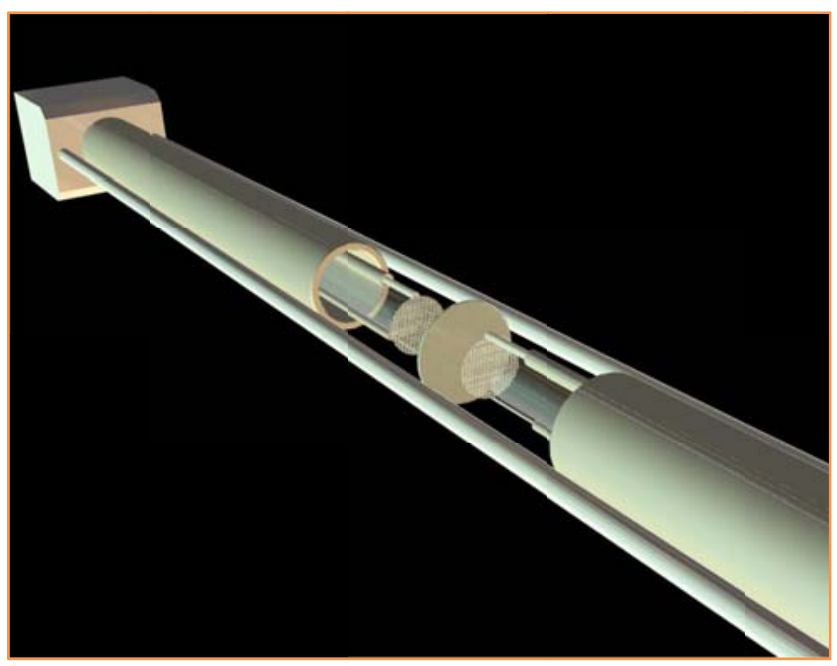

Figure 101. Exploded view of the spring-loaded single-cell test fixture designed for SOFC-SOFEC evaluation

\section{Task 5.1 Evaluation of effects of anode substrates on cells performance}

Experimental evaluations of various types of cells described in Task 2 were conducted. Four types of anode substrate were constructed: $\mathrm{NiO} / 8 \mathrm{YSZ}$ at $80 / 20$ ratio; $\mathrm{NiO} / 8 \mathrm{YSZ}$ at $67 / 33$ ratio added with Type A pore former; NiO/8YSZ at $65 / 35$ ratio added with Type B pore former; and $\mathrm{NiO} / 8 \mathrm{YSZ}$ (Unitec powder) at $65 / 35$ ratio added with Type B pore former. The same cathode materials (LSM) were applied to each of these cells. Tests were performed in SOFC mode; Figure 102 shows comparative performance levels. Several distinct characteristics were observed in the figure: 1 . adding pore former increased the cell performance; 2 . cells using Type B pore former exhibited better performance than those using Type A pore former; 3. cells made from Unitec zirconia powder showed as good performance as the cells using Tosoh powder. 


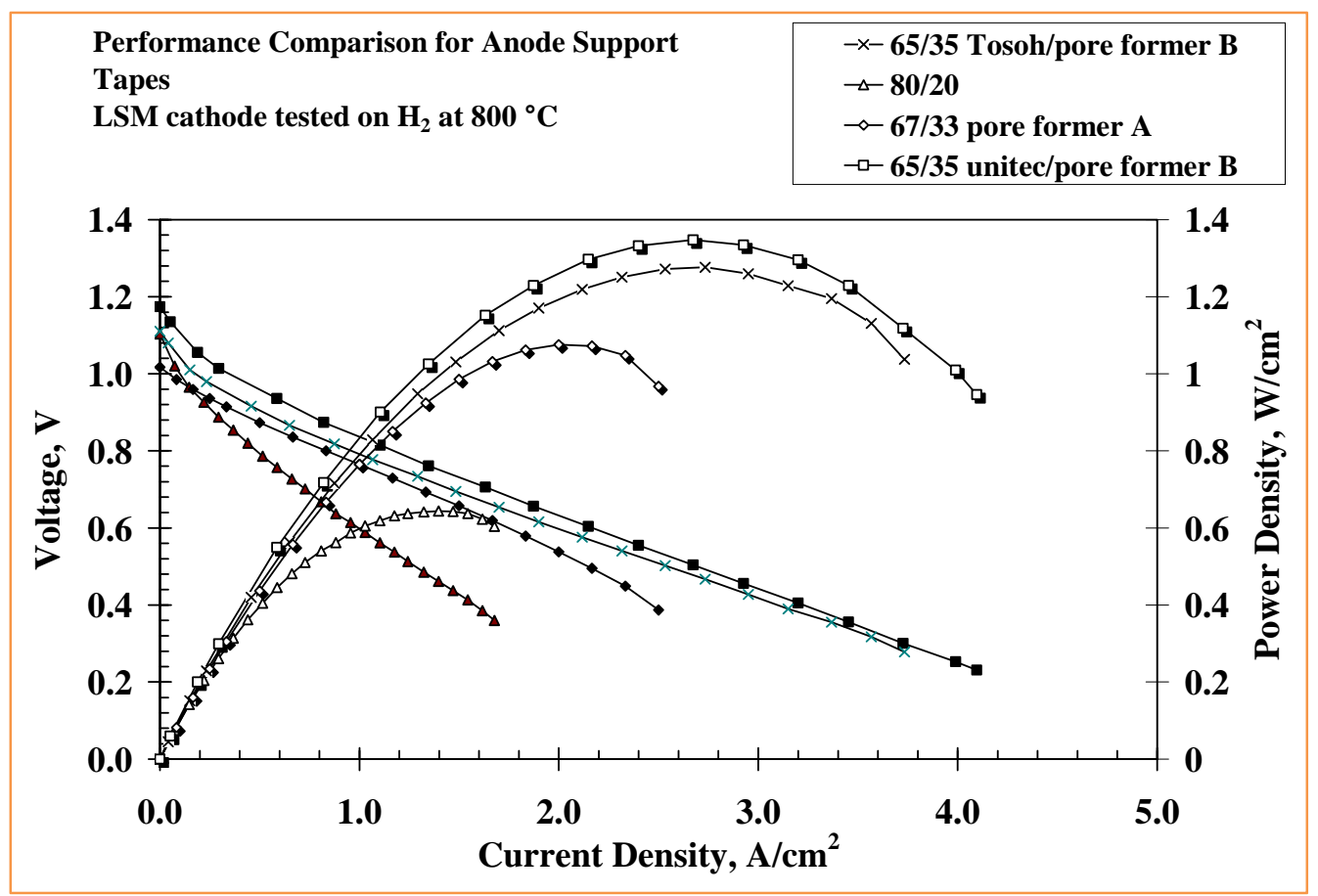

Figure 102. Performance comparison for anode support cells with LSM cathode and tested in SOFC mode with $\mathrm{H}_{2}$ fuel at $800^{\circ} \mathrm{C}$. Four types of anode substrates: NiO/8YSZ at $80 / 20$ ratio, NiO/8YSZ at $67 / 33$ ratio with Type A pore former, $\mathrm{NiO} / 8 \mathrm{YSZ}$ at $65 / 35$ ratio with Type B pore former, and NiO/8YSZ using Unitec powder at $65 / 35$ ratio with Type B pore former.

Cells made of Tosoh powder and Unitec Powder were also evaluated. As shown in Figure 103, shwn screen-printed with the same type of cathode material, LSM, the button-cell with Unitec powder achieves $1.7 \mathrm{~W} / \mathrm{cm}^{2}$ of power density, which was more than $21 \%$ increase comparing to the cell made of Tosoh powder. In order to simplify the cathoding process, various deposition methods were explored. Button cells made of Unitec powder were cathoded by the spraying and screen-printing methods. The test results, also plotted in Figure 103, showed that the cell cathoded with the screen-printing method had much higher performance than the cell cathoded with the spraying method. We suspected that the spraying approach may densify the cathode, resulting in high concentration overpotential, as indicated in the V-I curve. More work will be needed to engineer the spraying method for depositing a porous cathode in future development efforts. 


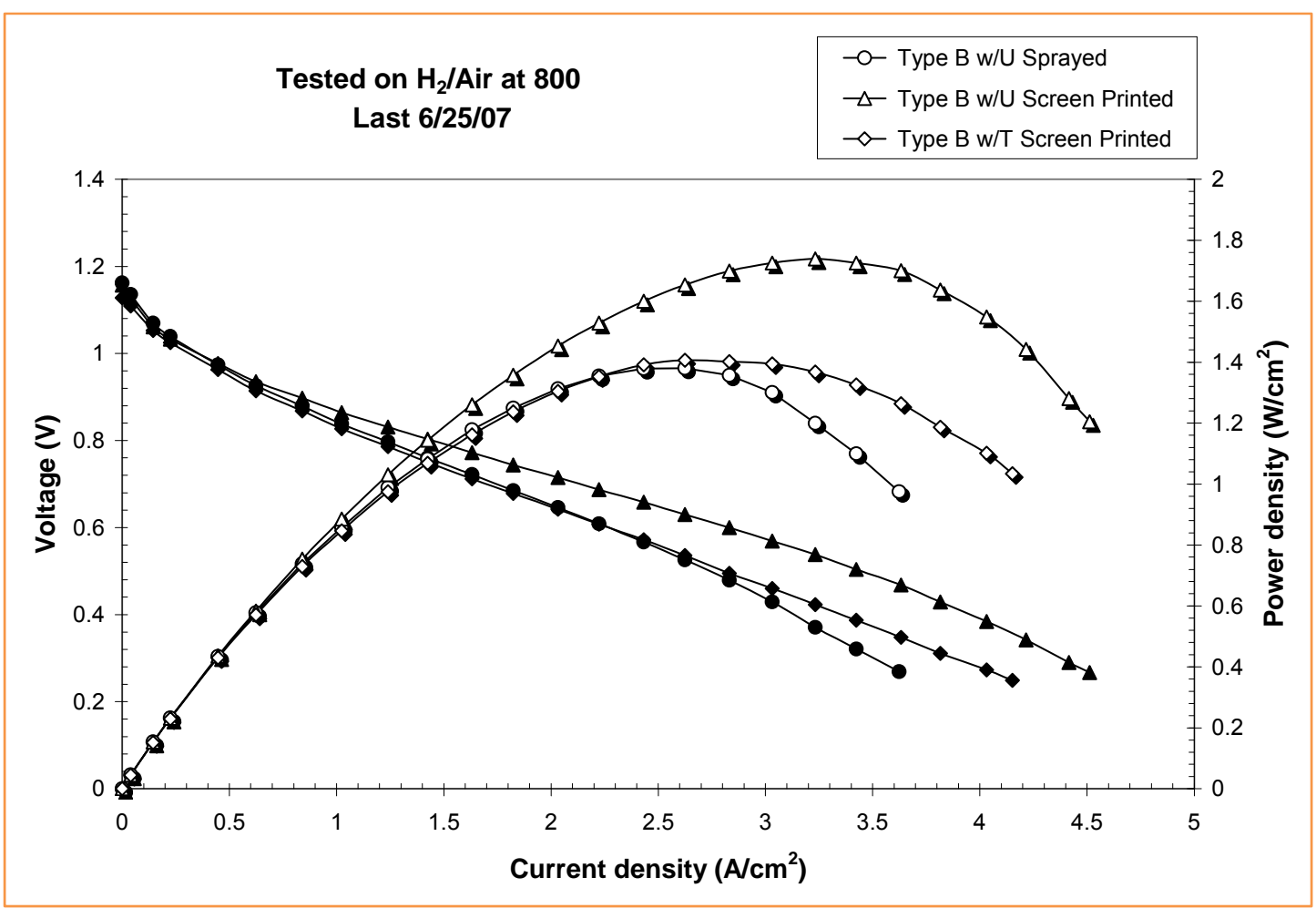

Figure 103. Performance comparisons for anode substrates made of Tosoh powder and Unitec powder. Type B pore former were used in both cases. Cells were tested in SOFC mode at $800^{\circ} \mathrm{C}$.

\section{Task 5.2 Development of a new approach for depositing cathodes}

Previous test results in the SOFC mode showed that a large portion of overpotential losses was from the cathode side. Mitigation strategies were thus taken to reduce the related overpotential losses by developing new means of cathode deposition. One approach taken was spraying a cathode solution onto the cell substrate to control the microstructures of the cathode. However, densification of the cathode particles after firing at elevated temperatures led to large concentration overpotential losses, as described in the previous section. Another new approach using an infiltration technique was developed to optimize cathode microstructures; this method resulted in lower overpotential losses through increased mass transport and a faster charge transfer process (reduced concentration and activation overpotential losses). Using the new approach, the composite cathode microstructures possessed the following characteristics:

a. both the solid electrolyte phase and the cathode catalytic phase were continuous,

b. triple phase boundary lengths were longer,

c. the porosity of the open pores was large enough.

The new cathode fabrication process involved following six steps: 1. Fabrication of an anodesupported substrate with the NiO+YSZ composite layer on the cathode side on top of the electrolyte; 2. reducing the $\mathrm{NiO}$ on the cathode side; 3. leaching $\mathrm{Ni}$ out using nitric acid, leaving the porous 8 YSZ structures with well sintered large necks; 4 . infiltrating catalyst of nitrate salt solution; 5. sintering the cathode at a low enough temperature to avoid the secondary phase formation, such as $\mathrm{LaZrO}_{3} ; 6$. screen-printing a cathode current collector layer and sintering it at 
$850 \sim 1000^{\circ} \mathrm{C}$ for an hour. Figure 104 shows the SEM micrograph of the composite cathode microstructures made by the new fabrication process. It clearly showed that the electrolyte phase (8YSZ) in large blocks was well sintered with large necks and wider open pores, while the catalytic phase (LSC) in nano size dispersed well along the electrolyte phase, forming lengthened triple phase boundaries. A closer look of the composite microstructures was shown in Figure 105. The average size of the YSZ particles was around $1 \sim 2 \mu \mathrm{m}$. The LSC particles were less necked with very small size.

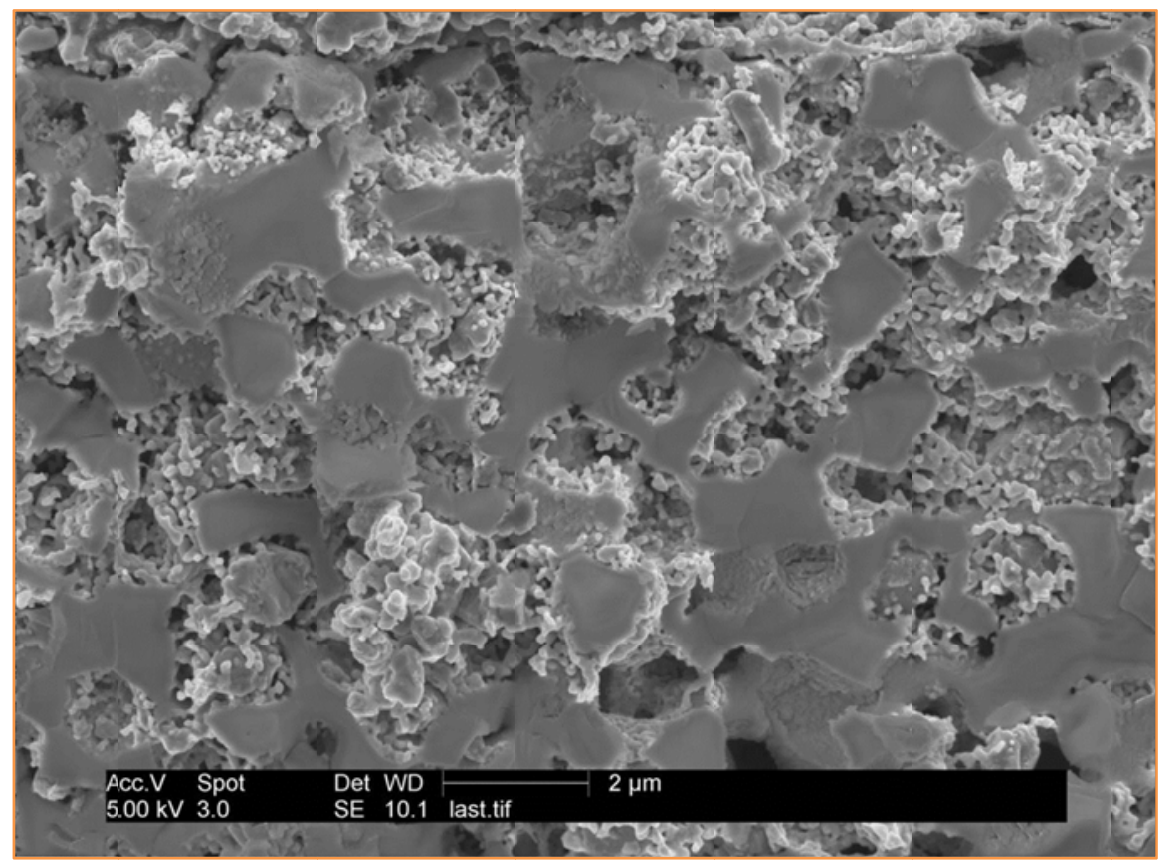

Figure 104. SEM micrograph of the modified composite cathode microstructures

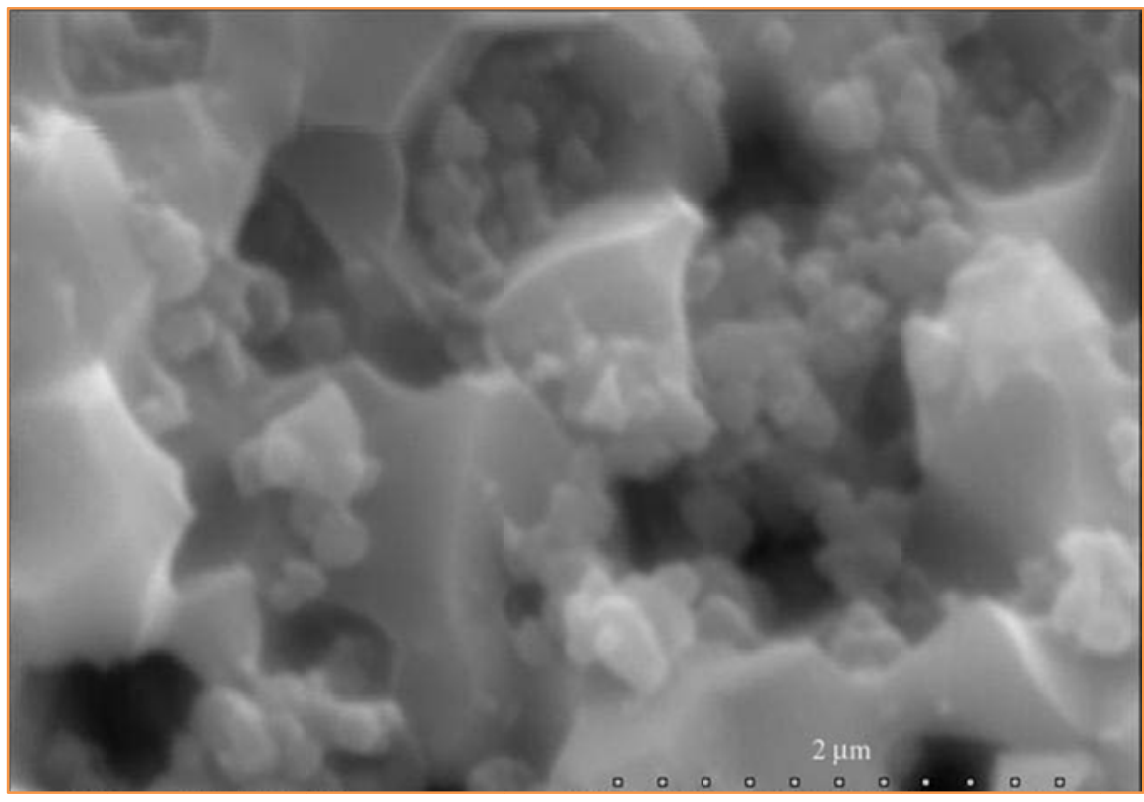

Figure 105. Close look of a SEM micrograph of the cathode microstructures 
Button cells with modified cathode microstructures using the infiltration process were tested in SOFC mode. Figure 106 shows the test results plotted in diamond symbols. LSC was used as the cathode material to evaluate the new fabrication process. Hydrogen was the fuel and air was the oxidant. At $800^{\circ} \mathrm{C}$, the cell reached a peak power density $2.12 \mathrm{~W} / \mathrm{cm}^{2}$ at $0.5 \mathrm{~V}$, while at $0.7 \mathrm{~V}$, the power density was about $1.72 \mathrm{~W} / \mathrm{cm}^{2}$. In order to make a comparison, another button cell printed with LSC cathode by the traditional screen-printing technique was constructed and tested in the same conditions as the infiltration cell was tested. The test results were plotted in Figure 106 in triangle symbols. At $0.54 \mathrm{~V}$, the cell produces $1.39 \mathrm{~W} / \mathrm{cm}^{2}$ peak power, while at $0.7 \mathrm{~V}$, it produces $1.0 \mathrm{~W} / \mathrm{cm}^{2}$. The comparisons between these two cells showed that more than $70 \%$ improvement was achieved using the infiltration technique.

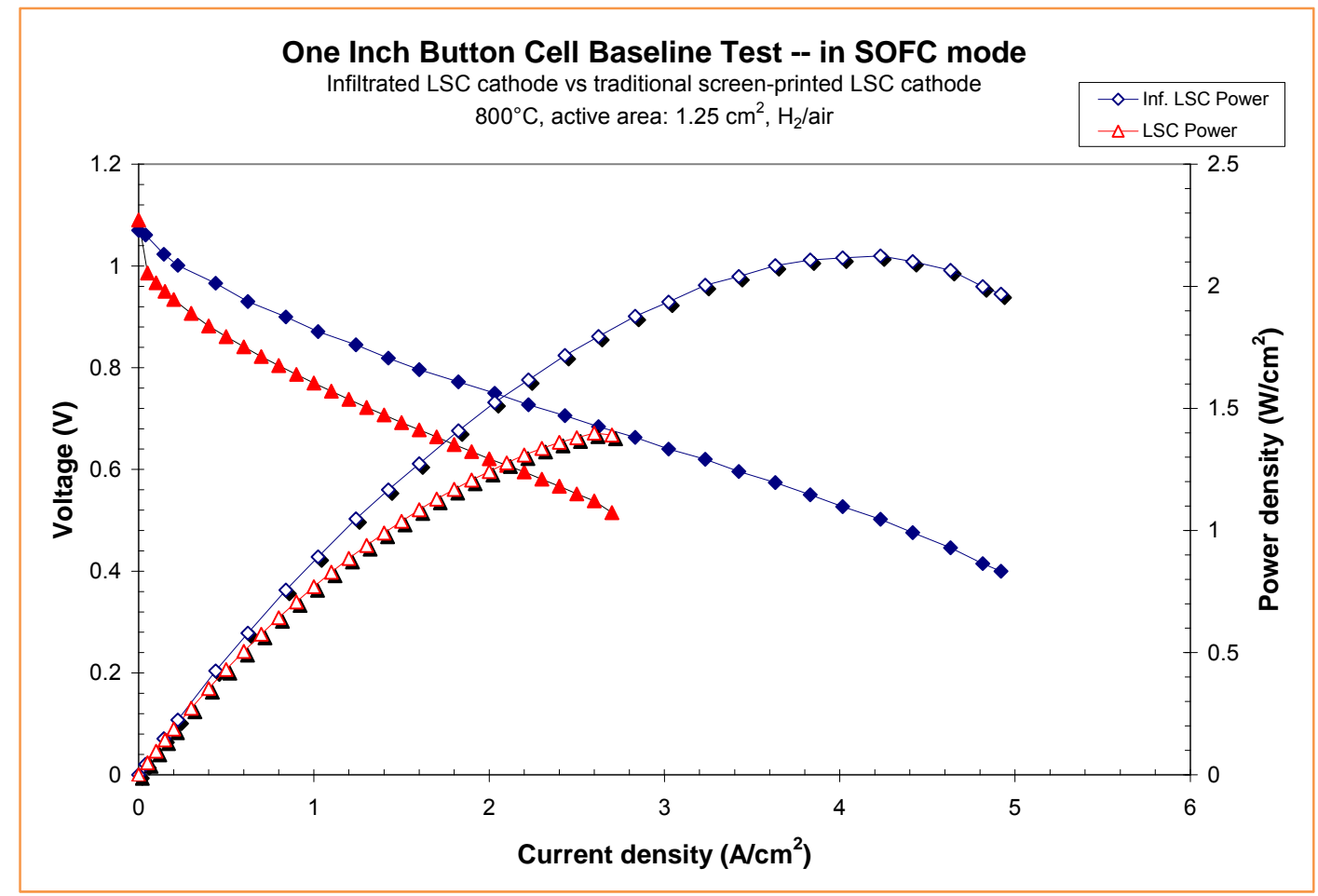

Figure 106. One inch button cell performance comparisons tested in SOFC mode.

Cells with LSCM cathode were also fabricated using the aforementioned leach-infiltration technique. Nitrate salts of $\mathrm{La}, \mathrm{Sr}, \mathrm{Cr}$, and $\mathrm{Mn}$ were supplied by Alfa. A salt solution was made based on the stoichiometric numbers of $\mathrm{La}_{0.8} \mathrm{Sr}_{0.2} \mathrm{Cr}_{0.5} \mathrm{Mn}_{0.5} \mathrm{O}_{3-\delta}$. The prepared cathode precursor was impregnated into the porous YSZ thin layer, which had previously had the Ni leached out. The impregnation process was carried out $3 \sim 5$ times and at each time the cathode-impregnated YSZ was annealed at $90^{\circ} \mathrm{C}$ on a hot plate for 15 minutes to dry. A final sintering process after the impregnation process was performed at $1100^{\circ} \mathrm{C}$ in air for 1 hour. A catalyst previously developed was also infiltrated after the cathode preparation. 


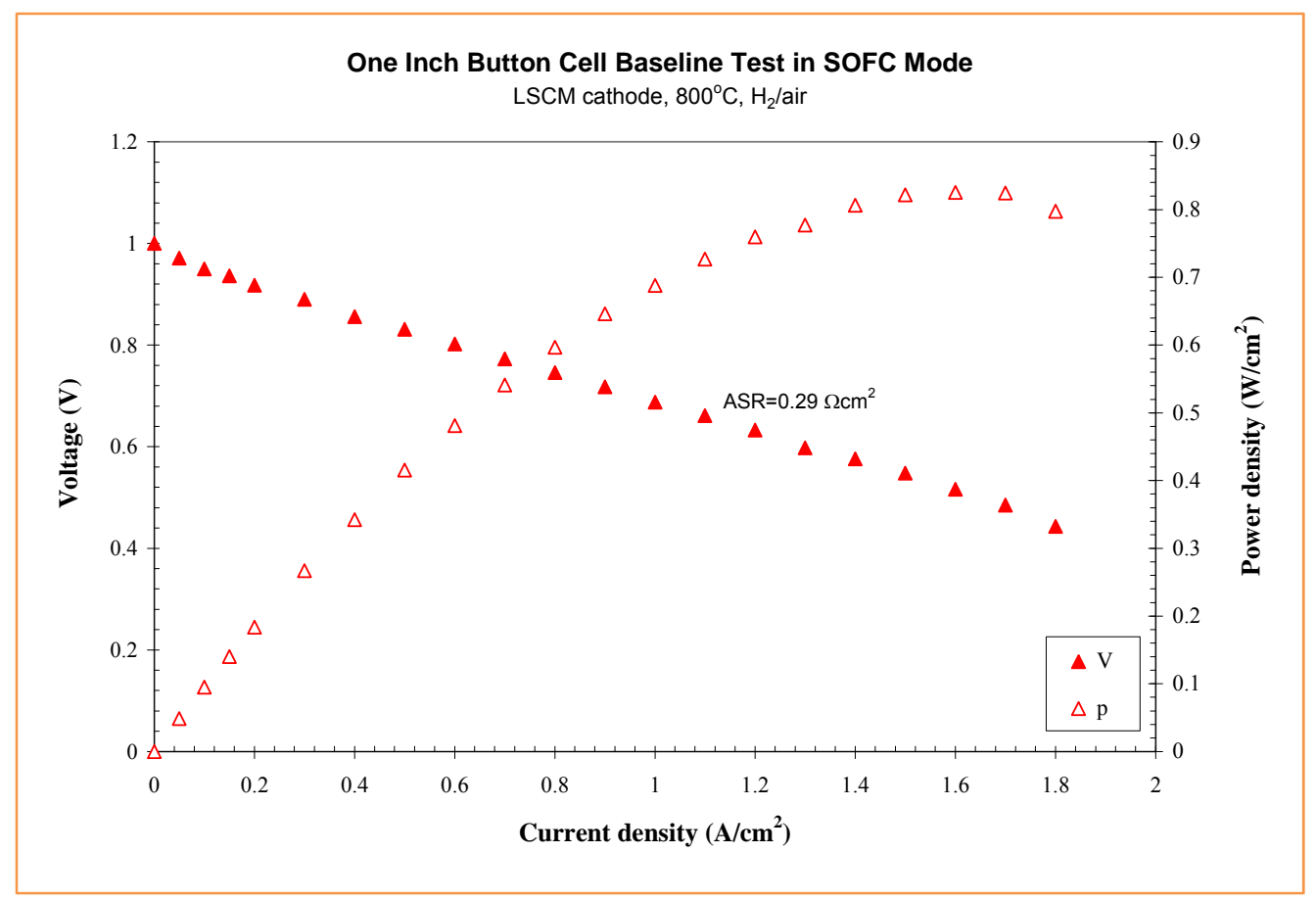

Figure 107. One inch button cell performance comparisons tested in SOFC mode

Figure 106 shows test results of a button cell with the infiltrated LSCM-based cathode. The cell was tested in SOFC mode with hydrogen as the fuel and air as the oxidant. At $800^{\circ} \mathrm{C}$, the cell reached a peak power density of $0.82 \mathrm{~W} / \mathrm{cm}^{2}$ at $0.49 \mathrm{~V}$, while at $0.7 \mathrm{~V}$, the power density was about $0.65 \mathrm{~W} / \mathrm{cm}^{2}$.

\section{Task 5.3 Development and evaluation of LSCM-based cathode}

\section{Task 5.3.1 $\quad \mathrm{La}_{0.5} \mathrm{Sr}_{0.5} \mathrm{Cr}_{0.5} \mathrm{Mn}_{0.5} \mathrm{O}_{3}$ development}

As discussed in Task 2, LSCM $\left(\mathrm{La}_{0.8} \mathrm{Sr}_{0.2} \mathrm{Cr}_{0.5} \mathrm{Mn}_{0.5} \mathrm{O}_{3}\right)$ was selected as the cathode material for the reversible SOFEC/SOFC modules. Extensive studies performed at MSRI have shown that LSCM possesses high chemical stability and high catalytic properties in both reducing and oxidizing atmospheres. In addition, several strategies were employed to increase the LSCM's electrical conductivity and catalytic activity: first, the doping level of $\mathrm{Sr}$ into the A-site could be increased to enhance its electronic conductivity. Second, other alkaline earth ions and transition elements could be doped into $\mathrm{A}$ and $\mathrm{B}$-site of the $\mathrm{ABO}_{3}$-type perovskite respectively to improve its catalytic activity and ionic conductivity correspondingly.

Synthesis of $\mathrm{La}_{0.5} \mathrm{Sr}_{0.5} \mathrm{Cr}_{0.5} \mathrm{Mn}_{0.5} \mathrm{O}_{3}$ (LSCM5555): To investigate the $\mathrm{Sr}$ doping level effect on the electronic conductivity, the composition of LSCM was chosen as $\mathrm{La}_{0.5} \mathrm{Sr}_{0.5} \mathrm{Cr}_{0.5} \mathrm{Mn}_{0.5} \mathrm{O}_{3}$. The material was prepared using combustion synthesis and conventional solid state reaction method. For combustion synthesis approach, the stoichiometric amounts of lanthanum nitrate, strontium nitrate, chromium nitrate and manganese nitrate were dissolved in distilled water with constant stirring. A stoichiometric amount of glycine was added into the solution. A gel was formed with continuous stirring and mild heating. The gel was heated continuously until combustion reaction 
occurred. The resulting powders were calcined at $1250^{\circ} \mathrm{C}$ for 12 hours. XRD studies were carried out to characterize the structural of specimens.

For conventional solid state reaction method, the mixture of $\mathrm{La}_{2} \mathrm{O}_{3}, \mathrm{Sr}_{2} \mathrm{O}_{3}, \mathrm{Cr}_{2} \mathrm{O}_{3}$ and $\mathrm{MnO}_{2}$ were mixed in alcohol and milled for 24 hours. The dry powder was calcined at $1300^{\circ} \mathrm{C}$ for 6 hours. Again, XRD studies were carried out to characterize the structural of specimens.

LSCM (5555) material characterization: Figure 108 shows the X-ray diffraction pattern of the perovskite powder obtained by the conventional solid oxide reaction method. It clearly shows the formation of nearly entirely perovskite single phase of the LSCM powder. Figure 109 shows the X-ray diffraction patterns of the perovskite powder obtained by the combustion synthesis method. The XRD pattern shows the presence of $\mathrm{Cr}_{2} \mathrm{O}_{3}$ and $\mathrm{SrCO}_{3}$ phases as impurities. The presence of $\mathrm{SrCO}_{3}$ in the perovskite-type oxide powders should be due to the reaction between $\mathrm{SrO}$ formed from the nitrate decomposition and $\mathrm{CO}_{2}$, produced from combustion process.

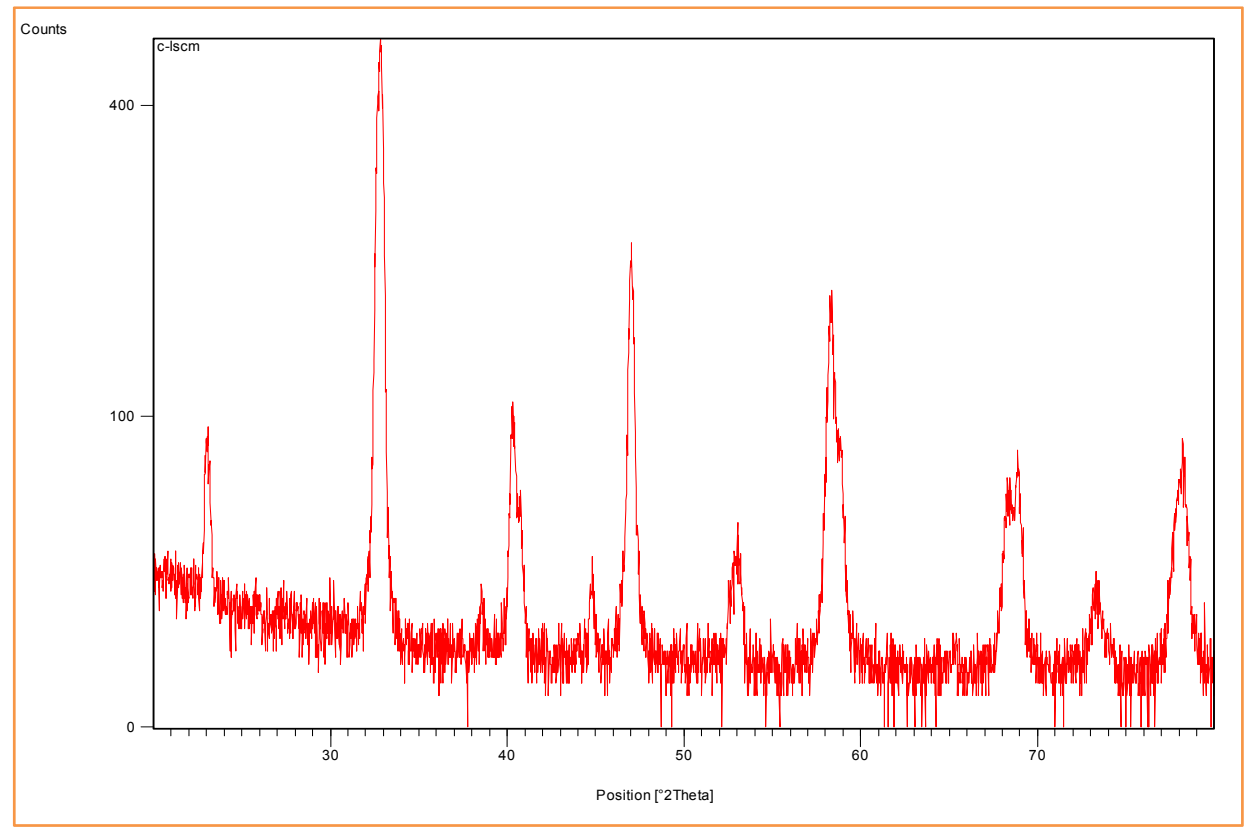

Figure 108. X-ray diffraction patterns of the perovskite powder using conventional solid oxide reaction method 


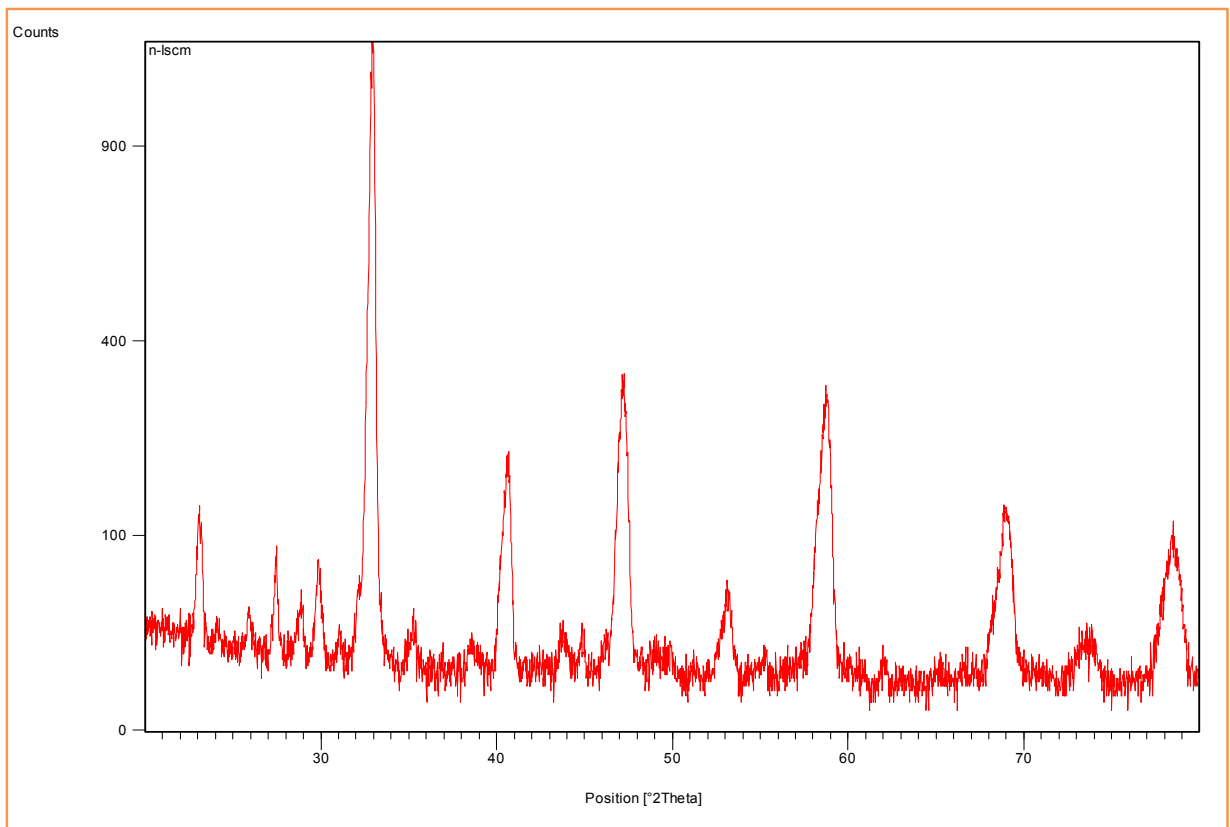

Figure 109. X-ray diffraction patterns of the perovskite powder using combustion synthesis method.

Task 5.3.2 Evaluation of button cells with LSCM (5555) cathode

Button cells were constructed with MSRI standard anode substrates and printed with the cathode prepared by the conventional solid state reaction method and the combustion synthesis method. The results were discussed below.

Table 8. Cell performance summary

\begin{tabular}{|l|c|}
\hline Cathodes & $\begin{array}{c}\text { Maximum Power Density } \\
(\mathrm{MPD}) \text { at } 800^{\circ} \mathrm{C}\left(\mathrm{W} / \mathrm{cm}^{2}\right)\end{array}$ \\
\hline Commercial LSCM & 0.30 \\
\hline Commercial LSCM+Co infiltration & 0.51 \\
\hline LSCM prepared by combustion method & 0.38 \\
\hline LSCM prepared by combustion method+ Co infiltration & 0.62 \\
\hline LSCM prepared by solid state reaction method & 0.42 \\
\hline LSCM prepared by solid state reaction method+ Co infiltration & 0.7 \\
\hline
\end{tabular}

Figure 110 through Figure 112 show the voltage and power density as a function of current density for cells with commercial LSCM and new LSCM (5555) prepared by the combustion and solid oxide reaction methods as the cathode, respectively. Some cathodes were infiltrated with cobalt nitrate as a catalyst. The performance of the cells was summarized in Table 8 . The Maximum Power Density (MPD) at $800^{\circ} \mathrm{C}$ for cells with the commercial cathode, the in-house combustion method cathode and the solid state reaction cathode were $0.3,0.38$ and $0.42 \mathrm{~W} / \mathrm{cm}^{2}$, respectively, which showed the effects of the increase of doping level of $\mathrm{Sr}$ in the A-site on electronic conductivity. The lower performance of cell with the combustion synthesis may be due to the existence of impurities, such as $\mathrm{SrCO}_{3}$ and $\mathrm{Cr}_{2} \mathrm{O}_{3}$ in the perovskite-type oxide powders. With cobalt infiltration, all cells shows significantly improved performance. 


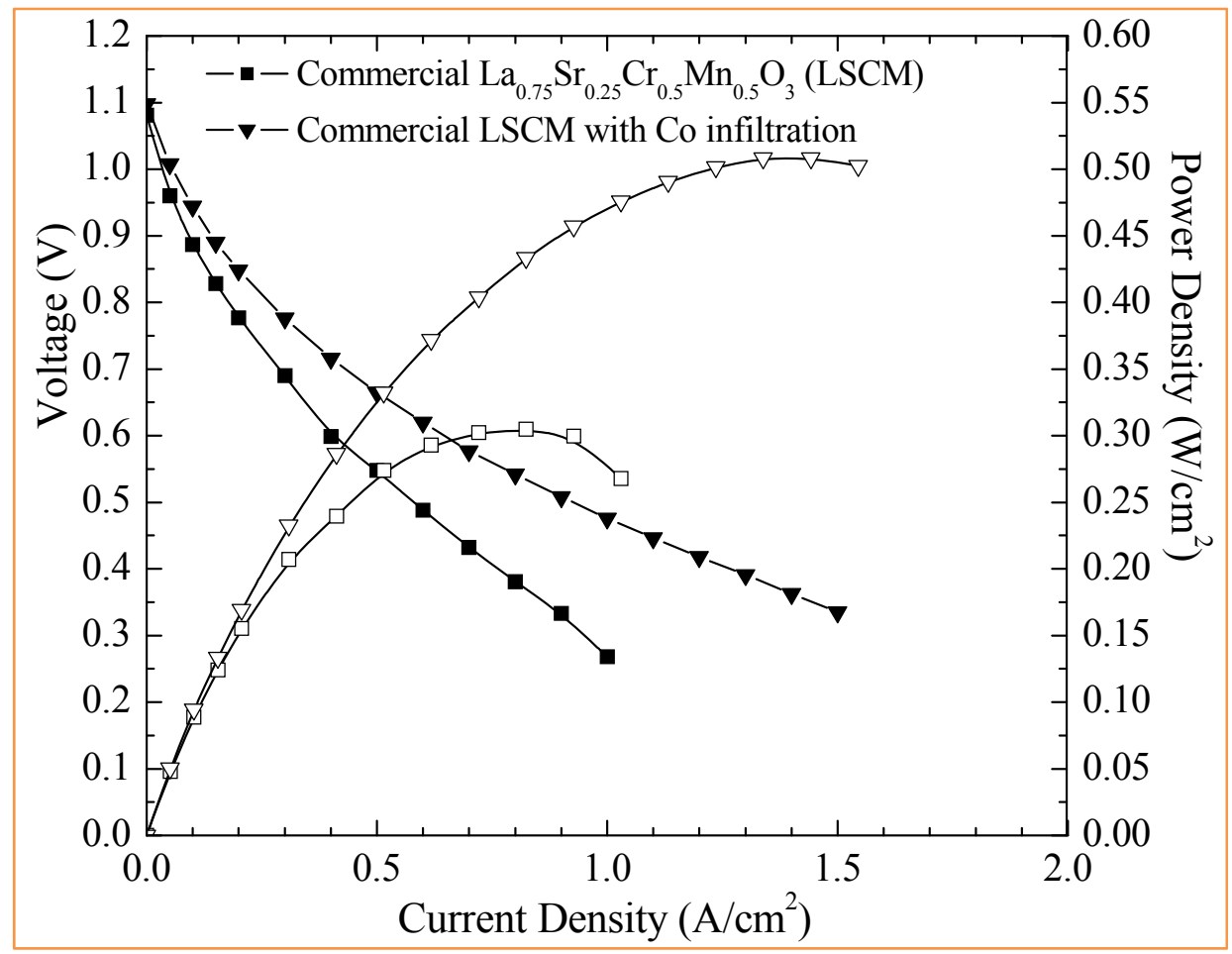

Figure 110. Voltage and power density as a function of current density for a cell with commercial LSCM and with commercial LSCM+cobalt nitrate infiltration as cathode.

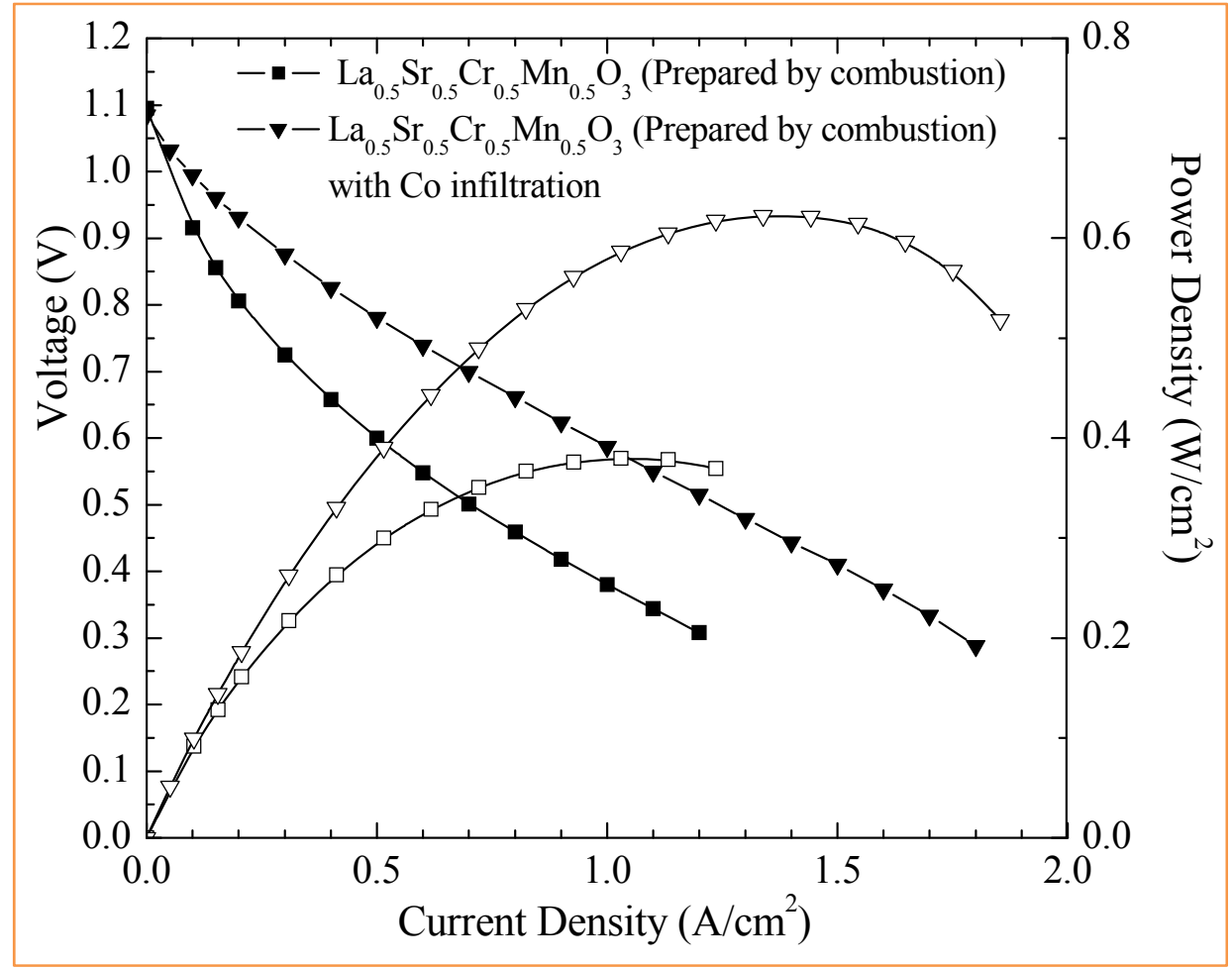

Figure 111. Voltage and power density as a function of current density for a cell with LSCM prepared by combustion method and LSCM prepared by combustion method+cobalt nitrate infiltration as cathode 


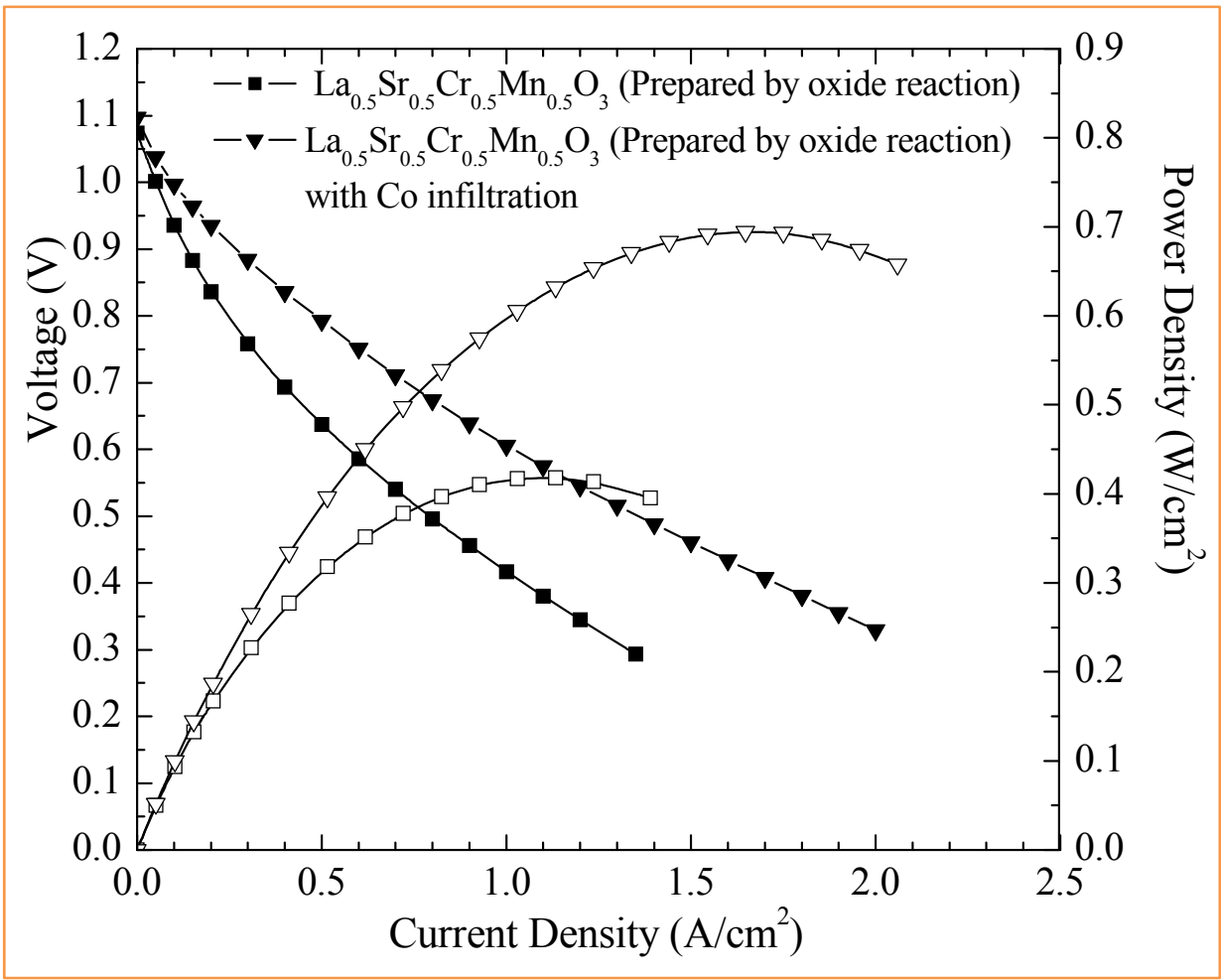

Figure 112. Voltage and power density as a function of current density for a cell with LSCM prepared by oxide reaction method and LSCM prepared by oxide reaction method + cobalt nitrate infiltration as cathode

Cells with the home-made LSCM-5555 cathode were also tested in the SOFEC modes. Figure 113 summarizes cells' typical performance characteristics tested in SOFEC and SOFC modes. In the SOFC mode, wet $\mathrm{H}_{2}$ (3\% steam) was supplied to the anode, and air was supplied to the cathode. In the SOFEC mode, wet $\mathrm{H}_{2}(30 \%$ steam) was fed to the anode, and a mixture of steam (90\%) with $\mathrm{H}_{2}$ as the carry gas was fed to the cathode. A 4-quadrant system was used to present the experimental data obtained in different modes. The first quadrant represented the SOFC mode, which consumed $\mathrm{H}_{2}$ to generate the electricity. The SOFEC mode was located across the first and fourth quadrants where the current flowed in the same direction as the SOFC mode.

As shown in the figure, in the SOFEC mode, the cell with LSCM-5555 co-generates both hydrogen and electricity if the current density is smaller than $0.1 \mathrm{~A} / \mathrm{cm}^{2}$. An external power supply, or negative voltage in the fourth quadrant, was required to increase the hydrogen production rate. The cell with commercial LSCM could only co-generate both hydrogen and electricity as the current density was less than $0.05 \mathrm{~A} / \mathrm{cm}^{2}$. Also at a current density $0.5 \mathrm{~A} / \mathrm{cm}^{2}$, or equivalent to $3.8 \mathrm{cc} / \mathrm{min}-\mathrm{cm}^{2}$ hydrogen production rate, the energy required to electrolyze steam was 0.384 and $0.5 \mathrm{~V}$ for cells with LSCM-5555 and commercial LSCM in the SOFEC mode, respectively. This directly resulted in profound electricity saving by the use of LSCM5555 cathode to generate hydrogen. In the SOFC mode, the cell with LSCM-5555 cathode showed better performance than that with the commercial LSCM, even though a slightly lower performance was observed comparing to the results shown in Figure 112. It was hypothesized that the discrepancy in the two curves was introduced through the use of multiple testing fixtures. 


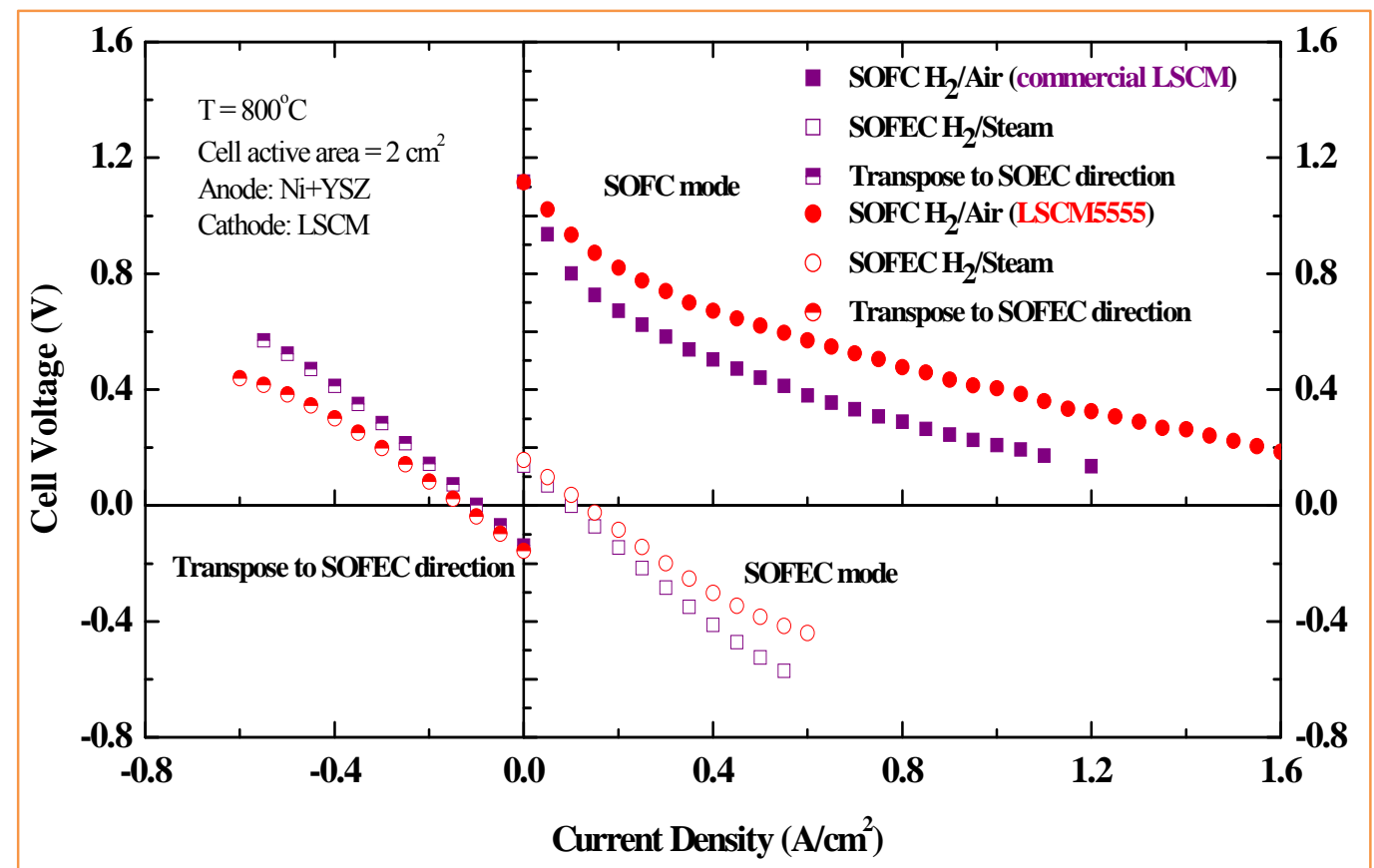

Figure 113. Typical performance characteristics of a button-cell operated in the reversible SOFC and SOFEC modes at $800^{\circ} \mathrm{C}$

Task 6 Design of Hybrid SOFEC-SOFC Stacks and a 5 kW System

Task 6.1 Hybrid stack design

The $5 \mathrm{~kW}$ system consisted of three SOFEC-SOFC composite stacks and three dedicated SOFC stacks for hydrogen production and power generation, respectively. Design and development of the SOFEC-SOFC composite stack and manifolding was successfully completed. The composite/hybrid design was based on MSRI's proprietary proven technology developed for SOFC power modules, but with changes to allow for the coupled SOFC and SOFEC operation. A concept for an internally manifolded cell geometry for the hybrid SOFEC-SOFC stack was developed that provided steam and air to the cathode sides of SOFECs and SOFCs, sepearately, and fuel to the anode sides of both SOFECs and SOFCs simultaneously. Use of an internal gas manifold offered many advantages to externally manifolded systems including ease of fabrication, low cost, and compliant seals to relieve internal stresses.

The operation of SOFEC cells required sealing be improved for above the levels sufficient for SOFC modules; for the SOFEC modules a unique glass seal was substituted for MSRI's tranditional compliant seal. In the case of non-hermetic seals, oxygen from the ambient surrounding can leak in and consume the electrolyzed hydrogen or be pumped across the electrolyte in place of the electrolyzed oxygen, resulting in decrease in hydrogen production. In the internally manifolded design, there was some gas diffusion through the porous anode supports resulting in limited intermixing of the gas streams between manifolds (cross-leaking) or the outside air. It was estimated that these losses could account for couple percent loss in the total system efficiency. It was therefore desirable to seal the edges of the cell anode support and 
the interior edges of the gas manifolds to limit these losses. Increasing the cell border width also reduced gas diffusion.

The need to switch between the fuel-assisted hydrogen production (SOFEC mode) and the electricity production (SOFC) mode introduced further complexity to the design. In the internally manifolded SOFC stack, the air manifolds were integral to the anode support so the region directly surrounding the manifolds was not reduced to nickel metal by the fuel stream. In the SOFC stack this was not a critical problem, since a reasonably stable equilibrium point was established between the two gasses. However, in the composite stack the cathode gases of the cells were switched from air to the steam-hydrogen mixture as the stack mode was changed. This changed the equilibrium point between the oxidizing and reducing atmospheres around the manifold channels, resulting in a destructive phenomenon of redox (reduction and re-oxidation). Similar redox degradation occured at the outer cell border where the edge of the anode support was exposed to air. To prevent redox, the air and steam manifolds were isolated from the anode support and the cell edges were sealed.

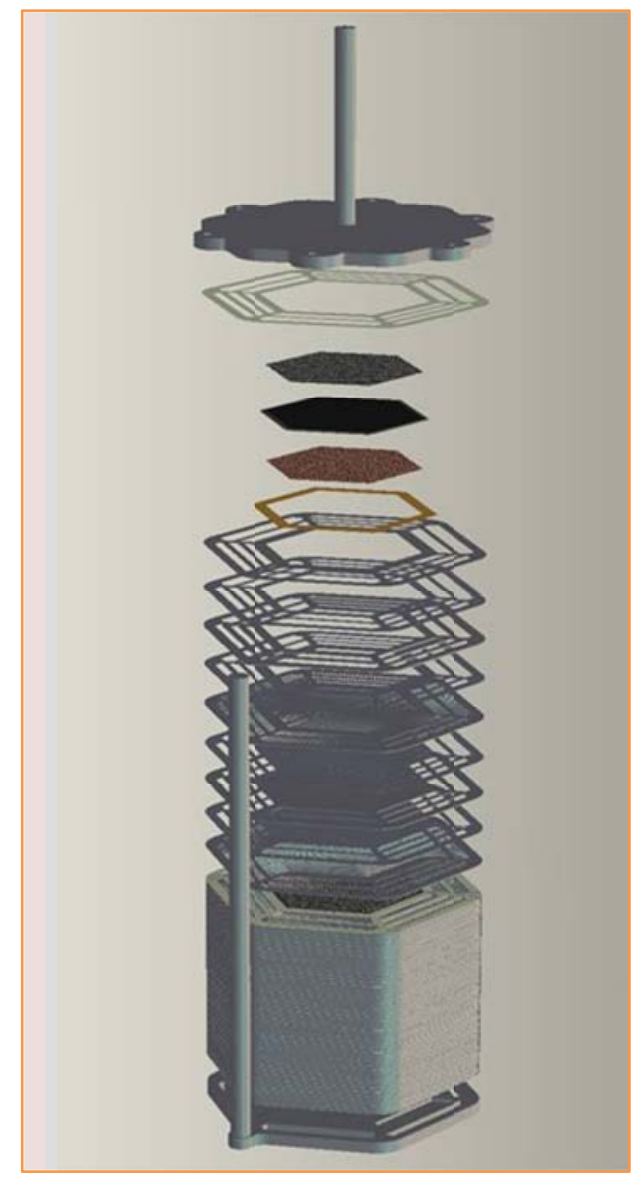

Figure 114. Exploded view of the SOFEC-SOFC hybrid stack design

Thermal management enhancement was also incorporated into the stack designs (for both the SOFEC-SOFC hybrid stack and dedicated SOFC stack). Past stack testing has shown that for a large stack (kW-class stack), there was a need to integrate a heat exchanger with the feed gasses (primarily the cathode air and steam) at an effective means of heat removal from the stacks at 
high currents. To this end, a novel stack geometry was developed that integrated high surface area heat exchangers into the stack and also ensured even flow distribution regardless of stack size. For this design, the standard internal manifold configuration was adapted to have passes for incoming and outgoing flows with ribs to transfer heat from the stack to the manifold gas. Several effects were achieved with this design. Heat was transferred outward from the stack through the interconnect assembly. The metal ribs in the interconnect spacer extended through the manifolds, drawing heat out from the stack and creating a high rate of convective heat transfer. The preheating prevented thermal shocking of the cells at the inlet manifolds of the first cell, while improving the robustness the stack, and eliminating the manifold cracking that was observed in the past. The internal manifolds to the stack were able to provide for a ' $Z$ '-flow pattern while maintaining a simple hot zone structure and ease of assembly and minimizing the stack pressure drop. A rendering of the SOFEC-SOFC hybrid stack is shown in Figure 114.

\section{Task 6.2 Compression hardware/manifold design}

During initial heat up, six stacks must be compressed in order to ensure good electrical contact and sealing as the glass seals crystallize. It was desirable to maintain stack compression during transport and installation to minimize the stresses on the seals and contact points. A spring-plate compression device was used with insulated tension rods and load plates allowing the springs to remain relatively cool while minimizing thermal losses from the stack enclosure. A cutaway view of the compression hardware is shown in Figure 115.

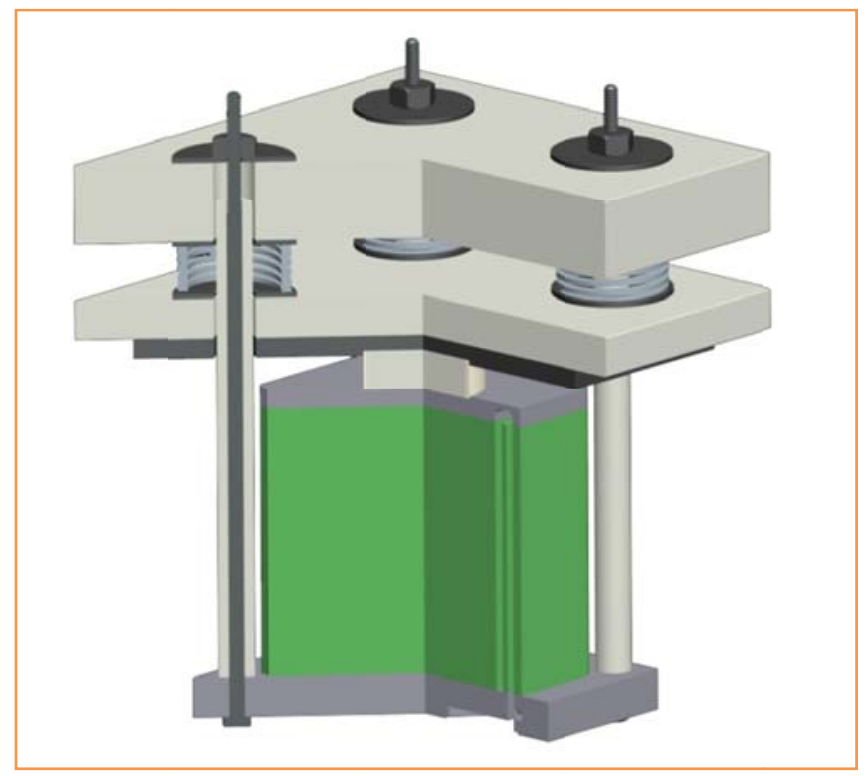

Figure 115. Cutaway view showing the insulated modulated compression hardware for a stack

The individual stack modules were assembled to an electrically insulating support plate that separated the stack hot-zone enclosure from the BOP components. Gas feed pipes, welded to each manifold/compression plate, passed through the support plate and sealed in compression fittings to the BOP piping. Figure 116 shows a rendering of the compression hardware assembly. If necessary to remove an individual stack for maintenance or replacement, it could be done without removing the compression force from the other stack modules. Differential 
shrinkages stack heights, thermal expansions, and loading were also maintained with this modular compression approach. The gap between the insulated plates doubled as the air intake manifold to the cathode blowers, so the springs were kept cool, without any additional heat loss.

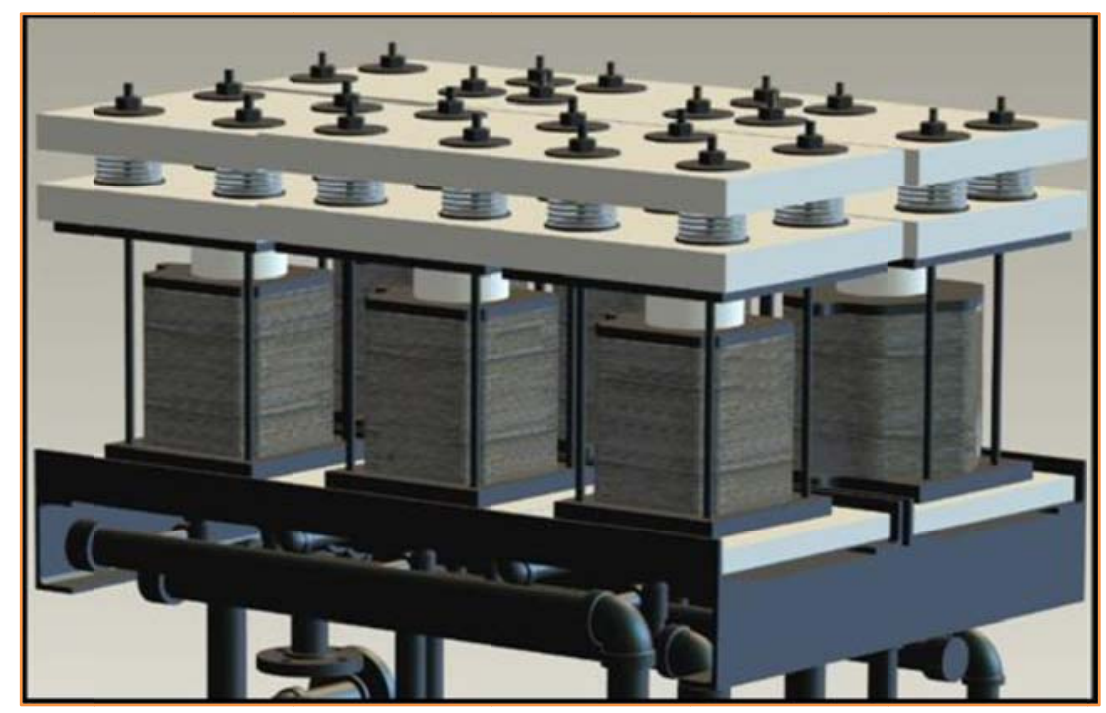

Figure 116. Rendering of the compression hardware assembly

Task 6.3 $5 \mathrm{~kW}$ system design

\section{Task 6.3.1 System configuration design}

The $5 \mathrm{~kW}$ system design was completed successfully. A system analysis was conducted first to determine the most feasible approach for creating a system capable of co-producing $5 \mathrm{~kW}$ of electricity or pure hydrogen from natural gas to meet demands. Three types of systems were under consideration: (A) a series or series-parallel arrangement of hybrid SOFC/SOFCEC stacks containing reversible SOFECs with switchable cathode gas flows, (B) a set of dedicated stacks, either SOFC or SOFEC, with switchable electrical connections, and (C) A set of three hybrid stacks designed for peak hydrogen production under short circuit conditions and three dedicated SOFCs for power production. These alternatives are shown schematically in Figure 117. 


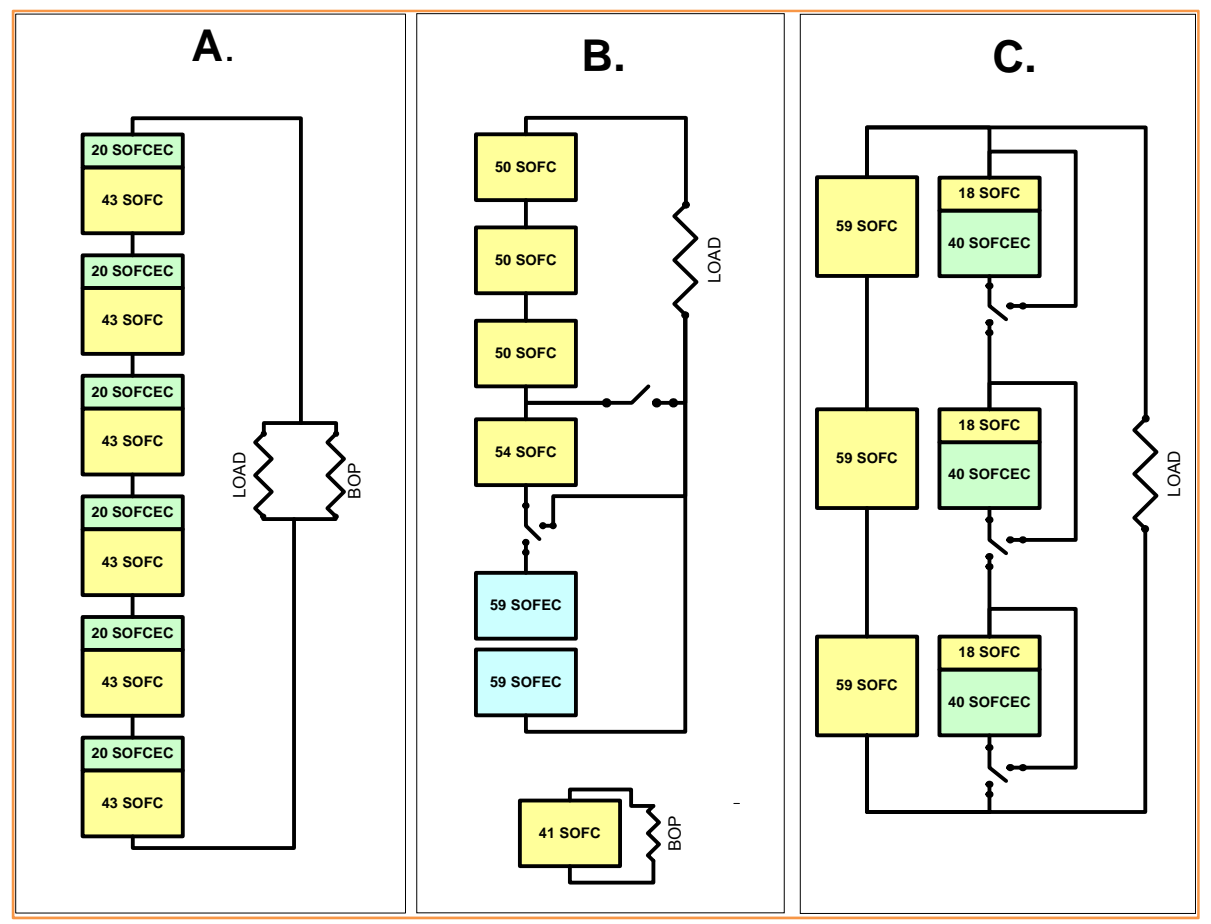

Figure 117. Three alternative system configurations

To compare these systems, a number of assumptions and constraints were applied using stack performance data:

- The per-cell active area was fixed to $100 \mathrm{~cm}^{2}$,

- The open circuit voltage (OCV) was assumed to be $0.95 \mathrm{~V}$ for the SOFCs and $0.10 \mathrm{~V}$ for the SOFECs,

- The BOP power consumption was $1 \mathrm{kWe}$,

- The cell ASR was assumed to be $0.71 \Omega \mathrm{cm}^{2}$ for the dedicated SOFCs and $1.2 \Omega \mathrm{cm}^{2}$ for the reversible SOFECs, in both modes of operation,

- The maximum operating current density was $0.35 \mathrm{~A} / \mathrm{cm}^{2}$ for the dedicated SOFCs, and the maximum operating current density was $0.208 \mathrm{~A} / \mathrm{cm}^{2}$ for the reversible SOFECs operating in SOFC mode,

- The energy density of hydrogen was $120 \mathrm{MJ} / \mathrm{kg}$,

- Natural gas was assumed to be methane with an energy density of $55.7 \mathrm{MJ} / \mathrm{kg}$.

"A" Configuration: For the "A" configuration, the polarization curve of the system was dependent on the switching position, i.e. the number of stacks for which the reversible SOFES were in SOFC mode vs. SOFEC mode. The requirement for electrical power output necessitated a large number of dedicated SOFCs. At the high current levels required for peak hydrogen production, the electrical power output from the system far exceeded that which was required by the BOP systems, so it was necessary to either supply $\sim 4 \mathrm{kWe}$ to an external load during hydrogen production. This was an inherent limitation of this design and was a result of the higher internal resistance of the reversible cells that limited the operating current in electricity 
production mode thereby necessitating a larger number of dedicated SOFCs to meet the electrical generation requirement.

" $B$ " Configuration: The " $\mathrm{B}$ " configuration was an alternative that eliminated the requirement of electrical power discharge during hydrogen production. This system adopted dedicated stacks containing either standard SOFCs (with LSCF cathodes) or SOFECs, but didn't allow for reversible operation of the SOFECs in SOFC mode. This was done for two reasons, first being that the dedicated SOFCs operated much more efficiently and at higher current densities than the reversible SOFECs in SOFC mode, and second because it allowed for full capacity hydrogen production without electrical output. In this system there were 5 dedicated SOFC stacks and two SOFEC stacks. One of the SOFC stacks operated independently to provide power for the BOP systems; one was able to be switched electrically to either drive the SOFECs or to act in combination with the other three SOFC stacks to provide electrical output. As such, the system had two modes of operation depending on the required electrical power output. If the external load drawed less than $3.5 \mathrm{kWe}$, the switchable SOFC stack drove the SOFECs to generate hydrogen at full capacity. The hydrogen produced was compressed into a storage vessel to be released on demand. If the external load drew more than $3.5 \mathrm{kWe}$ (up to $5 \mathrm{kWe}$ ), hydrogen production was suspended and the four SOFC stacks supplied the external load. In the coproduction mode, hydrogen was produced at full capacity ( $5 \mathrm{kWe}$ equivalent) independent of the output electrical current. Although the output characteristics were more flexible for this arrangement, the BOP system became very complicated since it was necessary to regulate gas flows to four sets of stacks independently, so that each operated at a different current density.

" $C$ " Configuration: The " $C$ " configuration combined elements of the " $A$ " and " $B$ " configurations, allowing for independent hydrogen production and for co-production while minimizing the number of separate gas flows and modes of operation. The system consisted of three dedicated SOFC stacks and three hybrid stacks comprising dedicated SOFCs and reversible SOFECs. The hybrid stacks were designed to operate independently under short circuit conditions with the reversible cells in SOFEC mode, driven by the dedicated SOFCs to produce pure hydrogen at the maximum allowable operating current density. The dedicated SOFC stacks powered the BOP systems and supplied electrical power to the external load. As in the "B" configuration, when peak electrical output was required, the production of hydrogen was suspended. During this mode of operation, the reversible cells were operated as SOFCs. The three hybrid stacks were connected in series, and acted in parallel with a series combination of the three dedicated SOFC stacks. In this way, both the dedicated stacks and the hybrid stacks operated at their respective maximum current densities. The two modes of operation were shown schematically in Figure 118. 


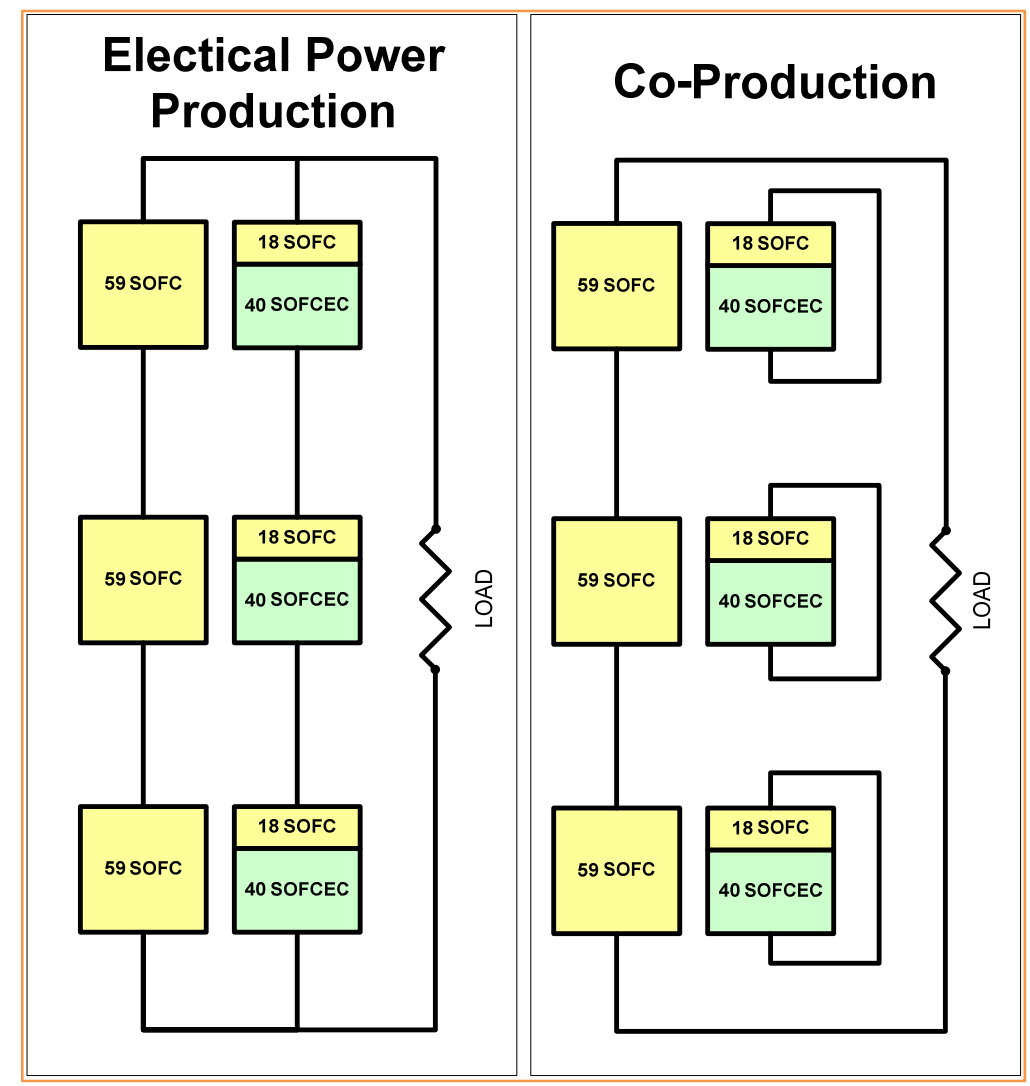

Figure 118. Schematic of the two operation modes for the "C" configuration

In this configuration it was possible to control the rate of hydrogen production by switching the number of stacks that were active, though it was likely that in practice the hydrogen production would be either at full capacity or suspended, and the variable control of hydrogen output was accomplished using an external storage tank.

The three hybrid stacks outputted $5 \mathrm{~kW}$ equivalent of hydrogen at a current density of 0.35 $\mathrm{A} / \mathrm{cm}^{2}$, driven by the dedicated SOFCs. This required 120 SOFECs, or 40-cell per stack. At the operating current density, the SOFEC operating voltage was $-0.32 \mathrm{~V} /$ cell, so the dedicated SOFCs supplied $12.8 \mathrm{~V}$ at $35 \mathrm{~A}$. This needed $18 \mathrm{SOFCs}$ operating at $0.7 \mathrm{~V} / \mathrm{cell}$. When the hybrid stacks were operated in SOFC mode, the maximum current density was limited by the reversible cells to $0.208 \mathrm{~A} / \mathrm{cm}^{2}$. At this current, the voltage across the reversible cells was $0.7 \mathrm{~V}$, and the voltage across the dedicated cells was $0.802 \mathrm{~V}$. Thus, the total voltage across the three hybrid stacks in series was $127.28 \mathrm{~V}$, and the power output from the hybrid stacks was $2.647 \mathrm{kWe}$. The remaining SOFC stacks supplied $3.353 \mathrm{kWe}$ at $127.28 \mathrm{~V}$ or a stack current of $26.34 \mathrm{~A}$. For a $100 \mathrm{~cm}^{2}$ cell, this current corresponded to a cell voltage of $0.762 \mathrm{~V}$, so 167 cells were required, i.e. 56 cells in each stack.

The peak power output of the three dedicated SOFC stacks was $4.11 \mathrm{kWe}$, or $\sim 3.1 \mathrm{kWe}$, net accounting for the parasitic losses in the BOP. Up to this output level, the system was simultaneously producing $5 \mathrm{~kW}$ equivalent of pure hydrogen. Though further gas and electrical switching could be implemented to increase the flexibility in the production rate, in the simplest case, the system had two modes of operation. In the first mode (co-production) the electrical 
output polarization curve was simple that of the three dedicated SOFC stacks in series. In the second mode (max electrical power output) the output was the result of connecting the two sets of stacks in parallel. The polarization curves for the gross electrical output in each mode were plotted in Figure 119.

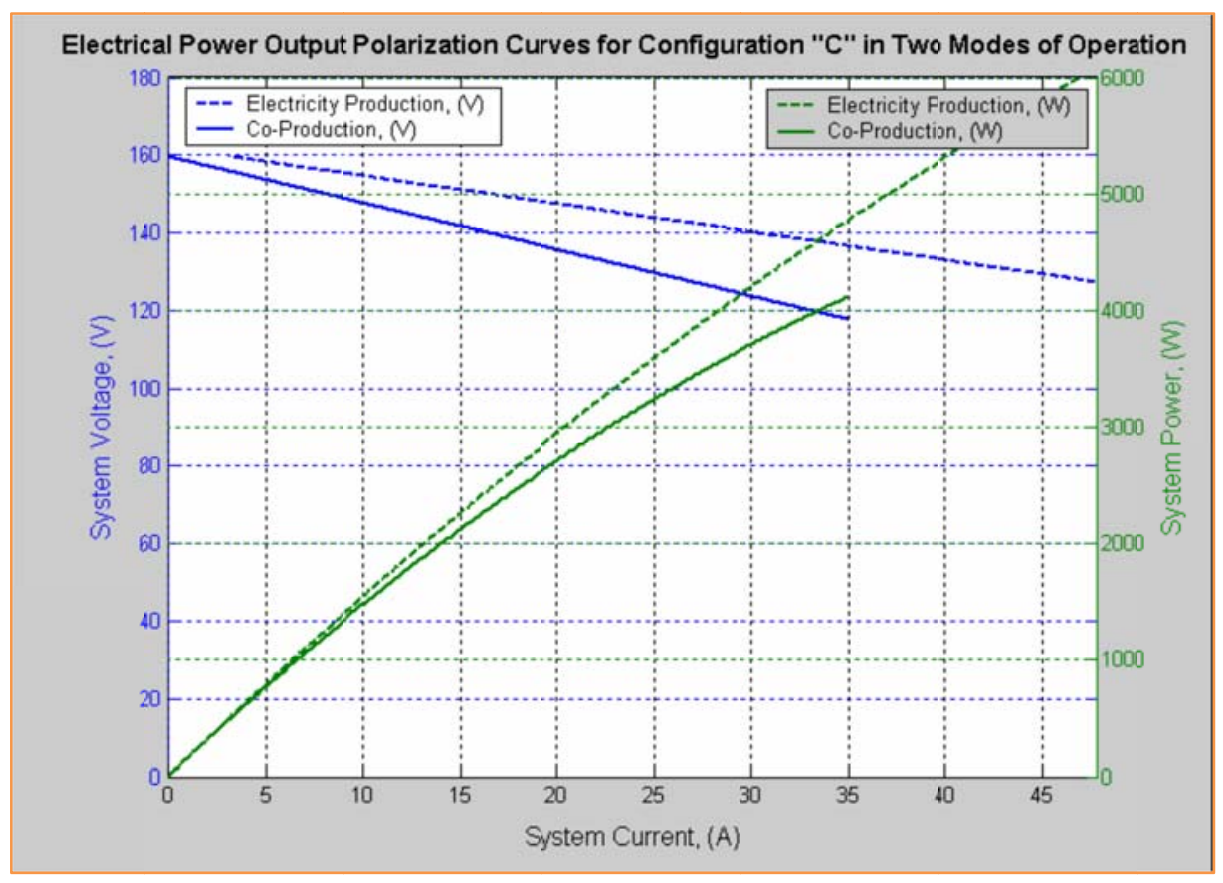

Figure 119. Polarization curves for configuration " $\mathrm{C}$ " in two operation modes

\section{Task 6.3.2 System efficiency evaluation}

The system efficiency was computed based on the measured performance of the hybrid and dedicated SOFC stacks (which will be described in Task 7), and the system operating conditions. The system operated such that the residual fuel in the stack anode exhaust was combusted to provide heat for the balance of plant components such that no excess heat was required during normal operation. As a result, the conversion efficiency of the stack, the product of the electrochemical efficiency of the cell and the fuel utilization, were used for evaluating the system efficiency - excluding additional balance of plant parasitic losses associated with the power consumption of the control systems, air blowers, and power electronics.

In the co-generation mode, the three hybrid stacks generated pure hydrogen with an external stack voltage of $0 \mathrm{~V}$, and the three dedicated SOFC stacks generated power for the BOP systems and an external mode. The system efficiency for the cogeneration mode was a function of the electrical output, the fuel utilization in the hybrid and dedicated stacks, and of the BOP losses. The efficiency was computed based on measured stack performance, specifications for the power consumption of the BOP systems as a function of total flow rate, and the system operating conditions regarding fuel, air, and steam utilization. Under the target conditions there was sufficient heat available and sufficient heat transfer capacity in the process/reformer heaters that no additional heat input was needed. The balance of plant losses were around $400 \mathrm{~W}$ fixed, plus up to $400 \mathrm{~W}$ additional based on the flow of the system, primarily dominated by the cathode air 
blowers. A stack current of just 4 amps in the three dedicated SOFC was sufficient to power the $\mathrm{BOP}$ at the flow rates required for hydrogen production; below that level the system drew power from the onboard batteries, and above that level power was produced. However, since the efficiency of the SOFC decreased at higher power densities, the peak system efficiency occured where the dedicated SOFC produce just enough power for the BOP systems, and the output was just over $5 \mathrm{~kW}$ equivalent of pure hydrogen.

The computed system efficiency was plotted in Figure 120 along with the net electrical power production as a function of dedicated SOFC stack current. For this calculation, $100 \%$ columbic efficiency was assumed, the fuel was assumed to be methane at the $60 \%$ utilization, and the energy content of the methane consumed and hydrogen produced were assessed at the lower heating value of each gas. The results indicated that the system efficiency for hydrogen production was $54 \%$, and that the peak electrical output during co-production was $3.2 \mathrm{~kW}$, for a total power output capacity $\left(\mathrm{H}_{2}+\right.$ electricity) of $8.4 \mathrm{~kW}$.

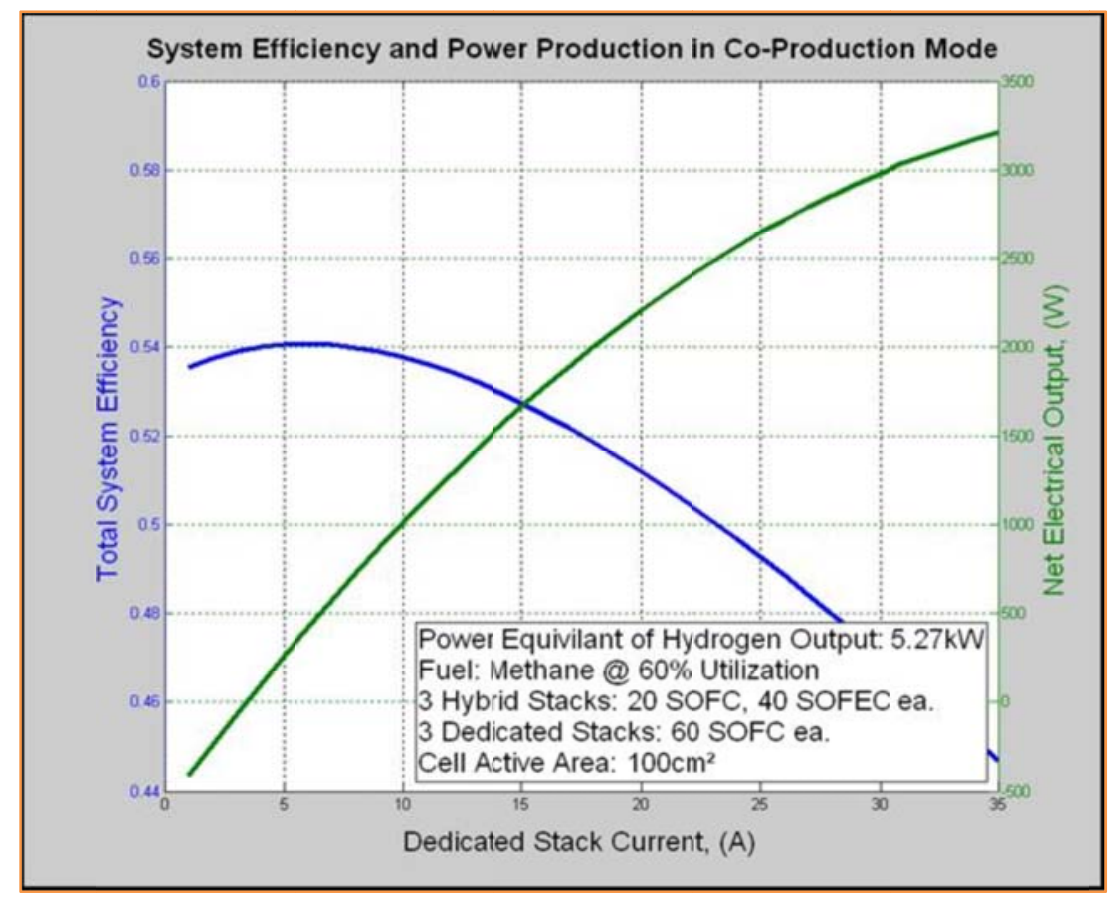

Figure 120. Computed system cogeneration efficiency based on measure hybrid stack performance

\section{Task 6.3.3 $5 \mathrm{~kW}$ system diagram design}

The " $\mathrm{C}$ " configuration offered numerous benefits relative to the " $\mathrm{A}$ " system including the ability to produce hydrogen independent of electrical discharge, the ability to operate dedicated and reversible SOFCs at different current densities to achieve higher operating efficiency, simplified operation with just two switching modes of operation, and a lower operating voltage which improved the safety of the system and reduced the demands on the load following power electronics. The piping and manifolding in the stack hot zone was simplified, but the tradeoff was the increased balance of plant complexity to allow for independent control of the dedicated SOFCs and the hybrid stacks. A system diagram of the "C" configuration showing the major system components were shown in Figure 121. 


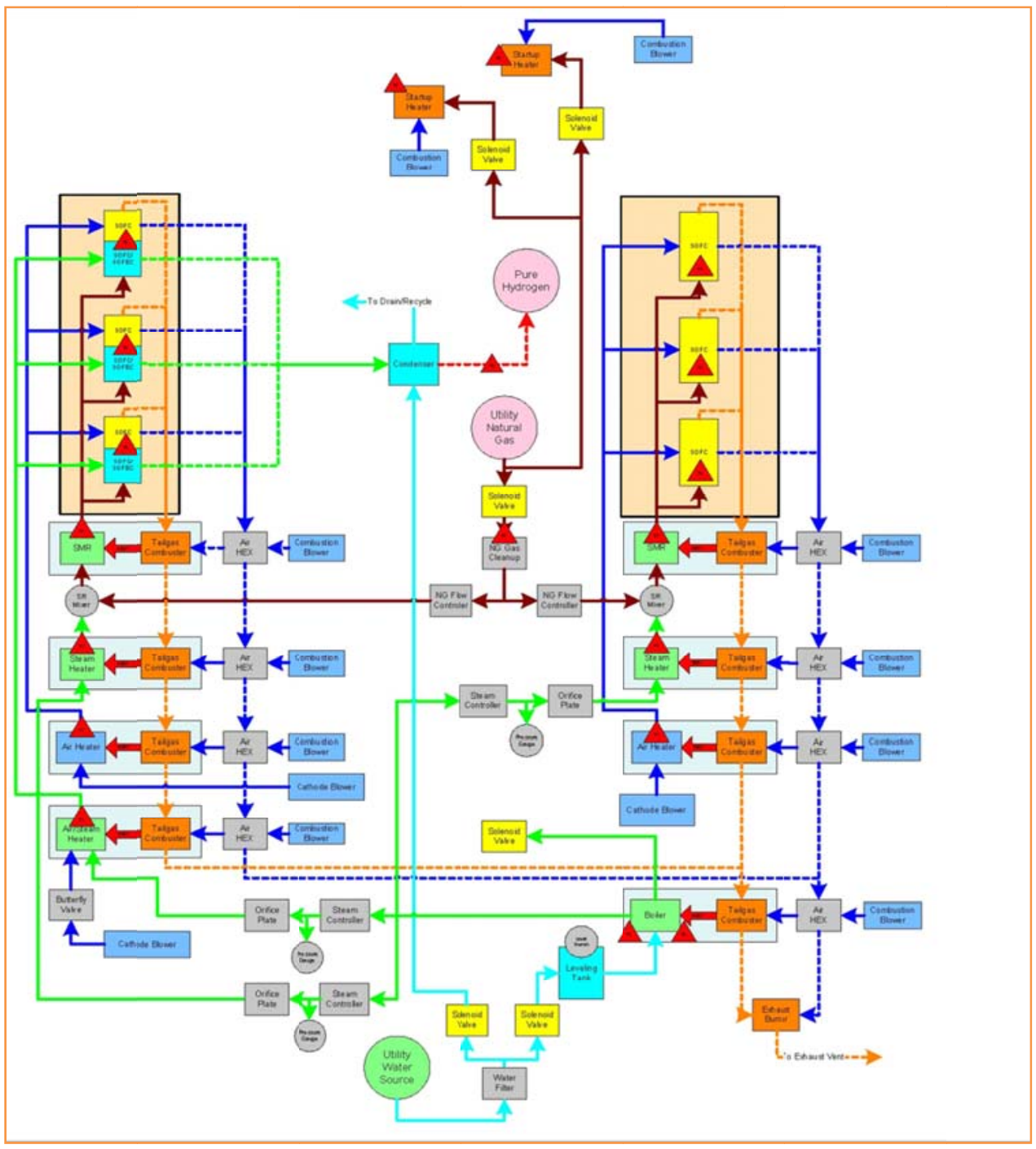

Figure 121. System diagram of the "C" configuration

\section{Task 6.3.4 $5 \mathrm{~kW}$ system integration design}

Figure 122 shows a rendering of the $5 \mathrm{~kW}$ system, with the key subsystems and interfaces identified. The stack hot zone assembly was designed for minimal thermal gradients and heat loss, while providing easy access for installation and inspection of the stack assemblies. As described previously, this system has of 3 hybrid reversible stacks each consisting of 60 repeat units, and 3 dedicated SOFC stacks, containing $~ 60$ internally manifolded frame cells with percell area of $100 \mathrm{~cm}^{2}$. Compression hardware for the stacks was designed such that a constant stack force was maintained throughout thermal cycling, and so that individual stacks were accessible or can be installed without affecting the compressive load on the other stacks, as shown in Figure 116. The hot BOP components are contained in an insulated chamber immediately below the stack manifold plate, allowing for a moderately compact assembly. The system was aslo designed to allow easy access to facilitate maintenance, inspection, and instrumentation to support the design process. 


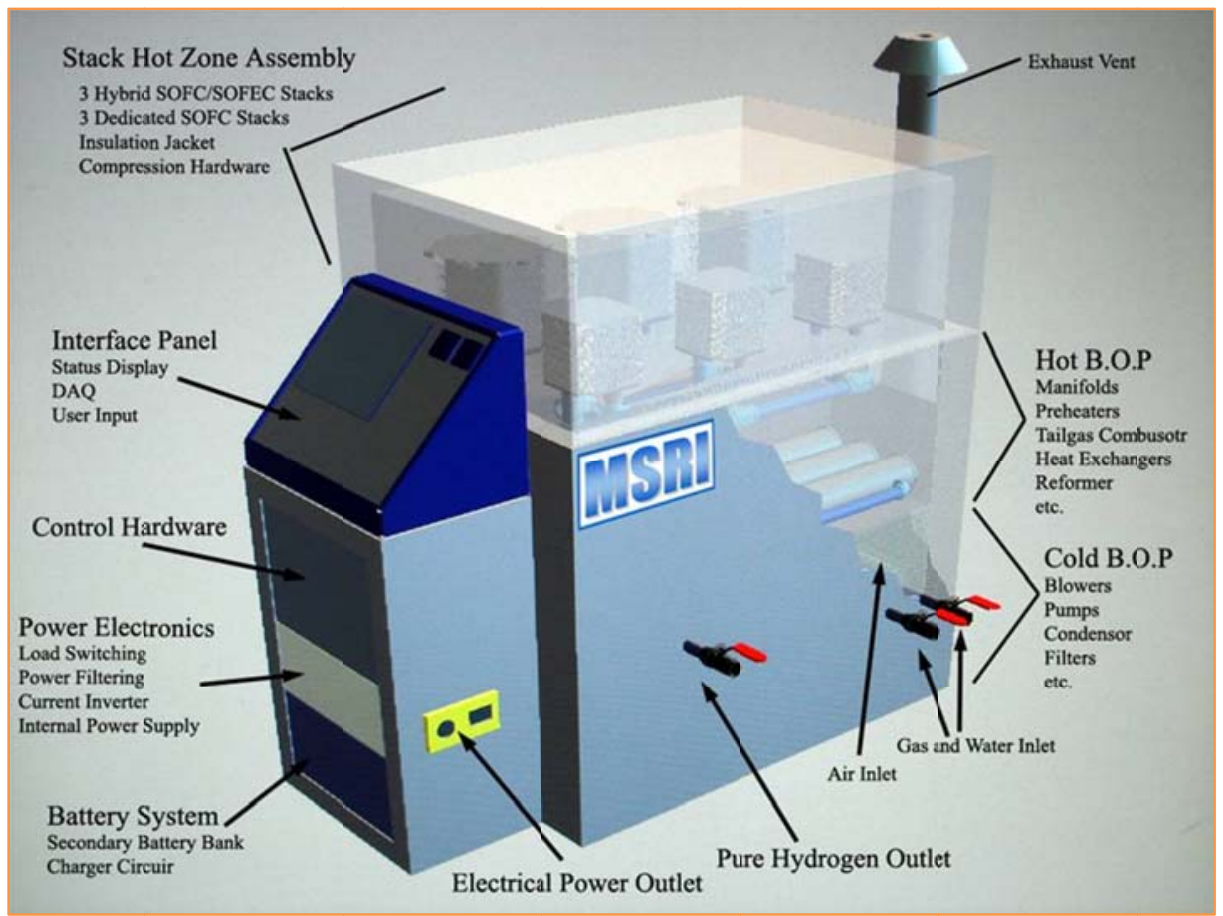

Figure 122. Rendering of the preliminary system configuration showing the major sub-systems, inlet and outlet streams.

The system was designed to produce $5 \mathrm{~kW}$ equivalent of pure hydrogen and/or electricity. Electricity was available in DC form. Hydrogen was high purity and produced at near atmospheric pressure, for delivery to an external storage or delivery system. Tailgas was combusted and vented through an exhaust port $\left(\mathrm{CO}\right.$ and $\mathrm{NO}_{\mathrm{x}}$ were minimal after catalytic combustion). The control interface was a PC-based Labview system, to allow for a great deal of flexibility in the control architecture as well as streamlined data acquisition and system monitoring. Control hardware and power conditioning systems were in an air-cooled housing. The air inlet to the system drew air through this enclosure to provide the necessary cooling, without adding any additional parasitic power drain. A rechargeable battery pack was considered to be included for providing power for the BOP systems during startup, and was charged by available excess power during normal operation, the battery pack was managed by an integrated charge controller from Apollo Solar.

\section{Task 6.4 Balance-of-plant component design}

Except the off-the-shell products (i.e., air blowers, mass flow controller, etc.), key balance-ofplant components were sized for the $5 \mathrm{~kW}$ system requirements, including a tailgas-fired steam generator and tail-gas fired process heaters.

\section{Task 6.4.1 Design of a tailgas-fired steam generator}

Steam was supplied to the two fuel reformers and to the SOFEC cathode from a single tailgasfired steam generator. The near-ambient steam fed high temperature mass flow controllers that 
supply each of the processes allowing for the precise metering and steady flow essential for maintaining a controlled temperature in the steam reformers. There were several commercially available high precision mass flow controllers that were designed to work at temperatures up to $150^{\circ} \mathrm{C}$. These fed into individually controlled super-heaters similar to the air preheater. A cutaway view of the steam generator design is shown in Figure 123; the design consisted of a shell-and-tube configuration with the partially depleted tailgas and combustion air mixing in an inlet manifold, then passing through a perforated screen, over a loosely packed bed of combustion catalyst and passing through an array of 240 tubes before exiting through an exhaust vent. The steam generator was the final thermal BOP component and the combined tailgas flow from the six stacks was approximately 1000 LPM at the operating temperature. The catalyst bed, diffuser screen, and piping were designed to minimize the overall pressure drop, which was less than 2 inches of $\mathrm{H}_{2} \mathrm{O}$ at full capacity. An external feed tank maintained the water level and contained a pressure relief mechanism as a safety measure.

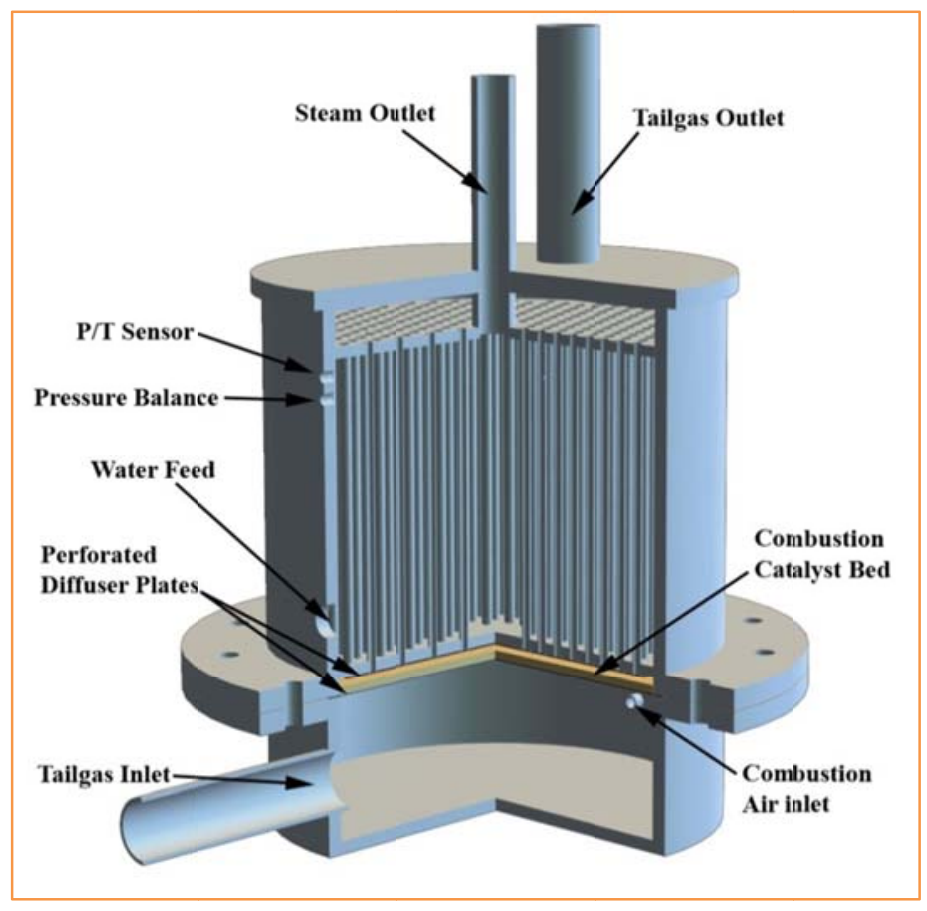

Figure 123. Rendering of the tailgas-fired generator design

Task 6.4.2 Design of a tailgas-fired process gas heater

The tailgas-fired process gas heaters that were used throughout the system were designed for improved manufacturability and to decrease the pressure drop across both the combustion and process chambers. Figure 124 shows a schematic of one of these preheaters. It is essentially a shell-and-tube type heat exchanger structure in which the shell is fed with a partially spent fuel mixture (i.e., stack tailgas) and air was supplied via a perforated diffuser pipe running central to the shell chamber. The process gas flew interior to an array of tubes that were welded a set of header plates. The steam reformer was of a similar design, but with a catalyst housed within the process tubes, accessible from a removable flange at one end of the assembly, and with a mixing chamber for fuel and steam at the inlet to the catalyst bed. 


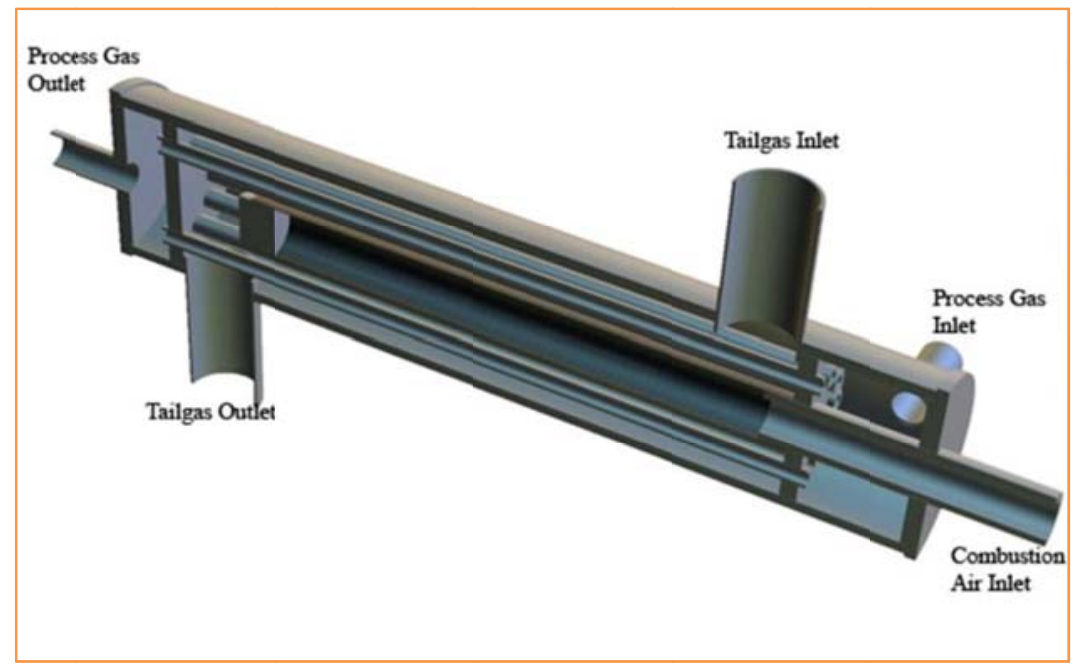

Figure 124. Cut-away view of the design for the tail-gas fired process heaters

\section{Task 6.4.3 Design of a control system}

The control system was built around multi-module C-DAQ (compact data acquisition) hardware commercially available from National Instruments. The system provided multiple analog voltage measurement terminals (many with thermocouple conditioning), digital outputs for the control of SSR's (solid state relays), analog voltage outputs for proportional cathode air and combustor control, and a user interface operating National Instrument's LabView software.

C-DAQ was chosen over other, more traditional instrument interfaces because it had a closer approximation of "real-time" control than GPIB or RS-232 and had a significantly decreased level of integration effort vs. in-house breadboard and analog controls. Via the LabView interface, system components could be constantly monitored and quickly adjusted to meet variable hydrogen and power production demands or to compensate in the event of a component failure or degradation during testing.

Task 7 Proof-of-concept Demonstration of the SOFEC-SOFC Hybrid Co-generating $\mathrm{H}_{2}$ and Electricity in Short Stacks of Anode-support Cells

\section{Task 7.1 SOFEC concept validation on 10-cell stacks}

In order to demonstrate hydrogen generation using the fuel-assisted electrolyzer technology, short stacks of 10 cells per stack were built and evaluated in the reversible SOFC/SOFEC modes. Cells, each having per-cell active areas of $100 \mathrm{~cm}^{2}$, were made from the optimum anode substrate and YSZ electrolyte. The cell fabrication process and equipment used to deposit the optimum LSCM+SDC-based cathode interlayer and cathode layer onto the larger cells were identical to those used for the button cells. The cobalt catalyst, which demonstrated the best catalytic characteristics over other catalysts, was used. Figure 125 is a photograph of a typical 10 -cell stack assembly ready for testing. Voltage leads were attached to each individual cell for 
recording cell voltages. The stacks were tested first in the SOFC mode as a baseline for power generation, followed by operation in the SOFEC mode for hydrogen production. During testing, polarization and power density data were recorded for a range of stack current densities. In addition, a current interruption technique was used to determine the ohmic contribution to the total stack overpotential.

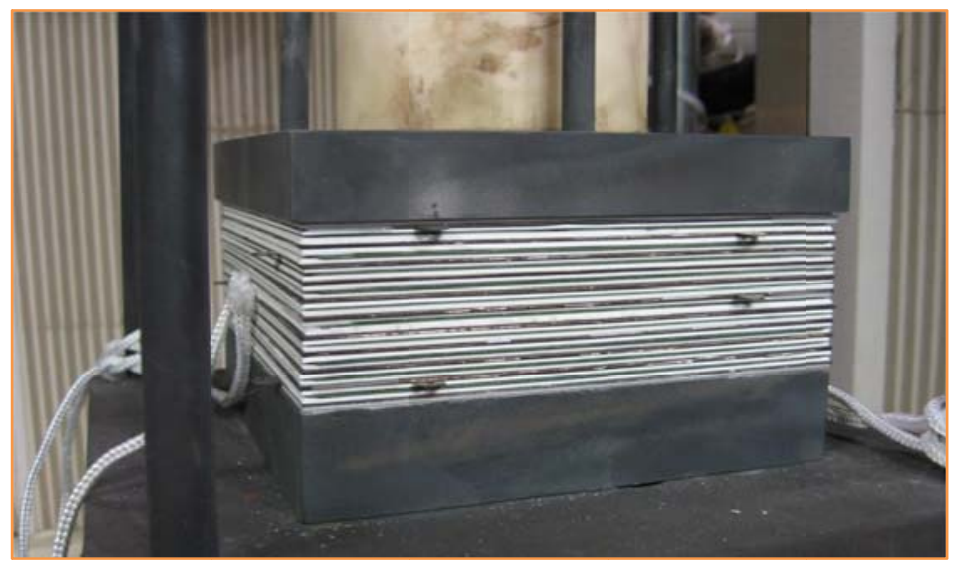

Figure 125. A photograph of a 10-cell stack assembly ready for testing. Each cell had $100 \mathrm{~cm}^{2}$ active area and attached with a voltage lead,

Figure 126 shows the 10-cell stack performance characteristics in the power generation mode. Wet syngas with $30 \%$ steam was used as the fuel and air was the oxidant. Both the fuel and oxidant utilizations were fixed at $40 \%$. The furnace temperature was set to $770^{\circ} \mathrm{C}$. At $30 \mathrm{~A}$, this stack generated 186 watts electricity.

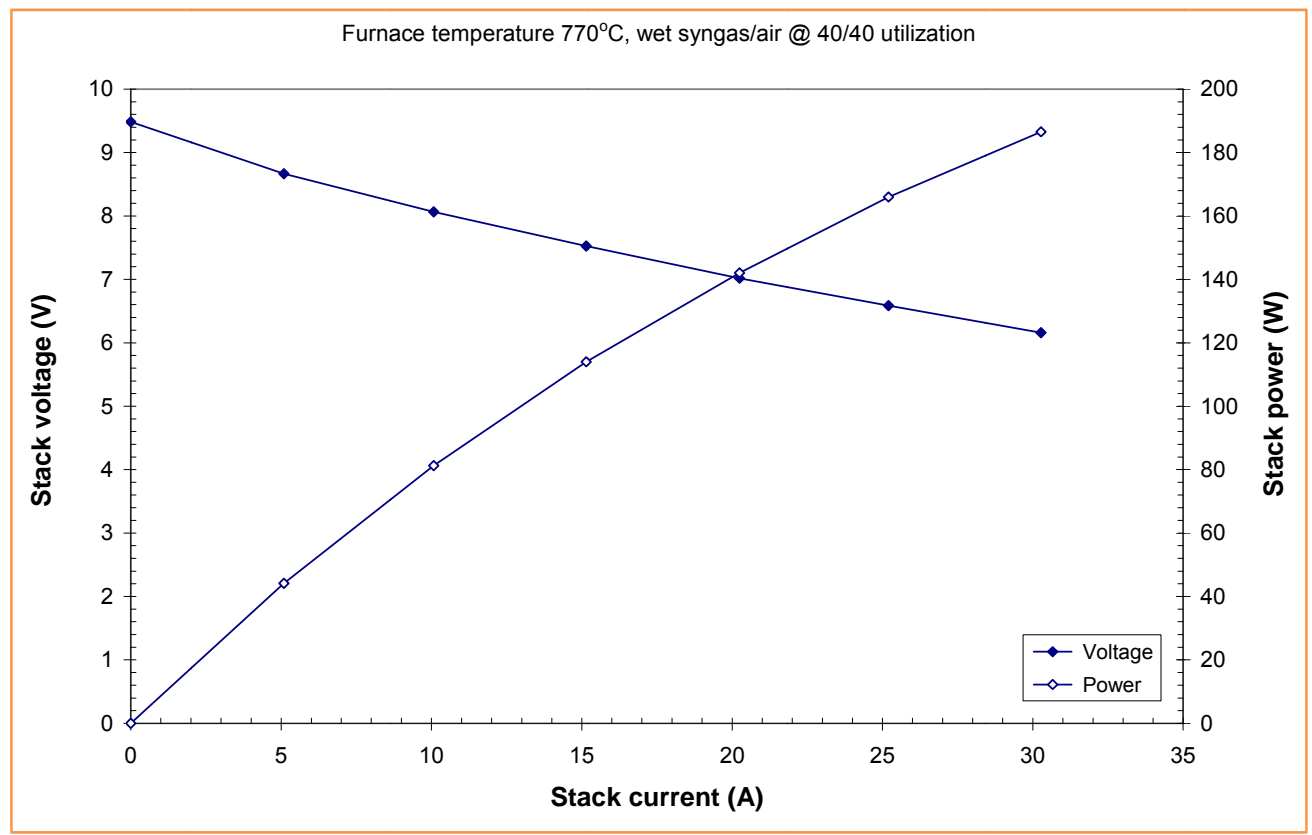

Figure 126. Performance characteristics of a 10-cell stack tested in SOFC mode as the baseline. Per-cell active area was $100 \mathrm{~cm}^{2}$. The furnace temperature was set at $770^{\circ} \mathrm{C}$. Wet Syngas (with $30 \%$ steam) was used as the fuel and air was the oxidant. Both the fuel and oxidant utilizations were fixed at $40 \%$. 
Following the SOFC baseline test, the same stack was tested in SOFEC mode with a fuel assisted at the anode. Figure 127 shows the stack performance of hydrogen generation from steam. The same syngas fuel used in the baseline test was fed to the anode, and steam was fed to the cathode. Both the fuel and steam utilizations were fixed at $40 \%$. OCVs were positive because of the high partial pressur of oxygen on the cathode. At $5 \mathrm{~A}$, the stack was under the self-driven mode for co-generating hydrogen and electricity. No external electrical power was needed to drive the steam electrolysis process. As the stack current increased, external power was applied to drive the electrolysis to a higher level of hydrogen production. As shown in the figure, at 30 A (or equivalent to 137 liters of hydrogen per hour), the net power required was just 59 Watts. Compared to the traditional solid oxide electrolysis cell (SOEC) technology without fuel assist, the SOFEC technology saved significant electrical power for the same hydrogen production rate.

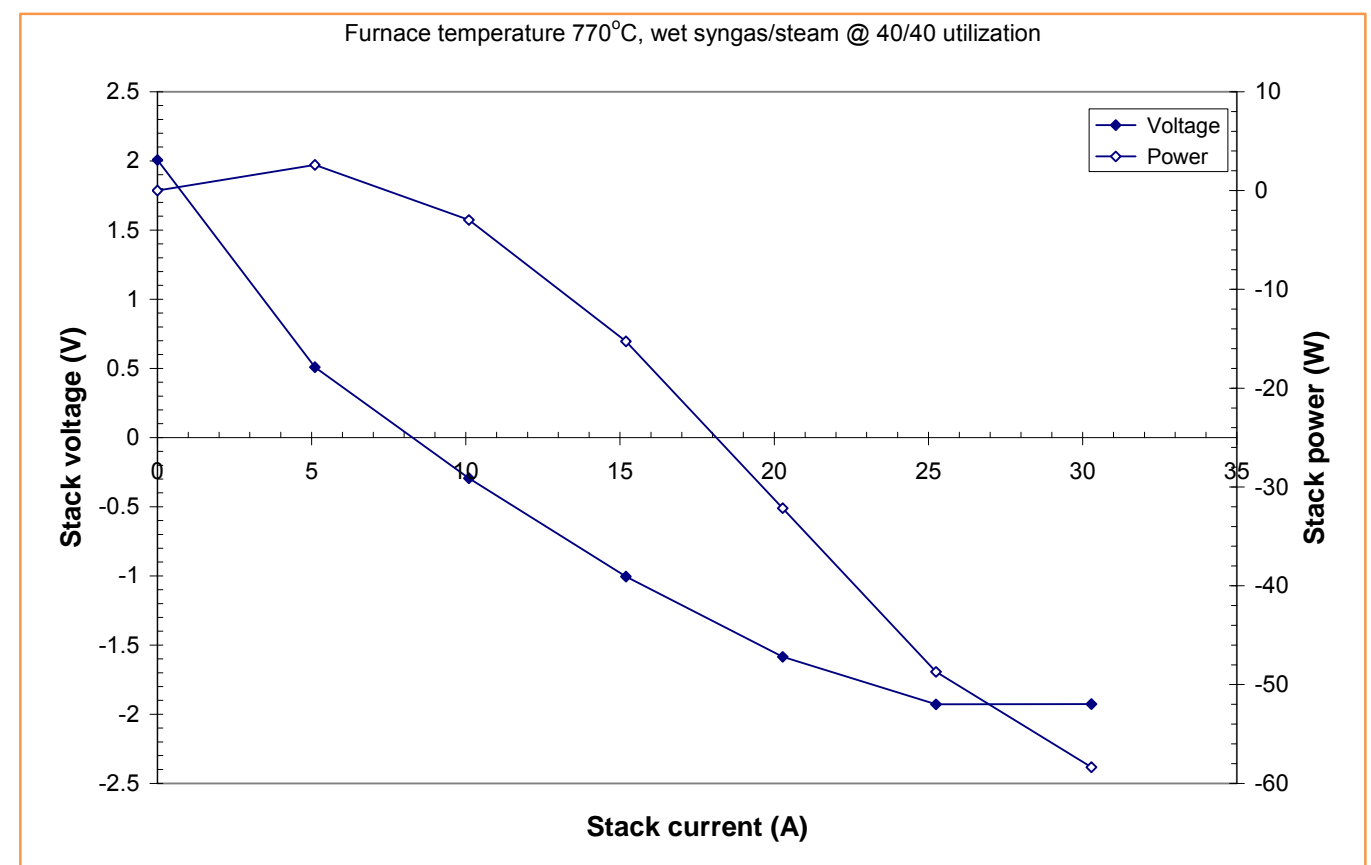

Figure 127. Performance characteristics of a 10-cell stack operated in the SOFEC mode for hydrogen production. Per-cell active area was $100 \mathrm{~cm}^{2}$. The furnace temperature was set at $770^{\circ} \mathrm{C}$. Wet Syngas (with $30 \%$ steam) was used as the fuel and steam was used as the oxidant. Both the fuel and steam utilizations were fixed at $40 \%$.

The effect of thermal cycling on the stack performance was examined on this 10-cell stack. Each cycle ranged from room temperature to a working temperature then back to room temperature. During each thermal cycle, the stack was tested in SOFC mode first and then in SOFEC mode. Figure 128 shows the effect of thermal cycling on the stack performance. At $30 \mathrm{~A}$, the voltage of the 10 -cell stack decreased by $8 \%$ in SOFC mode and $15 \%$ in SOFEC mode after four thermal cycles. V-I curves vs. thermal cycles were also plotted in Figure 129 in detail. 


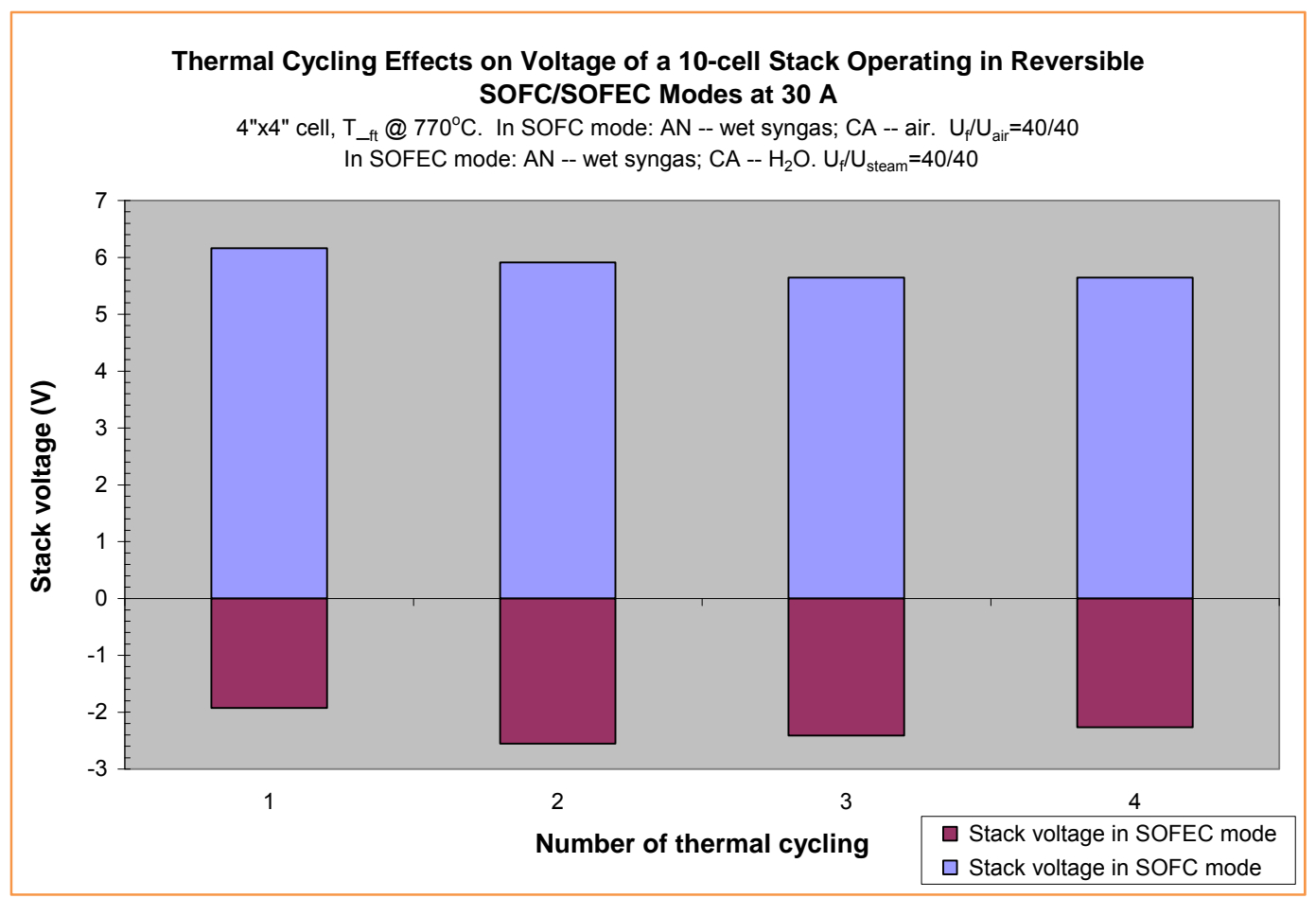

Figure 128. Thermal cycling effects on the stack performance. The temperature was cycled from the room temperature to $770^{\circ} \mathrm{C}$ and then back to the room temperature. The fuel was wet syngas, and the oxidant was either air in SOFC mode or steam in SOFEC mode.

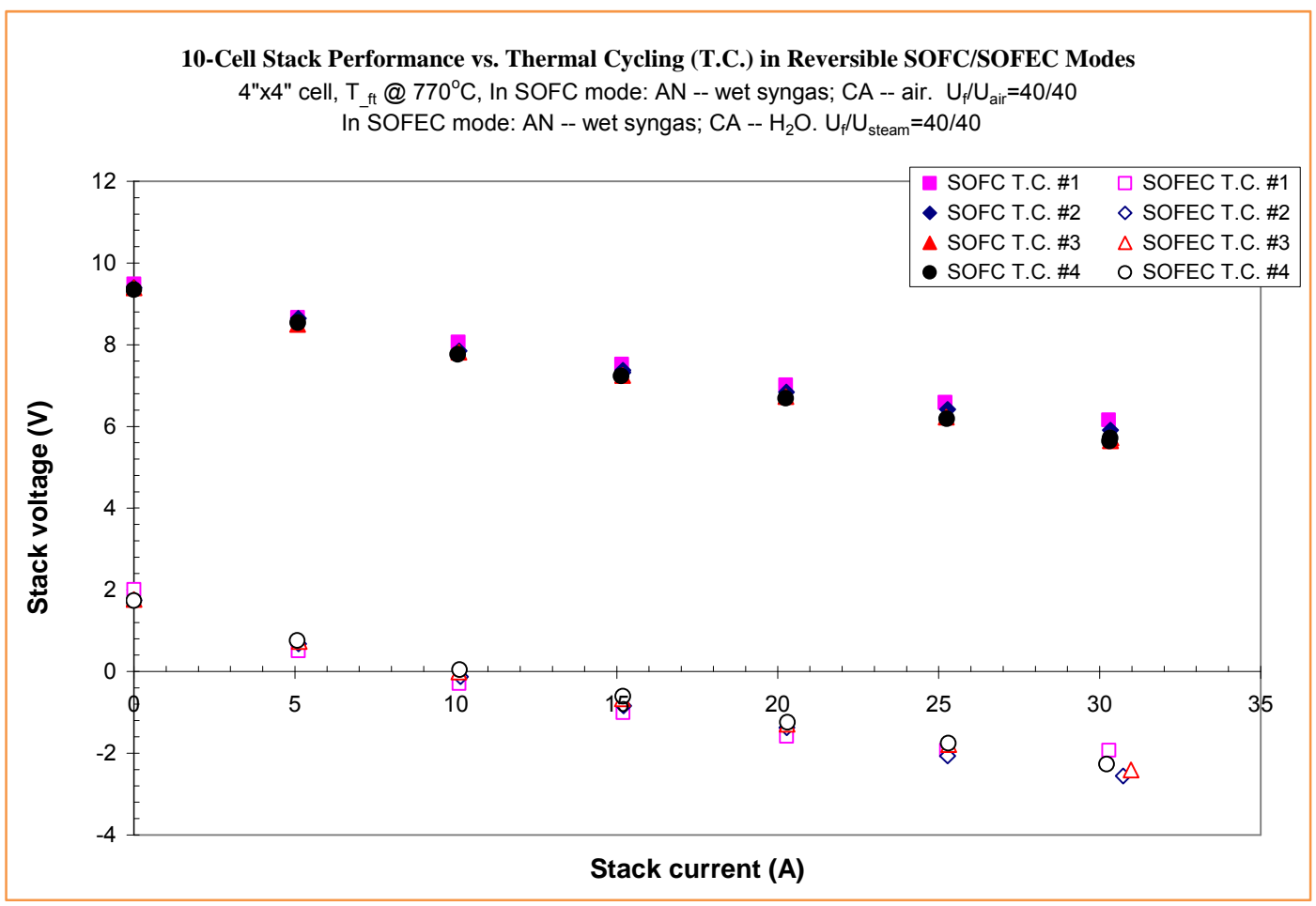

Figure 129. 10-cell stack performance vs. number of thermal cycle tested in the reversible SOFC/SOFEC modes. The temperature was cycled from room temperature to $770^{\circ} \mathrm{C}$ and then back to room temperature. The fuel was wet syngas, and the oxidant was either air in SOFC mode or steam in SOFEC mode. 
Task 7.2 Proof-of-concept demonstration of SOFEC-SOFC hybrid co-generating $\mathrm{H}_{2}$ and electricity

The concept of hydrogen and power cogeneration using the SOFEC-SOFC hybrid technology was demonstrated on composite stacks, providing data for the design and construction of the 5 $\mathrm{kW}$ cogeneration system. Each hybrid stack had 10 cells, six SOFECs and four SOFCs for hydrogen and power generation, respectively. The SOFCs were screen-printed with LSCF+SDC based cathode, and the SOFECs were screen-printed with LSCM+SDC based cathode. All cells were anode-supported with $100 \mathrm{~cm}^{2}$ per-cell active area. A glass seal was applied to the interfaces of the stack. The thickness of glass gaskets were adjusted to match contact aids thickness on both the anode and the cathode ensuring good electrical contacts. Similar to the stack tests described in Task 7.1, all hybrid stacks were evaluated in the SOFC mode first as a baseline for power generation, followed by operation in the hybrid mode (SOFEC-SOFC) for the cogeneration. During testing, polarization and power density data were recorded for a range of stack current densities. Hybrid stacks were tested over relatively long operating times, with the goal being the demonstration of stable, self-sustaining hydrogen and electricity co-production.

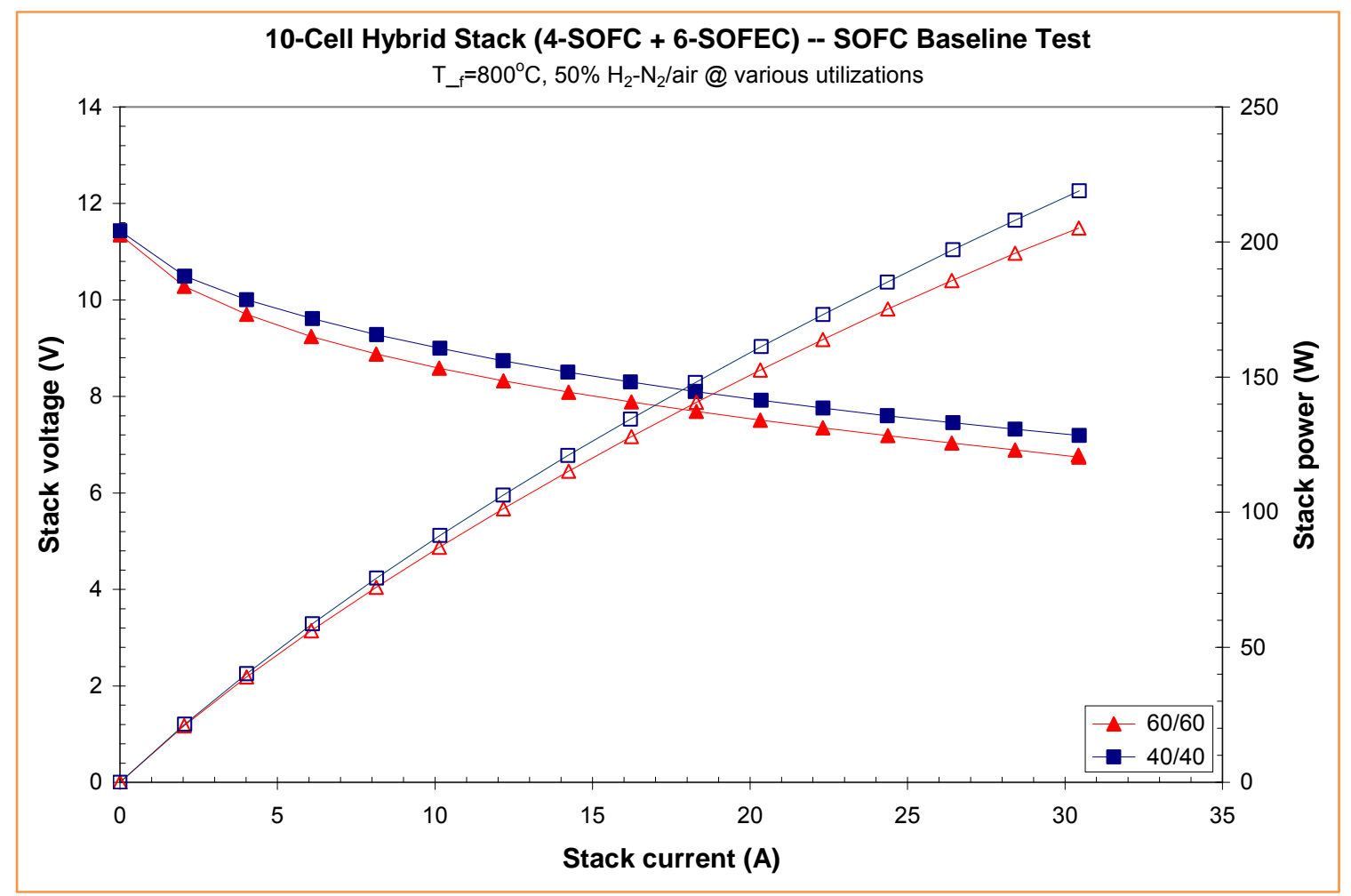

Figure 130. Performance characteristics of a 10-cell stack (4-SOFC +6-SOFEC) tested in SOFC mode as the baseline. The furnace temperature was set at $800^{\circ} \mathrm{C}$. Diluted hydrogen with $50 \% \mathrm{~N}_{2}$ was used as the fuel and air was the oxidant. Both the fuel and oxidant utilizations were increased from $40 \%$ to $60 \%$.

Figure 130 shows 10-cell stack performance characteristics in SOFC mode. Diluted hydrogen with $50 \% \mathrm{~N}_{2}$ was used as the fuel and air was the oxidant. Both the fuel and air utilizations were varied from $40 \%$ to $60 \%$. The furnace temperature was set to $800^{\circ} \mathrm{C}$. At $30 \mathrm{~A}$, this stack 
generated 220 and 205 watts power at 40\%/40\% (40/40) and 60\%/60\% (60/60) utilizations, respectively, showing a merely $7 \%$ performance drop when the fuel/air utilization increased from $40 \%$ to $60 \%$, thanks to the cell optimization performed under Task 2 .

Following the SOFC baseline tests, the same stack was tested in hybrid mode to co-generate hydrogen and electricity (complete with a fuel assist on the anode of the SOFECs). Figure 131 shows stack performance when diluted $\mathrm{H}_{2}$ bal. $50 \% \mathrm{~N}_{2}$ was used as the fuel on the anodes of the stack. The furnace temperature was set at $800^{\circ} \mathrm{C}$. It was observed that at the fixed fuel/air/steam utilizations at 60/60/40, at $30 \mathrm{~A}$, four SOFCs generated $\sim 90$ watts power, among of 20 watts was consumed by the six SOFECs to produce 80 liters of hydrogen per hour, and 70 watts net power output. The effect of the steam utilization on the performance was also evaluated by increasing its utilization from $40 \%$ to $60 \%$, while keeping the fuel and air utilizations unchanged at $60 \%$. As shown in the plot, beyond the 20 watts, extra 6 watts were consumed by the six SOFECs to producing the same amount of hydrogen, resulting in a slight loss of power output. The net power output was $\sim 64$ watts.

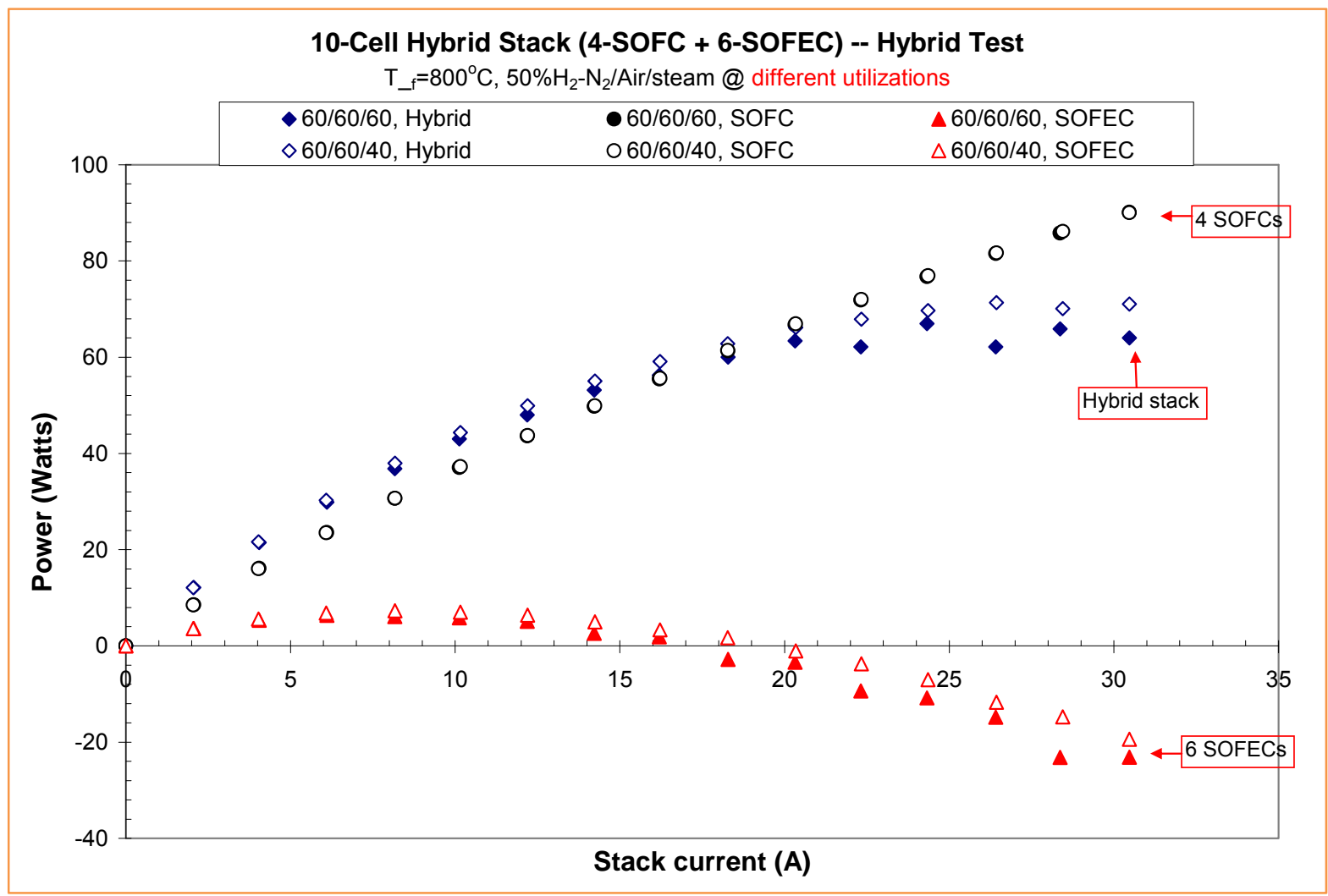

Figure 131. Performance characteristics of a 10-cell stack operated in the hybrid mode for hydrogen and electricity co-generation. The furnace temperature was set at $800^{\circ} \mathrm{C}$. Diluted hydrogen with $50 \% \mathrm{~N}_{2}$ was used as the fuel on the anodes of both 4-SOFC and 6-SOFEC. Air and steam were on the cathodes of the 4-SOFC and 6-SOFEC, respectively. Both the fuel and air utilizations were fixed at $60 \%$, while steam utilization changed from $40 \%$ to $60 \%$.

Syngas fuel was used to replace the diluted hydrogen fuel on the anodes of the hybrid for cogeneration of hydrogen and power. The performance comparisons of using these two types of 
fuels are shown in Figure 132. The performances of the two were almost identical under the same operating conditions.

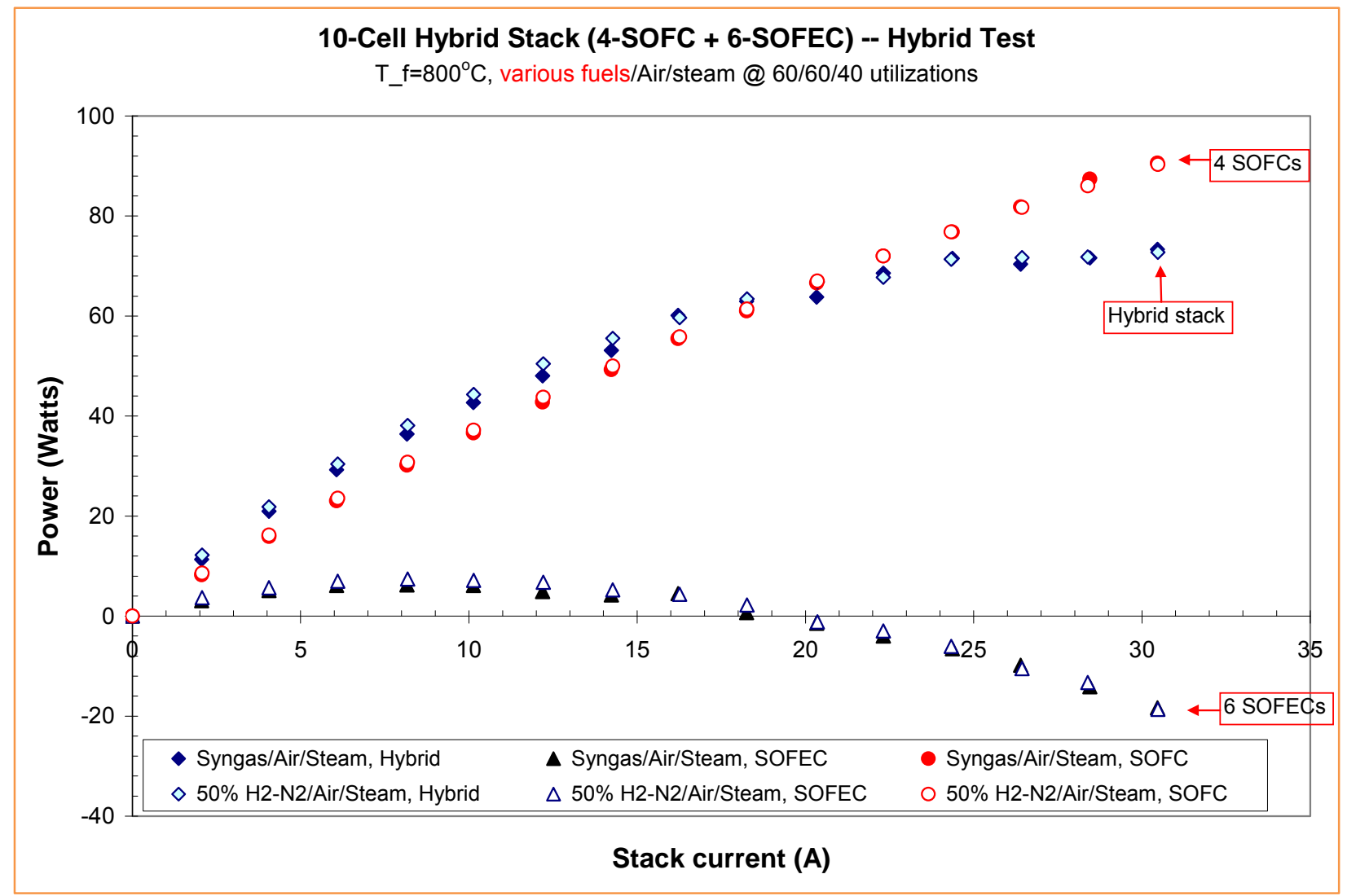

Figure 132. Performance comparisons of the 10-cell hybrid stack using two types of fuels: hydrogen diluted with $50 \% \mathrm{~N}_{2}$ and syngas. Under the both cases, the utilizations of the fuel, air and steam were fixed at $60 \%, 60 \%$ and $40 \%$, respectively. The furnace temperature was set at $800^{\circ} \mathrm{C}$.

A continuous test for the co-generation of hydrogen and electricity was set up and performed using the syngas as the fuel. As shown in Figure 133, over the 48 hours continuous test the hybrid demonstrated a very stable performance. The test was terminated due to the failure of a water pump during a weekend steady state discharge, causing coking issues. Figure 134 shows the voltage characteristics of each individual cell over the 48 hours continuous test. At $30 \mathrm{~A}$, the average cell voltage was about $0.73 \mathrm{~V}$ and $-0.15 \mathrm{~V}$ for the SOFC and SOFEC, respectively. No severe degradation was observed during the test. 


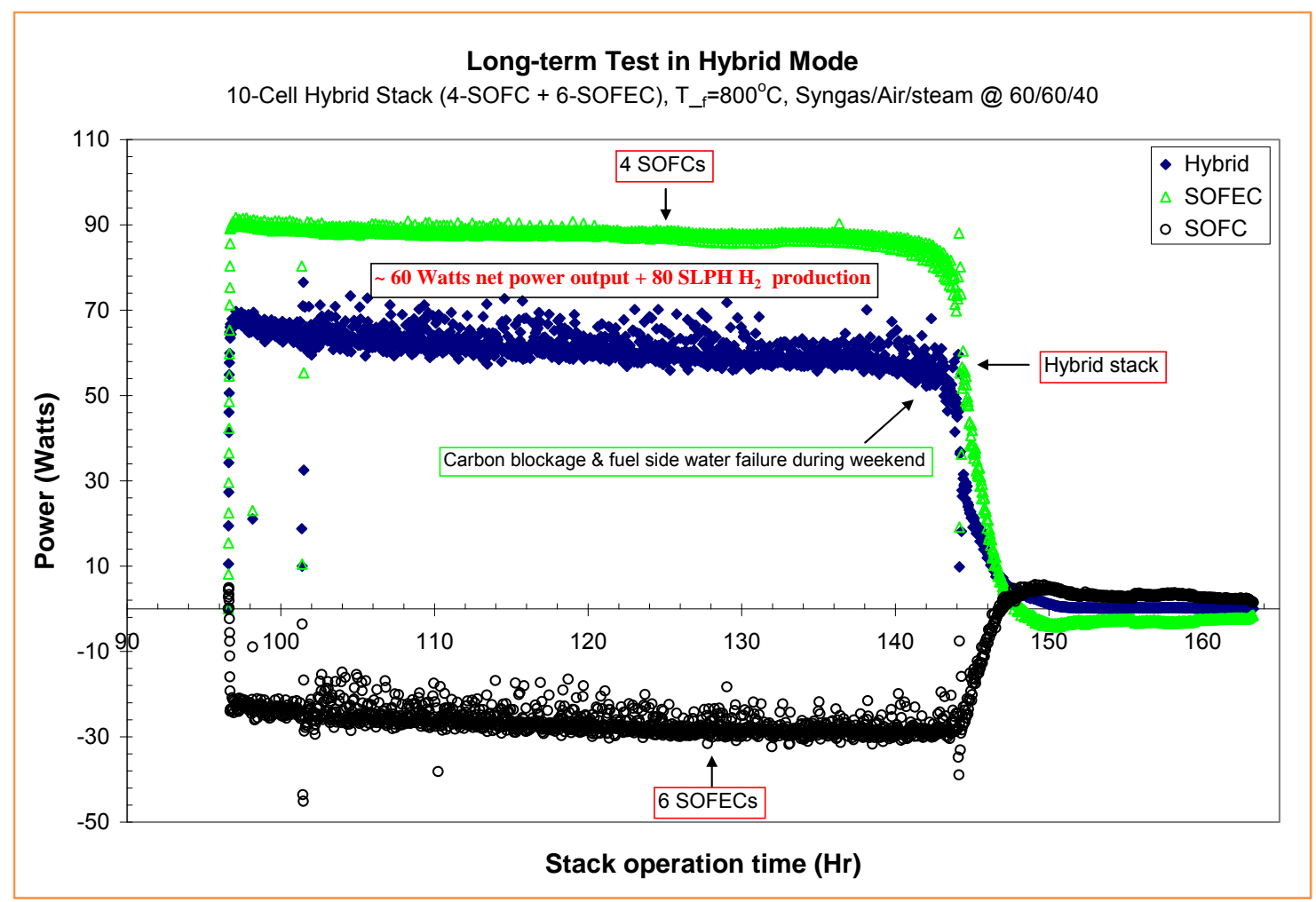

Figure 133. Continuous co-generation of hydrogen and electricity. Utilizations of syngas, air, and steam were fixed at $60 \%, 60 \%, 40 \%$, respectively. The furnace temperature was set at $800^{\circ} \mathrm{C}$.

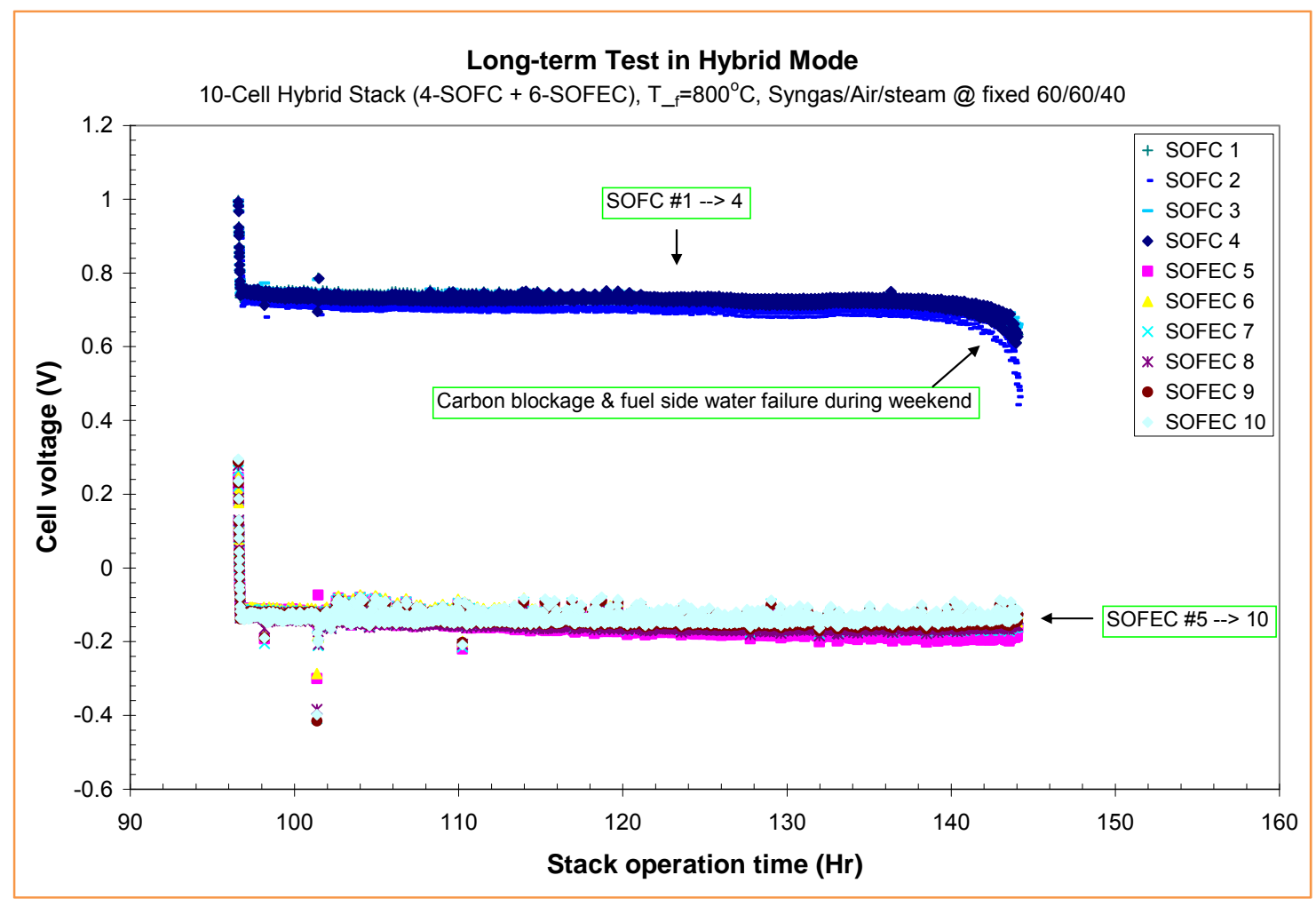

Figure 134. Voltage characteristics of each cell over the 48 hours continuous test. 
Task 7.3 SOFEC-SOFC hybrid stack performance characteristics under electrically selfsustaining operating condition

One of the desirable features of cogenerating hydrogen and electricity using a SOFEC-SOFC hybrid module is that the hybride stack is capable of operating in an electrically self-sustaining mode without any external power supply. The SOFEC-SOFC hybrid stacks were tested in short circuit conditions (zero power output/input) to prove this concept. Figure 135 shows the voltage characteristics of an 8-cell composite stack composed of three SOFCs and five SOFECs operating in cogeneration mode. Individual cell voltage was plotted in different colors. The stack current over time was also shown in the same figure in the bright green color. The stack was operated under two conditions: in the first 3.5 hours the hydrogen production rate (or the stack current) was controlled by a load through an external circuit; in the last hour the hybrid stack was short via bypassing the load box so that the hydrogen production rate could be selfadjusted by the stack itself. As shown in the figure, the hydrogen production rate was nearly doubled when the stack was shorted (with zero power output).

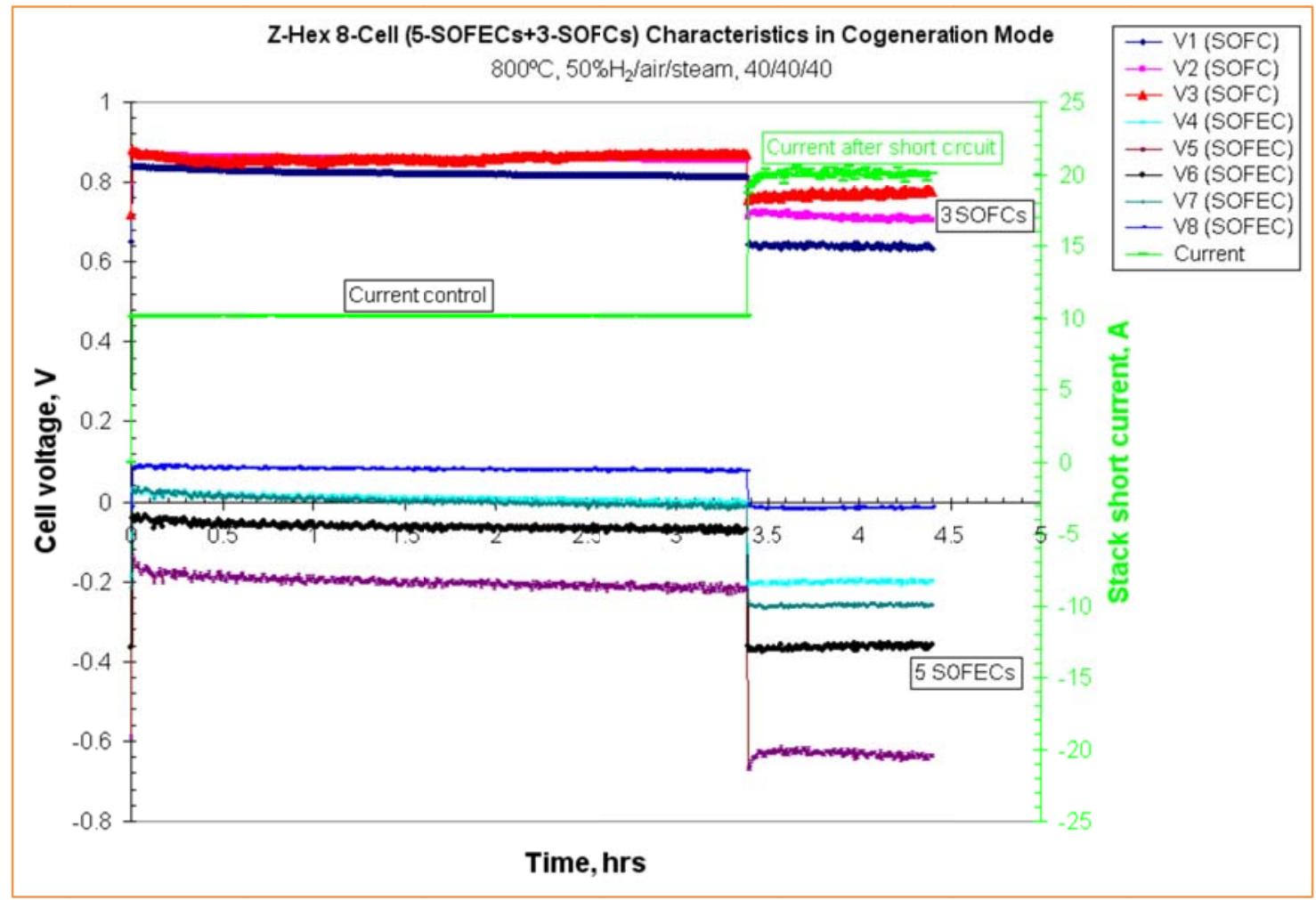

Figure 135. Continuous cogeneration of hydrogen and electricity

Another 10-cell stack composed of seven SOFECs and three SOFCs was constructed and tested continuously by shorting the stack over a week. Everyday, the test was interrupted for scheduled SOFC operations serving as check-points for the functionality of the stack and redox stability of the SOFEC cathode. Figure 136 shows the voltage characteristics plotted in various colors, including the blue, pink and red color for the total voltages of the hybrid stack, three SOFCs and the seven SOFECs, respectively. The stack current was plotted in the bright green color. Since 
the stack was shorted without being controlled by the external load, the stack current was selfadjusting. The power generated by the three SOFCs supplied the need for driving SOFECs and the external circuit (cables). Over the 93 hours test, the current gradually dropped from 18 A to $8 \mathrm{~A}$. The testing was terminated and postmortem analyses were performed to investigate the causes of the degradation, which was discussed below in detail.

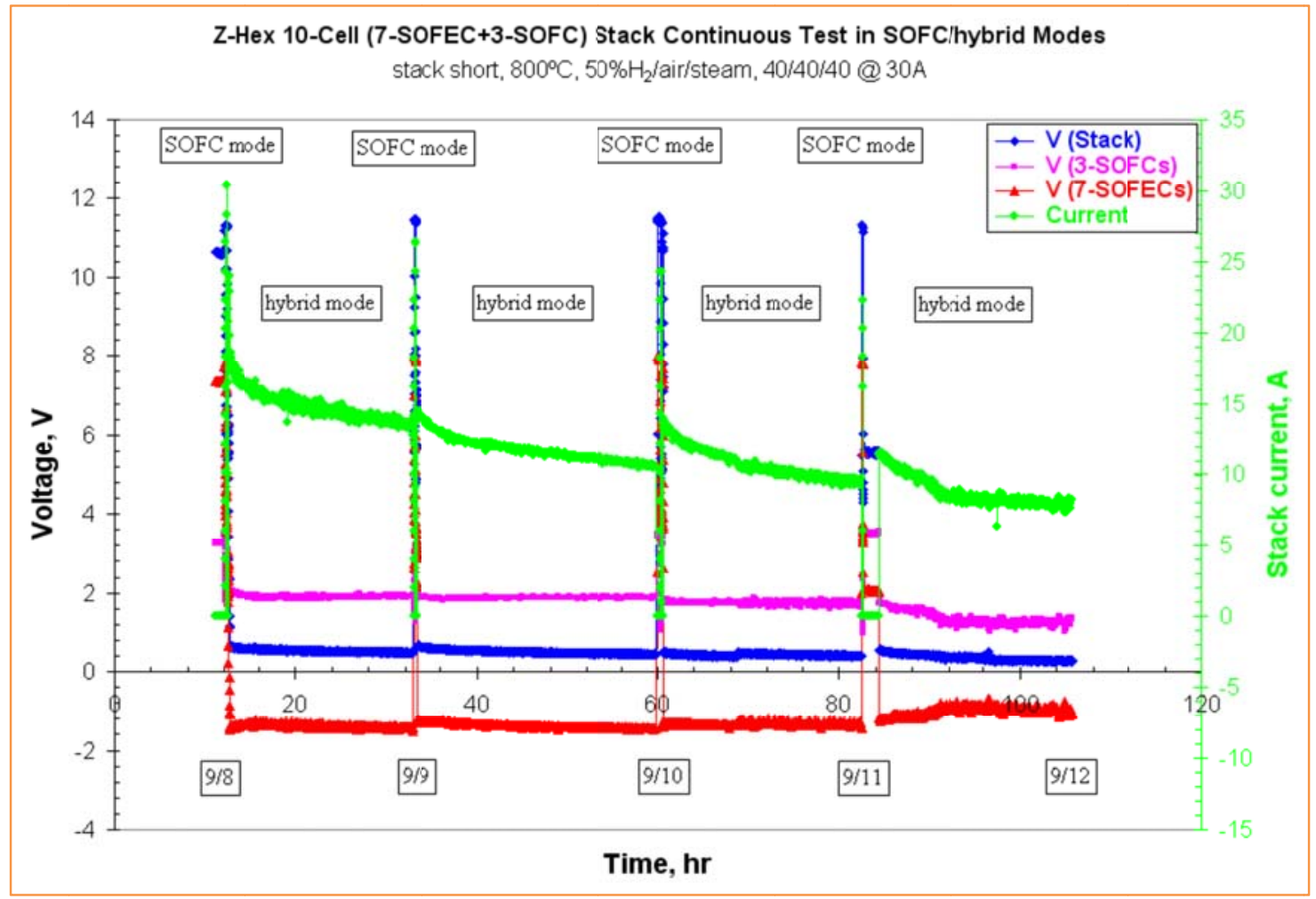

Figure 136. Continuous cogeneration of hydrogen and electricity

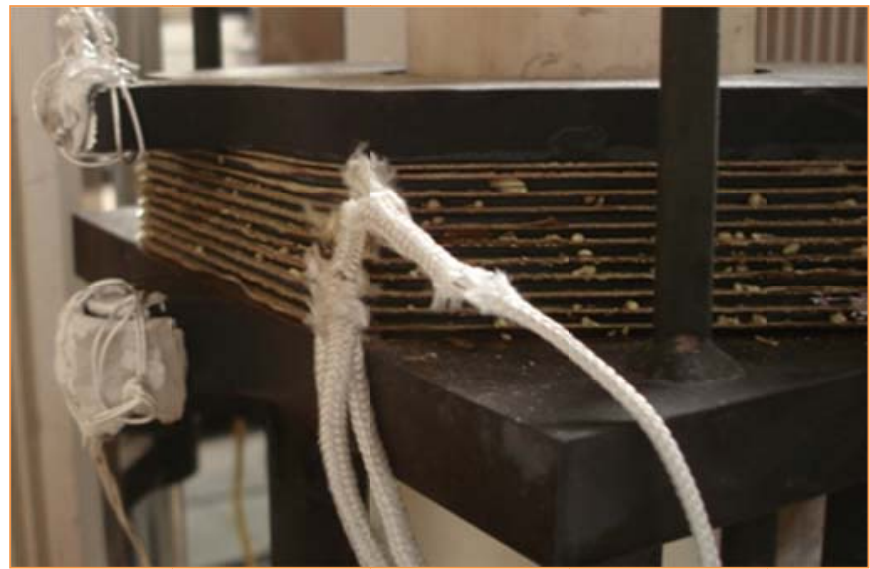

Figure 137. Photograph of the 10-cell hybrid stack (7-SOFEC \& 3-SOFC) after testing

Figure 137 was a photograph of the hybrid stack after the accumulated 10-days test. Each cell was marked and SEM microscopic analyses were conducted, as shown in Figure 138 through Figure 140. Delamination between the cathode functional layer and SDC barrier layer was 
observed on two SOFCs: cell No. 1 (Figure 138) and No. 3 (Figure 139). This could result in stack degradation. No delamination was observed on SOFEC cells.

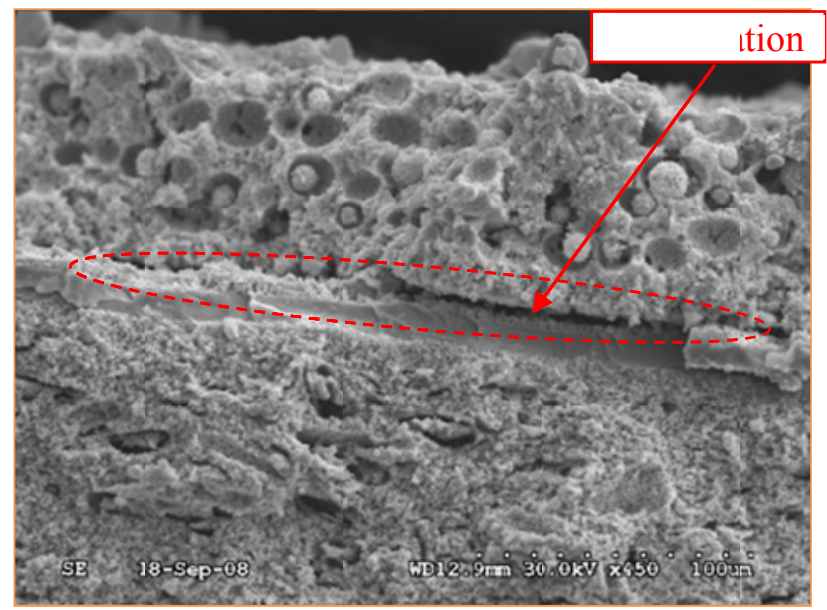

Figure 138. SEM micrograph of Cell No.1 (SOFC)

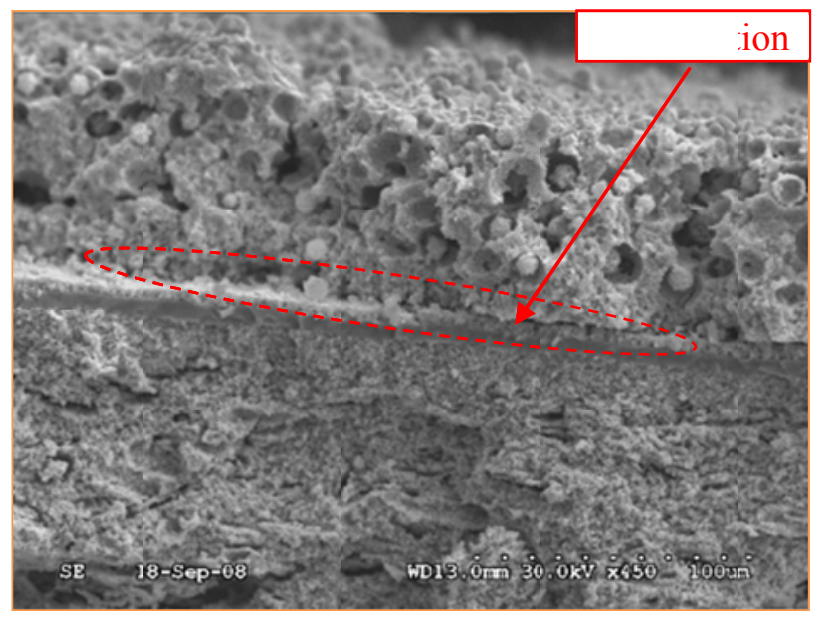

Figure 139. SEM micrograph of Cell No. 3 (SOFC)

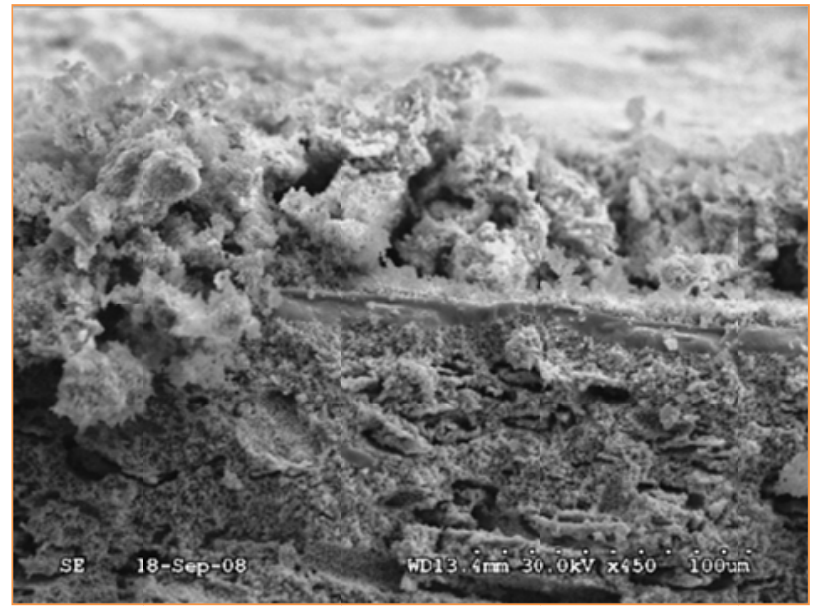

Figure 140. SEM micrograph of Cell No. 10 (SOFEC) 
Task 7.4 Long-term SOFEC stability tests in hydrogen production mode

Capital costs comprise a large portion of the cost of hydrogen production technology deployment. Prolonged stack life means less pre-allocated replacement costs. It is very important to perform long-term tests under usage conditions (a wide operating and cyclic conditions, etc.) to evaluate stack reliability.

In order to evaluate the SOFEC stability and to determine the amount of degradation over time, long-term tests of SOFEC stacks were conducted. Since the associated high costs of SOFEC operation over long-durations make large-stack tests economically unfeasible, single-cell stacks were constructed with SOFEC cells screen-printed with LSCM cathode. The SOFECs were MSRI standard anode-supported cells (70/30 with pore former Type A) having $100 \mathrm{~cm}^{2}$ per-cell active area. All SOFECs used for the long-term test were made from the same batch to eliminate any effects from variation amongst different batches. The glass seal was applied to the interfaces of stacks.

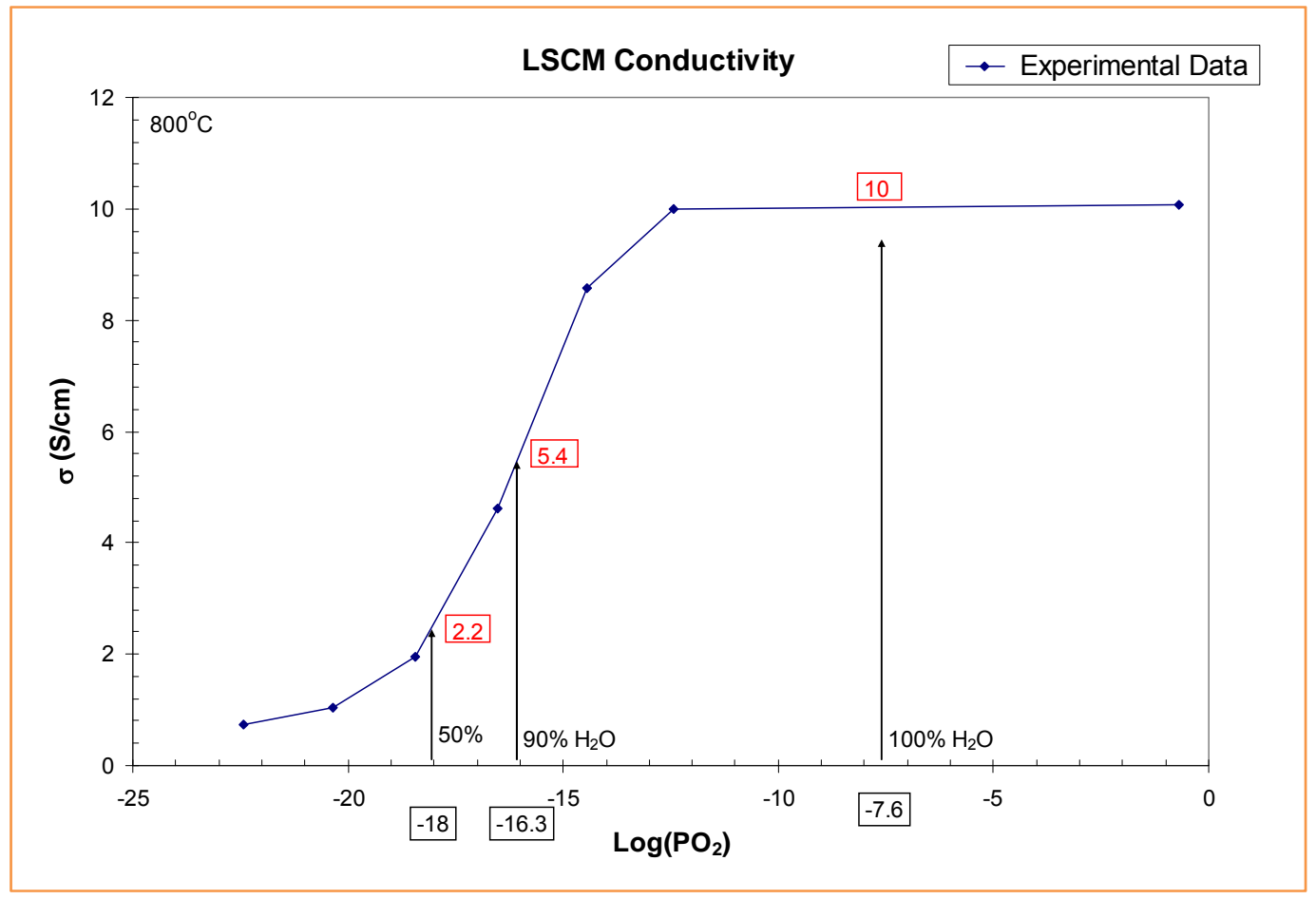

Figure 141. LSCM conductivity as a function of oxygen activity measured at $800^{\circ} \mathrm{C}$

As discussed above in Task 2, the conductivity of LSCM cathode was a strong function of the oxygen activity. Figure 141 shows the LSCM conductivity measurement as a function of the oxygen activity obtained at $800^{\circ} \mathrm{C}$. The conductivity was around $10 \mathrm{~S} / \mathrm{cm}$ and $1 \mathrm{~S} / \mathrm{cm}$ in air and $99 \%$ hydrogen environments, respectively, indicating one order of magnitude drop of the conductivity as the oxygen activity drops to -23 . The conductivity curve also exhibited a flat plateau when the oxygen activity expanded from 0 to -13 , equivalent to air to $99 \% \mathrm{H}_{2} \mathrm{O}$ bal. $\mathrm{H}_{2}$, respectively. By assuming that a pure steam was the feed to the SOFEC cathode and 50\% utilization of steam was achieved, the conductivity experienced drops from $10 \mathrm{~S} / \mathrm{cm}$ to $2.2 \mathrm{~S} / \mathrm{cm}$ 
along the cathode. An issue could emerge that the transition of the conductivity may result in electrode degradation. A potential solution to such drop could be made by using hydrogen gas as the carry gas of the steam. For example, in the case that $90 \% \mathrm{H}_{2} \mathrm{O}$ bal. $\mathrm{H}_{2}$ mixture was used as the cathode feed and $40 \%$ utilization was achieved, the corresponding conductivity of LSCM changed from $5.4 \mathrm{~S} / \mathrm{cm}$ to $2.2 \mathrm{~S} / \mathrm{cm}$, respectively, instead of changes from $10 \mathrm{~S} / \mathrm{cm}$ to $2.2 \mathrm{~S} / \mathrm{cm}$.

Experimental studies were performed using the aforementioned rational. Two identical 1-cell stacks $\left(100 \mathrm{~cm}^{2}\right.$ active area) were constructed and tested under two different operating conditions. The first stack was tested with $100 \% \mathrm{H}_{2} \mathrm{O}$ as the cathode gas, while the second stack was tested with $70 \% \mathrm{H}_{2} \mathrm{O}$ carried by hydrogen. As usual, the stack was tested in the SOFC mode first as a baseline, followed by the continuous test in the SOFEC mode with constant current (or at a fixed hydrogen production rate). As scheduled, the continuous SOFEC test was interrupted and a SOFC test was performed to check the functionality of the stack.

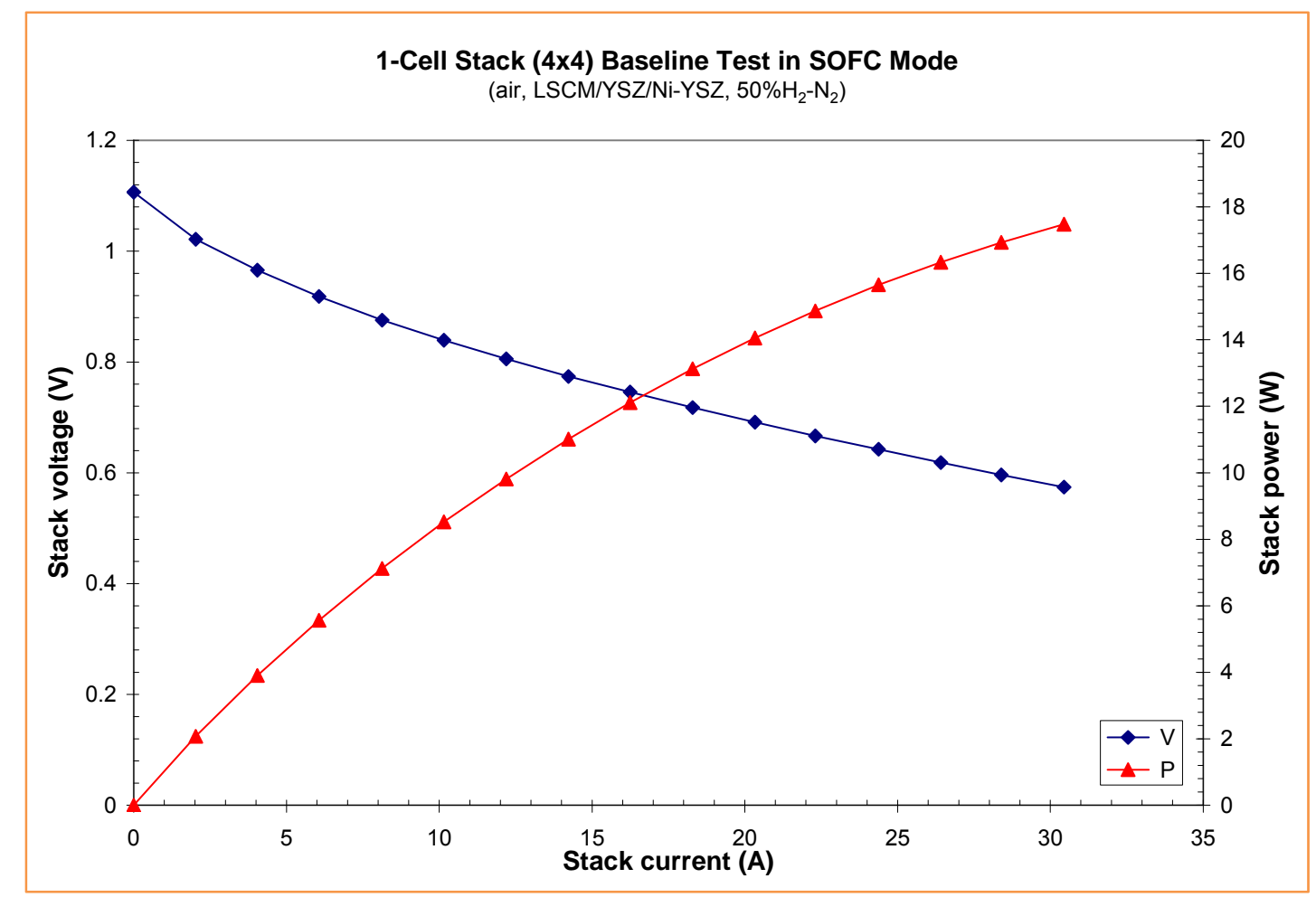

Figure 142. Performance characteristics of a 1-cell stack tested in SOFC mode as the baseline. The furnace temperature was set at $800^{\circ} \mathrm{C}$. Diluted hydrogen with $50 \% \mathrm{~N}_{2}$ was used as the fuel and air was the oxidant.

Figure 142 shows the first 1-cell stack performance characteristics operating in the SOFC mode as the baseline test. Diluted hydrogen with $50 \% \mathrm{~N}_{2}$ was used as the fuel and air was the oxidant. Both the fuel and air utilizations were fixed at $40 \%$. The furnace temperature was set to $800^{\circ} \mathrm{C}$. At $30 \mathrm{~A}$, this stack generated 17 watts power. Following the SOFC baseline test, a long-term test was carried out to study the effect of the LSCM cathode conductivity on the durability of the stack in the continuous hydrogen production mode. Figure 143 shows the stack long-term test results. Pure steam was used as the cathode feed gas in this study. Over the 200 hours long-term test, the stack voltage degraded from initial $-0.15 \mathrm{~V}$ to $-0.42 \mathrm{~V}$ at the constant current $30 \mathrm{~A}$ (or 


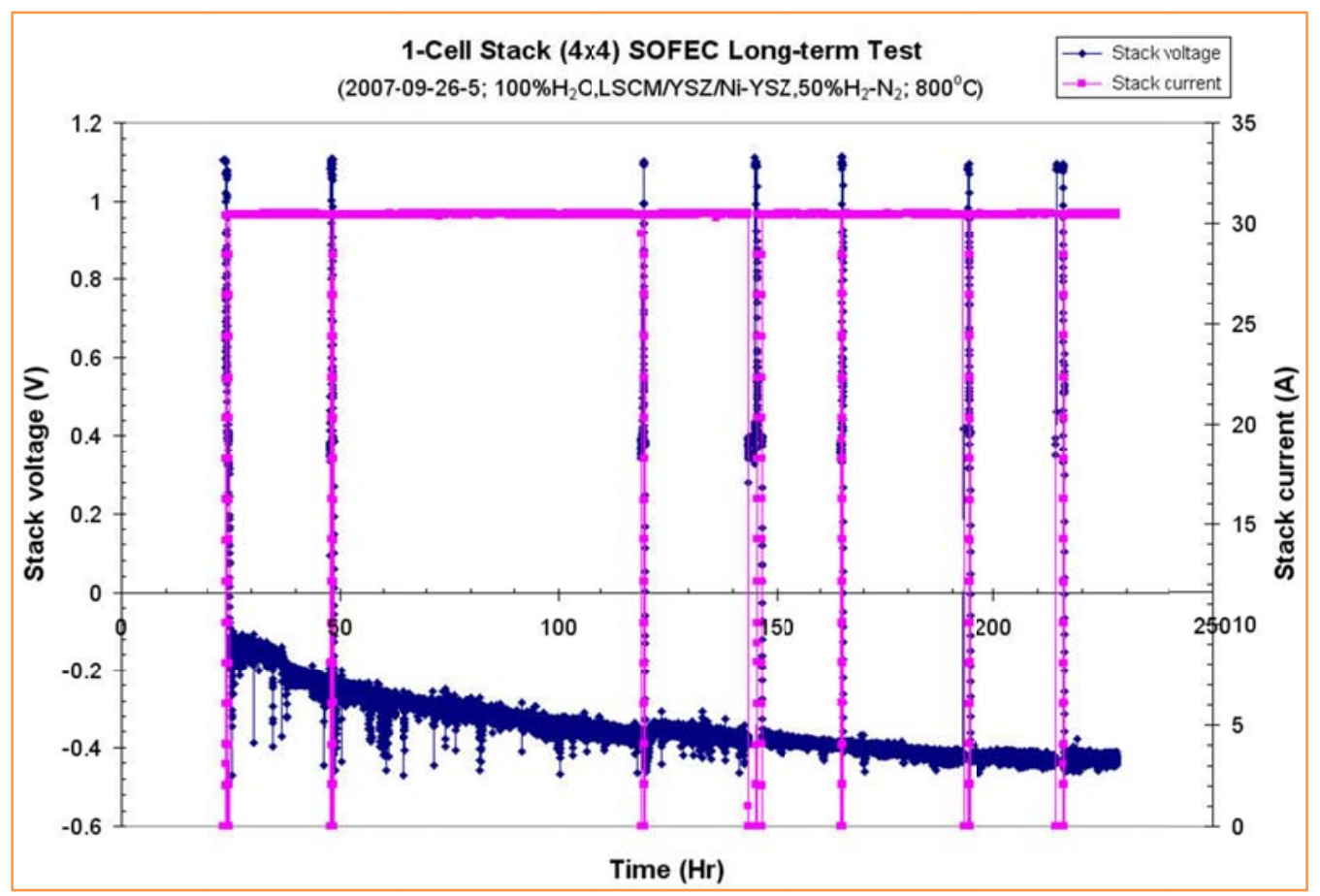

Figure 143. Long-term test of a 1-cell stack in the SOFEC mode for hydrogen production

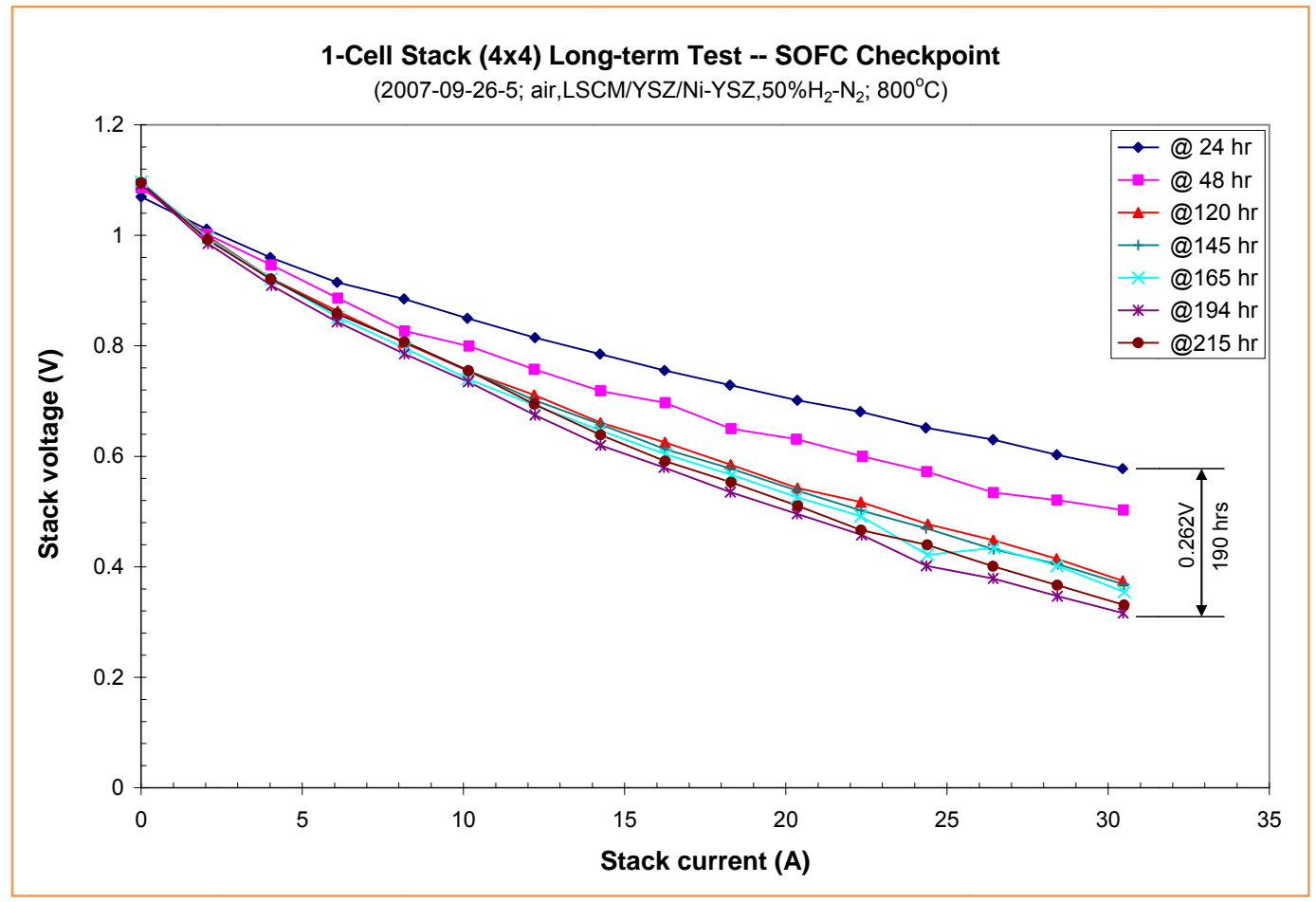

Figure 144. SOFC operation at scheduled time

equivalent to a production rate of 13.7 liters of hydrogen per hour). It was observed that the degradation rate was relatively high in initial 100 hours, and starts to level off in the following 
100 hours. A similar initial degradation phenomenon was also observed on typical SOFC stacks, though no clear degradation mechanisms have been defined by the SOFC industry.

The long-term tests in hydrogen production were interrupted for scheduled SOFC tests, serving as check-points for the functionality of the stack and redox stability of LSCM cathode. The stack OCV value and VI curve in the SOFC mode were measured at different times, as shown in Figure 144. The stack OCVs were constant over the time, while the stack voltage at 30A drops from $0.58 \mathrm{~V}$ to $0.32 \mathrm{~V}$ at the check points of 24 hours and 215 hours, respectively. Similar to the SOFEC test results, the major degradation took place within the first 100 hours.

A second 1-cell stack was constructed and tesed in the long-term of hydrogen production mode in the same way as the previous stack, except that the cathode feed gas was a mixture of $70 \% \mathrm{H}_{2} \mathrm{O}-\mathrm{H}_{2}$. Figure 145 shows the 100 hours test. Similar stack degradation was observed, though the stack functioned well in the SOFC mode. After termination of tests, both stacks were dissembled and visually inspected. The cathode current collection layer of both stacks was partially peeled off from the cathode functional layer, resulting in potential degradation of performance due to large ohmic losses. SEMs of the cells were performed to analyze cathode microstructure changes, and no delamination was observed at the interface of electrolyte layer and cathode functional layer.

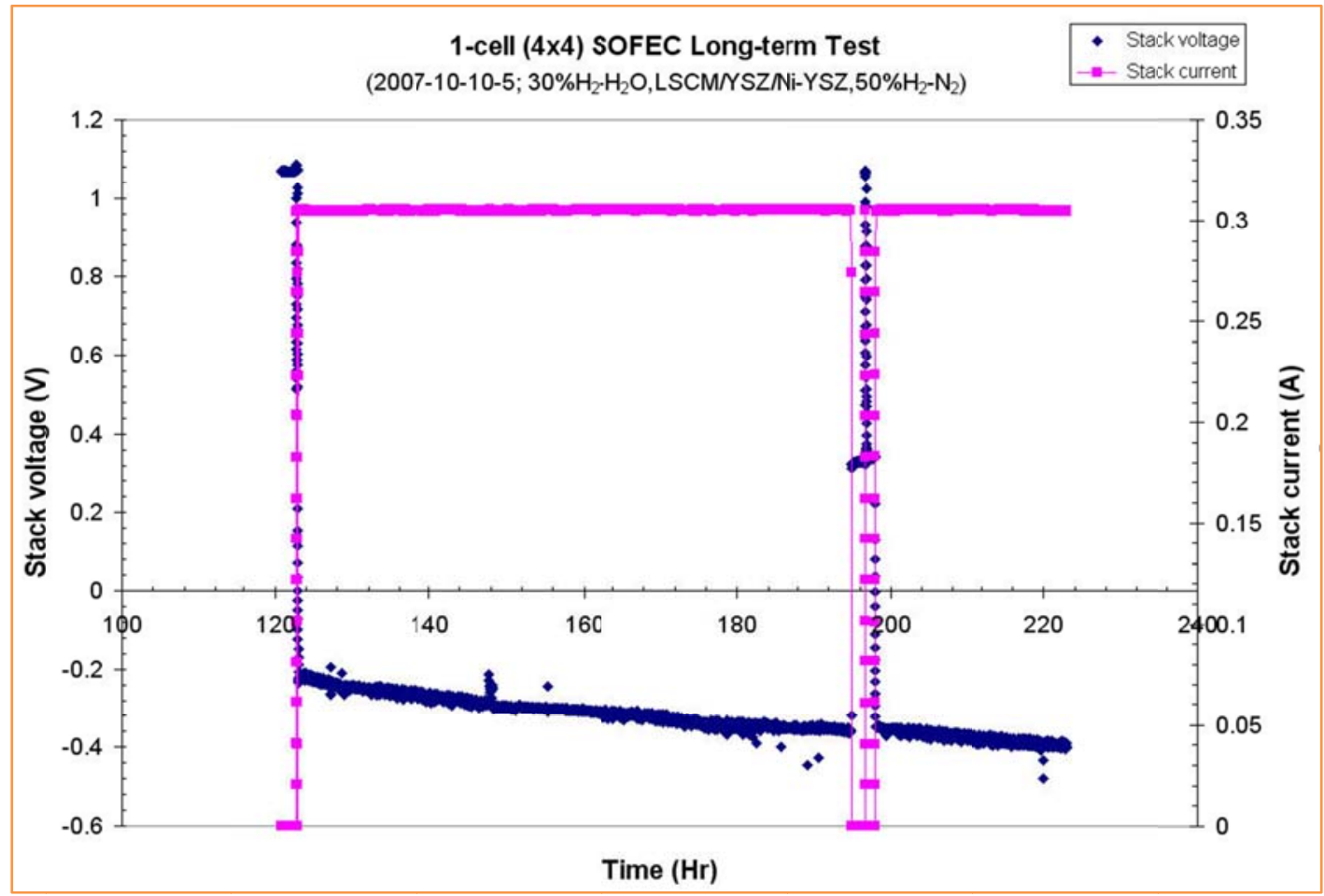

Figure 145. Long-term test of a 4"x4" 1-cell stack in the SOFEC mode

The cathoding procedure was modified to improve the bonding between multi-cathode layers, followed by construction and evaluation of another 1-cell stack in long-term hydrogen production mode. Using MSRI's standard testing protocol, the stack was tested in the SOFC mode first as a balseline, followed immediately by a continuous test in the SOFEC mode under 
constant current. As scheduled, the continuous SOFEC test was interrupted and a SOFC test was performed to check the functionality of the stack, and the redox stability of the LSCM-based cathode. Figure 146 shows the stack long-term test results. Pure steam was used as the cathode feed gas in this study, while a wet $\mathrm{H}_{2}+\mathrm{N}_{2}$ mixture was used as the fuel. Over a 360 hours longterm test, the stack voltage was fairly constant. No significant degradation was observed.

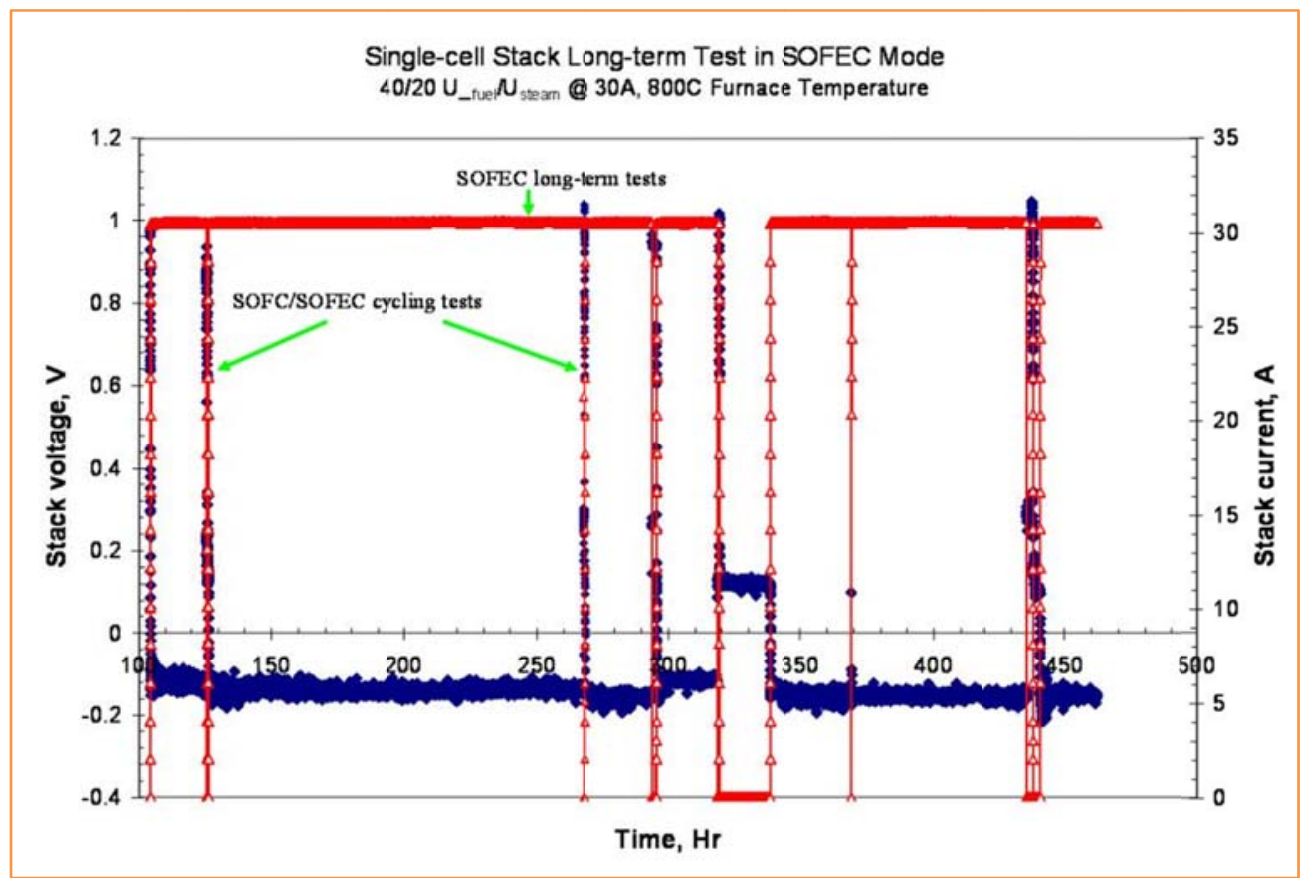

Figure 146. Long-term test of a 4"x4" 1-cell stack in the SOFEC mode

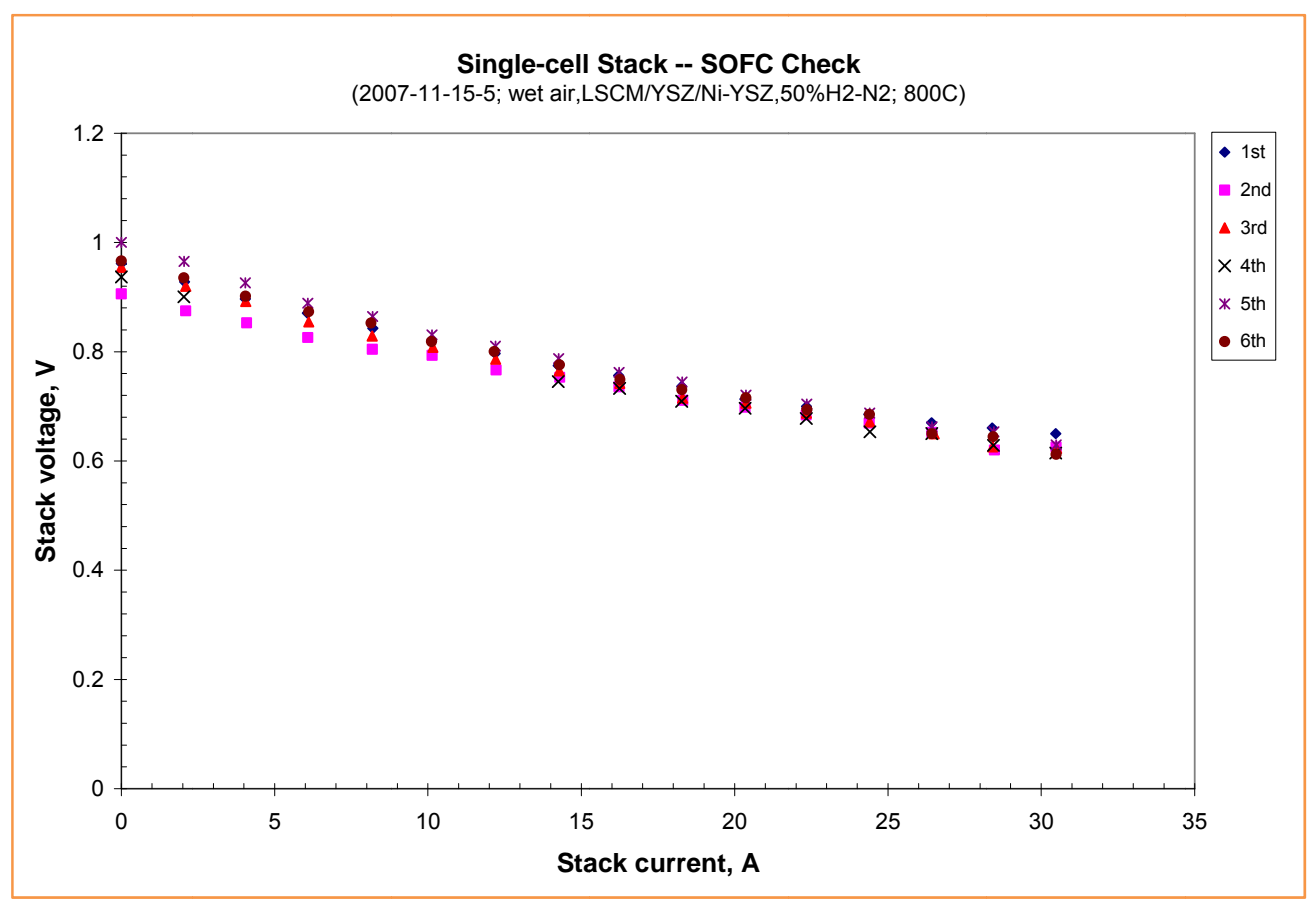

Figure 147. SOFC operation at scheduled time 
As usual, the long-term test of hydrogen production was interrupted for scheduled SOFC tests, serving as check-points for the functionality of the stack and redox stability of LSCM cathode. The stack OCV value and VI curve in the SOFC mode were measured at different times, as shown in Figure 147. Wet air with $30 \%$ steam was used as the oxidant. Similar to the SOFEC test results, no significant voltage drop was observed after 360 hours continuous tests. In the meanwhile, even after six SOFEC/SOFC cycling tests, the LSCM-based cathode material exhibited high redox stability under the given operating condition.

\section{Task 8 Development and Testing of a 5 kW SOFEC-SOFC Hybrid System}

The hybrid system design and component integration for co-generating hydrogen and electricity directly using natural gas was preceded by solid modeling of the various BOP components and creation of an assembly of these component models. As described previously in Task 6, the system was to be constructed with assembly of a hot-zone comprising six modular stacks, a BOP components zone, and an electronic control zone. Figure 148 shows a rendering of the system configuration with the major sub-systems included. In the hot-zone, a spring-plate compression device was used for each individual stack with insulated tension rods and load plates that allowed the springs to remain relatively cool while minimizing thermal losses from the stack enclosure. Six pairs of the compression devices were manufactured. The individual stack modules were then assembled to an electrically insulating support plate that separated the stack hot-zone enclosure from the BOP components. Gas feed pipes, to be welded to each manifold/compression plate, passed through the support plate and sealed in compression fittings to the BOP piping. If it was necessary to remove an individual stack for maintenance or replacement, this could be done without removing the compression force from the other stack modules.

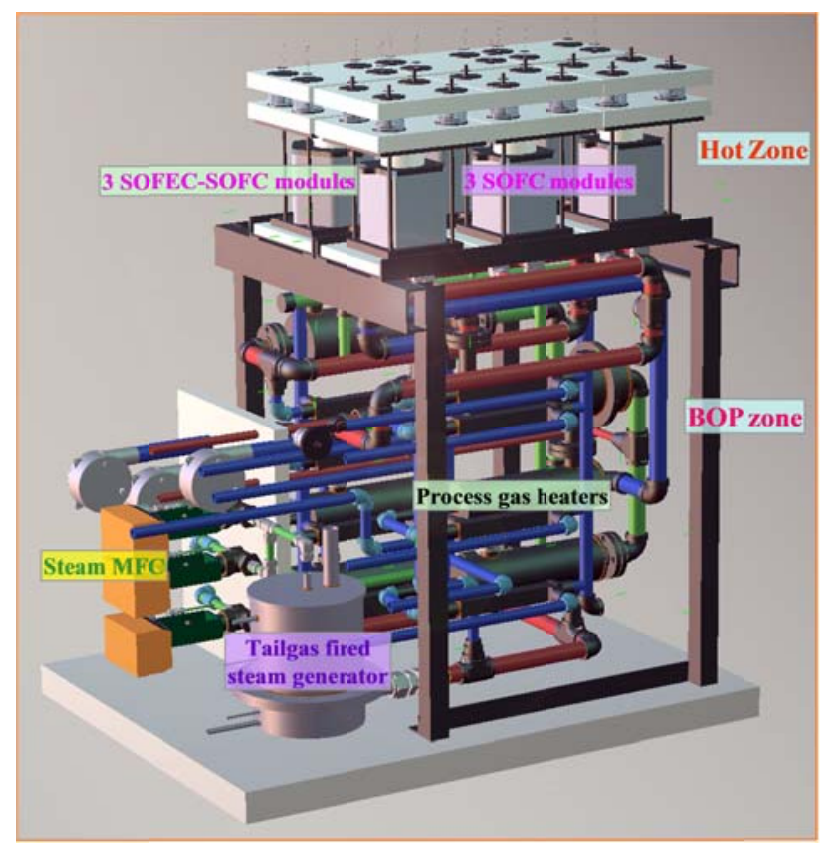

Figure 148. Rendering of the $5 \mathrm{~kW}$ hybrid system configuration in detail 
The major BOP components designed in Task 6 (including the tailgas-fired combustors and reformers) were manufactured with improved catalytic combustion features for stable flame and for heat transfer enhancement. Additional features were also considered for allowing for disassembly and replacement of individual BOP components, as well as access to the catalyst beds. Compact heat exchangers were purchased for recuperating heat from cathode gases to combustion air. A central tailgas-fired steam generator supplying steam to the reformers and SOFEC cathodes with separate control mechanisms was machined and evaluated in-house. A commercially available multi-module C-DAQ was purchased to build the control system with a user interface operating National Instrument's LabView software. An overall, integrated system assembly, however, was not completed because of limited resources. Nevertheless, achievements and progress made towards the hybrid system will be described below.

\section{Task 8.1 Development of an interconnect fabrication process}

The $5 \mathrm{~kW}$ SOFC-SOFEC hybrid system consisted of six modular stacks, requiring 300 interconnects. Unlike the typical commercial interconnect, MSRI has developed inexpensive metallic interconnects composed of multiple brazed laser-cut parts separating anode and cathode gas streams. A spray system, as shown in Figure 149, was installed and engineered for spraying brazing materials with controlled coating thickness. Figure 150 is a photograph of a retort furnace used for brazing high quality interconnects in-house in a controlled atmosphere.

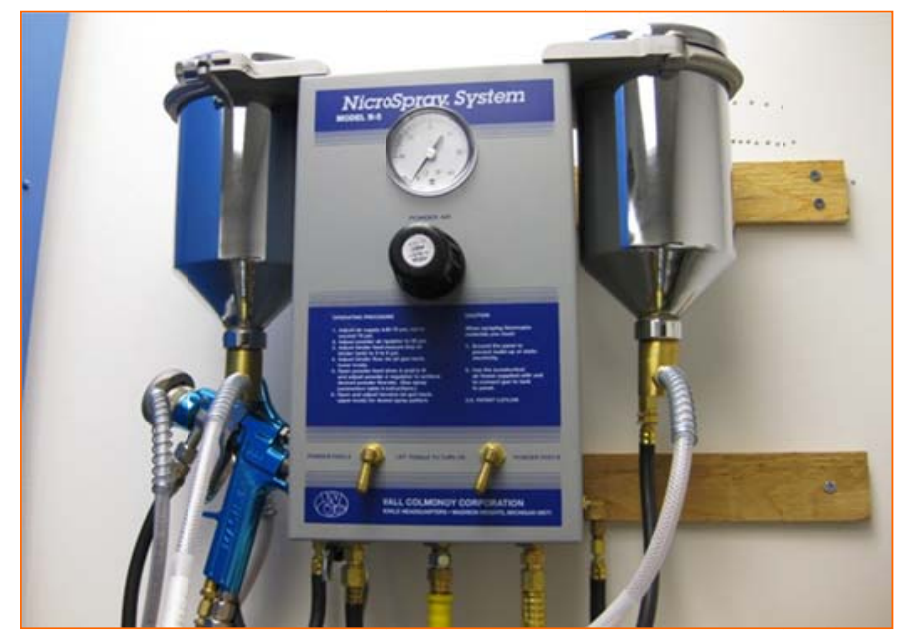

Figure 149. Nicro-spray system 


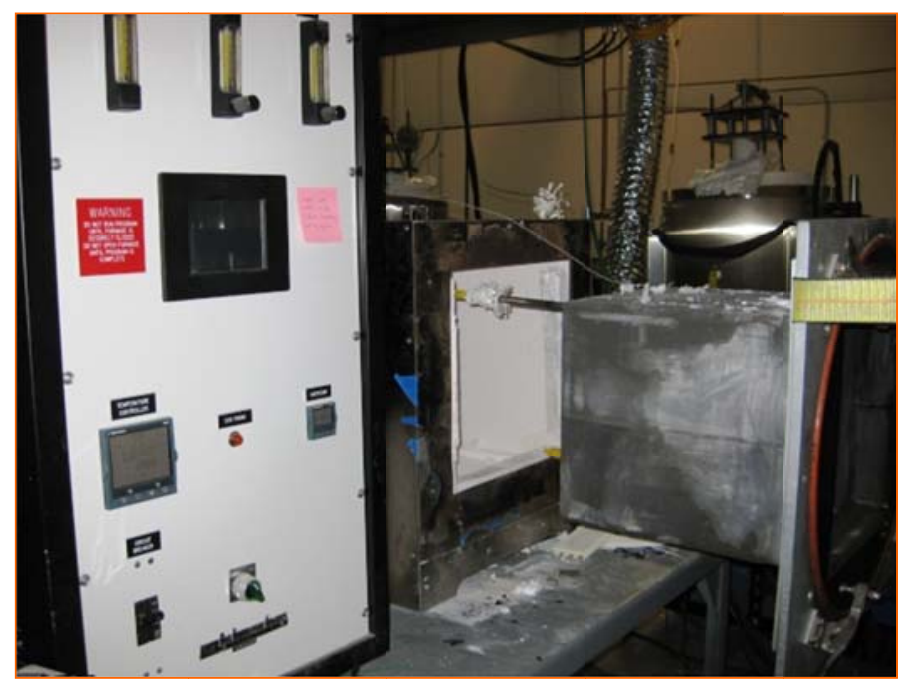

Figure 150. Photograph of the retort furnace used for fabricating interconnects

\section{Task 8.2 $\quad$ kW class stack evaluation}

Compression hardware for six individual stacks was machined, as shown in Figure 151. Each stack module was to be assembled and pre-tested in a furnace before being integrated into the hybrid system. Figure 152 (a) and (b) are photographs of a 40-cell stack assembly before and post test, respectively. Voltage probes were attached to each cell to trace the cell voltage as a function of the stack current, but will be removed before system integration.

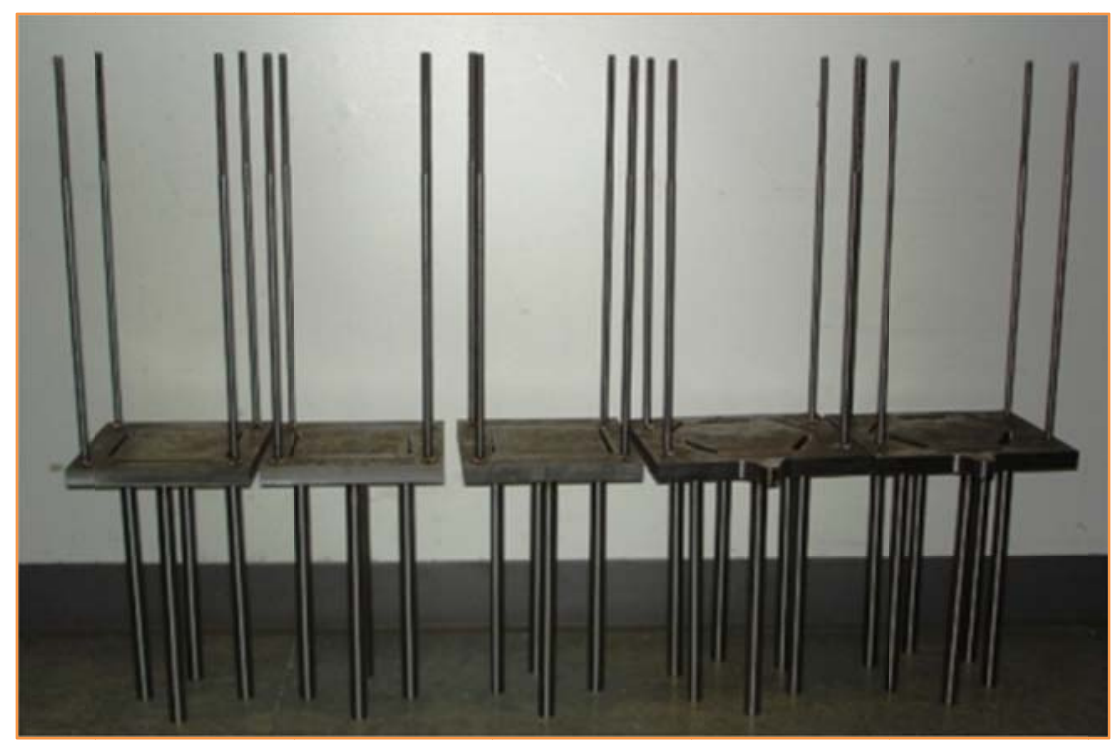

Figure 151. Photograph of five sets of compression hardware machined for modular stacks (the missing one was installed in test station already) 

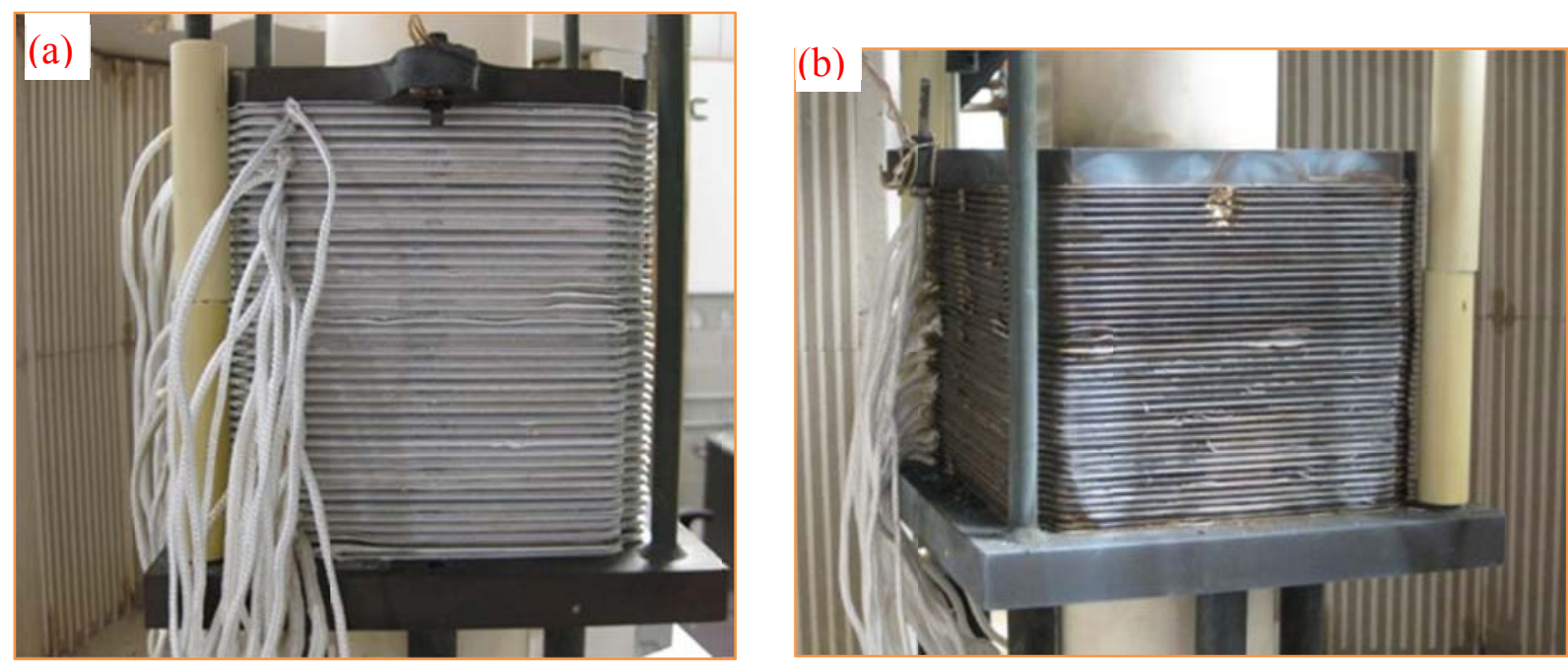

Figure 152. Photographs of the 40-cell stack before test (a) and post test (b)

Figure 153 shows the stack performance characteristics operated in the SOFC mode at $800^{\circ} \mathrm{C}$. Dilute hydrogen balanced with $50 \% \mathrm{~N}_{2}$ was the fuel, and air was the oxidant. At a fixed utilization of $40 \%$ for both the fuel and air, the stack generated 929 Watts electricity at 30 A. The average cell voltage was $0.774 \mathrm{~V}$.

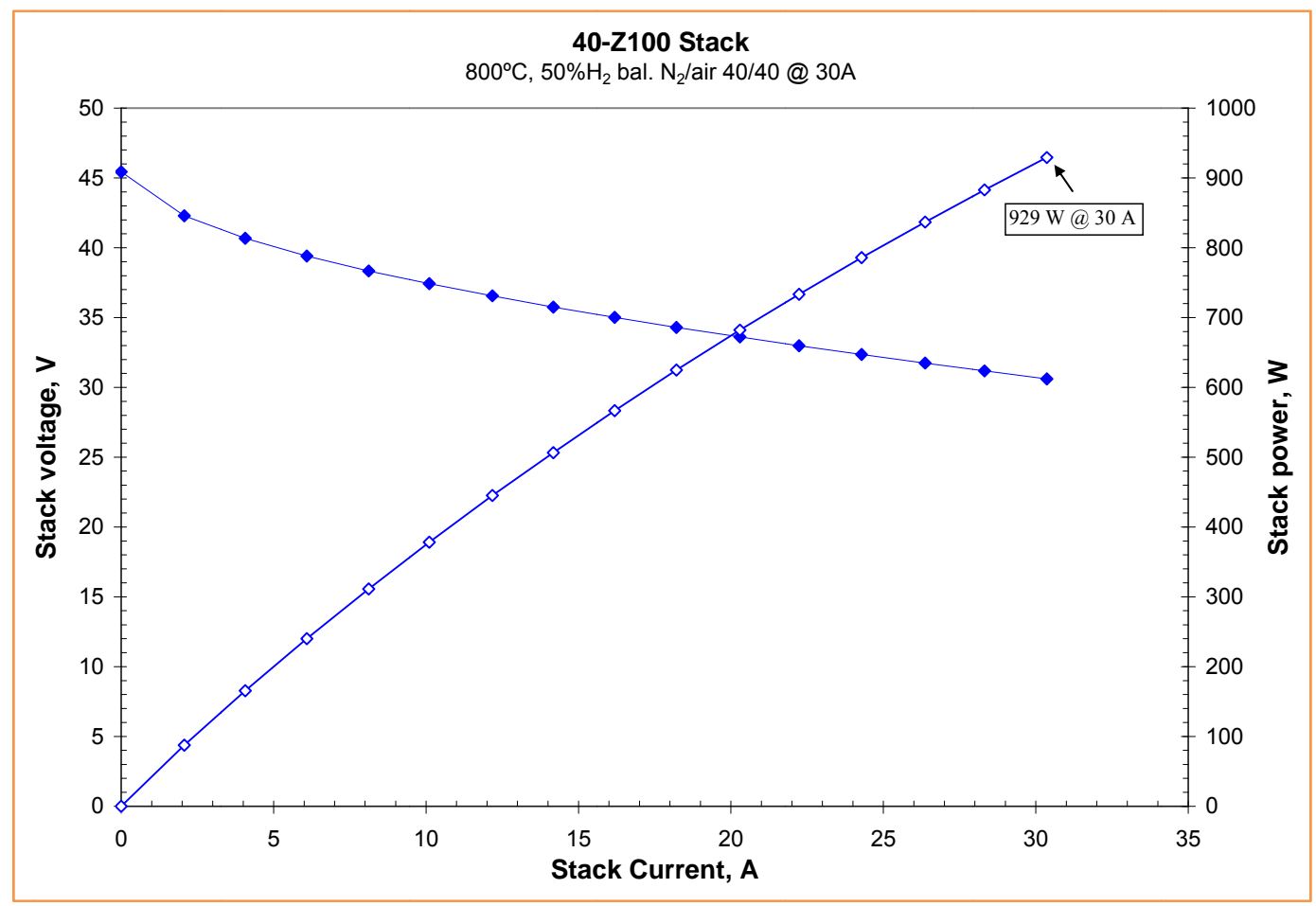

Figure 153. Performance characteristics of the 40-cell SOFC stack

A test of continuous power generation was performed over 43 hours, as shown in Figure 154. No apparent performance degradation was observed. 


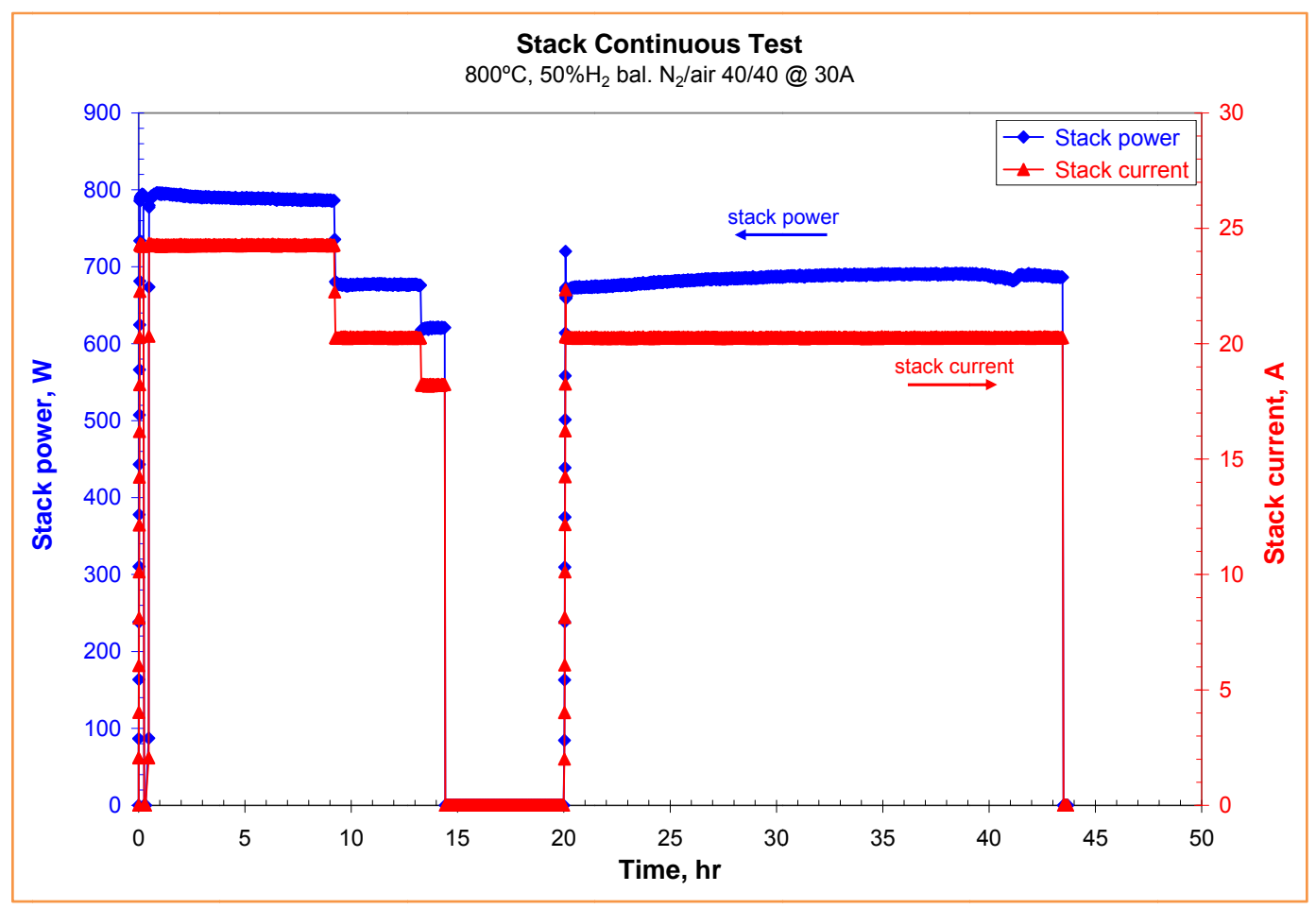

Figure 154. Continuous test in the power generation mode

\section{Task 8.3 Balance-of-plant component evaluations}

Task 8.3.1 Tailgas-fired steam generator

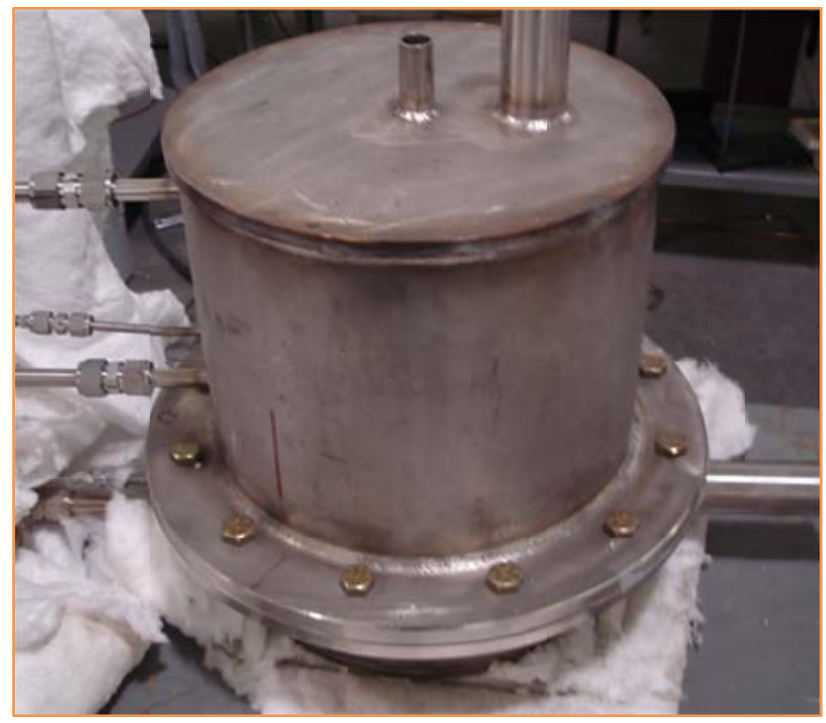

Figure 155. Photograph of the assembled steam generator before testing

Fabrication of the tailgas fired steam generator was completed, and the subsystem was tested both stand-alone and in a bench-top assembly, including a water fill control system. The 
generator was heated using the combustion of a high flow rate dilute simulated tailgas. Figure 155 is a photograph of the assembled tailgas-fired steam generator.

Figure 156 is a photograph of the bench-top test configuration. A utility water line fed the leveling tank (water reservoir), with the solenoid valve controlled directly by the float switch and a $24 \mathrm{~V}$ battery source. The gas flow was a mixture of hydrogen, nitrogen, and air, with the fuel composition and total heat capacity of the flow matched to the expected values for the $5 \mathrm{~kW}$ system tailgas. Electric preheaters were initially installed at the inlet to the steam generator, though for the final test these were not used. A small electric hotwire element was installed in the inlet manifold to act as an ignitor, just below the catalyst bed, and was controlled by a variable ac source. To measure the steam generation rate, the entire assembly was placed on a mass balance, and the loss in mass vs. time was recorded with the inlet water feed disconnected.

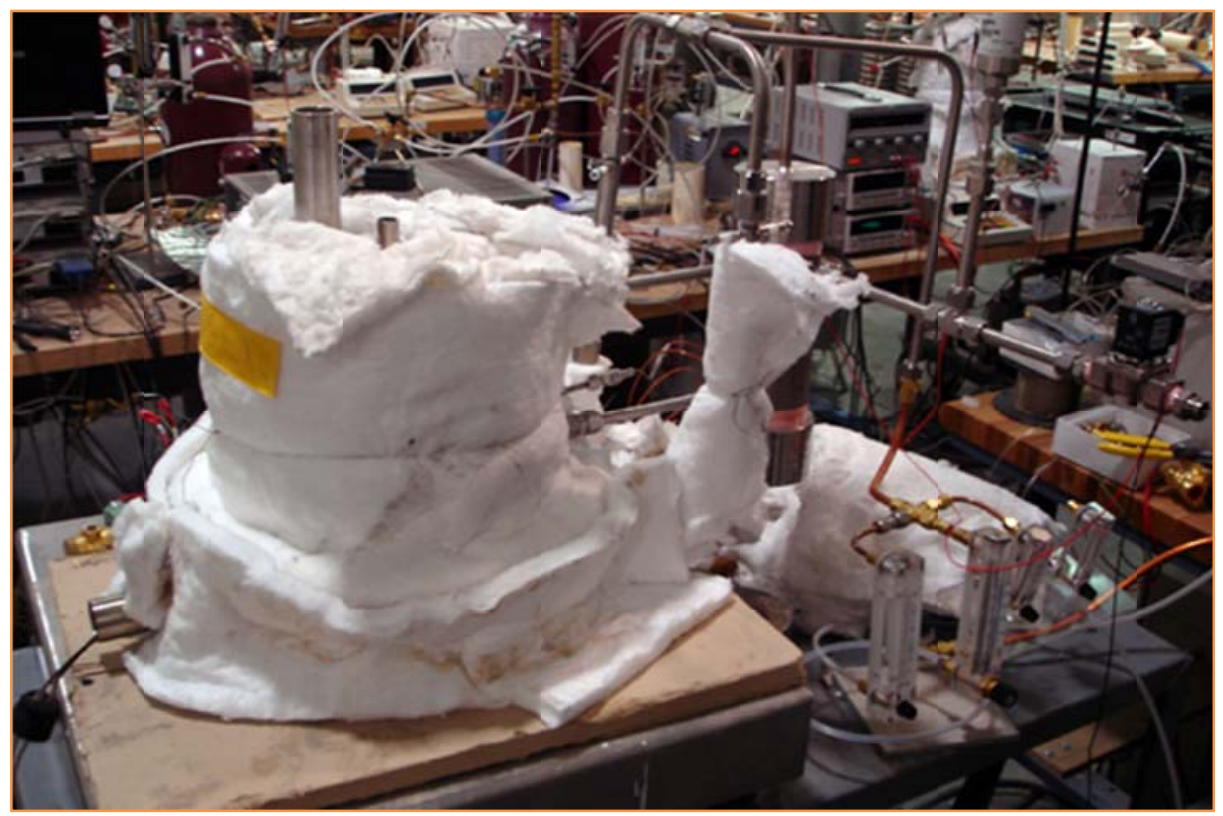

Figure 156. Photograph of the bench-top test configuration for the steam delivery system, after testing

Figure 157 shows the steam generation rate vs. time test results of the generator under the 150 SLPM flow of dilute hydrogen nitrogen gasses, with a small amount of excess air. The flow rates were computed to approximate those that were found in the real system operating at maximum output. The testing system was limited by the inability to preheat the high flow rate of air to $750^{\circ} \mathrm{C}$, which was the approximate gas temperature at the inlet to the combustion chamber in the steam generator during steady state operation; even so, the combustion bed maintained a temperature of $\sim 640^{\circ} \mathrm{C}$, without additional heat input or an ignition source. Under these conditions the steam generation was about $85 \%$ the required rate in the system; with a high temperature inlet stream the rated output will be fully realized. 


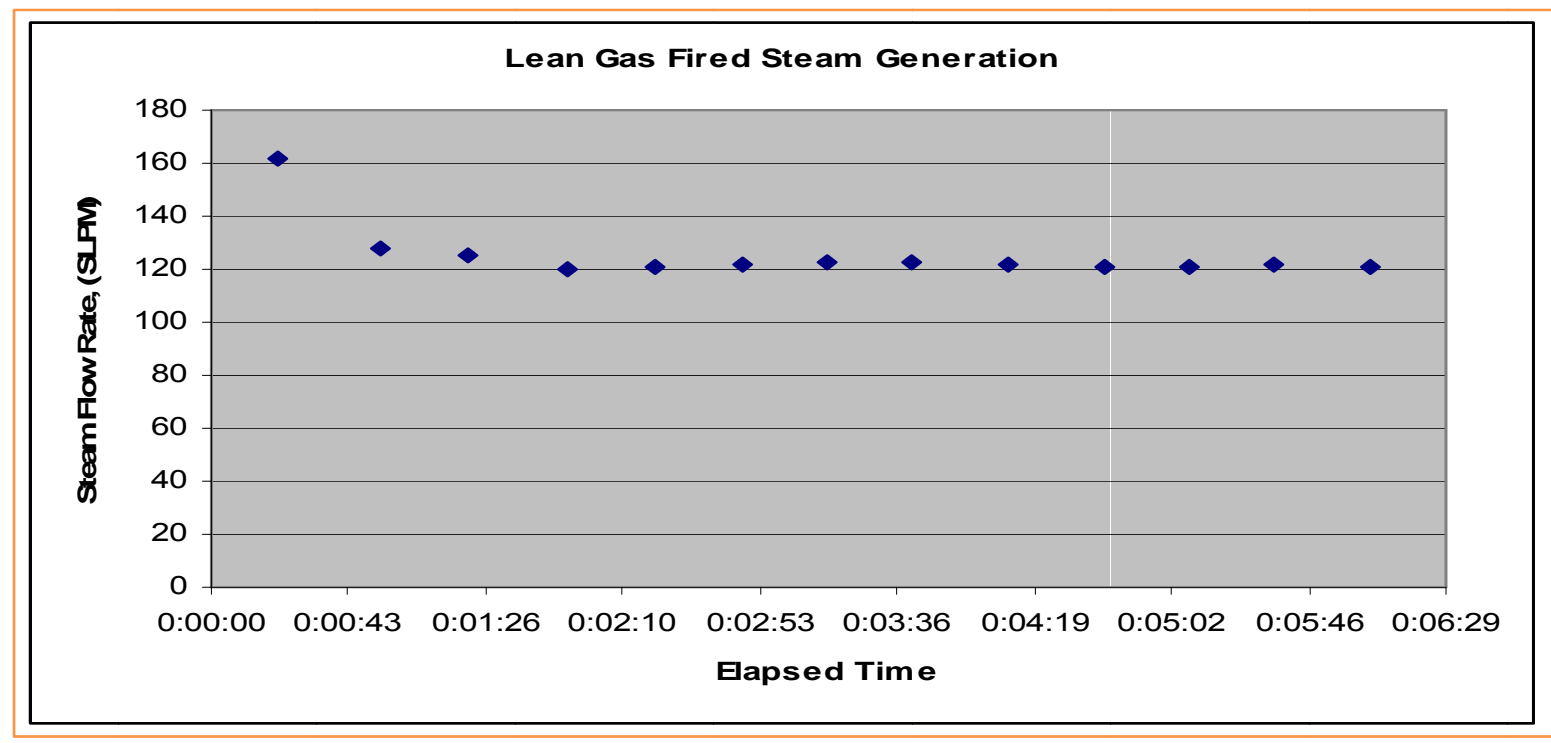

Figure 157. Flow rate measurements (based on mass balance) of steam generation under steady flow of simulated lean tailgas and air.

The testing of this BOP component was significant, first validating the performance of the steam generator and its capability to provide for SOFEC cathode feeds as well as for the SMR reactors, but more importantly the heat transfer and catalytic combustor design used both in this steam generator and in the other tailgas fired process heaters has been validated. In the tailgas side of the steam generator and the SMRs, the cross section was proportional to the expected flow rate, and to the area of the catalyst bed. Since the steam generator was located last in the series of combustors, where the fuel was the most dilute, the ability of the combustor catalyst bed to promote complete combustion of the fuel was indicative that the combustors sized for the more rich gasses in the other components were also adequate.

Task 8.3.2 Tailgas-fired process heater

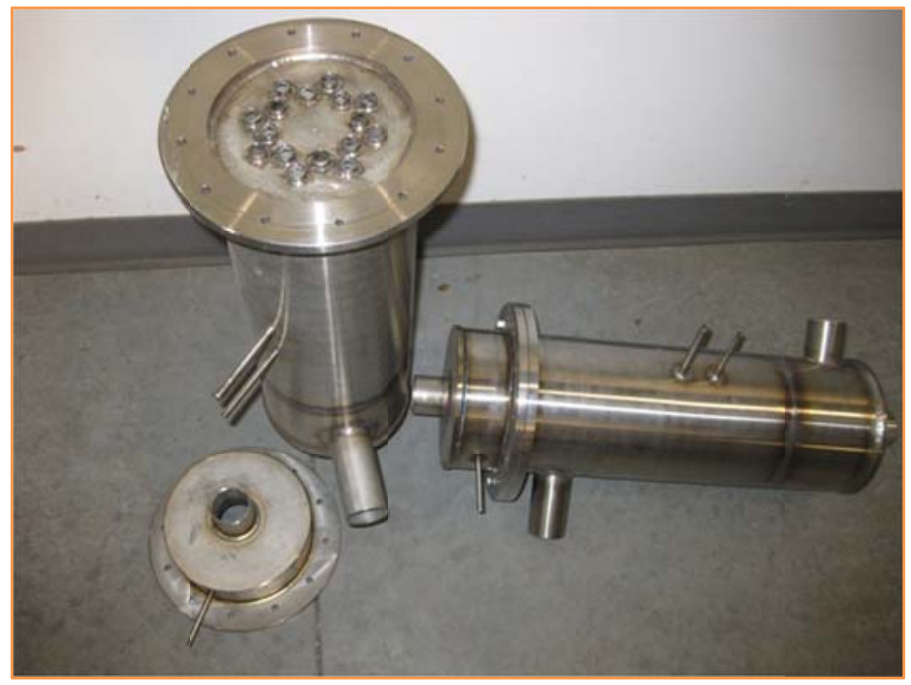

Figure 158. Two tailgas-fired process heaters packed with catalysts 
The tailgas-fried process gas heater was designed to preheat the natural gas, steam, and air, and supplying heat to the fuel reformer. Two reactors were fabricated, as shown in Figure 158, and the array of tests were conducted to validate the design calculations. The reactors were made from SS316, with welded construction, and a catalyst bed that was accessible via a bolted flange. The diffuser screens were micro perforated SS316 foils to promote evenly distributed combustion, preventing "hot-spots" and catalyst over-temperature. The catalyst material for combustion was a ceria-based commercial powder having a surface area of $77 \mathrm{~m}^{2} / \mathrm{g}$. In-house standalone testing of the catalyst material has shown that it was effective both for the SMR reaction, and for the combustion of stack anode tailgas with air, even at the very lean fuel concentrations that existed when operating at a high efficiency. Figure 159 shows the catalyst material, along with the perforated metal used as the air diffuser. Three exposed thermocouples along the length of the reactor measured the temperature of the gas in the catalyst bed, to determine whether even heating was achieved. Inlet and outlet process gas temperatures were also recorded to observe the effectiveness of the heating process.

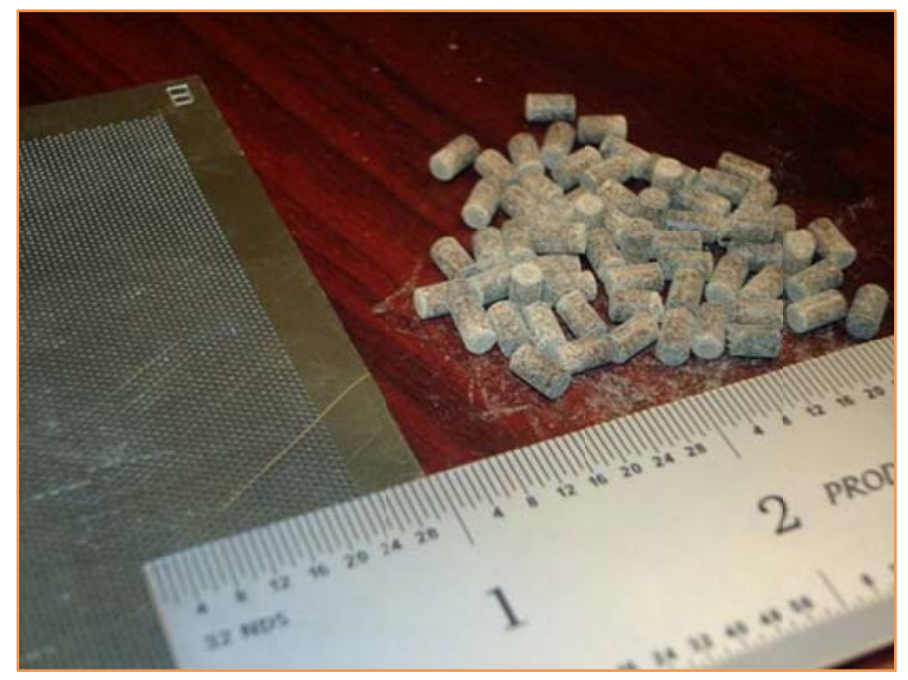

Figure 159. Photograph of the catalyst material used in the tailgas-fired process heaters, along with the micro-perforated SS foil used as the air diffuser

Figure 160 shows the temperature profile in the combustor for a baseline case in which a mixture of lean $\mathrm{H}_{2}$ and $\mathrm{N}_{2}$ were combusted with stoichiometric air. The process gas was air, heated from the room temperature at a flow rate of 100 SLPM. The results showed a $500^{\circ} \mathrm{C}$ temperature increase in the process gas, and a final outlet temperature exceeding the outlet temperature of the tailgas. This was consistent with the design calculations and indicated that the desired rate of heating and cooling was achieved with this design. In addition, the temperature variation along the length of the combustor was within $100^{\circ} \mathrm{C}$ (within the design spec). Figure 160 also shows the post-combustion compositions of the tailgas effluent measured by a gas chromotography, indicating that a complete combustion of the lean mixture was obtained. 

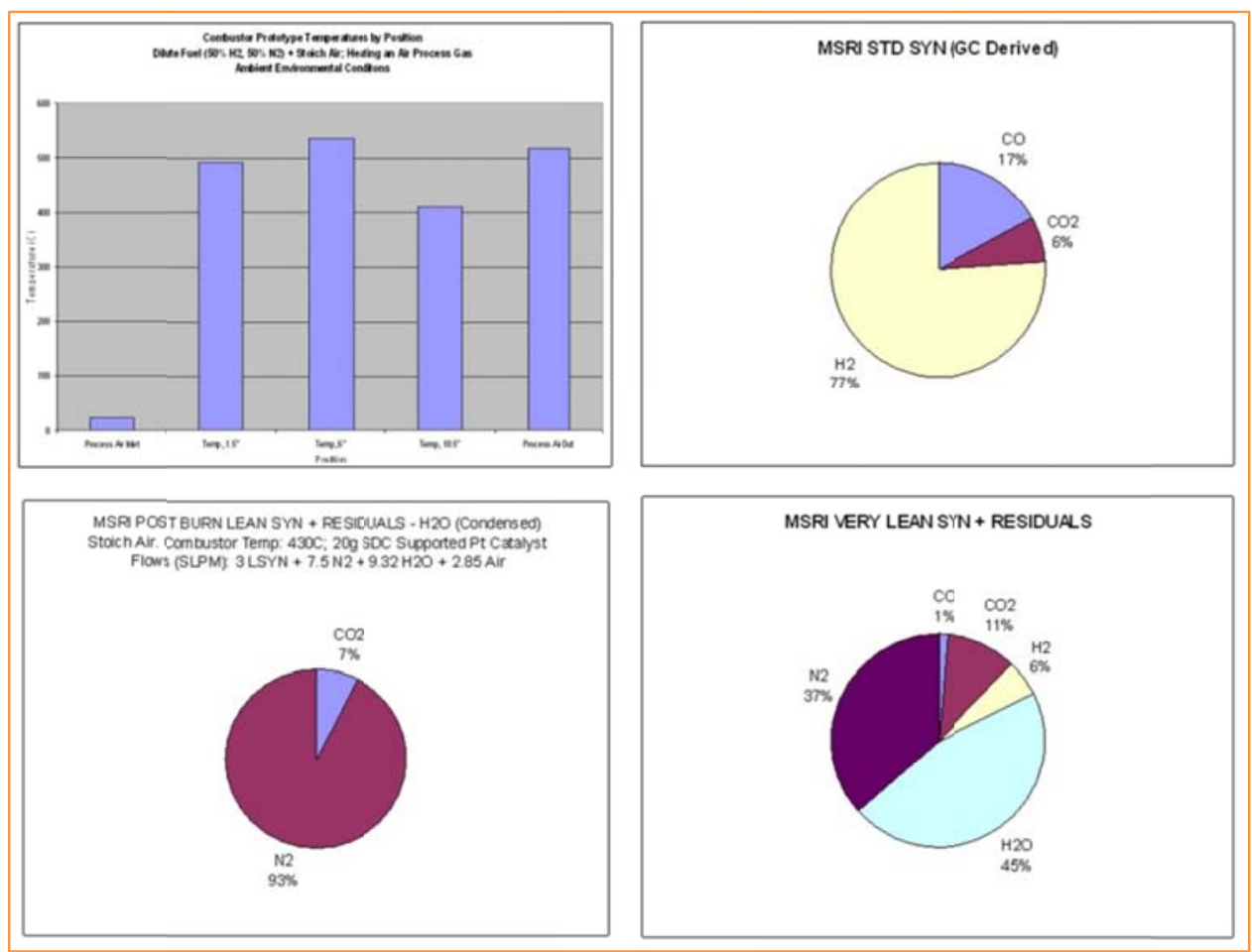

Figure 160. Temperature profile of the process gas heater operating on a dilute fuel $\left(50 / 50 \mathrm{~N}_{2} / \mathrm{H}_{2}\right)$, Stoich. air, and heating ambient air, and compositions of the combustion product stream for 3 cases.

\section{Task 8.3.3 Control system and power electronics}

Charge controllers were obtained which met the system specifications. The controllers are commercially available units designed for distributed charging of battery banks from PV solar arrays. Three of these units, obtained from Apollo Solar, connected in parallel with networked control have been configured to provide a $24 \mathrm{~V}$ DC source from the variable stack power output, at a high level of efficiency. Bench-top testing with the battery system was used to characterize the energy conversion efficiency when charging and discharging the battery bank.

The control system was designed at MSRI with the consultation with engineers at National Instruments and using experience from previous work with similar control systems. Components were purchased and a user interface was developed. A photograph of the components of the control systems and power regulators is shown in Figure 161. 


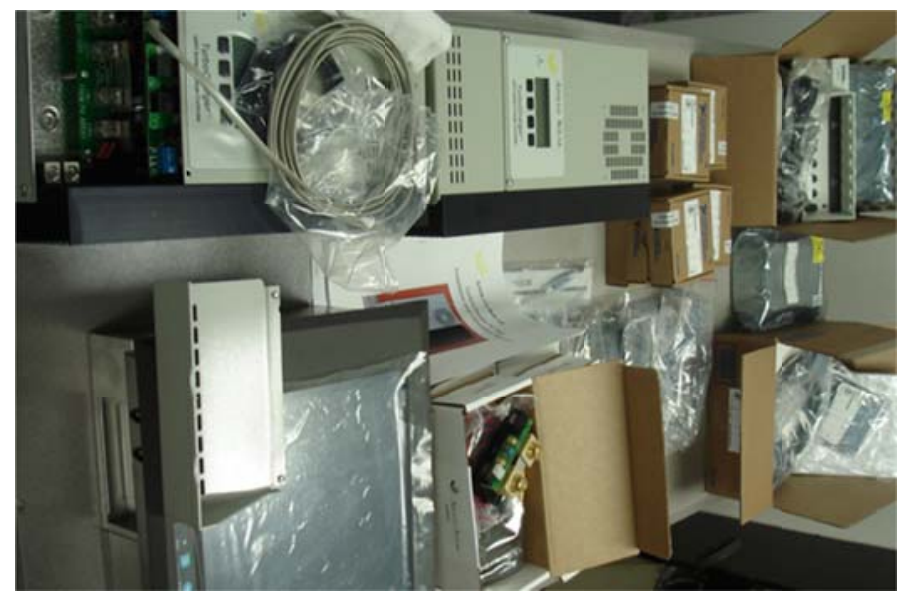

Figure 161 Photograph of the components of the control systems and power regulators

\section{Task 9 Hydrogen Cost Analysis}

The cost of hydrogen is a vital metric anytime for the hydrogen end-users considering the proposed technology; for viability the energy cost needs to be roughly equivalent to that of gasoline using DOE's guidelines. A cost analysis of the hybrid system was thus performed in this task, which incorporated hybrid stack performance and optimization for forecourt hydrogen production. Since the focus of this project has been the development of a hybrid SOFEC-SOFC technology and the providing of a solid proof of concept, as opposed to a system design or integration for large-scale hydrogen production, the preliminary economic assessment of the cost of hydrogen production using the targeted hybrid technology was for a generalized feasibility analysis only. The economic merits of the market penetration of the proposed fueling systems were also investigated, and results and recommendations could be used at MSRI for future system development optimization. However, the sensitivity studies on the effects of the capital cost, system fixed operation and maintenance costs (O\&M), variable production costs, byproduct credits, and decommission costs on the costs of hydrogen were not evaluated in this study due to lack of performance data from deployed systems.

Cost analyses were performed using the DOE H2A stationary model. Those costs included the capital cost for fabricating the SOFEC-SOFC hybrid and SOFC modules, SMR, BOP components, blowers, and replacement costs. The fixed operating \& maintenance costs covered the hydrogen production labor cost, overhead and G\&A, property taxes \& insurance, and production maintenance \& repairs. DOE's Solid State Energy Conversion Alliance (SECA) DOE-DG Phase I cost goal of $\$ 1000 / \mathrm{kW}$ was employed for the estimates of the SOFECs $/$ SOFCs and relevant balance-of-plant components. Due to lack of cost information for small-scale hydrogen compressors, a lump sum capital cost of $\$ 1000$ was used for the hydrogen postproduction treatment. The model assumed 15 years system life, and $50 \%$ of the stack components would be replaced in the course of the 15 years system life. $10 \%$ after-tax internal rate of return (IRR) was used. 


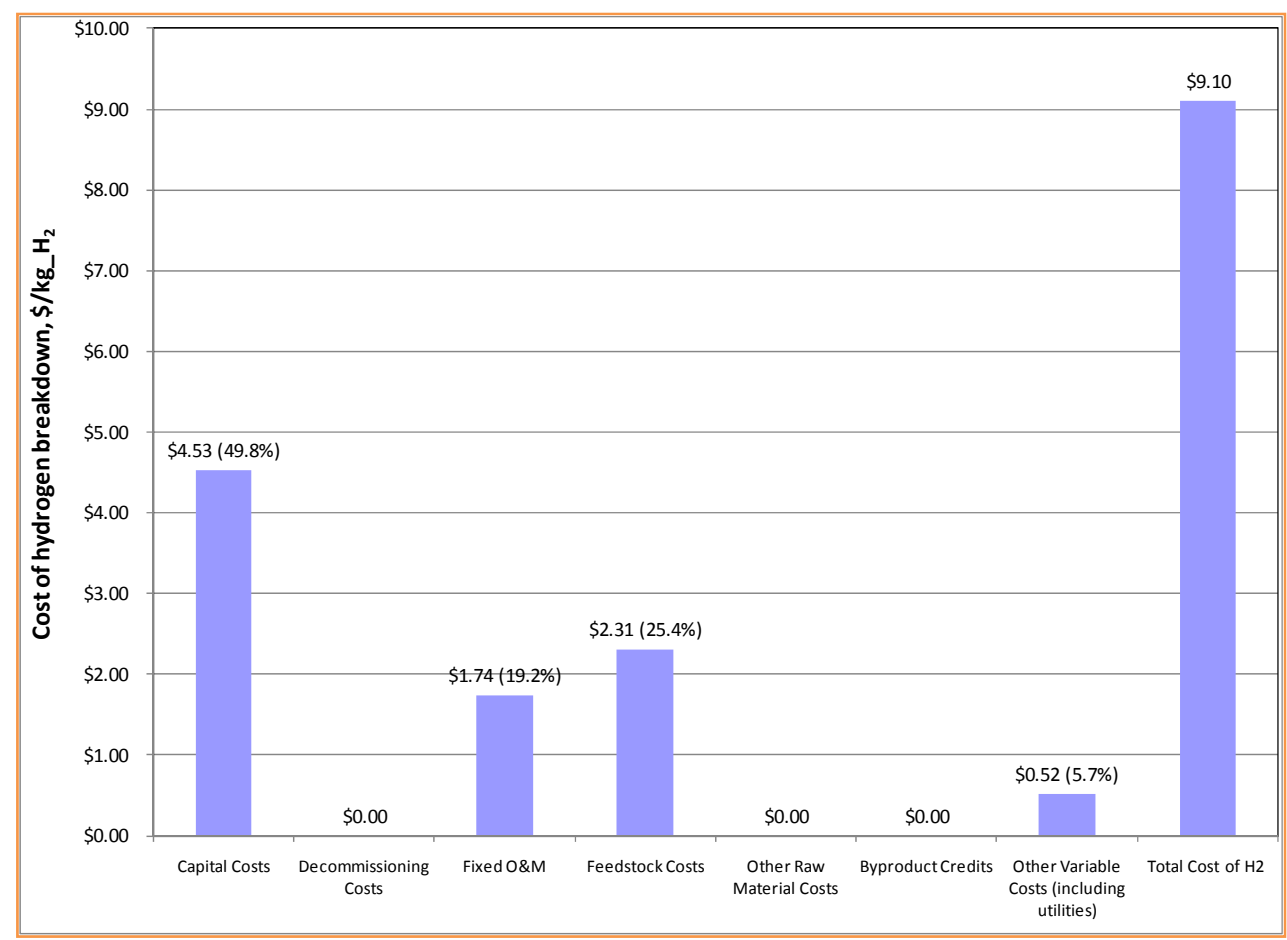

Figure 162. Cost profile of adopting the first system configuration (SOFEC-SOFC hybrid technology for hydrogen and electricity co-generation).

Figure 162 shows preliminary results of the estimates of the Cost of Hydrogen $(\mathrm{CoH})$ per $\mathrm{kg}$ for the proposed cogeneration system. With 30\% federal incentive, the $\mathrm{CoH}$ was around $\$ 9.10 / \mathrm{kg} \mathrm{H}_{2}$ for delivering per $\mathrm{kg}$ of hydrogen compressed to $5000 \mathrm{psig}$. As shown in the chart, the capital costs accounted for over $50 \%$ of the total cost, leaving much room for further improvement. Consequently, this cost estimation was presented as a means to understand the effects of factors (i.e. system costs, materials selection, incentive program, etc.) on the cost of hydrogen production and to guide future research and development and should not be construed as a prediction of the techno-economic limit of this technology in its fully developed form.

\section{Task $10 \quad$ Project Management and Reporting}

Through the joint efforts of MSRI and its subcontractors, UAF, MS\&T and the University of Utah, a large degree of success was achieved in this project. The team structure leveraged the strength and expertise of each team members; MSRI coordinated the teams' efforts, and collaborated closely with the other organizations to achieve project goals. The program kickoff meeting with the subcontractors was held successfully at the onset of the project at MSRI. PIs and key personnel from MSRI, UAF, MS\&T, and Utah defined and discussed the objectives and tasks of the program, and availability analyses of labor resources. Regular conference calls and annual meetings were held to discuss solutions to technical challenges which arose; all the quarterly reports, annual reports, and the final report were completed and submitted as required.

MSRI's Hydrogen Risk Mitigation Plan was modified using recommendations from the DOE Hydrogen Safety Panel, and the plan has been executing to minimize potential risks. MSRI 
Hydrogen Safety Plan covered key elements, including Identification of Safety Vulnerabilities (ISV), Safety Performance Monitoring, Management of Change, Employee Training, Equipment Integrity, Maintenance of Safety Documentation, Safety Events Reporting, and Emergency Response procedures. MSRI has been developing SOFC technologies using hydrogen as one of energy resources for more than 10 years, and extensive practical experience have been obtained for hydrogen handling and usage. To better manage hydrogen usage risks, MSRI has worked with the local office of Praxair to set up a hydrogen delivery system for large flow rate applications, including the construction of a shelter built outside of MSRI's main building to house hydrogen storage units. MSRI hosted a visit, post-construction, of the DOE hydrogen safety review team to verify compliance and recommend further actions that can be taken to increase safety during the handling of combustable gasses; these recommendations were incorporated into the MSRI hydrogen safety plan.

\section{Report Appendix}

\section{$\underline{\text { A1 }} \quad$ Figure Captions}

Figure 1. Electrical conductivity of LSCr, LSM and LSCM as a function of oxygen activity measured at $800^{\circ} \mathrm{C}$

Figure 2. Electrical conductivity of LSM as a function of oxygen activity and temperatures Figure 3. Electrical conductivity of LSCM as a function of oxygen activity and temperatures Figure 4. Impedance spectroscopy of LSCM in air

Figure 5. Impedance spectroscopy of LSCM-Ag in air after redox process

Figure 6. Impedance spectroscopy of LSCM-Ag during fuel cell test

Figure 7. Impedance spectroscopy of LSCM-Ag after fuel cell test

Figure 8. Impedance spectroscopy of LSCrM with Pt current collector in air

Figure 9. I-V charge profile of LSCM with Pt collector

Figure 10. The power density of a symmetric cell printed with LSCM cathode and Pt collector

Figure 11. Impedance spectroscopy of LSCM in both air and wet $10 \% \mathrm{H}_{2}$ at $800^{\circ} \mathrm{C}$

Figure 12. LST powders using ethylene glycol - nitrate method

Figure 13. LSCM powders using ethylene glycol - nitrate method

Figure 14. XRD of LST, LSCM and 50wt \%LST - 50wt\%LSCM mixture annealed at 600, 1000 and $1200^{\circ} \mathrm{C}$, respectively.

Figure 15. XRD of 50wt\%LST - 50wt \%LSCM sintered at 1200,1300 and $1400^{\circ} \mathrm{C}$

Figure 16. SEM micrographs at $10 \mathrm{KX}$ for LST/LSCM sintered between $900^{\circ} \mathrm{C}, 1000^{\circ} \mathrm{C}, 1100^{\circ} \mathrm{C}$, $1200^{\circ} \mathrm{C}, 1300^{\circ} \mathrm{C}$ and $1400^{\circ} \mathrm{C}$.

Figure 17. Conductivities of $\operatorname{LST}(0.8 / 0.2 / 1) / \operatorname{LSCM}(0.8 / 0.2 / 0.5 / 0.5)$ sintered at $1000-1400^{\circ} \mathrm{C}$ were measured as a function of oxygen activity at $900^{\circ} \mathrm{C}$

Figure 18. Electrical conductivity of $\operatorname{LST}(0.8 / 0.2 / 1)$ sintered at $1200^{\circ} \mathrm{C}$ as a function of oxygen activity at $900^{\circ} \mathrm{C}$

Figure 19. Chemical analysis of LST/LSCM sintered at $1100^{\circ} \mathrm{C}(\mathrm{a}, \mathrm{b})$ and at $1200^{\circ} \mathrm{C}(\mathrm{c}, \mathrm{d})$ 
Figure 20. Conductivity of $\mathrm{Gd}_{0.2} \mathrm{Ce}_{0.8} \mathrm{O}_{2-\delta}$ discs sintered at $1100^{\circ} \mathrm{C}$ and $1400^{\circ} \mathrm{C}(\sim 75$ and $>90 \%$ of theoretical density, respectively) measured as a function of temperature in air

Figure 21. Conductivity of a porous $\mathrm{Gd}_{0.2} \mathrm{Ce}_{0.8} \mathrm{O}_{2-\delta}$ pellet (sintered at $1100^{\circ} \mathrm{C}, \sim 75 \%$ of theoretical density) as a function of oxygen activity at $800^{\circ} \mathrm{C}$

Figure 22. Impedance spectroscopy of SDC discs as a function of temperature with frequency range between $1-1 \mathrm{e}^{6} \mathrm{~Hz}$ (surface area of the electrode was $0.5 \mathrm{~cm}^{2}$ )

Figure 22. Impedance spectroscopy of SDC discs as a function of temperature with frequency range between $1-1 \mathrm{e}^{6} \mathrm{~Hz}$ (surface area of the electrode was $0.5 \mathrm{~cm}^{2}$ )

Figure 23. Activation energy of SDC discs as a function of temperature.

Figure 24. Redox stability of GDC tested in air and wet-forming gas $\left(10 \% \mathrm{H}_{2}\right.$ bal. $\left.\mathrm{N}_{2}\right)$ at $800{ }^{\circ} \mathrm{C}$ Figure 25. Redox stability of SDC tested in air and wet-forming gas $\left(10 \% \mathrm{H}_{2}\right.$ bal. $\left.\mathrm{N}_{2}\right)$ between 500 and $800^{\circ} \mathrm{C}$

Figure 26. Conductivity of a mixture of n-type $\mathrm{Sm}_{0.2} \mathrm{Ce}_{0.8} \mathrm{O}_{2}$ and p-type $\mathrm{La}_{0.75} \mathrm{Sr}_{0.25} \mathrm{Cr}_{0.5} \mathrm{Mn}_{0.5} \mathrm{O}_{3}$ as a function of oxygen activities at $800^{\circ} \mathrm{C}$

Figure 27. XRD pattern of a mixture of $50 \mathrm{wt} \%$ of $\mathrm{Sm}_{0.2} \mathrm{Ce}_{0.8} \mathrm{O}_{2}$ and $50 \mathrm{wt} \%$ of $\mathrm{La}_{0.75} \mathrm{Sr}_{0.25} \mathrm{Cr}_{0.5} \mathrm{Mn}_{0.5} \mathrm{O}_{3}$ sintered at $1300^{\circ} \mathrm{C}$

Figure 28. MSRI anode-supported SOFCs.

Figure 29. Porosity and composite matrix for the NiO-YSZ system

Figure 30. SEM micrograph of a 80/20 cell with no pore former additive

Figure 31. SEM micrograph of a 70/30 cell with type A pore former additive

Figure 32. SEM micrograph of a 70/30 cell type A pore former

Figure 33. SEM micrograph of a 70/30 cell type A pore former polished

Figure 34 SEM micrograph of a 70/30 cell type B pore former

Figure 35. A SEM micrograph of an anode substrate using Unitec powder with Type B pore former additive

Figure 36. a picture of cells fabricated for the $5 \mathrm{~kW}$ hybrid system

Figure 37. Photographs of the NiO-8YSZ (4"x4") and NiO-4YSZ (1" dia) as-received samples

Figure 38. Schematic diagram of the experimental design used for evaluating Young's modulus as a function of temperature

Figure 39. A schematic of the specimen and loading configuration in the ring-on-ring test Figure 40. (a) Optical micrographs showing the cross sectional view of the as-received NiO8 YSZ half-cell samples (Batch I : $600 \mu \mathrm{m}$ thick; batch II : $900 \mu \mathrm{m}$ thick); (b) Electrolyte and anode layers observed in as-received $\mathrm{NiO}-8 \mathrm{YSZ}$ batch II samples at a higher magnification Figure 41. Optical micrographs of the anode surface of as-received and the heat treated NiO8YSZ samples (Batch I) : (a) as-received, (b) $800^{\circ} \mathrm{C}$, (c) $1000^{\circ} \mathrm{C}$, (d) $1250^{\circ} \mathrm{C}$, and (e) $1500^{\circ} \mathrm{C}$. Note that the pore distribution was not uniform and the pores were mostly interconnected.

Figure 42. Optical micrographs of the electrolyte surface of as-received and the heat treated $\mathrm{NiO}-8 \mathrm{YSZ}$ samples (Batch I) : (a) as-received, (b) $800^{\circ} \mathrm{C}$, (c) $1000^{\circ} \mathrm{C}$, (d) $1250^{\circ} \mathrm{C}$, and (e \& f) $1500^{\circ} \mathrm{C}$.

Figure 43. Grain size distribution in $8 \mathrm{YSZ}$ electrolytes (Batch I) after heat treating at $1500^{\circ} \mathrm{C}$. The average grain size was $\sim 10 \mu \mathrm{m}$. 
Figure 44. SEM micrographs of NiO-4YSZ button cell samples (cross sectional view).

Figure 45. SEM micrograph of the NiO-4YSZ (a) anode and (b) electrolyte layer.

Figure 46. SEM micrographs of NiO-8YSZ samples (Batch I) in cross section. Low magnifications : (a) secondary electron image and (b) back scattered electron image. (c \& d) high magnifications. Note the irregular shaped pores dispersed in the anode structure. The electrolyte was dense and showed no delamination or cracks at the interface.

Figure 47. Secondary electron image (a) and back scattered electron image (b) of the NiO-4YSZ button cell anode, (c \& d) EDX spectra taken from the NiO and YSZ grains respectively.

Figure 48. Secondary electron image (a) and back scattered electron image (b) of the NiO-8YSZ anode (Batch I). EDX spectra taken from the NiO and YSZ grains respectively.

Figure 49. Effect of reduction on development of microstructure in NiO-8YSZ half-cells (Batch II). $\mathrm{NiO}$ gradually reduced from the edge of the anode and spread across the half-cell towards the electrolyte layer as the time of exposure increases.

Figure 50. Development of Ni-8YSZ microstructure (Batch II) in details. The reducing atmosphere formed a thin layer of $\mathrm{Ni}$ on the $\mathrm{NiO}$ grains, which gradually growed until the whole $\mathrm{NiO}$ grain was reduced to $\mathrm{Ni}$.

Figure 51. SEM micrographs in the anode surface of (a) as-received, (b) $10 \mathrm{~min}$, (c) $30 \mathrm{~min}$, (d) $2 \mathrm{~h}$ and (e) $8 \mathrm{~h}$ reduced NiO-8YSZ samples (Batch I).

Figure 52. A back scattered image of the NiO-8YSZ anode reduced at $800^{\circ} \mathrm{C}$ in $5 \% \mathrm{H}_{2}$ for 10 min. (Note the formation of Ni layers on the NiO particles)

Figure 53. X-ray diffractograms of (a) electrolyte and (b) anode of a NiO-4YSZ button cell. "** denotes $\mathrm{NiO}$ peaks.

Figure 54. X-ray diffractograms of (a) electrolyte and (b) anode of a NiO-8YSZ cell (Batch I, $600 \mu \mathrm{m}$ thick). "**” and "**" denoted $t-\mathrm{ZrO}_{2}$ and $\mathrm{NiO}$ peaks respectively.

Figure 55. Measured values of (a) porosity and (b) density in the reduced NiO-8YSZ (Batch I) half-cell samples as a function of reduction time

Figure 56. TG thermograms, showing the oxidation of Ni in the NiO-8YSZ (Batch I) samples reduced for (b) $10 \mathrm{~min}$, (c) $30 \mathrm{~min}$, (d) $2 \mathrm{~h}$ and (e) $8 \mathrm{~h}$ when subjected to a temperature profile (a) in air.

Figure 57. The fraction of reduced $\mathrm{NiO}(\%)$ in the NiO-8YSZ (Batch I) samples as a function of reduction time. The inset figure showed the x-ray diffractograms in the anode surface of the asreceived and the reduced samples.

Figure 58. X-ray diffractograms of pulverized half-cell samples of (a) as-received NiO-8YSZ (Batch I) and after reducing at $800{ }^{\circ} \mathrm{C}$ in $5 \% \mathrm{H}_{2}-95 \%$ Ar atmosphere for (b) $10 \mathrm{~min}$, (c) $30 \mathrm{~min}$, (d) $2 \mathrm{~h}$ and (e) $8 \mathrm{~h}$.

Figure 59. Measured values of (a) porosity and (b) density in the reduced NiO-8YSZ (Batch II) half-cell samples as a function of reduction time

Figure 60. (a) Weight loss (\%) and (b) reduced $\mathrm{NiO}(\%)$ observed in the reduced NiO-8YSZ (Batch II, $900 \mu \mathrm{m}$ thick) half-cell samples as a function of reduction time.

Figure 61. X-ray diffractograms of the anode surface of (a) as-received ( $900 \mu \mathrm{m}$ thick, batch II) half-cells and the samples reduced for (b) $10 \mathrm{~min}$, (c) $30 \mathrm{~min}$, (d) $1 \mathrm{~h}$, (e) $2 \mathrm{~h}$, (f) $8 \mathrm{~h}$ and the samples $(\mathrm{g})$ boiled in water for $2 \mathrm{~h}$ after reducing for $8 \mathrm{~h}$. 
Figure 62. XRD patterns of pulverized (a) as-received and (b) $8 \mathrm{~h}$ reduced NiO-8YSZ (900 $\mu \mathrm{m}$ thick, Batch II) half-cell samples.

Figure 63. Hardness values measured in the anode surface of the heat treated NiO-4YSZ samples.

Figure 64. The effect of heat treatment on the hardness of the NiO-8YSZ anode.

Figure 65. The effect of heat treatment on the hardness of the electrolyte.

Figure 66. The effect of heat treatment on the fracture toughness of the NiO-8YSZ anodes.

Figure 67. Hardness values plotted as a function of porosity in the as-received and the reduced NiO-8YSZ (600 $\mu \mathrm{m}$ thick, batch I) samples.

Figure 68. Hardness values plotted as a function of porosity in the as-received and the reduced NiO-8YSZ (900 $\mu \mathrm{m}$ thick, batch II) anode samples.

Figure 69. Room temperature Young's and shear moduli values plotted as a function of porosity in the as-received and the reduced NiO-8YSZ (Batch I) anode samples.

Figure 70. Room temperature (a) Young's and (b) shear moduli values plotted as a function of porosity in the as-received and the reduced NiO-8YSZ (Batch II) anode samples.

Figure 71. The variation of the total expansion coefficients of as-received NiO-8YSZ (600 $\mu \mathrm{m}$ thick, batch I) samples on heating (a) and cooling (b) in air at $3 \mathrm{~K} / \mathrm{min}$. The insert showed the change in thermal expansion behavior at the vicinity of the temperature at which structural/magnetic transition of $\mathrm{NiO}$ occurs during heating and cooling.

Figure 72. The thermal expansion coefficient values of as-received NiO-8YSZ $(900 \mu \mathrm{m}$ thick, batch II) samples on (a) heating and (b) cooling in air at $3 \mathrm{~K} / \mathrm{min}$.

Figure 73. Young's moduli values plotted as a function of temperature in the as-received and the reduced NiO-8YSZ (600 $\mu \mathrm{m}$ thick, batch I) anode samples

Figure 74. The variation of Young's modulus with temperature in (a) as-received, (b) $10 \mathrm{~min}$, (c) $30 \mathrm{~min}$, (d) $1 \mathrm{~h}$, (e) $2 \mathrm{~h}$ and (f) $8 \mathrm{~h}$ reduced NiO-8YSZ (900 $\mu \mathrm{m}$ thick, batch II) samples.

Figure 75. Young's moduli values of the as-received and $8 \mathrm{~h}$ reduced Ni-8YSZ half-cells as a function of temperature.

Figure 76. Photographs of biaxial fixture (a) and fractured half-cell (b).

Figure 77. Effect of reduction on the biaxial strength (measured at room temperature in ambient air) and development of porosity in the $900 \mu \mathrm{m}$ thick, batch II samples.

Figure 78. Effect of reduction on the equibiaxial strength of the reduced NiO-8YSZ (batch I) half-cells at room temperature. The influence of reduction on porosity was also given for comparison.

Figure 79. Typical failure origined closer to the tensile surface (batch I samples): (a) agglomerate of YSZ; (b) pull out of $\mathrm{NiO}$ agglomerate; (c, d, e and f) cavities formed during casting.

Figure 80 . The typical fracture behavior of the fully reduced half-cells at $800{ }^{0} \mathrm{C}$ in $5 \% \mathrm{H}_{2}$ atmosphere.

Figure 81. Typical load-displacement curves of the half-cells at room temperature in air and $800^{\circ} \mathrm{C}$ in reducing atmosphere.

Figure 82. The near-surface volume flaws observed in the as-received $900 \mu \mathrm{m}$ thick, batch II half-cells. 
Figure 83. Fracture surface of a fully reduced half-cell with a volume flaw.

Figure 84 . Weibull plots for equibiaxial tests at (a) room temperature and (b) at reducing conditions $\left(800^{\circ} \mathrm{C}\right.$ in $\left.5 \% \mathrm{H}_{2}\right)$ for as-received half-cells (batch II)

Figure 85. The variation of porosity (a) and density (b) with the number of thermal cycles treated to the $900 \mu \mathrm{m}$ thick, unreduced NiO-8YSZ samples.

Figure 86. Cross sectional view of a fractured NiO-8YSZ sample treated for 50 cycles.

Figure 87. Hardness values in the anode surface of the thermal cycled NiO-8YSZ samples.

Figure 88. Room temperature Young's and shear moduli values in the NiO-8YSZ samples

plotted as a function of the number of thermal cycles treated.

Figure 89. Damage modes that may be observed in a bi-layer system subjected to an indentation loading.

Figure 90. The finite element model used in the simulations.

Figure 91. Plane views of stress distributions in as-received NiO-8YSZ (Batch I) samples.

Figure 92. Three-dimensional simulation of stress distributions in as-received NiO-8YSZ (Batch I) samples.

Figure 93. The 3D contour of the maximum principal stress.

Figure 94. Simulated indentation force versus depth curve. The force and depth are normalized by their maximum values.

Figure 95. (a) Simulated indentation mark on electrolyte side. Colors represent different stress levels on the indented samples. (b) Optical image of indentation mark on the electrolyte (Load 50 gm at 500x).

Figure 96. Thermal expansion coefficient for sealing glass compositions after heating to $800^{\circ} \mathrm{C}$ in air for over an extended period

Figure 97. Electrical conductivity for $\mathrm{G} \# 81$ sealing glass-ceramics as a function of time in air and $\mathrm{H}_{2}$ at $800^{\circ} \mathrm{C}$

Figure 98. Differential thermal analyses of glass \#50 powders with different average particle sizes, at a heating rate of $10^{\circ} \mathrm{C} / \mathrm{min}$

Figure 99. Pictures of the hermeticity test showing in (a) tubular furnace and the apparatus used for the test and in (b) seals between 430SS discs and Ni-YSZ used during the test

Figure 100. SEM picture of a seal between $8 \%$ YSZ (left) and G\#81 (right) with $25 \mu \mathrm{m}$ particle size treated at $850^{\circ} \mathrm{C}$ for 1 hour in air

Figure 101. Exploded view of the spring-loaded single-cell test fixture designed for SOFCSOFEC evaluation

Figure 102. Performance comparison for anode support cells with LSM cathode and tested in SOFC mode with $\mathrm{H}_{2}$ fuel at $800^{\circ} \mathrm{C}$. Four types of anode substrates: NiO/8YSZ at 80/20 ratio, $\mathrm{NiO} / 8 \mathrm{YSZ}$ at $67 / 33$ ratio with Type A pore former, NiO/8YSZ at 65/35 ratio with Type B pore former, and $\mathrm{NiO} / 8 \mathrm{YSZ}$ using Unitec powder at 65/35 ratio with Type B pore former.

Figure 103. Performance comparisons for anode substrates made of Tosoh powder and Unitec powder. Type B pore former were used in both cases. Cells were tested in SOFC mode at $800^{\circ} \mathrm{C}$.

Figure 104. SEM micrograph of the modified composite cathode microstructures

Figure 105. Close look of a SEM micrograph of the cathode microstructures 
Figure 106. One inch button cell performance comparisons tested in SOFC mode.

Figure 107. One inch button cell performance comparisons tested in SOFC mode

Figure 108. X-ray diffraction patterns of the perovskite powder using conventional solid oxide reaction method

Figure 109. X-ray diffraction patterns of the perovskite powder using combustion synthesis method.

Figure 110. Voltage and power density as a function of current density for a cell with commercial LSCM and with commercial LSCM+cobalt nitrate infiltration as cathode.

Figure 111. Voltage and power density as a function of current density for a cell with LSCM prepared by combustion method and LSCM prepared by combustion method + cobalt nitrate infiltration as cathode

Figure 112. Voltage and power density as a function of current density for a cell with LSCM prepared by oxide reaction method and LSCM prepared by oxide reaction method + cobalt nitrate infiltration as cathode

Figure 113. Typical performance characteristics of a button-cell operated in the reversible SOFC and SOFEC modes at $800^{\circ} \mathrm{C}$

Figure 114. Exploded view of the SOFEC-SOFC hybrid stack design

Figure 115. Cutaway view showing the insulated modulated compression hardware for a stack

Figure 116. Rendering of the compression hardware assembly

Figure 117. Three alternative system configurations

Figure 118. Schematic of the two operation modes for the "C" configuration

Figure 119. Polarization curves for configuration " $\mathrm{C}$ " in two operation modes

Figure 120. Computed system cogeneration efficiency based on measure hybrid stack performance

Figure 121. System diagram of the "C" configuration

Figure 122. Rendering of the preliminary system configuration showing the major sub-systems, inlet and outlet streams.

Figure 123. Rendering of the tailgas-fired generator design

Figure 124. Cut-away view of the design for the tail-gas fired process heaters

Figure 125. A photograph of a 10-cell stack assembly ready for testing. Each cell had $100 \mathrm{~cm}^{2}$ active area and attached with a voltage lead,

Figure 126. Performance characteristics of a 10-cell stack tested in SOFC mode as the baseline. Per-cell active area was $100 \mathrm{~cm}^{2}$. The furnace temperature was set at $770^{\circ} \mathrm{C}$. Wet Syngas (with $30 \%$ steam) was used as the fuel and air was the oxidant. Both the fuel and oxidant utilizations were fixed at $40 \%$.

Figure 127. Performance characteristics of a 10-cell stack operated in the SOFEC mode for hydrogen production. Per-cell active area was $100 \mathrm{~cm}^{2}$. The furnace temperature was set at $770^{\circ} \mathrm{C}$. Wet Syngas (with 30\% steam) was used as the fuel and steam was used as the oxidant. Both the fuel and steam utilizations were fixed at $40 \%$.

Figure 128. Thermal cycling effects on the stack performance. The temperature was cycled from the room temperature to $770^{\circ} \mathrm{C}$ and then back to the room temperature. The fuel was wet syngas, and the oxidant was either air in SOFC mode or steam in SOFEC mode. 
Figure 129. 10-cell stack performance vs. number of thermal cycle tested in the reversible $\mathrm{SOFC} / \mathrm{SOFEC}$ modes. The temperature was cycled from room temperature to $770^{\circ} \mathrm{C}$ and then back to room temperature. The fuel was wet syngas, and the oxidant was either air in SOFC mode or steam in SOFEC mode.

Figure 130. Performance characteristics of a 10-cell stack (4-SOFC + 6-SOFEC) tested in SOFC mode as the baseline. The furnace temperature was set at $800^{\circ} \mathrm{C}$. Diluted hydrogen with $50 \% \mathrm{~N}_{2}$ was used as the fuel and air was the oxidant. Both the fuel and oxidant utilizations were increased from $40 \%$ to $60 \%$.

Figure 131. Performance characteristics of a 10-cell stack operated in the hybrid mode for hydrogen and electricity co-generation. The furnace temperature was set at $800^{\circ} \mathrm{C}$. Diluted hydrogen with $50 \% \mathrm{~N}_{2}$ was used as the fuel on the anodes of both 4-SOFC and 6-SOFEC. Air and steam were on the cathodes of the 4-SOFC and 6-SOFEC, respectively. Both the fuel and air utilizations were fixed at $60 \%$, while steam utilization changed from $40 \%$ to $60 \%$.

Figure 132. Performance comparisons of the 10-cell hybrid stack using two types of fuels: hydrogen diluted with $50 \% \mathrm{~N}_{2}$ and syngas. Under the both cases, the utilizations of the fuel, air and steam were fixed at $60 \%, 60 \%$ and $40 \%$, respectively. The furnace temperature was set at $800^{\circ} \mathrm{C}$.

Figure 133. Continuous co-generation of hydrogen and electricity. Utilizations of syngas, air, and steam were fixed at $60 \%, 60 \%, 40 \%$, respectively. The furnace temperature was set at $800^{\circ} \mathrm{C}$.

Figure 134. Voltage characteristics of each cell over the 48 hours continuous test.

Figure 135. Continuous cogeneration of hydrogen and electricity

Figure 136. Continuous cogeneration of hydrogen and electricity

Figure 137. Photograph of the 10-cell hybrid stack (7-SOFEC \& 3-SOFC) after testing

Figure 138. SEM micrograph of Cell No.1 (SOFC)

Figure 139. SEM micrograph of Cell No. 3 (SOFC)

Figure 140. SEM micrograph of Cell No. 10 (SOFEC)

Figure 141 . LSCM conductivity as a function of oxygen activity measured at $800^{\circ} \mathrm{C}$

Figure 142. Performance characteristics of a 1-cell stack tested in SOFC mode as the baseline. The furnace temperature was set at $800^{\circ} \mathrm{C}$. Diluted hydrogen with $50 \% \mathrm{~N}_{2}$ was used as the fuel and air was the oxidant.

Figure 143. Long-term test of a 1-cell stack in the SOFEC mode for hydrogen production

Figure 144. SOFC operation at scheduled time

Figure 145. Long-term test of a 4"x4" 1-cell stack in the SOFEC mode

Figure 146. Long-term test of a 4"x4" 1-cell stack in the SOFEC mode

Figure 147. SOFC operation at scheduled time

Figure 148. Rendering of the $5 \mathrm{~kW}$ hybrid system configuration in detail

Figure 149. Nicro-spray system

Figure 150. Photograph of the retort furnace used for fabricating interconnects

Figure 151. Photograph of five sets of compression hardware machined for modular stacks (the missing one was installed in test station already) 
Figure 152. Photographs of the 40-cell stack before test (a) and post test (b)

Figure 153. Performance characteristics of the 40-cell SOFC stack

Figure 154. Continuous test in the power generation mode

Figure 155. Photograph of the assembled steam generator before testing

Figure 156. Photograph of the bench-top test configuration for the steam delivery system, after testing

Figure 157. Flow rate measurements (based on mass balance) of steam generation under steady flow of simulated lean tailgas and air.

Figure 158. Two tailgas-fired process heaters packed with catalysts

Figure 159. Photograph of the catalyst material used in the tailgas-fired process heaters, along with the micro-perforated SS foil used as the air diffuser

Figure 160. Temperature profile of the process gas heater operating on a dilute fuel (50/50

$\mathrm{N}_{2} / \mathrm{H}_{2}$ ), Stoich. air, and heating ambient air, and compositions of the combustion product stream for 3 cases.

Figure 161 Photograph of the components of the control systems and power regulators

Figure 162. Cost profile of adopting the first system configuration (SOFEC-SOFC hybrid technology for hydrogen and electricity co-generation).

A2 Table Captions

Table 1. Samples studied and characterized

Table 2. Bulk density and apparent porosity of the as-received half-cell samples

Table 3 Lattice parameters and lattice volumes observed in as-received and reduced NiO-8YSZ (Batch II) samples.

Table 4. Equibiaxial strength of the half-cells at $800{ }^{\circ} \mathrm{C}$ in ambient air and reducing atmosphere

Table 5. Characteristic temperature for G\#50 glasses with different particle sizes

Table 6. DTA and HSM data for G\#50 with different average particle sizes, at heating rate of $5^{\circ} \mathrm{C} / \mathrm{min}$.

Table 7. Summary of recent thermal cycling tests of glass seals.*

Table 8. Cell performance summary

$\underline{\text { A3 Abbreviations }}$

- $\quad \mathrm{ASR}$ - area specific resistance

- $\quad$ BOP - balance-of-plant

- $\quad$ C-DAQ - compact data acquisition

- $\mathrm{CL}$ - current collector layer

- $\quad$ CIL - current functional layer

- $\quad$ DTA - differential thermal analyses

- $\quad$ DIR - direct internal reforming

- EDAX - energy dispersive X-Ray 


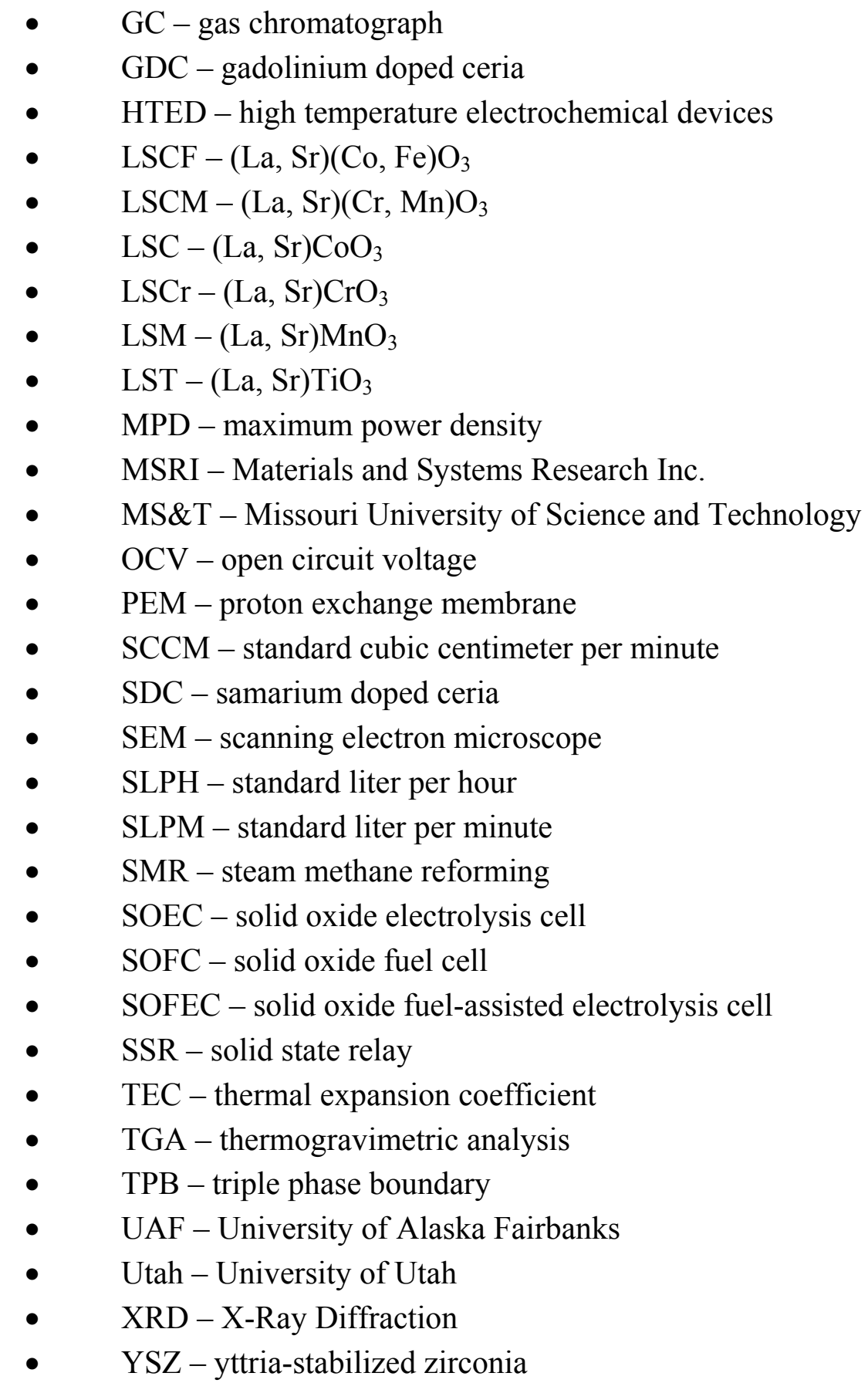

